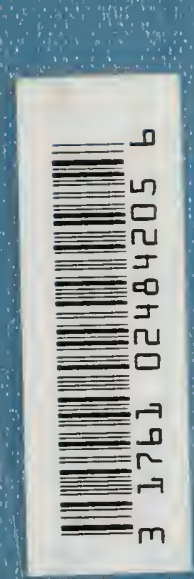

Wf

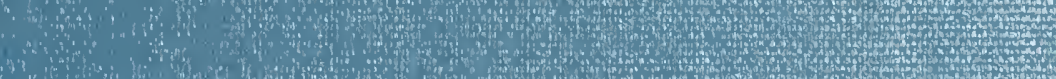
a

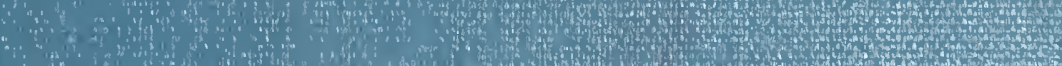

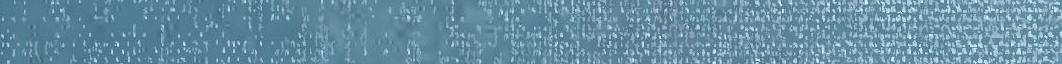

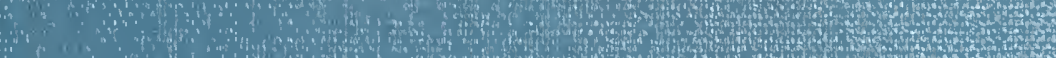
1.

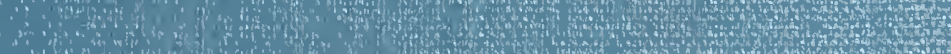

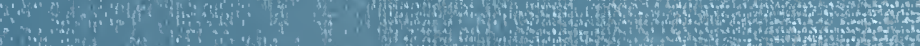

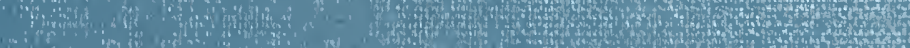

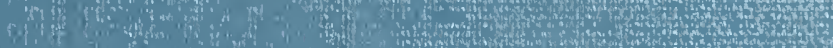
the

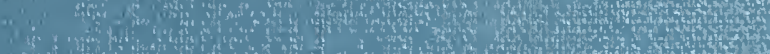

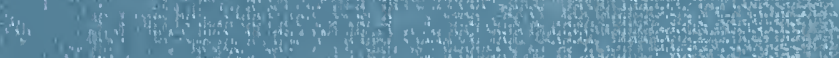

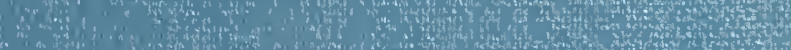

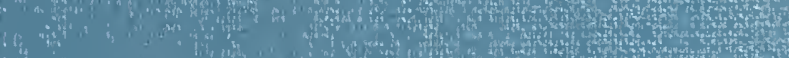

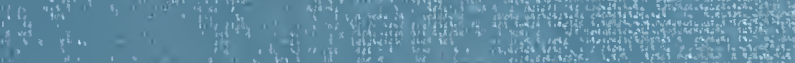
Q

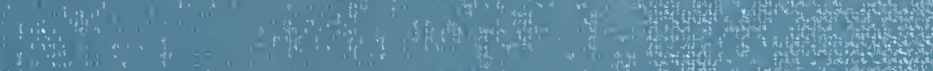
(y.

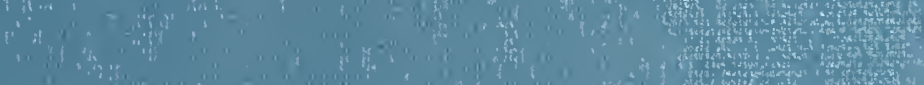
(1)

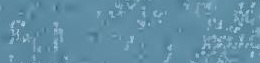
(n) Hith

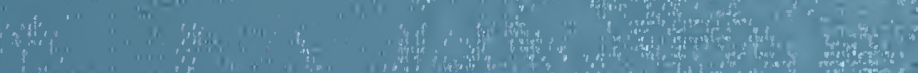

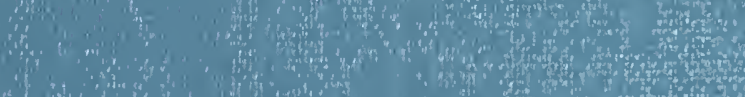
(1) 4. and

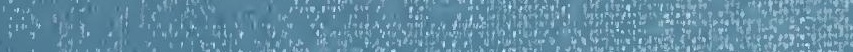

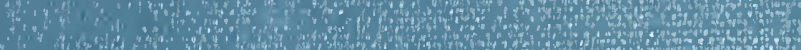

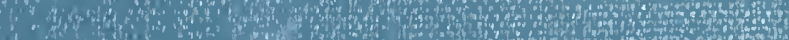
biln

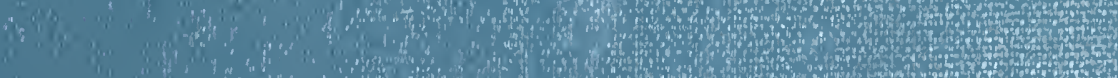
$\therefore$,

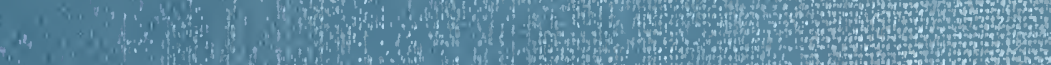
Wis a What Path , 4 (f) 
Digitized by the Internet Archive in 2007 with funding from Microsoft Corporation 




\section{PLANT PHYSIOLOGY}

A. (I)

\section{ECOLOGY}

BT

FREDERIC EDWARL CLEMENTS. PH.D.

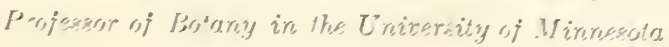

\section{WITH 125 ILLLSTRATIONS}

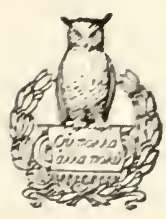

NEW YORK

HENRY IIOLT AND COMPANY

MICROFILMED BY
UNIVERSITY OF TORONTO
LIBRARY
MASTER NEGATIVE NO.:
930016


Copyright, 1907,

BY

HENRY HOLT AND COMPANY 


\section{PREFACE}

The point of view and the methods of study first advaneed in "Research Methods in Ecology" have proved so satisfactory in teaching as to make it desirable to embody them in a text-book. The present text has been based largely upon "Researeh Methodls," though most of the matter is new or rewritten. The manner of treatment is essentially the same, but the subject-matter has heen rearranged and broken up into a larger number of chapters. The plant is first consiclered as an individual, with respect to factor, function, and form, and then as a member of a plant group or formation.

The reasons for regarding ecology and physiology as essentially the same have been given elsewhere, and need not be repeated here. An endeavor has been made to give the various parts of this vast field their proper importance. Since ecology and physiolony are merged, it is manifestly impossible to give to either what would be regarded as a complete treatment by a specialist in either line. No attempt has been made to touch all the points in early, but it is thought that nothing realy fundamental has been omited.

The book is intended for use with clisses in secomkl-yon botany in college and university. In manuscript form, it has heen in such use for two year's with good results. Althougly the anount of laboratory and fiekd work is large, it is possible to acrompliste all of it in a course requiring 6-S hours of laboratory time eatrols werk. This can be done only by careful plamning on the part of both instructor and student, and for this reason the following sugresestions are offered as aids.

The instructor will find it imperative to plan in arlvanee for the experiments for the whole year, in oreler that plints may bo ranly as needed. Seeds and fruits for the sturly of migration slmuld lo collected in the fall. Sharle tents, water-ontent ceries, anut com- 
petition cultures must also be prepared early in the year. Types of hydrophytes, xerophytes, ete., should be grown in the planthouse in so far as possible. Students should be instructed to make cluplicate plantings of all plants to be used in order to make sure of an adequate supply at all times. It has ako been found desirable to teach the students the use of the paraffin method of embedding tissues, thus saving much time and securing better results. The work on adaptation to water and light is best carried on in the form of joint experiments, in which each student is assigned a definite part. In the experiments much use has been made of the common sunflower. This is on account of the ease with which it may be secured and grown, but when a larger choice is possible other plants may often be substituted to advantage.

In just as far as possible, the work of the student should be among plants out-of-doors. This is imperative in the chapters on vegetation, and is very desirable in all cases where it is feasible, even in the study of plant functions. For vegetation work, the knowledge of the more important genera and species of the several formations is indispensable. If the student does not already have this knowledge, the names should be furnished him by any desirable method, without taking the time necessary for identification.

A bibilography has not seemed necessary and has not been given. A fairly full list of the more important works is found in "Research Methods." Apart from the latter, Pfeffer's "Pflanzenphysiologie," MacDougal's "Text-book of Plant Physiology," Sach's "Text-book of Botany," Vines' "Lectures on the Physiology of Plants," and Kerner's "Pflanzenteben" have been frequently consulted in the preparation of the text.

Grateful acknowledgment is made of the kindness of Dr. C. E. Bessey, Dr. D. 'T. MacDougal, and Dr. Edith Clements in reading and criticizing the text. The author is also indebted to Dr. Edith Clements for many drawings, and for the use of cuts from "The Relation of Leaf Structure to Physical Factors," and to Mr. R. J. Pool and Mr. A. W. Sampson for the loan of several photographs. Frederic Edward Clenients.

The University of Nebraski, March 1907. 


\section{CONTENTS}

\section{CHAPTER I \\ STIMULUS AND RESPONSE}

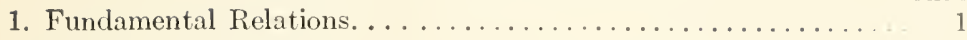

2. The Nature of Stimuli. . . . . . . . . . . . . . . . . . . . 1

3. The Kinds of Stimuli........................ 3

4. The Nature of Response....................... 3

5. Adjustment and Adaptation. ......................

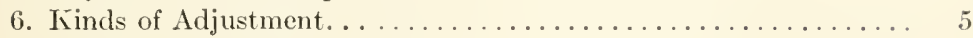

7. Normal and Abnormal Adjustment................ 5

\section{CHAPTER II}

\section{THE WATER OF THE HABITAT}

8. Relation of the Plant to Water. . . . . . . . . . . . .

9. The Nature of Water Stimuli. ........................ 7

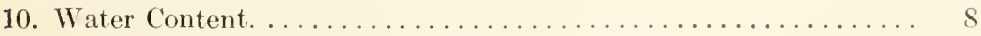

11. Influence of other Factors upon Water Content. ........... 9

12. Available and Non-available Water Content............. 9

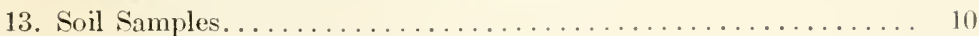

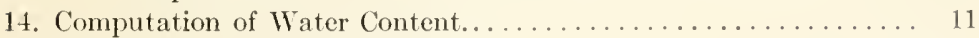

15. Time of Water Content Readings ................. 12

16. Location of Readings. . . . . . . . . . . . . . . . . . . .

17. Depth of Samples.............................. 12

Experiment 1. Measurement of Water Content. .......... 13

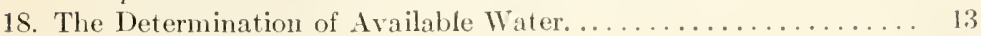

19. Chresard of Habitats. ......................... 14

Experiment 2. Determination of Available Water.......... 14

Modifying Factors

20. Influence of Soil upon Water Content................ 15

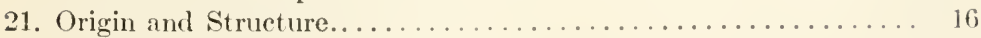

22. Water Capacity................................ 17 


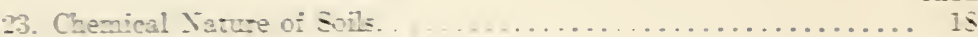

$2 \frac{1}{1}$ - Contert. . . . . . . . . . . . . . . . . . . . . . . . 19

25. Determinstion of Soll Properties. . . . . . . . . . . . . . . 19

Experiment 3. Ponoitg and Pate of Eraporation... . . . . . . . 20

25. In Euence oi Precipitation upon $\pi$ ste- Content . . . . . . . . . . . 21

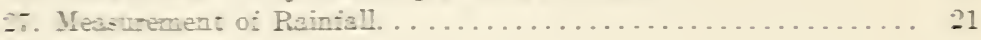

2. Phy=i zryhy. . . . . . . . . . . . . . . . . . . . . .

20. The Influence of Stope. . . . . . . . . . . . . . . . . . . .

31). The Intuence of suriace. . . . . . . . . . . . . . . . . . . . 23

31. The Inticence of Climatic Factors................. 24

32. Humitirs... . . . . . . . . . . . . . . . . . . . . . . . . $2 \frac{1}{2}$

33. Mutiviz= Inzuence of Temperature and Wind............ 25

3\%. Ir zuence of Presenre and Phrsiograptic Factors........... 26

3.5. Ëfect of Climaie and Habiat. . . . . . . . . . . . . . . . 27

35. Meastemeni oi Humitit. . . . . . . . . . . . . . . . . . . . 2i

37. Sing and Cog Psychrometer...................... 25

3. Mskings Reading. . . . . . . . . . . . . . . . . . . . . 29

39. Tse of Humitity Tables. . . . . . . . . . . . . . . . . . . . . 30

Experiment . Meastring Humilig. . . . . . . . . . . . . . 30

4i. WethoI o: Habitat Study...................... 30

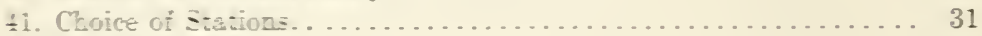

$\because$ Corstant Faciors. . . . . . . . . . . . . . . . . . . . . . . 31

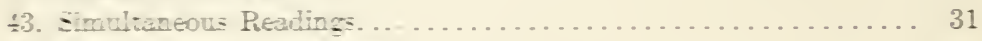

$\div$. Poin: and Hour Peacing=. . . . . . . . . . . . . . . . . . . 33

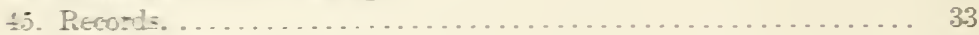

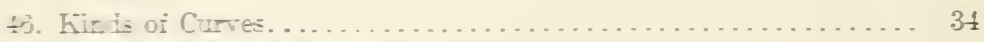

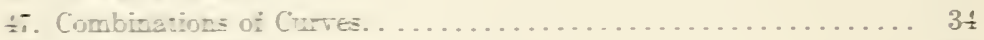

๓. Plotting Curtes. . . . . . . . . . . . . . . . . . . . . . . 35

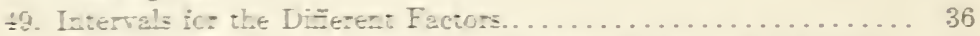

Experiment. 5. Deterccining the Physical Factors oì Habitats. . 36

\section{CHAPTER III}

$A D J T T I E N T$ TO WATER

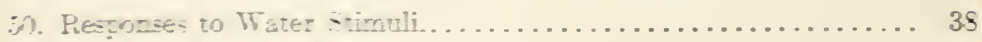

ABSORPTIO:

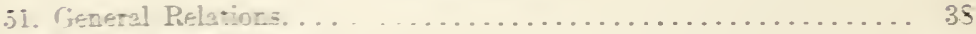

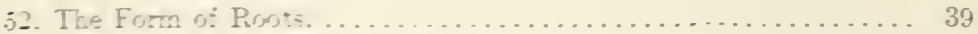

53. Primar: Pegio $=0$ the Prost. . . . . . . . . . . . . . . . 39

j: Letsiled structue . . . . . . . . . . . . . . . . . . . .

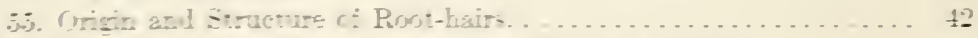

jfo. Efert o: Water Conten: urn Prot-hairs arrl Prots. . . . . . . . 43

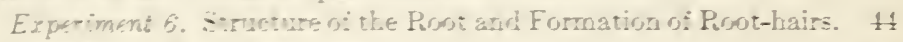

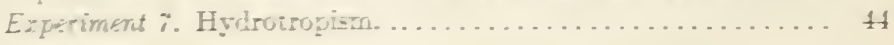


57. Imbibition

PASE

59. Osmosis in Poot-hairs. . . . . . . . . . . . . . . . . . . 16

60. Influence of soluble salts.....................

Experiment 9. Demonstration of Osmosis..............

Experiment 10. The Effect of Soluble salts............. t7

61. Effect of Protoplasm upon the Absorption of Soluble salts..... is

62. Diffusion. ............................ 4 .

Experiment 11. Difiusion in Liquid and in Tissues.......... 49

63. Turgidity. .............................. 49

Experiment 12. Demonstration of Turgidity........... 50

TRANSPORT

64. General Iature............................ 50

65. Trpes of Stem Structure. . . . . . . . . . . . . . . . . 51

66. Stem Structure of an Herbaceous Dicotyledon. . . . . . . . . . 52

67 . Stems of Monocotyledons. . . . . . . . . . . . . . . . . . 53

6s. Structure of Woody Stems. . . . . . . . . . . . . . . . . 5.3

69. Functions of the stem. . . . . . . . . . . . . . . . . . . $5 \frac{1}{1}$

Experiment 13. Structure of Stems................ 51

70. The Lpward Movement of the Water................. $5 t$

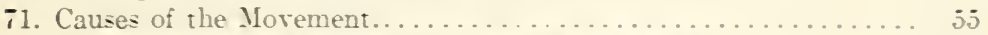

Experiment 1f. Pathway and Rate of Morement........... 50

TraISPIRATION

i2. The Structure of a Representative Leaf. . . . . . . . . . . . . 56

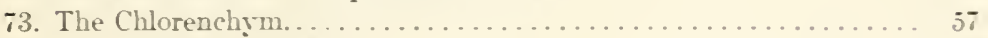

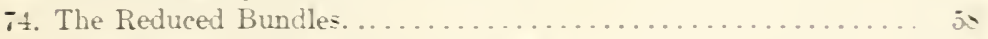

Experiment 15. Structure of a Leaf.................. ss

75. Diffusion in the Leai. ............................. is

76. Transpiring surface. . . . . . . . . . . . . . . . . . 59

Experiment 16. Measurenent of the Actual Transpiring suriace. 59

7 . Structure and Position of Stomata................... 60

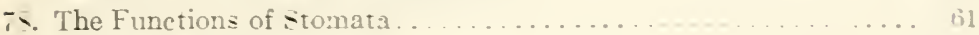

79. Morements of Guard-cells....................... 61

Experiment 1\%. Movement of Guard-cells............. 6. 62

Experiment 15. Position of stomata and Water Loss........ 62

s0. The Influence of Physical Factors lipon Transpiration......... 0.3

81. The Measurement of Transpiration. . . . . . . . . . . . . 64

s. Measuring Transpiration in the Field. . . . . . . . . . . . 65

Experiment 19. Infuence of Factors upon the Rate of Transpira-

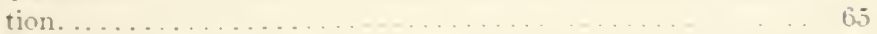

83. The Amount of Transpiration in Plants ............ (x)

st. Relation between Transpiration and Aburption ............ 6 os

s5. Compensation for Increased Transpiration . . . . . . . . 6 \& 
S6. Details of the Adjustment. . . . . . . . . . . . . . . . . 69

Experiment 20. Pathway of Adjustment............. T0

\section{CHAPTER IV}

\section{ADJTSTMENT 'TO LIGHT}

87. Relations of the Plant to Light. ................. 71

S8. The Nature of Light Stimuli. . . . . . . . . . . . . . . . 72

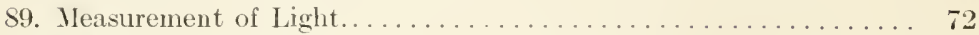

90. Making a Standard. . . . . . . . . . . . . . . . . . . . 73

91. Making Readings. . . . . . . . . . . . . . . . . . .

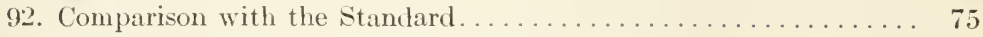

93. Causes of Variation in Light Intensity. . . . . . . . . . . 75

94. The Effect of Time. . . . . . . . . . . . . . . . . . . 75

95. The Effect of Altitude. . . . . . . . . . . . . . . . 6

Experiment 21. Measuring Light Intensity. ........... 77

96. Reception and Absorption of Light. . . . . . . . . . . . .

97. The Amount Absorbed. . . . . . . . . . . . . . . . . . . . . . . 77

Experiment 22. Epidermis and Leaf Prints............ 78

98. The Production of Chlorophyll. ................. 79

99. The Nature of Clilorophyll. . . . . . . . . . . . . . . . . 79

100. The Influence of Darkness. . . . . . . . . . . . . . . . . . so

Experiment 23. Influence of Light and Darkness........... 81

101. Photosynthesis........................... 81

102. Absorption and Diffusion of Carbon Dioxide............. $\$ 1$

103. Chemical Changes during Photosynthesis................ 82

Experiment 24. Dependence of Photosynthesis upon Aeration

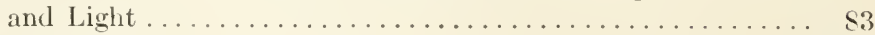

104. Measurement of Photosynthesis. . . . . . . . . . . . . 83

Experiment 25. Relation of Photosynthesis to Sun and shade. . 83

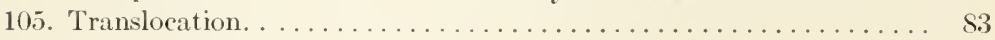

Experiment 26. Translocation................. 84

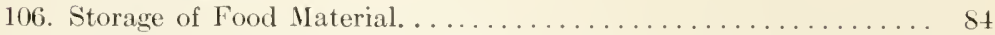

Experiment 27. Storage Tissues................. 85

107. Influence of Light upon the Number and Position of Chloroplasts. 85

Experiment 28. Arrangement of Chloroplasts........... st

108. Movement of Stems and Leaves..................... si

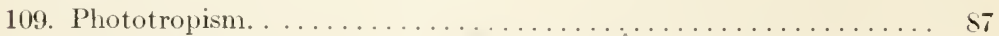

Experiment 29. Plototropic Movements............. 89

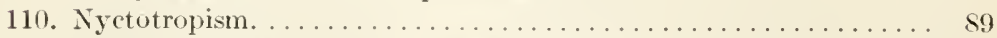

Experiment 30. Nyctotropic Hovements.............. 89

\section{CHAPTER $\mathrm{V}$}

\section{ADJLSTMENT TO TEMPERATURE}

111. Relations of Plants to Temperature.................... 90

112. The Measurement of Temperature................. 91 


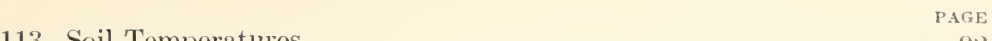

113. Soil Temperatures. ........................ 92

114. Plant Temperatures....................... 92

Experiment 31. Temperatures of Plant and Habitat......... 93

115. Variations of Temperature. . . . . . . . . . . . . . . . $9 t$

116. The Influence of Other Factors. . . . . . . . . . . . . . . 9.)

117. Favorable and Unfavorable Temperatures.............. 9.

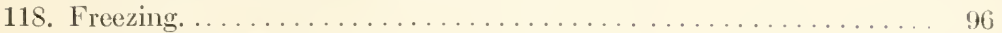

Experiment 32. Effects of Freezing. . . . . . . . . . . 97

119. The Sum of Temperatures. . . . . . . . . . . . . . . . . 97

120. Influence upon Vegetation ...................... 9s

121. Digestion. . . . . . . . . . . . . . . . . . . . . . 99

122. Chemosynthesis of Digested Materials. . . . . . . . . . . . 100

123. Respiration. . . . . . . . . . . . . . . . . . . . . 101

124. Fermentation. . . . . . . . . . . . . . . . . . . . . . . 102

125. Germination. . . . . . . . . . . . . . . . . . . . . . 102

Experiment 33. Digestion and Respiration in Seeds.......... 103

126. Nutrition of Hysterophytes. . . . . . . . . . . . . . 10t

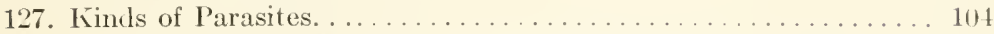

Experiment 34. Nutrition of Representative Hysterophytes. . . . 10.5

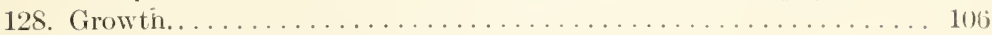

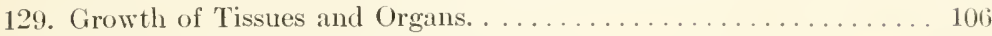

Experiment 35. Regions of Growth ............... 10 . . . . . .

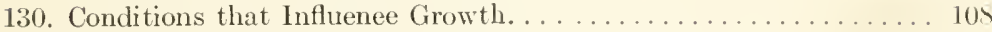

131. The Amount and Rate of Growth. .................... 108

132. Regions of Greatest Growth in Various Organs............... 109

Experiment 36. Influenee of Temperature, Water and Light upon

Regions of Growth. . . . . . . . . . . . . . . . . . . 110

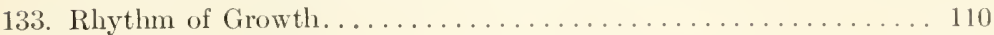

134. The Age of a Plant. . . . . . . . . . . . . . . . . . .

135. Reproduction. . . . . . . . . . . . . . . . . . . .

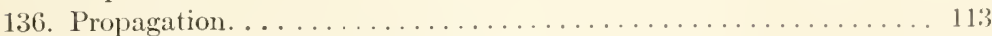

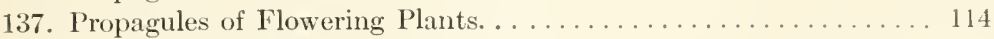

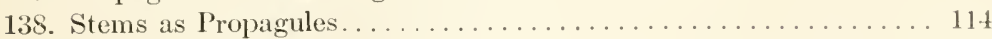

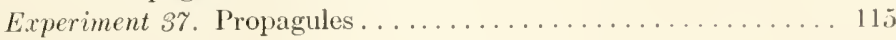

139. Sexual Reproduetion........................ 115

140. Produetion of Pollen. ....................... 116

Experiment 38. Amount of Pollen. . ............... 118

141. Protection of Pollen. . . . . . . . . . . . . . . . . . . . . 11 s

142. Structural Proteetion. . . . . . . . . . . . . . . . . . . 119

143. Proteetion by Movement. . . . . . . . . . . . . . . . . 120

144. Seasonal Proteetion. .......................... 1:1

Experiment 39. Proteetion of Pollen. . . . . . . . . . . 122

145. Disposition of the Stamens and Pistils............... 122

Experiment 40. Grouping of Stamens and Pistils. . . . . . . 1:3

146. Source and Destination of Pollen. . . . . . . . . .

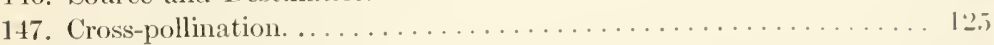

148. Pollination by Inseets. . . . . . . . . . . . . . 


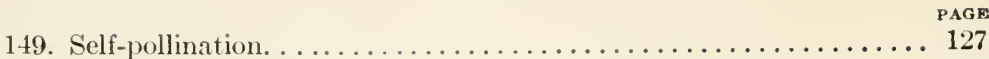

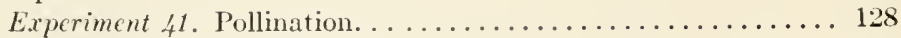

150. The Period of Flowering. . . . . . . . . . . . . . . . . 128

151. Time of Daily Flowering. . . . . . . . . . . . . . . . 130

Experiment 42. Time of Flowering. ............. 131

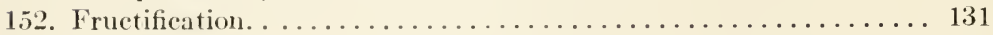

153. Fleshy Fruits. . . . . . . . . . . . . . . . . . . 131

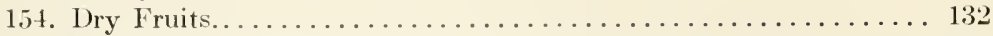

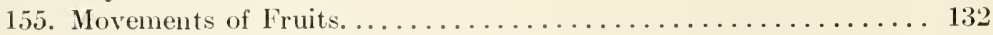

Experiment 43. Kinds of Fruits................ 133

\section{CHAPTER VI}

\section{ADJUSTMENT TO GRAVITY, CONTACT AND SHOCK}

156. The Relation of the Plant to Gravity. . . . . . . . . . . 135

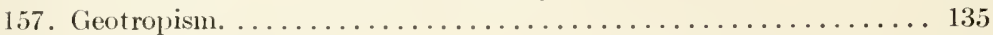

158. Cause and Reaction........................... 137

159. Region of Curvature......................... 138

160. Ecologieal Signifieanee of Geotropism................ 139

Experiment 44. Cieotropism.................... 139

161. Response to Contaet. . ....................... 141

Experiment 45. The Behavior of Tendrils ............ 142

162. Response to Shoek. . . . . . . . . . . . . . . . . . . 142

Experiment 46. Response to Shock. .............. 143

\section{CHAPTER VII}

\section{ADAPTATION TO WATER}

163. The Relation of Struetures to Water................. 114

164. Adaptation to a Small Water Supply. ................. 144

165. Decrease of Water Loss through Leaf Position . . . . . . . . . . . 145

166. Deerease through the Rolling of the Leaf . . . . . . . . . . 145

167 Reduction of Leaf or Stem. . . . . . . . . . . . . . . 147

168. Changes of the Epidermal Cells. . . . . . . . . . . . . 147

169. Modifications of the Stomata. . . . . . . . . . . . . . . 148

170. Changes in the Chlorenehym. . . . . . . . . . . . . . . 150

171. Increase and Storage of IVater Supply............... 151

172. Adaptation to Excessive Water Supply. . . . . . . . . . . 152

Experiment 47. Experimental Adaptation to Water........ 153

173. Types of Plant Body. . . . . . . . . . . . . . . . . . 154

17. Types Produced by Adaptation to Water................ 155

175. Ceneral Features of Serophytes. . . . . . . . . . . . . . 156

176. Types of Leaf Xerophytes . . . . . . . . . . . . . . . 156

177. Normal Leaf Xerophytes.......... . . . . . . . . . . . . . 157

178. Storage Leaves. . . . . . . . . . . . . . . . . 158 
179. Lanate Leaves.

Experiment 48. Study of Normal Leaf Xerophytes. . . . . . . . 159

180. Other Leaf Xerophytes... . . . . . . . . . . . . . . . . . . . 159

Experiment 49. Study of Nerophytie Leaves. . . . . . . . . . . 162

181. Stem Xerophytes........................... 162

182. Types of Stem Xerophytes. . . . . . . . . . . . . . . . 162

Experiment 50. Form and Structure of Stem Xerophytes.... 164

183. Mesophytes................................. 164

Experiment 51. Comparison of Mesophyte and Xerophyte.... 165

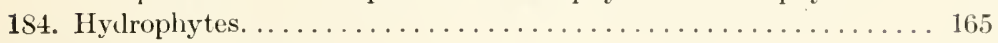

185. Amphibious Plants. . . . .................... 166

Experiment 52. Structure of Amphibious Plants. ... . . . . . . 167

186. Floating Plants. . . . . . . . . . . . . . . . . . . 167

Experiment 5s. Strueture of Floating Plants............ 168

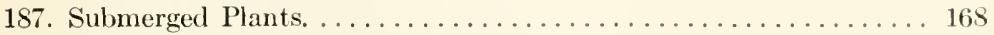

Experiment 54. Structure of Submerged Plants............. 169

188. Bog Plants. . . . . . . . . . . . . . . . . . . . . . 168

Experiment 55. Study of Water Content Types........... 170

\section{CHAPTER VIII}

\section{ADAPTATHON TO LIGHT}

189. The Relation of Organs to Light. ................... 171

190. Influenee of the Chloroplasts. . . . . . . . . . . . . . . . 171

191. Modifications of the Chlorenchym. . . . . . . . . . . . . . 172

192. Sponge Tissue. . . . . . . . . . . . . . . . . . . . . . 17

193. Palisade Tissue. . . . . . . . . . . . . . . . . . . . 176

194. Changes of the Epidermis. . . . . . . . . . . . . . . . . 177

195. The Form of Leaves. . . . . . . . . . . . . . . . . . 178

196. Changes of Outline, Size and Thickness................ 178

197. The Form of Stems. . . . . . . . . . . . . . . . . 179

Experiment 56. The Produetion of Adaptations to Light. . . . . . 181

198. Types of Leaves as Determined by Light. . . . . . . . . . . . . . 18:2

199. Sun Plants and Shade Plants. . . . . . . . . . . . . . . 18:3

Experiment 5\%. Sun and shade Forms in Nature........... 1st

\section{CHAPTER IX}

\section{THE ORIGIN OF NEW FORMS}

200. The Law of Evolution. . . . . . . . . . . . . . . . . . 18.5

201. Stability and Plastieity. . . . . . . . . . . . . . . . . . 1 . . . . . . . . . . . .

202. Constant and Inconstant Forms. . . . . . . . . . . . . . . . . 1

203. Origin by Descent lefore 1)arwin . . . . . . . . . . . . . . .

204. Darwin and the Origin of Species. . . . . . . . . .

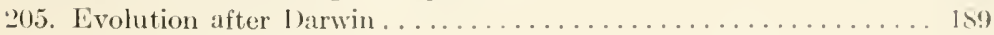


206. Fundamental Methods of Erolution. . . . . . . . . . . . . . . 191

207. Origin by Adaptation. . . . . . . . . . . . . . . . . . . 192

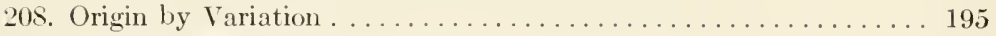

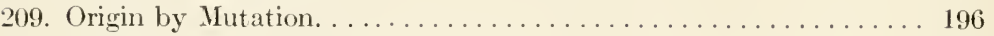

210. Origin by Hybridation. . . . . . . . . . . . . . . . . . . . 197

Experiment 58. The Occurrence of New Forms in Nature... . . 198

211. Natural Selection. ........................... 198

212. Isolation. . . . . . . . . . . . . . . . . . . . . . . . . 199

213. Polygenesis. . . . . . . . . . . . . . . . . . . . . . . . . . 199

214. Experimental Evolution...................... 201

CHAPTER X

\section{METHODS OF STUDYING VEGETATION}

215. The Study of Vegetation. . . . . . . . . . . . . . . . . . . . 202

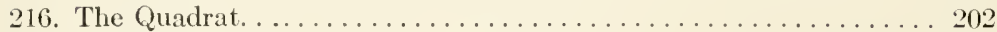

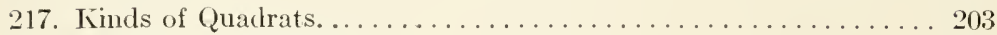

218. Marking out Quadrats. . . . . . . . . . . . . . . . . . . . 204

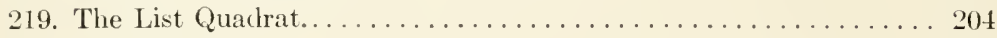

220. Abundance. . . . . . . . . . . . . . . . . . . . . . . . . 205

221. The Chart Quadrat. ........................... 205

222. Making Quadrat Charts. . . . . . . . . . . . . . . . . . . 206

223. The Permanent Quadrat. . . . . . . . . . . . . . . . . . . . . 208

224. The Denuded Quachrat. . . . . . . . . . . . . . . . . . . . . . . 209

225 . Transects. . . . . . . . . . . . . . . . . . . . . . . 210

226. The Line Transect. . . . . . . . . . . . . . . . . . . . 210

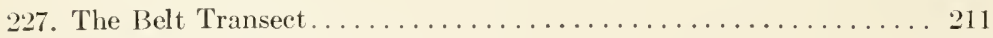

22S. The Migration Circle. . . . . . . . . . . . . . . . . . 212

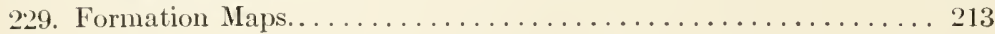

\section{CHAPTER XI}

\section{THE PLANT FORMATION}

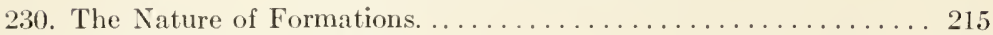

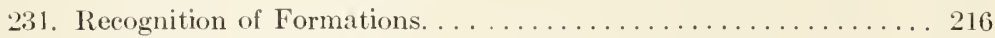

232. Rehation between Habitat and Formation............... 218

233. The Historical Factor. . . . . . . . . . . . . . . . . . . 219

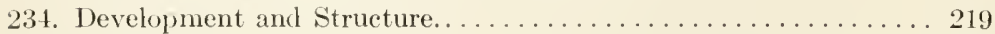

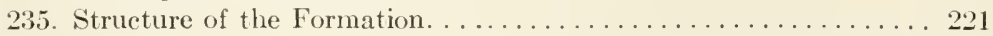

236. Facies. . . . . . . . . . . . . . . . . . . . . . 221

237. Principal and Secondary Species. . . . . . . . . . . . . 222

238. Aspects. . . . . . . . . . . . . . . . . . . . . . . . 223

Experiment 59. Study of Abunclance and of Aspects. . . . . . . 224

239. The Parts of a Formation: the Consocies. . . . . . . . . . . 225

240. The Society. . . . . . . . . . . . . . . . . . . . 226 
241. The Community. ......................... 227

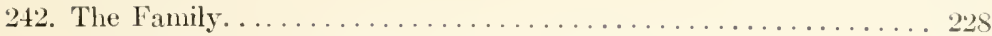

Experiment 60. The Structure of a Formation. . . . . . . . . 229

243. Layers. . . . . . . . . . . . . . . . . . . . . . 229

Experiment 61. Layered Formations. ............... 230

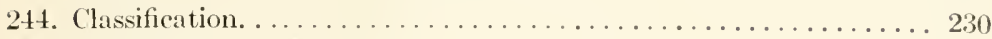

245. Classification by Habitats. . . . . . . . . . . . . . . 231

246. Types of Formations....................... 232

247. Developmental or Physiographic Classification. ............. 233

248. Regional Classification. . . . . . . . . . . . . . . . . . . 234

249. Open and Closed Formations. . . . . . . . . . . . . . . 235

250. Mixed Formations. . . . . . . . . . . . . . . . . . . . 235

Experiment 62. Comparison of Formations............ 236

\section{CHAPTER XII \\ AGGREGATION AND MIGRATION}

251. Aggregation. . . . . . . . . . . . . . . . . . . . . 237

252. Simple Aggregation. . . . . . . . . . . . . . . . . . . 237

253. Mixed Aggregation. . . . . . . . . . . . . . . . . . . . . 239

Experiment 63. Study of Families and Communities........ . 240

254. Migration. . . . . . . . . . . . . . . . . . . . . . . . . . . 240

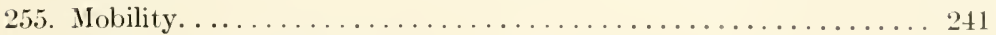

256. Organs of Dissemination. . . . . . . . . . . . . . . . 241

257. Modifications for Migration. . . . . . . . . . . . . . . . 242

258. Influence of Seed Production. . . . . . . . . . . . . . . . 243

259. Position of Disseminules........................ 244

260. The Agents of Migration. . . . . . . . . . . . . . . . . 44

261. The Work of Migration Agents................... 248

Experiment 64. Modifications for Migration............... 249

262. The Dircetion of Migration. . . . . . . . . . . . . . . 249

Experiment 65. Amount and Direction of Migration......... 250

\section{CHAPTER XIII \\ COMPETITION AND ECESIS}

26.3. Competition. . . . . . . . . . . . . . . . . . . . 51

264. The Struggle for Existence. . . . . . . . . . . . . . . . . . .

265. The Nature of Competition . . . . . . . . . . . . . . . . . . . . . . . . . . .

266. The Factors Involved. . . . . . . . . . . . . . . . . . 25:3

267 . Competition for Water and Light. . . . . . . . . . . . . 5.3

268. Competition between Parents and Offspring............. 25t

269. Competition between Jifferent Species. . . . . . . . . . . . . 25.)

270. Influence of Vegetation Form and Habitat Form. . . . . . . . 256

271. The Effect of Position. . . . . . . . . . . . . . . . 256 


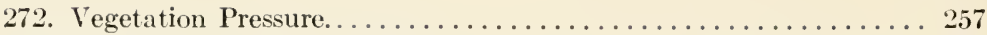

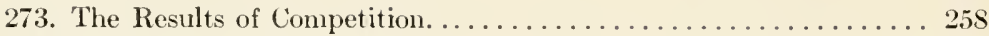

274. The Study of Competition. . . . . . . . . . . . . . . . 259

275. Competition Cultures........................... 259

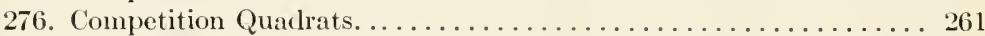

Experiment 66. Competition. .....................261

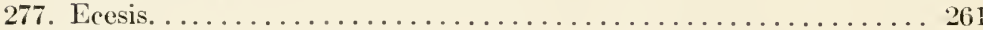

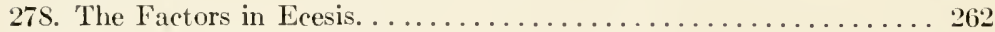

279. Germination of the Seed........................ 263

280. The Effect of Habitat................................... 264

281. Adjustment to the Habitat...................... 265

Experiment 67. Influence of Habitat Form upon Ecesis. . . . . . 265

282. Barriers. ................................. 265

283. Physical and Biological Barriers...................... 266

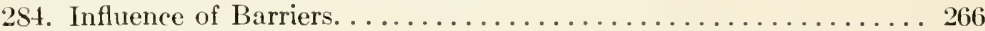

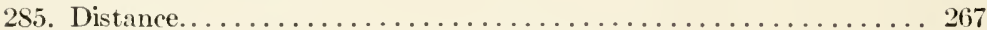

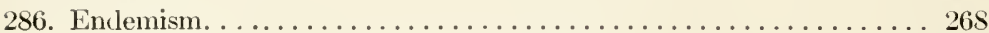

Experiment 68. Barriers and Endemism............... 269

CHAPTER XIV

\section{INVASION AND SUCCESSION}

287. Invasion................................ 270

288. The Manner of Invasion. ........................ 270

289. Invasion at Different Levels. ..................... 272

290. Kinds of Invasion. . . . . . . . . . . . . . . . . . 272

291. Indigenous and Derived Species. .................. 273

Experiment 69. Invasion. . .................... 273

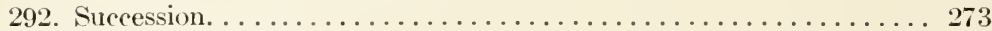

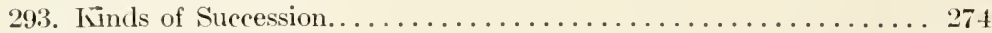

294. Primary Successions. . . . . . . . . . . . . . . . . . 275

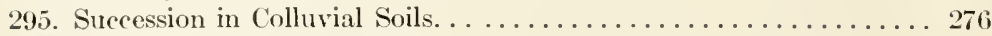

296. Succession in Alluvial Soils. ........................ 277

297. Succession in Eolian Soils ...................... 278

298. Secondary Successions. . . . . . . . . . . . . . . . . .

299. Succession in Eroded Soils....................... 279

300. Succession in Flooded Soils........................... 280

301. Successions Due to Man. . . . . . . . . . . . . . . . . . 280

302. Successions in Burned Areas. .......................281

303. Succession in Lumbered Areas. ................... 282

304. Succession by Cultivation. . . . . . . . . . . . . . . . . 282

305. Reactions of Plants upon the IIabitat.................. 282

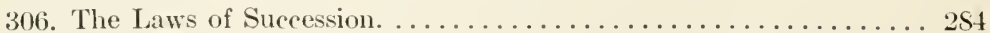

307. The Study of Sucessions........................ 286

308. Nethod of Alternating Areas. ..................... 286

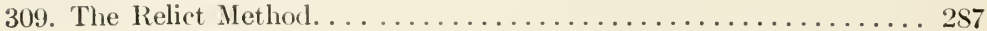

Experiment 70. The Sturly of a Eecondary Succession......... 2SS 


\section{CHAPTER XV}

\section{ALTERNATION AND ZONATION}

310. The Relation between Alternation and Zonation.............289

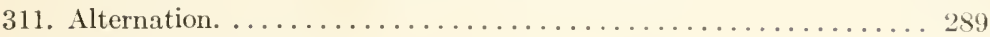

312. Causes of Alternation. . . . . . . . . . . . . . . . . . 289

313. Alternation Due to Ecesis. ......................... . 290

314. Alternation Due to Competition...................... 291

315. Finds of Alternation. . . . . . . . . . . . . . . . . 291

316. Normal Alternation of Facies, Consocies, ete............. 292

317. Normal Alternation of Species. . . . . . . . . . . . . . . . . . . . . 293

318. Numerical Alternation. . . . . . . . . . . . . . . . . . . . . . . 293

319. Corresponsive Alternation. . . . . . . . . . . . . . . . . 294

Experiment 71. Alternation of Species. . . . ...........294

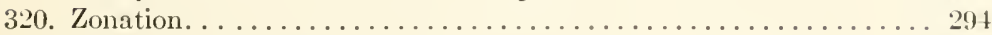

321. Zones Due to Growth. . . . . . . . . . . . . . . . . . . . . . . 295

322. Zones Due to Migration and Ecesis. ................. 296

323. Zones Due to Reaction. .......................... 296

324. Zones Due to Physical Factors. . . . . . . . . . . . . . . . 297

325. Physiographic Symmetry....................... 298

326. Symmetry in Vegetation. . . . . . . . . . . . . . . . . . 298

327. Kinds of Zonation. . . . . . . . . . . . . . . . . . . 299

328. Radial Zonation. ............................... 299

329. Bilateral Zonation................................ 300

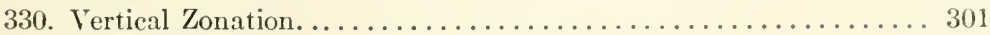

331. Vegetation Zones. .......................... 302

Experiment 72. Zonation of Pond and Meadow Formations.... . 30:3

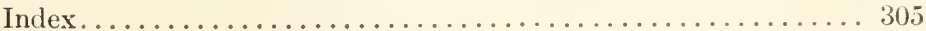





\title{
PLANT PHYSIOLOGY AND ECOLOGY
}

\author{
CHAPTER I

\section{STIMULUS AND RESPONSE}

I. Fundamental relations. A plant is an organism capable of nourishing itself under the control of external conditions, and of modifying its form and structure in accordance with this fact. Hence the most important matter in the study of plants as living things is to find out how the making and the using of food take place, and how the carrying out of these processes affects the structure of the plant. In seeking to explain the behavior of the living plant, i.e., its activities or functions, the first need is to discover the external forces that control it. We must next determine the effects which these produce. These are first seen in the functions of the plant, and in some cases they beeme evident here alone. As a rule, however, many of them appear sooner or later as a change in the minute structure or form of the plant. The proper task of physiology is the study of the external factors of the environment or habitat in which the plant lives, and of the activities and structures which these factors call forth. The former are causes, the latter effects. The sequence of study is consequently factor, function, and form, and the primary ohject to discover the nature and amount of this fundamental connection between the causative factors and the resulting functions and forms.

Physiology was originally understood to he an inquiry into the origin and nature of plants. This is the view that pervades the following pages, and in accordance with this the subject-matter of ecology is merged with that of physiology.

2. The nature of stimuli. Any factor of the habitat that produces a change in the functions of a plant is a stimulus. The 
real test of the latter is therefore furnished by the plant, since the presence of a stimulus can only be ascertained by the response made by the plant. Moreover, while it is possible for the effect of a stimulus to remain invisible or latent for a time, a factor which works in this way can never be recognized as a stimulus until its effect becomes apparent. Stimulus and response are consequently not only inseparably connected, but the latter is the only obtainable evidence of the action of habitat factors. Since plants grow constantly under slight fluctuations in the habitat, it has come about that they do not respond to minute differences of factors. Living plants are in constant response to stimuli, and they are stimulated anew only by an increase or decrease in the factor sufficient to bring about an appreciable change in a function. Sometimes the total withdrawal of a factor acts as a profound stimulus, as in the case of a plant placed in darkness. The nature of the plant itself is of the utmost importance in determining what differences are sufficient to constitute stimuli. A species whose characters have been fixed by heredity responds much less readily to external factors than does one in which the structures are variable or plastic. In other words, a difference sufficient to produce a change in the latter has no effect upon the former. Such a difference constitutes a stimulus for the one, but not for the other. Thus, while light acts as a stimulus to all green plants, a certain change in the intensity of the light is a stimulus only to those plants that are plastic enough to show a response to it.

It has been the practice to distinguish between the tonic action of external factors, such, for example, as that of light upon the chloroplast, and the stimulatory action of such forces, as seen in the bending of leaves toward the light, or the movement of sensitive leaves in response to a shock. In the one case the energy of the impinging factors results in an immediate and usually proportionate amount of work being done. In the other this factor brings about the release of stored-up energy in the plant, which in many instances results in a disproportionate amount of work. However, a careful analysis of these two processes shows that at the bottom they are essentially the same. Furthermore, they are seen to differ only in degree, and not in kind, when one examines the many processes intermediate between the two. 
3. The kinds of stimuli. The simplest grouping of stimuli is with respect to the force concerned. The factors of a habitat are water, soluble salts, humidity, light, temperature, wind, soil, pressure, physiography, gravity, polarity, and biotic factors. Certain ones of these, namely, soil, physiography, pressure, and biotic factors, can act upon plants only through the action of other factors, as a rule. For example, the wind normally influences the plant only through humidity, and the soil through water content. Since a stimulus can be determined only by the response of the plant to it, only those factors that act immediately upon a function can be termed stimuli. These are the universal forces, gravity and polarity, and the physical factors, water, soluble salts, humidity, light, and temperature. With respect to certain mechanical effects, wind may also act as a stimulus, and the same is often true of biotic factors in the case of sensitive, insectivorous, and gall-producing plants. Stimuli are often distinguished as internal and external, but the distinction is of little value. This is due to the fact that internal stimuli are obscure in nature and effect: it is not improbable that they are merely the latent results of external stimuli. In any event, little can be done with them until more is known of the precise action of external stimuli. It is with the latter alone that our present study is concerned.

4. The nature of response. Plants seem to have no special senseorgans for perceiving stimuli, and no definite sensory tracts for transmitting them. Consequently an external stimulus acting upon a plant is ordinarily converted into a response at once. The latter, as a rule, becomes evident immediately. In many cases some time elapses before the final response becomes visible, and in rare instances the response remains latent or imperceptible. A marked decrease in humidity calls forth an immediate increase in the amount of water evaporated from the leaf, but a final response is seen in the closing of the stomata. The response to decreased light, on the contrary, is much less rapid and obvious. This difference in behavior is largely due to the functional response being more marked and more easily perceptible in the first case.

The first response of a plant to a stimulus is always functional. The nature and intensity of the stimulus determine whether this is followed by a structural response also. The amount of re- 
sponse is dependent upon the intensity of the stimulus, and it is in many cases proportional to it. The same stimulus may not produce the same response in two different species, or necessarily in two plants of the same species. It does have this effect in individuals and species that are equally plastic. The study of response is facilitated by distinguishing two kinds, viz., functional and structural. Many reactions to stimuli are functional alone. In a large number of cases a structural change also occurs, and this is the rule when the functional change is pronounced. Consequently, it becomes convenient to distinguish functional response as adjustment, and structural response as adaptation.

5. Adjustment and adaptation. The adjustment of a plant to the stimuli of its habitat is taking place constantly. It is seen daily in the processes of nutrition and growth. As long as the stimuli are normal for the habitat, the adjustment of the plant is restricted to its ordinary activities. But when the stimuli become unusual in amount or in kind, either by a change of habitat or by a modification within it, the consequent adjustment becomes more evident, and is then usually recorded in the plant's structure. Adjustment may be expressed in the movement of parts or organs, such as the closing of stomata or a change in the position of leaves, or in growth or modification of structure. Slight or periodic adjustment usually concerns function alone. Adjustment is profoundly affected by the nature of the factor, and is in direct relation to the intensity of the latter. Adaptation comprises all structural changes resulting from adjustment. It includes both growth and modification. The latter is really growth in response to unusual stimuli, a fact that furnishes the clue to all evolution. Growth is periodic and quantitative: it is the result of the normal and continuous adjustment of the plant to the stimuli of its own habitat. On the contrary, modification is relatively permanent and qualitative: it is the response to stimuli of an unusual kind or intensity. A good knowledge of the way in which growth occurs is indispensable to the understanding of modification. In endearoring to find the connection between habitat and plant, however, it is in the modification of the plant and not so much in its growth that the significant responses to stimuli are to be sought.

In the following survey of the relation between the stimuli, functions, and structures of the plant, the physical factors of the 
habitat and the functional responses to them are considered under adjustment. Growth is also placed here both for convenience and for the reason that it leads logically to the study of modifications. In consequence, the treatment of adabtation is practically confined to modifications of structure.

6. Kinds of adjustment. With respect to the factor concerned, the functional responses of the plant are distinguished primarily as adjustment to water, light, or temperature. Responses to soluble salts are properly considered under water, while the direct changes due to wind usually affect the form of the plant alone. The response to gravity is so universal, final, and absolute that it hardly falls within adjustment proper. Indirect factors, i.e., such as soil, wind, rainfall, pressure, and physiography, which can affect a function only by acting upon another or direct factor, do not properly produce response, but the change resulting from their influence is to be ascribed to the direct factor concerned. For example, the effects of soil, physiography, wind, and pressure are chiefly to be sought under adjustment to water, because of their action upon water content or upon humidity.

7. Normal and abnormal adjustment. The unusual stimuli resulting from a greatly changed habitat or from a new one produce an unusual or abnormal response in function and often in form. Adjustment is consequently to be regarded as normal or abnormal. Normal adjustment is characteristic of a plant that passes from youth to maturity in its own habitat. The functions are carried on in the manner usual to the species, and there is in consequence no modification of structure. Abnomal adjustment occurs in those plants that migrate into a new or different habitat. or those whose habitat is seriously changed. It is characterized, as a rule, by profound disturbance of function, though the latter clearly depends upon the intensity of the change. The most familiar cases of abnormal response are due to biotic factors, particularly parasitic fungi and insects. In most instances of this sort. the disturbance is merely functional, but often also the change in function is follower by a modification in growth or structure, as in the "cedar" apples" and "witches. brooms" produced by rusts, and in the galls due to inserts.

A plant acted upon by a parasitic fungus or insert is said to be in a pathological condition. The study of the effert of the parasite upon the host-plant is called pathology, and it is regarded 
as a subdivision of physiology. A plant that is more or less hindered in carrying out its usual functions by the presence of a fungus exhibits abnormal adjustment due to a biotic factor of the habitat. A sun plant that finds itself placed in the shade has likewise to adjust itself to light stimuli that are abnormal to it. During the period of adjustment it also is in a pathological condition. In both cases the adjustment must be successfully carried out or the plant dies. Consequently normal functioning is physiological and abnornal functioning is pathological. There is elearly no hardand-fast line between the two, since any plant is acted upon by abnormal stimuli while it is getting established in a new habitat, but these same stimuli become entirely normal when the plant has become adapted to them. In studying the behavior of plants, it is both illogical and inconvenient to separate the normal and the abnormal. In the practical study of specific plant diseases, such separation is a matter of convenience, but in an elementary treatment it is undesirable to distinguish pathology from physiology. 


\section{CHAPTER II}

\section{THE WATER OF THE HABITAT}

8. Relation of the plant to water. The responses of the plant to the water of its habitat are so numerous and so essential that water must be regarded as the most important of all factors which affect the plant. This is emphasized by the fact that practically all indirect factors, i.e., soil, wind, etc., can influence the plant only through their action upon water. Water is no more indispensable to ordinary plants than is light or temperature, since a green plant can not live and function if any of these is lacking. It is proper to speak of it as more important, for the reason that water is the immediate cause of a larger number of vital functions. Perhaps the greatest value of water to the plant lies in its use as food. In addition it is the vehicle by which solid foods, i.e., soluble salts, are taken from the soil, and gases, carbon dioxide and oxygen, from the air, and by which the foods made by the leaves are carried to all parts of the plant. It is water that causes the stretching of the cell wall by which growth is made possible, and it also gives the rigidity so essential to stems of herbaceous plants. As a factor of the habitat, though not as a stimulus, water is an important agency in the reproduction of mosses and ferns and in the distribution of the plant body, or seeds of water plants. In the form of humidity, water regulates the loss of water from leaves. Finally, as is to be expected from the above summary, water exerts a much greater influence upon the form and structure of the plant than any other factor.

9. The nature of water stimuli. A terrestrial plant is constantly subjected to the simultaneous action of water stimuli, the water content of the soil acting upon the roots, and the humidity of the air upon the leaves. Water content regulates the water supply, humidity the water loss. The two are compensatory, and 
the final response to a stimulus of either sort can only be determined by reference to the action of the other. An increase or decrease in water loss produces a corresponding change in the amount of water absorbed, and a change in watel supply tends to produce a consequent change in water loss. This is strictly true only when the stimuli are normal. For example, a decrease in humidity causes increased water loss, which is compensated, as a rule, by increased activity at the root surface. Frequently the water supply is insufficient to compensate for heavy or rapid water loss, and the proper balance can be reached only by closing the stomata. In the case of excessive supply or loss, neither compensation suffices, and the plant dies. A change of structure, i.e., adaptation to water stimuli, results when the compensation of supply for loss or the reverse is more or less inadequate, but not to a degree sufficient to cause death. In addition to this fundamental compensating action of water stimuli upon the plant as a whole, water content affects the growth of roots in such a way that the direction of growth is determined by the distribution of the moisture of the soil. The rule is that roots turn and grow toward the area of greatest moisture. This phenomenon is known as hydrotropism: it will be discussed under absorption.

Io. Water content. The water content of a habitat is the total amount of water found in the layer of soil occupied by the roots. The water of lower strata may be raised, and ultimately used by the plant, but it is not properly water content until it reaches the roots. The water is found in the form of thin films surrounding the soil particles. The amount depends upon the thickness of these films. In soils that are saturated the films run together, forming drops and masses of water. In air-dry soils there is still a very thin film about the smallest particles. The amount of water content varies most widely in different habitats. Impervious rocks contain practically none, until cracks and rifts are formed by weathering. Marshes, ponds, streams, etc., represent habitats with maximum water. Dry habitats, such as prairies, plains, gravel slides, sand-hills, ete., have a low water content, varying as a rule from $3-15 \%$. Wet habitats vary from saturation, as in stream banks, wet meadows, bog hummocks, etc., where the pere entage ranges from $20-80 \%$ in accordance with the soil, to the maximum found in bodies of water. Moist habitats, meadows, forests, and eultivated fields nsually contain from $15-30 \%$. 
II. Influence of other factors upon water content. The most important differences between habitats are due to differences of water content. The latter arise largely from the effect of the other factors of the habitat. All of these have an influence either direct or indirect upon the amount of water present, but soil, rainfall, physiography, and humidity are the most important. A sandy soil contains less water than a clay soil, even when both receive the same amount of rain. It goes without saying that a habitat in a desert region has a lower water content than one in a humid region, because of differences in precipitation and humidity. Two habitats with the same soil and atmospheric conditions may owe their difference to slope, which tends to decrease water content. The latter is likewise affected by cover, which prevents rainfall from running away before it can be absorbed, and also decreases the loss by evaporation from the surface of the soil. Heat and wind decrease water content indirectly by decreasing the humidity, particularly upon exposed slopes. The plant covering itself has the effect of a dead cover in reducing evaporation from the soil, but on the other hand it tends to decrease water content, owing to the use of water by the plants.

12. Available and non-available water content. If a rooted plant is allowed to wilt and die, a careful examination of the soil shows that some water still remains. The amount depends upon the kind of soil, but all soils agree in the ability to retain some portion of the water content. This is due to the fact that the attraction of soil particles for the water films increases as the film grows thinner, until finally it is greater than the attraction exerted by the root-hairs. At this point the plant is unable to obtain water, and it rapidly dies by wilting. The water thus held by the soil can not be used by the plant, and it is hence called the nona vailable water, or echard. It is usually hut a small part of the water commonly present, particularly in moist or saturated soils. In a fine-grained compact soil, like clay, the amount of non-available water is large; in coarse-grained soils, e.g., sand and gravel, it is very small. Of the total water content, or holded, the larger portion can be absorbed by the plant, and is comserquently temed available water. The response of the plant to water antent is determined by the amount available for absorption and not by the total amount present. This available water, or chrestrd, differs for the different soils, and for dissimilar species of plants. It is 
diminished by the presence of excessive amounts of salts in the soil, and also by unusually low temperatures. Hence in measuring the water content of habitats the best practice is to determine both holard and chresard, bearing in mind that it is the latter alone that results in adjustment and adaptation.

13. Soil samples. In obtaining samples of soil for finding the water content, the usual practice is to remove the air-dried sur-

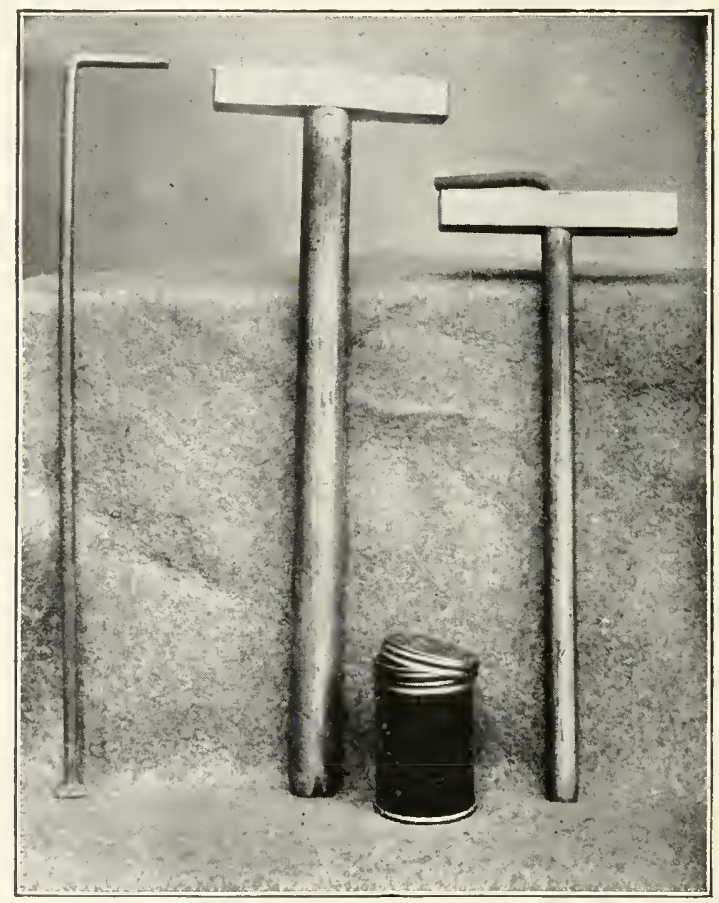

FIG. 1. Geotomes and soil can, showing at the left the plunger for removing the soil core.

face, noting its depth, and then to sink the soil-cutter or geotome, with a slow, boring movement, in order to aroid packing the soil. This tendency is further reduced by cutting a long core a decimeter at a time. As soon as the sample is dug, the plunger is used to press the core from the geotome directly into an air-tight soil can. The lid is serewed on as quickly as possible, and the number recorded immediately with such notes as are desirable. The cans should 
be numbered with paint on both lid and side in such a way that the number may be read at a glance. The rule is to weigh the cans as quickly as possible after the sample is taken, though when necessary they can be kept for several days without appreciable error. For weighing, delicate balances are to be preferred, but when these are not available, coarser balances which weigh accurately to one centigram give satisfactory results. The best method is to weigh the soil sample in the can. Turning the soil out upon the pan or upon paper saves one weighing, but there is always some slight loss, and the chances of serious mishap are many. After weighing, the sample is dried in a water-bath or oven. At a temperature of $100^{\circ} \mathrm{C}$. this is ordinarily done in twenty-four hours; stiff clays require a longer time. High temperatures must be avoided with soils that contain much leaf-mold or other organic matter, in order that this may not be volatilized, and hence lead to an error in the result. When a drying-oven is not accessible, soil samples are dried in the air, preferably in sunshine. This usually takes several days, and a test weighing is generally necessary to determine that the drying-out is completed. The weighing of the dried soil is made as before. The can is carefully brushed out and weighed also.

I4. Computation of water content. To find the percent of water content, the second weight, i.e., of the dried sample and can, $w^{\prime}$, is subtracted from the first weight, $w$, of the original sample and can. The weight of the can, $w^{2}$, is taken from the dried weight, $w^{\prime}$. The first result is then divided by the second, and the result is the percent of total water content, i.e., holard, figured upon the dry soil as a basis. The formula is $\frac{w-w^{\prime}}{w^{\prime}-w^{2}}=W$, in which $W^{r}$ is the holard in percent. Water content has generally been computed upon the moist soil as a basis. ${ }^{1}$ This method leads to inexactness in the comparison of habitats, however, and should be abandoned. Since most of the results so far obtained have been made in this way, it is necessary at present that the basis be taken into account in comparing the results of different workers. The most satisfactory method for the present is to express the results in grams per hundred grams of moist soil. For example, 20/100 indicates a water content that is $20 \%$ of the moist weight or $25 \%$ of the dry weight. 
I5. Time of water content readings. Fince conditions in a plant-house are nearly constant. a single reading of water content made at any time is iairly representative. This is not the case in the field. oming to the infuence of rainiall. eraporation. and gravity in changing the amount of soil water. An isolated reading has rery slight value. and it is thereiore necessary to obiain a basi- for comparison by making either a series of readings in one place ai different times or in different places at the same time. Whenever the proper amount oi time can be given to feld work. the best method is to select a series ô stations or habitats. and to take readings throughout the entire series at differen imes. Under ordinary conditions the time of day at which a particular sample is taken is of little importance. since the rariation during a day is usually slight. This does not apply to exposed wet soils or to soils which have just been wetted by rain. When a series of readings is made in different places. however. it is better that the readings be made in rapid succession. Simultaneous readings are necessary only when it is desired to determine whether there is a difference in the rate of loss in the various habitats.

I6. Location of readings. In determining the location of readings in the field. it is desirable to obtain as great a range as possible. Where the topography is much broken. as in mountain resions. a series of stations a mile long will include a number of different habitats. In general. fewer habitats are accessible, and it is then recessary to locate a station in each of the more or less diverse areas of each habitat. Gras-land. woodland. and marsh show striking differences of water content as well as of other iartors. A hilly prairie that drops through meadowland into fores offers an unusually good opportunity for a series of stations that will show the effect of soil. slope. corer. etc.. upon the water content. On account of the small differences always present. each station should be definitely lorated where differences of soil. Sope. eic.. are the most striking. For the sate of future resrlings. the exact location of each station is permanently markerl and rerorderl. Successive readings are made as nesr to the prererling ones as possible. though new samples should not be taken tor near the old holes. A difierence of a few ifet prorlures no appreriable error. if the station is uniform in charecier. 
17. Depth of samples. The general rule is that the depih oi soil samples is determined by the distance to which the roots penetrate. The practice is to remore the air-dried suriace in which no roots are found. and to take a sample to the proper depth. When the actively absorbing root suriaces are localized. as in deep-rooted plants. it is necessary to confine samples to the area in which absorption occurs. This is especially true when the water supply of a particular species of plani is to be determined. but, in the case of regetation in general. roots penetrate to such difierent depths that a sample which includes the greater part of the distance concerned is satistactory. The usual depth oi a sample is 3 decimeters. In shallow or wet soils. cores to a depth of 1 or 2 decimeters suffice. while in very dry soils. and in the case of shrubs and irees, deeper samples are required.

Experiment I. Measurement of water content. Take a $2-d m$. sample from a dry soil and another irom a mois soil: take one also from a sand and a loam. Weigh. dry, and compute percentages upon the basis of the dry soil.

18. The determination of available water. The amount of water that a plant can absorb from the soil can be readily determined only by finding the amount leit when the plant wits completely. This determination can easily be made in the laboratory or plant-house. though in the field it is attended with some difficulty. A thrifty plant growing in a pot of medium size is the best for the purpose. It is necessary that the pot be glazed or covered with sheet rubber in order io prevent too rapid drying of the soil. At the beciming of the experiment. three soil samples are taken in such a manner that they will indicate any variation in water content in different parts of the soil. The depth of the core is regulated by the size of the por and the position of the roots. The holard is found in the usual way. and is expresical upon the basis of $1(x)$ grams of dry soil. e. . 2.) $1(x)$. The average of the three samples is taken as representative: this arerare is most readily arrived at by weighing and drying the samples in one can. The soil is then permitted to dry out slowly. sudden drouth often impairs the power of aheorption. and the plant wilts even though considerable arailahle water is present. The proper time to take the second reading is indicatenl by the ihorough wilting of the leaves. It is undesirahle to wait for con- 
plete wilting, since the younger parts are able to draw upon $t$ watery tissues of stem and root for some time after the pla is unable to obtain water from the soil. Three samples are aga taken from the soil, and the average water content determint as before. This is the non-available water or echard. This likewise computed for 100 grams of dry soil, and the result subtracted from the holard. The final result is the availab. water, or chresard, expressed in the number of grams to 100 gram of dry soil.

I9. Chresard of habitats. In order to find the amount c water available for a plant in its own habitat, it is necessary $t$ produce wilting by cutting off the water-supply. 'This is accom plished by digging up a plant in its own soil and transferring it to a pot of good size. The pot is placed in the hole from which the plant is taken, and a canvas awning arranged to prevent wetting by the rain. Where the distance of the habitat makes this method difficult or impracticable, the plant is transferrec to the plant-house. In either case the soil samples are takes as indicated above, and the chresard is arrived at in exactly th same way. 'The available and non-available water of six rep resentative soils, together with the amount necessary for satu ration, are indicated in the following table. The figures servt equally well to indicate percentages and the number of grams of water for each 100 grams of dry soil. It must be clearly recognized that these figures will not be exactly the same for erery kind of sand, elay, etc.:

\begin{tabular}{|c|c|c|c|}
\hline Soil & Holard & Echard & Chresard \\
\hline 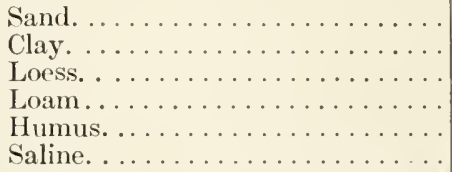 & $\begin{array}{l}14.3 \\
47.4 \\
59.3 \\
64.1 \\
65.3 \\
68.5\end{array}$ & $\begin{array}{r}9.3 \\
10.1 \\
10.9 \\
11.9 \\
16.2\end{array}$ & $\begin{array}{l}14 \\
38.1 \\
49.2 \\
53.2 \\
53.4 \\
52.3\end{array}$ \\
\hline
\end{tabular}

Experiment 2. Determination of available water. Germinate sunflower seeds in sand and in rich garden soil. Transplant the seedlings from time to time so that they will be from 1 to 2 feet in height when they reach a 6 -inch pot. Find the holard and echard in the way indicated, and from these compute the available water content of each soil. 


\section{MODIFYING FACTORS}

20. Influence of soil upon water content. The soil of a habitat is of the greatest importance in determining the amount of water content, and also the kind of water, i.e., the chemical substances found in solution. The amount of water present is directly dependent upon the texture or fineness of the soil, that is, upon its physical properties. The kind and amount of nutrient material dissolved in the water are determined by the chemical nature of the soil. In studying the influence of the latter, it is conse-

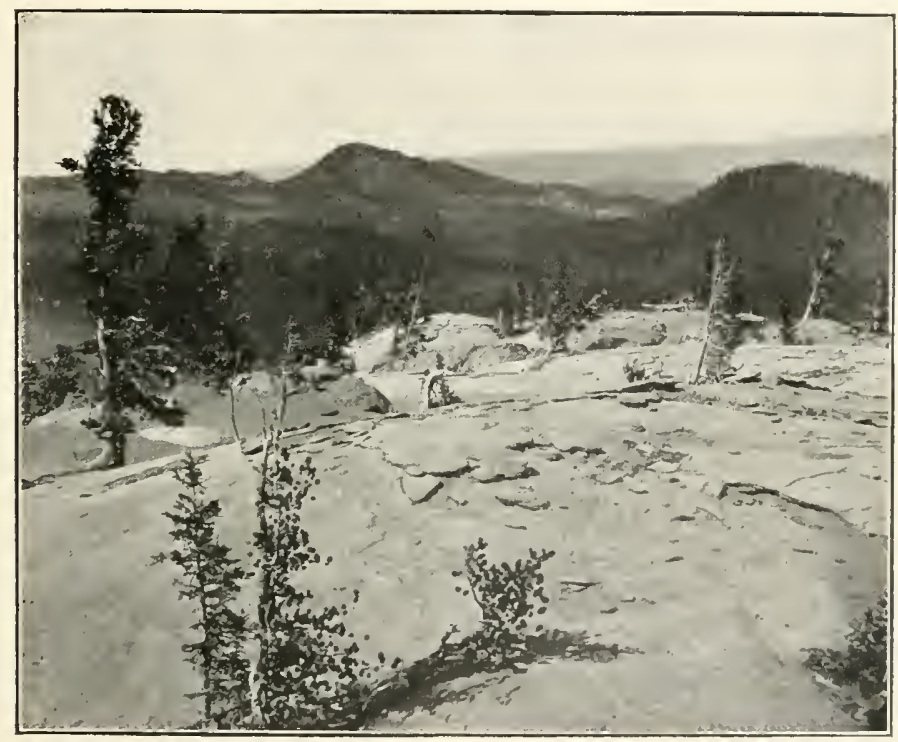

FIg. 2.-Glacial boulders at Lake Moraine, helow Pike's Prak, in which the clisintegrating action of weather is aided by the roots of trees.

quently necessary to examine the physical structure and to determine the chemical composition. These are not of equal value. however. The amounts and kinds of soluble materials in all ordinary habitats are so nearly alike that differences in chemical composition are of little importance. They play a large part only where soluble chemical compounds are present in excessive amomnts, as in alkaline soils, or when the amount of humus is 1musually large or deficient. An exeess of soluble salts himlers absorption 
and reduces the chresard. while an excess of acids has the opposite effect. The structure of the soil, on the contrary, has an almost absolute control upon the fate of the water that enters the ground, in addition to its influence upon the water that runs off. It determines the amount of water drained away in response to gravity, and also the amount that can be raised from the lower layers by means of capillary action. The total water content is dependent in the first place upon the amount of water that soaks into the soil. Of this, the holard is that part which the soil holds in spite of the action of gravity, together with that which may be raised from time to time by capillarity. The chresard, however, is only that part which the root-hairs are able to take up in opposition to the pull of the soil particles.

2I. Origin and structure. Soils are formed from rock by the action of weathering. The latter is due to the influence of

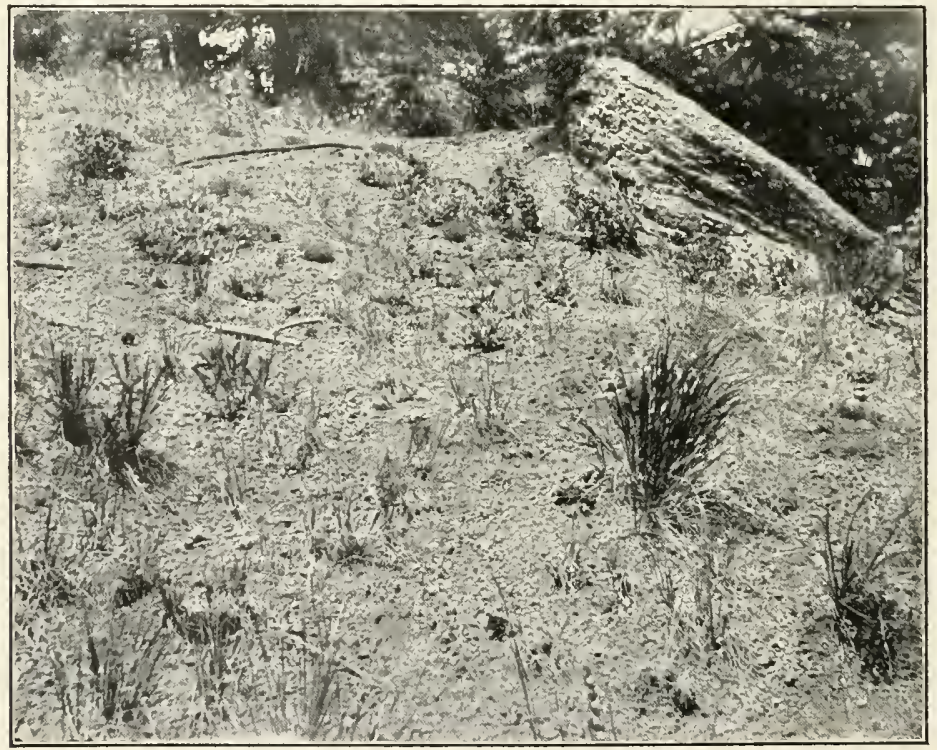

FIG. 3.-Decomposition of a granite boulder into gravel and sand, and the further breaking down of these by the roots of herbaceous plants.

both physical and biological factors, acting separately or together. Weathering consists of two processes. The one is disintegration, by which the rock is broken into fragments of various sizes; the 
other is decomposition, by means of which the original rock, or its fragments, is broken down into minute particles. These two processes usually go hand in hand, although as a rule one is more marked than the other. Their relative importance is determined by the character of the rock, and by the forces that act upon it. Hard rocks, e.g. granite, as a rule, disintegrate more rapidly than they decompose, while sedimentary rocks, such as sandstone, limestone, etc., tend to decompose more rapidly than they disintegrate. In many cases of weathering, the two processes are of equal importance.

22. Water capacity. A soil owes its capacity for water to the fineness of its particles. Since the water is in the form of

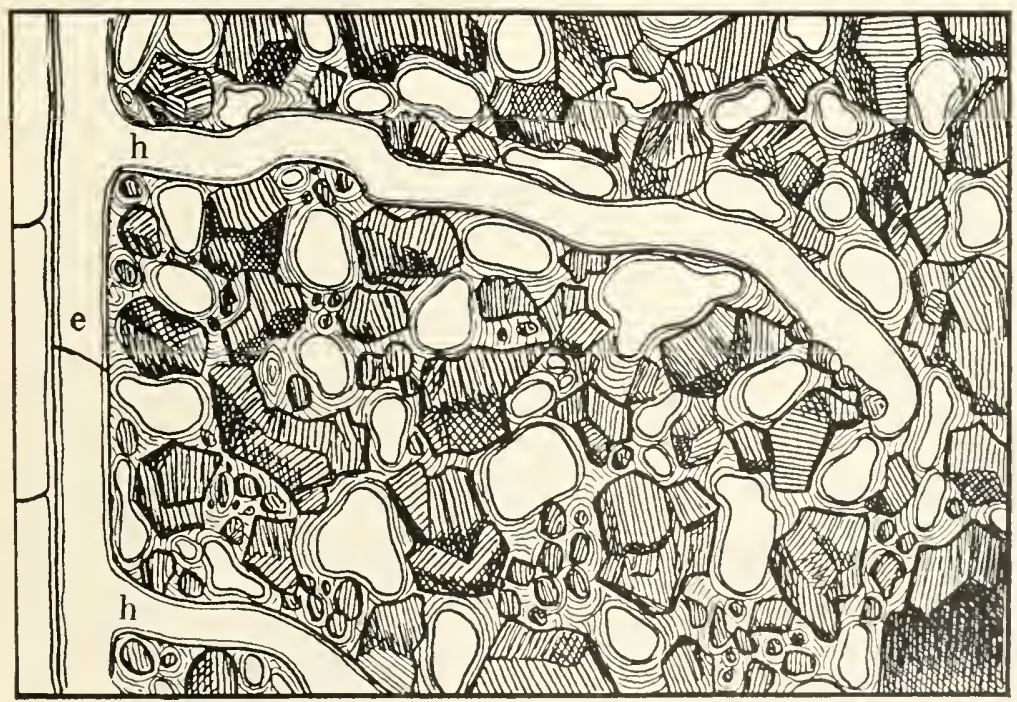

FIG. 4.-Diagrammatic sketch showing the structure of a fine soil and the position of root-hairs in it. The rnot epidermis (e) gives rise to roothairs $(h)$ which push their way between the angular soil particles surrounded by thin water films. The air spaces are white. (After Sachs.)

thin films upon the soil particles, the amount necessarily increases with an increase in the water-holding surface. The latter is increased as the particles become finer and more numerous, and thus produce a greater aggregate surface. The movement of water upward and downward in the soil is likewise dependent upon the size of the particles. As the latter become finer, the 
irregular eapillary spaces between them grow smaller, and the upward or capillary movement is increased. On the contrary, the downward movement of water, i.e., pereolation, which is caused by gravity, is retarded by a decreasee in the size of the soil grains, and hastened by an increase. The properties of the soil which regulate the upward and downward movement of water are respectively capillarity and porosity. Both are dependent upon the structure or fineness of the soil, though in a manner directly opposite to each other. Capillarity increases with the fineness of the soil, porosity with its coarseness. Capillarity augments the water content of the upper layers, while porosity decreases it. Upon this basis alone, soils fall into two groups, capillary soils and porous soils, the former fine-grained and of high water content, the latter coarse-grained and with relatively little water. However, a third factor of great importance must be taken into account. This is the pull exerted upon each water film by the soil particle itself. The pull seems to increase in strength as the film grows thinner, and this explains why it finally becomes impossible for the root-hairs to draw moisture from the soil. This property, like capillarity, is most pronounced in fine-grained soils, such as clays, and is least evident in the coarser sands and gravels. It furnishes the explanation of non-available water, and indicates that the chresard is directly connected with soil texture.

23. Chemical nature of soils. Apart from the effect of excessive amounts of acids or salts, the chemical nature of the soil is of slight importanee, except in the case of soils exhausted by intensive cultivation. In nature the necessary nutrient salts are so uniformly distributed that the chemical composition of the origmal rock is immaterial. A soil can modify the plants upon it only through its water content, or the soluble salts, or solutes, that it contains. Hence, when differences of structure or distribution occur between habitats with different soils, the cause is not to be sought in the fact that the soil is silicious, calcareous, or argillaceous, but in the effect of the texture upon water content. It now appears entirely incorrect to ascribe the presence or absence of eertain species on limestone soils to the chemical nature of the latter. The most important chemical elements in the soil appearing in the form of salts and connected with the growth of green plants are nitrogen, sulphur, phosphorus, iron, 
potassium, calcium, and magnesium. These occur usually as nitrates, sulphates, phosphates, chlorides, carbonates, or oxides.

The effect of alkalies and acids in the soil upon water content and absorption is not altogether understood. Experiments indicate that alkalies hinder absorption, and acids promote it. In other words, alkalies reduce the amount of available water, while acids increase it. Alkaline soils are really dry soils, a fact clearly established by the character of the plants that grow upon them. On the contrary, acid soils are wet; usually indeed they show maximum water content. They contain plants which are adjusted to an excessive water supply. The majority of such plants exhibit adaptations to water, but some of them have the appearance of dry land plants, or xerophytes. A careful examination of the structure of the latter reveals modifications due to water. Consequently, it seems almost certain that such "bog xerophytes" are dry land plants, which in coming to grow in ? water have retained certain superficial ear-marks of the original habitats.

24. Air content. In all soils, but particularly in acid ones, the air content is a factor of considerable importance, owing to the constant use of oxygen by the roots. The amount of air present depends upon the water content and the compactness of the soil. Air content varies inversely as the water content: it is large in dry soils and very small in wet ones, especially those covered with water. Water plants, i.e., hydrophytes, show characteristic modifications called forth in response to a low air content. When a soil becomes packed, the movement of the air into and through the soil is impeded, and a very important task of cultivation is to keep the soil so stirred that the air content does not fall too low. "Sour" soils, including "sour" bogs, owe their nature to the production of organic acids in the presence of a low supply of oxygen. When stirring the soil is possible, "sourness" is easily remedied, since complete decomposition prevents the formation of acids.

25. Determination of soil properties. Since the soil is primarily important because of its influence upon water content, the determination of soil texture is the principal task in this connection. In an elementary study of habitats it is sufficient to know that a soil, or the soil water, is acid or alkaline, without further reference to amount. Such a test is readily made in the field by means of fresh strips of litmus paper. Air content is in large degree a result 
of water content, and has but an indirect or obscure effect upon the water present. The texture of the soil is chiefly a matter of size of grains or fineness. The latter can best be ascertained by the use of sieves. Two sieves of $1 \mathrm{~mm}$. and of $.05 \mathrm{~mm}$. mesh will make it possible to separate the soil into gravel, sand, and silt-clay. The structure of the soil is then expressed in percents, e.g., gravel $10 \%$, sand $15 \%$, silt-clay $75 \%$.

A mechanical analysis of a soil throws little additional light upon its behavior with respect to water. It is much more helpful to know its porosity and capillarity under conditions as nearly natural as possible. Both of these are determined by using a cylinder of the soil concerned and noting the rate with which water moves downward or upward through it. For general purposes, however, a measurement of porosity suffices for both, since capillarity varies inversely as the porosity. Thus sand is extremely porous, but possesses very little capillarity. Clay, at the other extreme, exhibits strong capillary movement, but is very slightly porous, while intermediate soils approach the one or the other in behavior in direct proportion to the amount of the predominant constituent. The use of soil-cores from typical habitats yields the most satisfactory data concerning porosity and capillarity in relation to actual water content. When these are not obtainable, instructive results can be obtained by using loose soils in the planthouse, provided that the soils are well packed before the experiments are made. The presence of decaying regetable matter increases the porosity of a soil, and correspondingly decreases its capillarity, but after complete decomposition humus tends to increase capillary action, especially in coarse soils. The amount of humus may be readily ascertained by weighing a soil before and after it is thoroughly burned.

Experiment 3. Porosity and rate of evaporation. Fill three 2-inch flower-pots respectively with sand, loam, and clay that are nearly dry but not powdery. Pack each soil firmly until its surface is a half-inch below the edge of the pot. Place each pot in a tall Stender dish, and slowly pour water upon the clay until the former runs into the dish through the hole in the pot. Pour the same amount upon both sand and loam, and measure the amount of water that percolates through each. Weigh each pot of soil, and, together with a graduate of water having an equal surface, put them in a sunny place. Weigh each every day or two for a week or more. As soon as the sand shows no further 
loss, place the three soils in a water-bath and dry them out completely. Make a final weighing. Compute the percentage of water in the saturated soils at the beginning, the rate of loss from each as compared with the water surface, and the amount of water in each at the time the sand showed no further loss in the air.

26. Influence of precipitation upon water content. In all habitats except those where the supply of water is constant, owing to the presence of springs, streams, ponds, or other bodies of water, the dependence of water content upon rainfall is absolute. Soil and slope determine how much of the latter finds its way into the ground, but their action is secondary. Daily rains are able to keep practically any soil saturated, regardless of its character or the slope. All habitats not covered with water reach their maximum water content immediately after a heary rain or during the rainy season. The water decreases gradually throughout a dry period or season, only to again approach the maximum when precipitation takes place. The latter occurs in various forms, such as rain, hail, dew, frost, and snow. Of all these, rain is by far the most important. In spite of local exceptions to the rule, hail is too infrequent to be taken into account. lrosts have at best only a slight and fleeting effect upon water content, especially in view of the fact that they usually fall outside the growing season. Snowfall is often of great importance. It not only acts as a cover to prevent evaporation, but upon thawing it also enters the soil directly just as rain does. The loss by run-off from slopes is much greater, owing to the frozen condition of the ground. The exact importance of dew is not easily determined. Dew is almost always too small in amount and too fleeting to add directly to the water content of the soil. By its own evaporation it doubtless decreases in a slight degree the amount of water lost by the soil and by bedewed plants. In studying the water content of habitats a knowledge of the amount of rain usually suffices, though in the study of habitats in spring, the amount and distribution of snows must also be taken into account.

27. Measurement of rainfall. Rainfall is measured by means of a rain-gauge, an instrument which collects in a nirrow ressel the rain falling upon a large surface. In the standard instrmment the ratio of surface between receiver and tube is 10 to 1 . A direct measurement of the water in the tube must be divided by 10 to give the rainfall, or a standard measuriner-rod, upon which this 
compensation is already made, may be used. In elementary work it is impracticable to measure the rainfall in different habitats. It is fairly satisfactory to use the reports of rainfall obtained from a neighboring weather station when the latter is not more than a few miles distant. The effect of rainfall upon water content is best ascert ained by taking soil samples in different habitats immediately after a rain, and then determining the increase in water content. In open, hilly regions there sometimes occur in spring differences in water content which can only be explained by a knowledge of the distribution of the late snows of winter.

28. Physiography. Physiographic factors are altitude, exposure, slope, and surface. There are in addition certain physio-

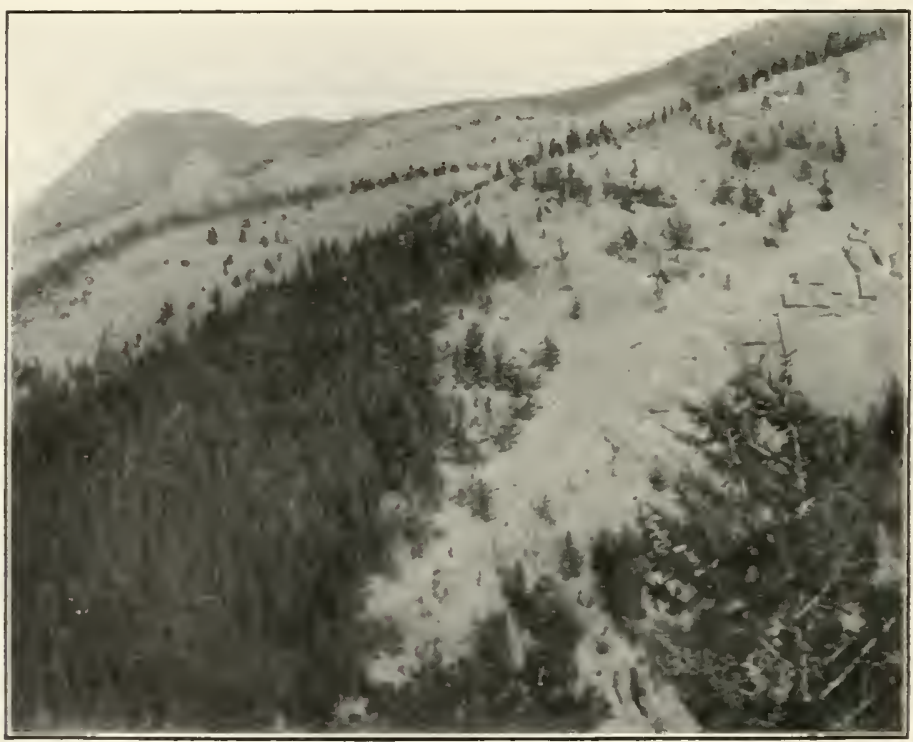

Fig. 5.-Mountain sides showing differences of slope, exposure, and cover.

graphic processes, such as weathering, erosion, and sedimentation, which play a fundamental part in changing habitats, but these do not act directly upon water content. The latter is directly infuenced by slope and surface, while altitude and exposure operate only through humidity. Corer, either dead or living, while not exactly a physographic feature, affects water content in much the manner of surface, under which it may well be considered. 
29. The influence of slope. By slope is meant the inclination of the surface of a habitat with respect to the horizon. The principal effect of slope is in controlling run-off and drainage, and through them water content, although they are at the same time affected by surface and soil texture. Slope has also a less direct influence through its action upon heat and wind, which in turn modify humidity and thus affect the water content. Slope is expressed in degrees of the angle made by the intersection of a line bounding the surface and the base line. It is measured by means of a clinometer, a simple instrument in which a line and plummet indicate the angle of slope upon a semicircle graduated in degrees. In making a reading, it is desirable to use a basing strip, a piece of wood 1 meter long and 5 centimeters wide, with a true edge. The basing strip is placed upon an area typical of the slope, and is pressed down firmly to equalize irregularities. The clinometer is moved gently along the upper edge, causing the marker to swing freely. When the latter comes to rest, the instrument is carefully turned upon its back, and the angle of slope read directly in degrees. Two or three readings in different parts give a very satisfactory mean for the entire habitat. The angle of slope can not be directly connected with the amount of water content, because of the other factor's concerned. The rule is that the rainfall lost by run-off increases with the angle, and the water absorbed correspondingly decreases. In two or more areas essentially alike in soil, cover, and rainfall, differences in water content are directly determined by differences in slope.

30. The influence of surface. The surface of a habitat often shows irregularities which retard the movement of run-off and cause more of the rainfall to soak into the soil. The soil itself often shows such irregularities, e.g., the rocks of boulder and rock fields, the hummorks of meadows and bogs, the mounds of prairie-dog towns, the raised tufts of prairies and sand-hills. the minute gullies and ridges due to erosion, etc. The influence of these is usually not great, but it is always appreciable, and in some cases of considerable importance. Their effects are often measurable by means of soil samples, but it is impossible to express the character of the surface in definite terms. It must suffice to describe the surface as even or uneven, and to indicate the kind and amount of unevenness. 
The same is true of cover, which is usually of far greater and more universal importance. Dead and living cover retard runoff and reduce the amount of water lost from the surface of the soil. By their decay, plants add humus to the soil, thereby increasing its capacity for absorbing and retaining water. Dead cover is of less importance, since it is found chiefly during the resting period alone, but it plays a part of some value by catching and holding drifting snow. The cover of living vegetation reacts upon the habitat in a much more vital fashion. While it has a powerful effect in increasing water content, it reduces it also by reason of the water lost through evaporation from the plants. Cover can be expressed only in general terms of density and height at present, and it suffices, as a rule, to indicate the character of the plant covering. In this connection it should be noted that other biological factors, viz., man and other animals, often exert an influence upon water content. Except in special cases, such as irrigation and drainage, this effect is exerted through other factors, and does not need further consideration here.

31. The influence of climatic factors. All the atmospheric or climatic factors of a habitat have an effect upon water content, either immediate or otherwise. Such factors are humidity, temperature, wind, pressure, and light. The influence of the last is slight and very indirect. Temperature, wind, and pressure can change the amount of water in the soil only through humidity, and hence they will be further considered under the latter. Humidity acts upon the plant and upon soil water in the same way, i.e., by controlling evaporation. It affects water content direstly through water loss from the soil, and indirectly inasmuch as the water lost by the plant is first drawn from the soil. Since it is a direct factor, it will be more fully considered in the following sections. It is mentioned here merely to complete the list of factors that play a larger or smaller part in modifying or controlling the water content of the habitat.

32. Humidity. The moisture of the air, which is in the form of vapor, is termed humidity. Owing to the nature of the medium in which it occurs, humidity is much more uniformly distributed than the water content of the soil. For the same reason it fluctuates to a much greater degree. It differs from water content also in that a part of the latter, i.e., the echard, is always non- 
available for the purposes of the plant, while the whole humidity of the air is the stimulus that controls the water loss of a leaf. The actual amount of water present in the air is called the absolute humidity, and is expressed in milligrams per cubic centimeter. The relative humidity is the relation between the amount of moisture in the air and the amount necessary to saturate the air under given conditions. It is expressed in percents, and is in common use as the expression of humidity.

33. Modifying influence of temperature and wind. Humidity is affected by temperature, wind, pressure, altitude, exposure,

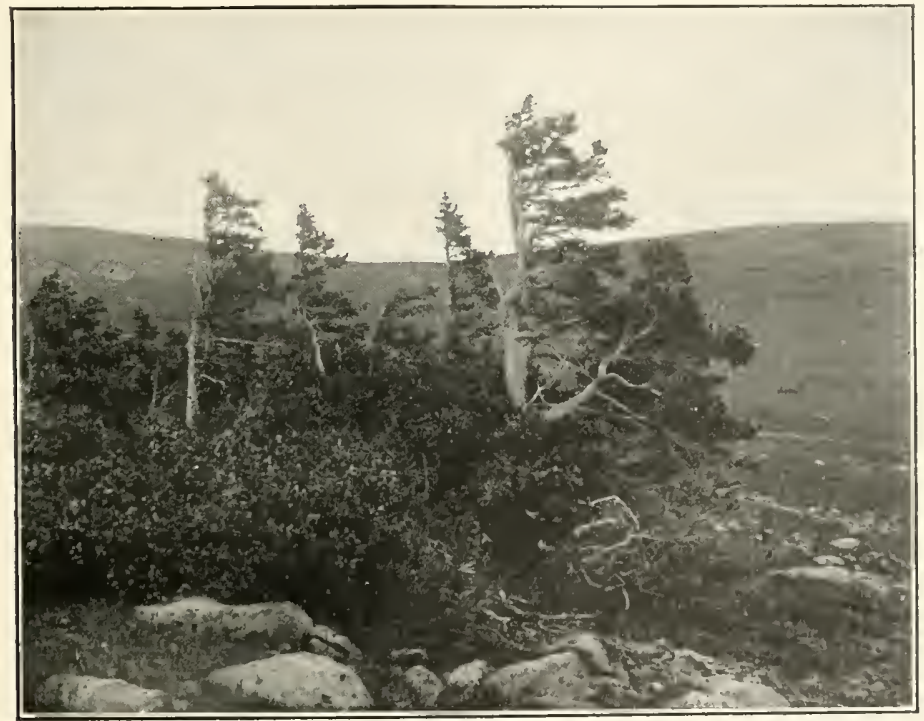

FIG. 6.-Dwarf spruces at timber line on Pike's P'eak, produced by the drying and the mechanical action of almost constant winds.

cover, and water content. High temperatures increase the capacity of the air for moisture and low temperatures dininish it; the former lower the percent of relative humidity, the latter raise it. Of two regions, or two habitats with the same rainfall, the warmer is the drier. During the day the relative humidity falls as the temperature rises, and rises in the evening as the air grows cooler. Wind has also a powerful effect upon humiclity in that dry winds lower the amount of air moisture by nixture or removal, while 
moist winds exert an opposite influence. The most important action of wind is the removal of the more humid air ordinarily occurring above the plants of a habitat, and its replacement by a drier air. This has the effect of keeping the immediate humidity low. This may be readily verified by taking readings of humidity in a sheltered area and in one exposed to the full effect of a strong wind. The moist winds that blow across a large body of water or those that precede a rain either do not have this effect or possess it in but a slight degree. The exact influence of wind upon humidity is best shown in a hilly habitat, such as an undulating prairie. If the velocity of the wind is determined by means of a hand anemometer for ravine, slope, and ridge, and simultaneous readings of humidity are taken, the relative humidity will be found to decrease with the increase in wind velocity.

34. Influence of pressure and physiographic factors. Pressure modifies humidity by varying the density of the air, and hence its

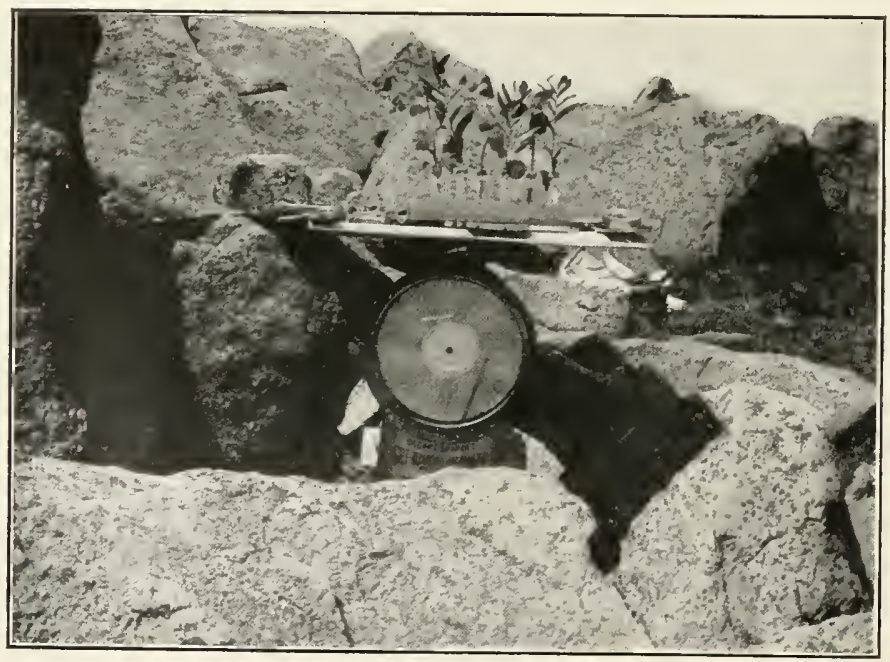

Fig. 7.- Station on the summit of Mount Garfield $(3800 \mathrm{~m}$.) for determining the effects of altitude by means of plants and instruments,

power to hold moisture. The daily fluctuations which constitute weather are slight and are of little importance, except in their relation to rainfall. The effect upon humidity is much more pronounced when differences in altitude bring about permanent differences in 
pressure. Altitude has been thought to influence vegetation chiefly by virtue of increased light and decreased heat. Recent studies of the author seem to prove conclusively that light is of practically no importance, and that the marked dwarfing of alpine plants is due largely to the great rarefaction of air by which evaporation is increased. Exposure, i.e., the position of a slope with respect to the sun affects humidity through the action of sun and wind. Slopes longest exposed to the sun's rays receive the most heat; consequently slopes with a southern exposure regularly show somewhat lower humidities than those with northern exposures. The effect of wind is most pronounced upon those slopes exposed to prevailing dry winds. As a rule, these are southern or southwestern, and for reasons both of temperature and wind these are usually the driest slopes of hills and mountains. Cover increases humidity by reducing the influence of temperature and wind. In addition a living cover supplies moisture to the air in consequence of evaporation from the plants that compose it. A similar effect is prochuced by the water content of moist soils, particularly in forests and thickets where the air is sheltered from sun and wind.

35. Effect of climate and habitat. The general humidity of a habitat depends upon climate and location with respect to bodies of water. In comparison with each other forested regions show high humidities, while deserts have low humidities. Coast regions are moist, inland regions relatively dry, lowlands are more humith, table-lands and mountains less humid as a rule. In a particular habitat the relative humidity approaches or reaches saturation during rain or fog, and then gradually decreases to a minimum just before the next rain-storm. There is also a daily maximum and minimum. The highest relative humidity, except when disturbed by rain, usually falls at 3 or 4 a.m. It decreases slowly until 7 or $\$$ a.m. and then falls more rapidly to a minimum at about 4 p.m., from which point it rises slowly to the maximum. Variations within the habitat arise chiefly through differences in protertion from sun and wind. For somewhat similar reasons the relative humidity is greatest just above the surface of the soil; it is less at the level of the vegetation, and still less a meter or more above the latter.

36. Measurement of humidity. Humidity is measured by means of a psychrometer. Of the latter there are three types: the sling. the cog, and the stationary psychrometer. All consist. of a wet-bulb and a dry-bulb themometer set in a case. The first 
two are designed to be moved or whirled in the air. The same principle is applied in each, viz., that evaporation produces a decrease in temperature proportional to the amount of moisture in the air. The dry-bulb thermometer is an ordinary thermometer, while the wet-bulb one is covered with a cloth that can be moistened. The former indicates the normal temperature of the air, the latter gives the reduced temperature due to evaporation. The relative humidity of the air is ascertained by means of the proper tables, from two terms, i.e., the air temperature and the amount of reduction shown by the wet bulb.

37. Sling and cog psychrometers. For field work the sling and $\operatorname{cog}$ psychrometers are much more convenient than the station-

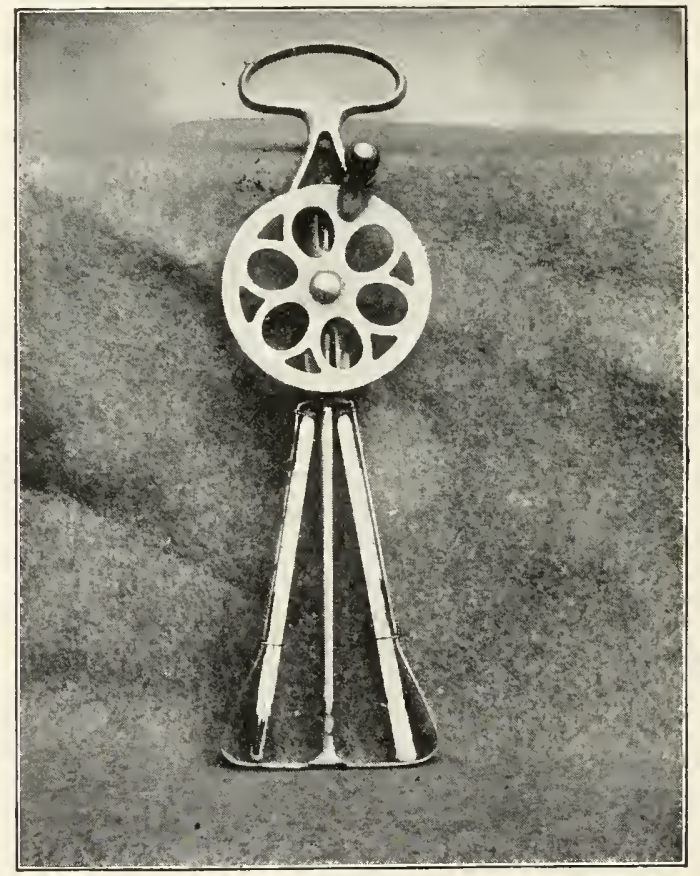

FIG. 8.-The $\operatorname{cog}$ psychrometer. The wet bulb is the one covered with eloth.

ary form. They are generally considered to be more accurate also, since the movement prevents the accumulation of moisture about the wet bulb. Of the two, the $\operatorname{cog}$ psychrometer is the more con- 
venient and satisfactory. It is smaller, more compact, and the danger of breakage in use or in carriage is extremely small. It has the further advantage of making it possible to take readings in a layer of air less than 3 centimeters in thickness, and in any position. The use of the sling psychrometer is attended with grave danger to the instrument in a free space less than two yards across. The eog psychrometer has a single disadvant age owing to the necessary use of short thermometers. To secure the proper range, Centigrade thermometers must be used, and the readings thus obtained must be converted into Fahrenheit temperatures before the humidity can be determined from the usual tables. ${ }^{1}$

38. Making a reading. In general, observations should be taken facing the wind. It is also a wise precaution to shift the position of the instrument a foot or more during the reading, except when the humidity of a definite layer is desired. The cloth of the wet bulb is first moistened with water carried in a small 50-ce. bottle for this purpose. Distilled water is preferable, but tapwater and the water of streams may be used without appreciable error, if the cloth about the wet bulb is changed occasionally to prevent the accumulation of dissolved material. The water is poured slowly upon the cloth of the bulb until it is completely wetted, care being taken not to wet the dry bulb. As the cloth absorbs water reluctantly when perfectly dry, a pipette or a brush is usually a valuable aid in wetting it quickly. The temperature of the water used is of slight consequence, though readings can be made more quickly when the temperature is not too far from that of the air. The psychrometer is held in the proper position, i.e., the bulbs are placed in the laver of air to be studied, unless a general reading is to be made, and are then rotated at an even rate and at a moderate rapidity. As the reading must be made when the mercury of the wet bulb reaches the lowest point, the instrument is usually stopped after 100 revolutions, and the position of the column is noted. The lowest point is often indirated hy the tendency of the mereury to remain stationary. As a rule, the lowest point can be known with cert ainty only when the next glance shows a rise in the column. Check readings of this nature must be made every 25 or 50 revolutions in order to make sure that the mereury has not reached the minimum and then besun to rise while the instrument is in motion. In noting the final reading, care must be

${ }^{1}$ Researel, Methods, 39. 
taken to secure it before the mercury begins to rise in consequence of stopping the movement. For this reason it is desirable to shade the psychrometer with the body when looking at it in the sunshine, and to take pains not to breathe upon the bulbs or to bring them too near the body. At the moment when the wet bulb registers the lowest point, the dry bulb should also be read and the results recorded.

39. Use of humidity tables. To ascertain the relative humidity, the difference between the wet- and dry-bulb figures is obtained. This difference, together with the dry-bulb temperature, is referred to the tables. A rariation in temperature has less effect than a variation in the difference. In consequence, the dry-bulb reading is expressed in the nearest unit, and the difference is reckoned to the nearest .5. Since the humidity varies with the air pressure, it is necessary to use the table computed for the normal barometric pressure of the place under consideration. Humidity tables are usually computed for pressures of $30,29,27,25$, and 23 inches $(76$, $73.5,68.5,63.5,58.5 \mathrm{~cm}$.). For mountain regions over 2100 meters (7000 feet) additional tables are desirable, but the table for 23 inches will meet all ordinary requirements, since the effect of pressure is small within the usual range of growing-period temperatures.

Experiment 4. Measuring humidity. Use a cog psychrometer to determine the range of humidity at $\delta$ a.m., $12 \mathrm{~m}$., and 4 p.m. Make readings in quick succession in the plant-house, and in sun and shade out-of-doors, and find the relative humidity for each.

40. Method of habitat study. A real knowledge of physical factors, and of the habitats which are constituted by them, can be obtained only by the use of factor instruments in the field. Such knowledge is of the most fundamental importance in discorering the causes which control the functions and structures of plants, and their grouping into plant formations. All these objects can be obtained by establishing a series of stations, and using the members of the class to take simult aneous readings in them at different times of the year. The ideal method is to begin such a series just before the opening of spring, and to continue it at proper intervals throughout the entire growing period. This is scarcely feasible in the great majority of cases, and the most practicable method is to take a set or two of readings in the fall, and the same number in winter. Then, 
in the spring, readings should be taken every week or two until the work closes.

4I. Choice of stations. The stations of a series should be chosen with care, and as a result of considerable previous knowledge of the locality to be studied. The stations must not be ton numerous nor too far apart. Within these restrictions, however, they should represent several distinct formations, and as many dissinilar areas in each as possible. A series can not well be more than two miles long, and one of a mile, or even a half mile, is to be preferred. A good series will contain at least a dry, a wet, and a shady habitat, e.g., a prairie, a swamp, and a forest. In class work of this sort at Lineoln, two series were first established, one in prairie, the other in woodland. For reasons of convenience and timesaving, these are now replaced by a prairie series consisting of the following stations: (1) meadow, (2) crest of ridge, (3) northenst slope, (4) ravine, (5) southwest slope, (6) sandy ridge, (7) willow thicket, (\$) high prairie, (9) bog, (10) south slope.

42. Constant factors. After the stations have been chosen, their location should be permanently indicated in such a way that they can be readily found from time to time. In orcher to aroid mistakes, the instructor should first take the entire class through all the stations, pointing out the general differences and illustrating the use of instruments not already familiar. If this does not take too long. readings of the more constant factors, water content, slope, exposure, surface, and cover are made at the last station, and a student equipped with thermometer, psychroneter, and photometer is left in charge. At each suceeding station the same plan is followed, so that upon reaching the first station the constant factors have all been read, and there is an observer at each station prepared to make readings of the variable factors. When the preliminary survey has necupied all the time available, the same method is employed upon the second risit, but the beginning is naturally made at the first station. The observers are shifted upon successive visits so that each student has an opportunity to become acquainted with every station. When the class is large, two or more students may be left at a station, and the work divided between them.

43. Simultaneous readings. The task of olotaining reaclings at the same moment is met by taking observations upon sirnal. The instructor places himself at a commanding station, prefera- 
bly near the middle of the series, and gives the signals by a shout or whistle at the proper interval. Considerable care and practice are required in order to do the last satisfactorily. Sufficient time must be given for the operation of the instrument and the nuaking of the record. In addition, a perior which is long enough for each instrument to reach the proper reading must be permitted to elapse. For example, in a series which contains a gravel slide and a forest, a thermoneter which has

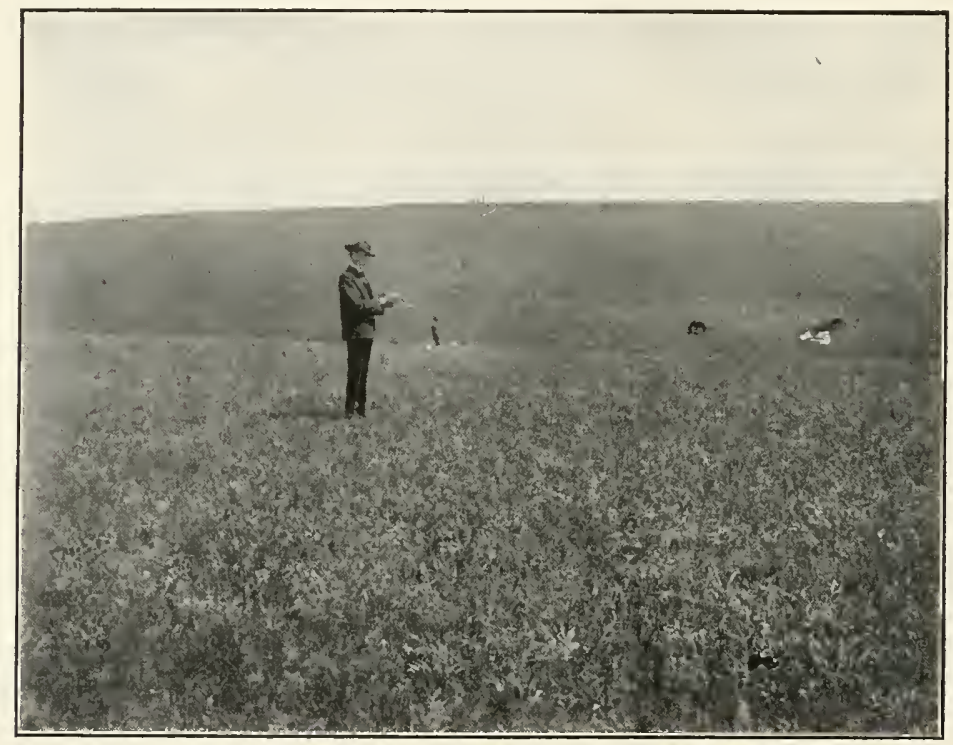

FIG. 9.-Observers making simultaneous readings of humidity in a series of stations in the prairie formation at Lincoln.

just been used for an air reading will require four or five times as long an interval to respond to the temperature of the gravel as to that of the cool forest floor. In such a series, the place where the response is slowest or greatest often makes the best signal-station. The instructor records the exact time of each signal, and notes any general changes of sky or wind that produce fluctuations at the time of reading. Temperature, humidity, and wind are read usually at $1 \frac{1}{2}$ meters, and at the surface of the soil. Soil temperatures are obtained from the holes left in making soil samples. These holes are closed with corks to pre- 
vent a change in temperature, and are used only on the day they are made. Light readings are of course necessary only when one or nore stations are shaded. For the sake of convenience and accuracy, factors are always determined in the same order, viz., temperature, humidity, wind, light; and the same is true of the various points or levels, e.g., $1 \frac{1}{2}$ meters, surface, and soil.

44. Point and hour readings. Readings taken as above at the same point in the stations of a series are said to be made at the same level, as the $1 \frac{1}{2}$-meter level, the surface level, etc. Readings may also be taken simultaneously through the different points of a single station. In this work, the observers are grouped in each station in such fashion that they do not interfere with the correct reading of each instrument. Such determinations are most valuable in the case of temperature, which shows greater differences at the various levels. Important differences of humidity and wind are also discovered, and, in layered formations. marked variations in the amount of light. Series of this sort are likewise read upon signal. Hour series are indispensable for obtaining the variation of each factor during the day. They are read for each level upon signal in the manner already indicated, but the series is repeated every hour throughout the day, The number and position of the levels in all of the different series are properly determined by the character of the vegetation. In general, there should be levels corresponding to the surfare, to the height of the herbaceous vegetation, and an air level above the latter. For temperature, one or two soil levels are necessary also.

45. Records. A definite form of field record saves much time and prevents many mistakes. Printed blanks of the form indicated below, $7 \frac{3}{4} \times 9 \frac{1}{2}$ inches in size. have been found to he the most satisfactory. Each blank suffices for recording two full sets of readings through ten stations. The details may of course be modified as seems desirable. The blanks are carried in a cover protected with oil-cloth. The field readings are entered directly in ink in the case of temperature and wind, while light, humidity, and water content are recorded only when the finil results are obtained, field memoranda being employed for the direct readings. 


\section{Oak-hickory forest.}

April 20, 1901. Clear. Southeast wind.

\begin{tabular}{|c|c|c|c|c|c|c|c|c|c|c|c|c|}
\hline \multirow{3}{*}{$\begin{array}{l}\text { Time, } \\
\text { A.M. } \\
\text { Sta. }\end{array}$} & \multicolumn{5}{|c|}{ Temperature. } & \multicolumn{2}{|c|}{ Light. } & \multicolumn{2}{|c|}{ Humidity: } & \multirow{2}{*}{$\frac{\text { W"ater content. }}{\text { Percent. }}$} & \multicolumn{2}{|c|}{ Wind. } \\
\hline & $10: 40$ & $10: 46$ & $10: 50$ & $10: 55$ & $11: 00$ & $12: 00$ & $12: 05$ & $11: 10$ & $11: 20$ & & $11: 3$ & 11: \\
\hline & $1 \neq m$. & Surf. & $1 \mathrm{dm}$. & $2 \mathrm{dm}$. & $4 \mathrm{dm}$. & $1 \ddagger \mathrm{m}$. & Surf. & $\mathrm{m}$ & Surf. & $1 \mathrm{dm} .2 \mathrm{dm} .4 \mathrm{dm}$ & $1 \pm m$. & surf. \\
\hline 1 & 16 & 25 & 9.6 & 5.4 & $7 . \&$ & . $0 \mathrm{~s}$ & 06 & 73 & s1 & 24.219 .21 & $29 \mathrm{~s}$ & 0 \\
\hline 2 & 16.2 & 30.5 & 8.5 & 6) 8.4 & 7.8 & 11 & 09 & 73 & s6 & 22.51 & 4375 & 2 \\
\hline 3 & 16.2 & 17.8 & 7.6 & $7 . S$ & S & $0 s$ & 06 & 73 & 95 & 22.120 .421 .6 & 5640 & 6 \\
\hline 4 & 15.6 & 26.2 & 10.6 & 8.4 & S. 2 & .06 & .03 & 81 & 95 & 25.423 .122 .4 & 4275 & 12 \\
\hline 5 & 17 & 25.4 & 7. 6 & 7.4 & 7.2 & .03 & 02 & 9 & 95 & 27.219 .518 .5 & $17 \mathrm{~s}$ & 2 \\
\hline 6 & 16.2 & 20.2 & S. 4 & 7 & 6.2 & 02 & .01 & s. & 90 & 27.620 .518 .5 & 115 & 4 \\
\hline 7 & 15.8 & 17.2 & 6.4 & 6.4 & 6.1 & 05 & .04 & S2 & 90 & $23 . \$ 19$ & 60 & 0 \\
\hline
\end{tabular}

46. Kinds of curves. The most graphic way of bringing out the factor differences between habitats or stations is by means of curves. The factors that lend themselves most readily to this method are the variable ones, water content, humidity, light, temperature. and wind. Curves representing these are spoken of respectively as water-content curres. humidity curves, etc. With regard to the time and position of the readings upon which they are based, they are divided into level, station, and point curves. A level curve is one based upon readings made at the same level through a series of stations, e.g.. the level curve of surface temperature. The station curve shows the rariation of a factor through the different points at which readings are made in a single station. The point curve has for its basis the hourly or daily rariation of a factor at a single point in a station, such as the variation in humidity during the day at the surface of a barren ridge. All of these may be simple curves when based upon a single reading through a level, station or day, or mean curves when they are based upon the arerage of a number of such readings.

47. Combinations of curves. Curves are often combined in order to permit of a ready comparison between them. Combination is brought about by tracing upon the same sheet the curves to be compared. Dissimilar curves. e.g., level and station. can not be combined. Colored inks are an absolute necessity in making combinations. The principle underlying their use is that curves which approach closely or cross each other must be traced in inks that contrast sharply. It is important to use the same color invariably for the same level or point. The rariety 


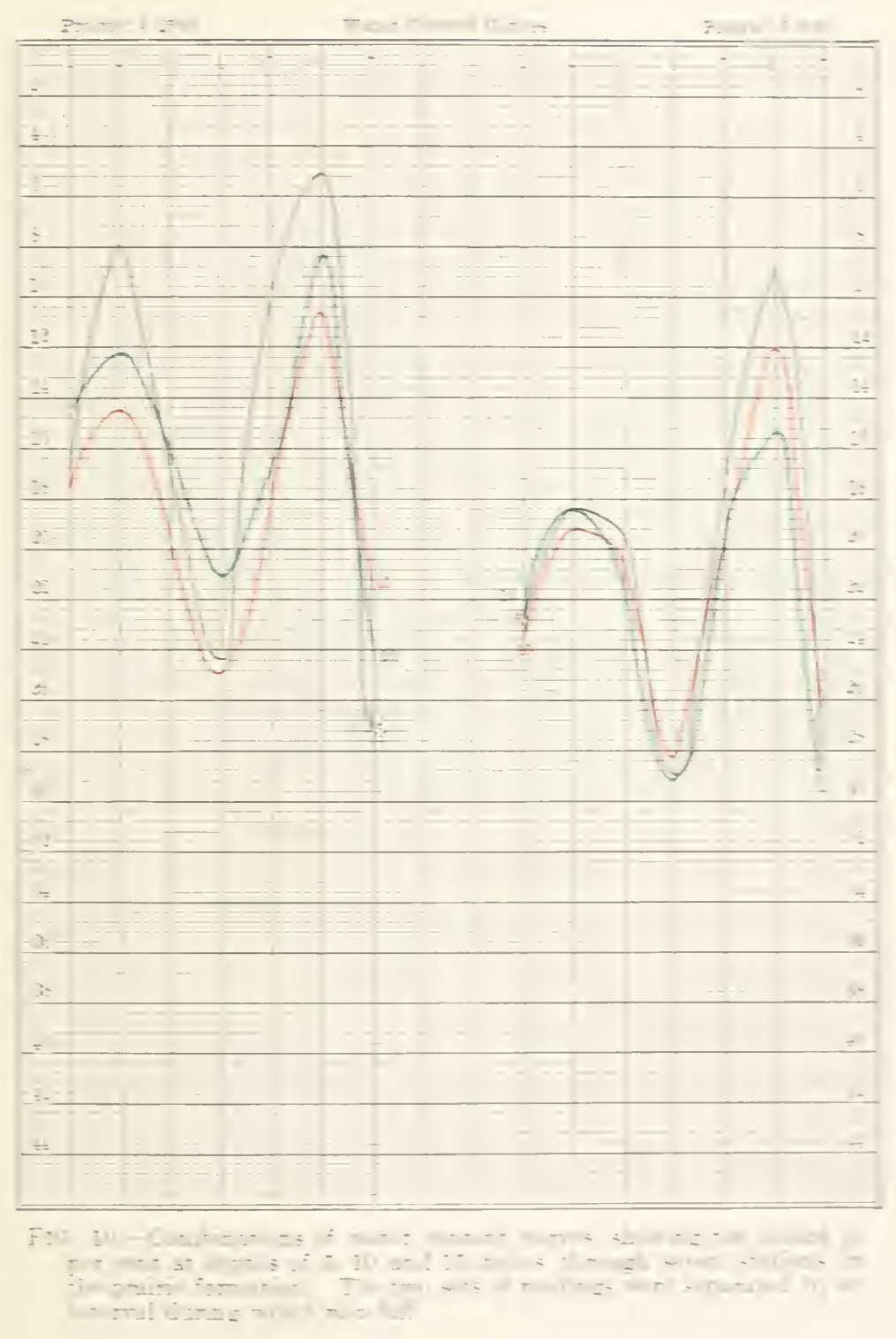



of ways in which curves can be combined is almost endless. For the beginner, however, the most satisfactory are those in which but one factor is taken into account. The most useful are those in which the curves of temperature, or of any other factor, for the different levels are drawn together. Similarly, the curves showing the variations of temperature for each station may be combined. A combination of the greatest value is obtained by contrasting the curves of holard and chresard for a series of stations. A very interesting combination may be obtained by arranging the series of curves for two distinct habitats, such as prairie and forest, side by side upon the same sheet, thus permitting the direct comparison of the curves for various factors.

48. Plotting curves. The plotting-paper employed is ruled in centimeter squares which are divided into 2-millimeter units. The sheet is $24 \times 18 \mathrm{~cm}$. in size, thus making it possible to file the curves in the record book. A fine-pointed pen, such as the Spencerian No. 1, is used for plotting. The inks used are the Higgins Waterproof Inks, which are made in the following colors: black, violet, indigo, blue, green, yellow, orange, brown, brick red, carmine, and scarlet. In addition to being waterproof, they make it possible to combine curves readily without destroying their identity. It is also a great advantage to use the same color invariably for the same kind of curve.

In plotting a curve, it is first necessary to fix the vahue of the centimeter square or interval, as well as the extreme range of the curve itself. For example, in the case of temperature, a value of $1^{\circ}$ Centigrade is assigned to each centimeter, since the thermometers used read to one-fifth of a degree, which thus corresponds with the value of the 2-millimeter units of each square. The length of the sheet permits a range of 22 degrees Centigrade, within which the greater number of temperature curves for a particular season will fall. It is very desirable that the unit interval and the range be the same for each factor, in order that all curve sheets for the same region may admit of direct comparison. The major intervals are indicated at both sides of the sheet, and the time or the space intervals at the top. The readings upon which the curve is based are taken from the fiekl record, and the proper position of each is indicated by a dot. The dots are first connected by a pencil line, the curves being marle angular rather than flowing. After being carefully checkerl, the line is 
traced in ink. Each curve sheet is properly labeled, and such explanatory notes as are desirable are written upon the back.

49. Intervals for the different factors. In practice, the intervals and ranges of the curves of the other factors have been arbitrarily fixed, as in the case of temperature. For water-content curves each square represents a value of $2 \%$, the smaller squares being $0.4 \%$, and the range $2-48 \%$. The unit value for humidity curves is taken as 5 percent, thus giving room on the sheet for the entire range from 1-100 percent. When a hand anemometer is used, curves of wind velocity are based upon the number of feet per minute. One hundred feet is taken as the unit value, and the range is from $0-2200$ feet. The unit value for the curve of light intensity is .05. Each small square is .01, which permits a range of .01 to 1 . on a sheet. Consequently, in plotting the curve of a series of habitats with a range in intensity greater than this, it is necessary to paste two sheets together end to end. This is the usual device when the range of curves is too great, except when the excess is slight. In this case, the curve is left open at the top, and the maximum value is indicated at one side. All curves in combination are labeled at the beginning or left to indicate the level, station, or point, and at the end or right to show the time or day, when this is not the basis of the curve or series.

Experiment 5. Determining the physical factors of habitats. The instructor first chooses a series of stations comprising as many different habitats as can be conveniently studied. Each station, and especially those that fall within the same habitat, is located with respect to striking differences of vegetation as well as physical factors. The position of each is fixed permanently by means of a stake. The number of stations is necessarily determined by the size of the class and the number of instruments available. Each observer is furnished with thermometer and psychrometer, and, when the variation in light warrants, with a photometer also. Geotomes, clinometer, compass, barometer, and usually also an anemometcr, are carricd through upon the preliminary survey by the class and the readings made in common. Returning through the scrics, an observer is left in cach station, and the instructor then places himself at the proper point for signaling. Readings are always made in a fixed sequence. Temperature is taken first, in the order of air, surface, and soil; humidity follows, and finally light. To familiarize the student with methods, and to have a slight check upon 
results, it is advisable to take two or three complete sets of readings in rapid succession.

A complete set of habitat readings should be taken at least once during the fall and winter respectively. A similar set of readings should be taken just before the beginning of the growing period. After the opening of spring, readings are taken once every week in connection with the field study of the development and structure of the various formations. Simultaneous readings through the different levels are of the greatest value, and are the ones regularly madc. Once during the spring, however, it is arranged to have the class spend the whole day in the field for the sake of ascertaining the hourly variation of the factors. Likewise considerable value attaches to readings made simultaneously in the different points of a single station, the stations being read successively. Each student should enter all the readings made in his record-book. Representative curves and combinations should also be made and filed with the records. 


\section{CHAPTER III}

\section{ADJUSTMENT TO WATER}

50. Responses to water stimuli. The primary responses of the plant to the water of the habitat are four: namely, absorption, diffusion, transport, and transpiration. Absorption is the response of the root to water content. Transpiration is the evaporation of water from the leaf, and in some measure from the stem also, in response to the humidity of the air. Diffusion is the process by which water is carried from cell to cell through the various tissues. Transport is the movement of water along certain prescribed pathways in its journey through the stem to the leaves. None of these are simple processes; all involve several factors that will be considered in the proper place. Absorption is the initial activity. It is followed by diffusion and this by transport. The water transported to the leares is carried to the various cells by diffusion and finally passes off in consequence of transpiration. In any living plant, all of these processes are ordinarily taking place at the same moment, though it is equally clear that transpiration must be preceded logically by transport, transport by diffusion, and diffusion by absorption.

\section{ABsORPTION}

51. General relations. Absorption is the function by which water is taken into the body of the plant. It is an essential property of every living cell in contact with water supply, and is practically the same for the smallest one-celled water plant, and for the largest tree. Primitive water plants, i.e., the algæ, such as pondscums, seaweeds, etc., ordinarily use the entire surface of the plant body for absorbing water. Terrestrial plants, on the other hand, have reduced the absorbing surface as the plant emerged 
more and more into the air. In consequence, such plants have developed the part of the body in contact with the witer supply into a special organ for absorption, i.e., the root. The funclamental nature of this relation is seen clearly in those terrestrial forms that have come to be submerocl. The absorptive orran is lost and the function of absorption is again distributed over the entire surface.

Absorption is an inherent property of protoplasm. In terrestrial forms, and in flowering plants especially, it is confined to the root, and the form and structure of the latter have an immediate bearing upon this function. Absorption consists of three processes or factors: imbibition, osmosis, and protoplasmic attraction. These act in unison, but for the sake of clearness they will first be considered separately, following a preliminary account of the root.

52. The form of roots. The most primitive terrestrial plants, liverworts, mosses, fern prothallia, and a few alga, such as Botrydium, possess filamentous roots or rhizoids. The higher terrestrial forms, the ferns and flowering plants, possess massive roots, in which the absorbing surface is regularly modified to form roothairs. The latter are long, tube-like cells, which correspond in structure and function to the rhizoids of simpler plants. The form of the root is variously modified in response to the character of the habitat, and to the need of storing foor material. Such changes are structural responses and are considered unler alaptation. The structure of the root, on the other hand, is more or less the same for all flowering plants, and a knowledge of it is essential to an understanding of the functions of the root.

53. Primary regions of the root. Ronts, likestems and leaves, consist of three primary regions, which are clistinguishalle in the embryo, and remain more or less distinct throughout the life of the plant. These regions when in the condition of prinary merist ent are termed dermatogen, periblem, and plerome. The dernituren or "epidermis producer" is the outermost layer of the cutime plant body. It normally persists throughout the life of the flint as a single layer, owing to the fact that the division of its crilly occurs in two planes only. The plerene is the contral rylinter or core of the plant. It develops primarily into the fitmoxamentar

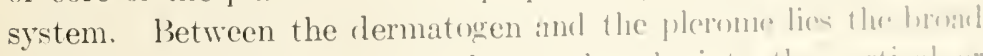
area of the periblem, which changes lingely into the ontical or 
nutritive parenchyma. In addition to these three regions, common to root, stem, and leaf, the root possesses a fourth, the root-cap, which is peculiar to it. The root-cap usually arises from the dermatogen of the root-tip. It consists for the most part of parenchyma-like cells, which act as a cushion to protect the more delicate

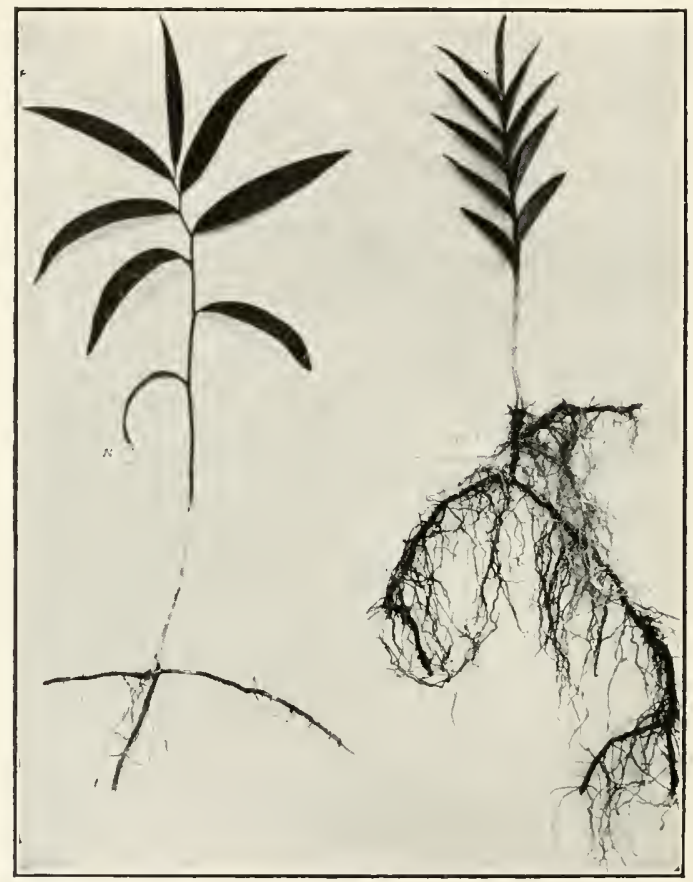

FIG. 11.-The root system of the shade and sun forms of the false Solomon's seal, Wagnera stellata. The shade form with few rootlets grows at the edges of brooks where the holard is $30-60 \%$; the sun form is a gravel plant with a holard of $5-6 \%$.

meristem against tearing and crushing. As the root elongates, the cells of the cap are extended along the surface, where they gradually wear away or exfoliate. The same process occurs also at the lower end of the cap, causing it to wear away as it grows.

54. Detailed structure. A section of a typical root reveals the three primary regions changed into epidermal, cortical, and vascular tissues. The epidermal layer is merely the dermatogen changed into a layer of permanent parenchyma-like cells. It consists of epidermal cells, here and there drawn out into a long 
tube, the root-hair. The cortical region consists of a varying number of parenchyma layers. The cells, like those of the epidermal layer, have thin cellulose walls, covered on the inner surface by a thin layer of protoplasm. They are filled with water, but usually lack other inclusions, although crystals are sometimes present. Although the layers appear but slightly differentiated, the outermost and innermost differ from the intermediate ones in their final development. The outermost layer is the exoderm. Its especial task is to replace the epidermis when the latter is exfoliated, and accordingly to act as a root-hair producing surface. The innermost layer is the endoderm. It is used for storage and as a nutritive layer in the formation of lateral rootlets. When the

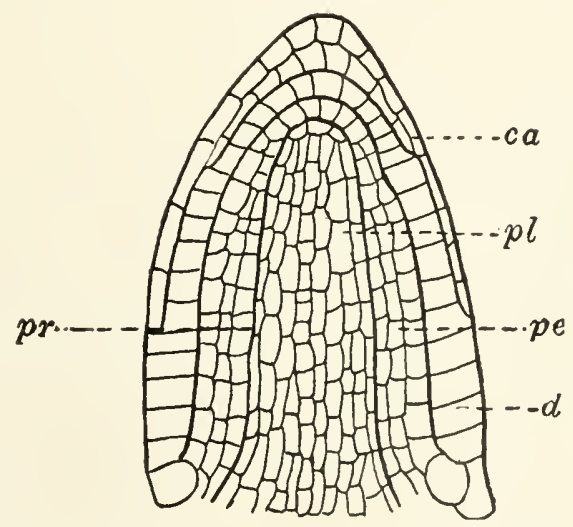

Fig. 12.-Longiseetion of a root tip of the eommon dock, Rumex altissimus. The primary regions are: $d$, dematogen; $p e$, periblem; $p l$, plerome; $c a$, calyptra. The outer row of cells in the plerome is the pericycle, $\mathrm{pr}$.

other cortical layers have been exfoliated, in consequence of the growth of the root in thickness, the cells of the endoderm divide to form a several-layered corky covering for the root.

The vascular region consists of a single fibrovascular bundle surrounded by a layer called the pericycle. The latter, by the periclinal division of several cells, produces the three primary layers of rootlets. By a similar division of the cells in front of the tracheirls of the bundle, it completes the ring of cambium which makes possible the secondary growth of the root, i.e., its growth in thickness. The bundle of the root is of the rarlial type. It consists of woody tissue or xylem and sieve tissue or phloem. These are separated by a meristematic tissue termed mescuchym. 
The xylem usually occurs in narrow strands, which are united in the middle. The number of xylem strands is usually two or four, but it varies for different species. The phloem occurs in a corresponding number of plates or masses, alternating with the xylem strands, and lying near or next to the pericycle. The mesenchym gives rise to the major portion of the cambium ring necessary for secondary growth, and sometimes produces a pith.

55. Origin and structure of root-hairs. The particular function of the epidermal layer is absorption. The cortical region has no

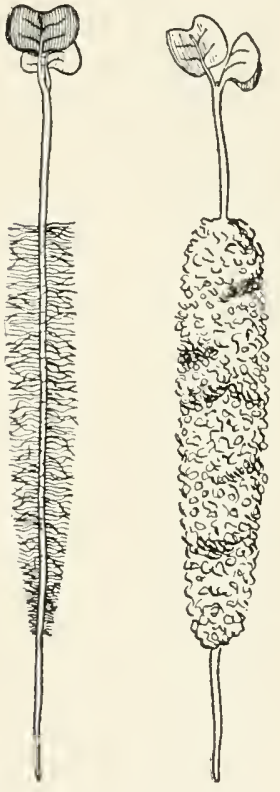

FIG, 13.-Seedlings of white mustard, Brassica alba, grown in sand, showing the position of the root-hairs and their relation to the particles of sand. (After Sachs.) special function, though diffusion is confined to it very largely. The vascular region serves as a pathway for the transport of water. The function of mechanical support, which is peculiar to the fibrovascular bundies, is entirely secondary in importance, owing to the support afforded by the soil. The epidermal layer of the roots of water plants shows practically no differentiation with respect to absorption. Practically all cells of the surface, except those that are very young or very old, absorb water with equal readiness. The roots of all land plants, except of those that grow in very wet places, are especially adapted to the absorption of water from the soil by means of root-hairs. The latter are not separate cells, but threadlike prolongations of the epidermal cells from which they arise. They have thin unmodified walls lined with a scarcely demonstrable layer of protoplasm. Root-hairs do not arise over the whole surface, but are confined to a particular resion behind the tip which consists of meristem. As the root elongates, the older hairs die off as new ones are formed, and the zone of root-hairs maintains an almost constant width. Not all of the epidermal cells produce root-hairs, two or more unmodified cells standing between adjacent hairs. These unmodified cells are doubtless able to absorb water, but they can not be very active under ordinary conditions, since the root-hairs obtain most of the water available. Behind 
the zone of root-hairs the outer wall of the epidermal cells is rendered more or less impervious, i.e., cutinized, in order to prevent the cells from drying. A similar fate apparently overtakes the root-hair cells after the hair has shriveled and disappeared.

56. Effect of water content upon root-hairs and roots. The formation of root-hairs is closely connected with the amount of water present. Water plants do not form root-hairs at all, or only to a small degree. The same species, indeed the same root, will form abundant root-hairs in moderately dry soil or in moist air, while in the water few or no hairs are produced. The reason for this seems evident, when it is borne in mind that roothairs are primarily for the purpose of increasing the absorbing surface. In streams, ponds, etc., the water supply is not only unlimited, but the water is constantly brought into contact with the epidermal cells. In soils, on the contrary, tlıe amount of available water is usually limited. Moreover, soil water moves much less readily, and consequently the epidermal celis must themselves move toward the water. They accomplish this by extending their surface in the form of a long, narrow hair.

While the shape and position of roots are largely determined by water content and other soil factors, most roots possess the common property of growing in the direction of the greatest moisture. This property is termed hydrotropism, i.e., a turning toward water. It is not only possible to demonstrate by experiment that the growth of root-hairs is in the direction of the greatest water content, but it can also be shown that the root actually curves toward moisture. The curvature takes place in the region of greater growth, i.e., at a place some distance behind the tip. The stimulus, however, seems to be received by the tip, and is then transmitted to the region that is growing most rapidly. The advantages of hydrotropism are evident, inasmuch as it enables the plant practically to go in search of water at those times when the supply is more or less inadequate.

The extent of the root system differs widely in different plints. In some species the root soon stops growing, and in consequence always remains poorly developed; in others the root systen grows throughout the life of the plant or at least for a long time. Plants that grow in deep soil usually have more extensive root systems than those in shallow soils, but there are many exceptions to this. Ioreover, the prevalent opinion that there is a 


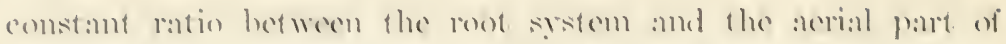

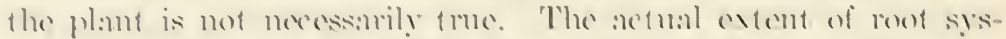

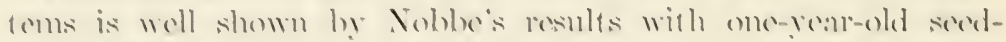
lings of the pinc and the fir. The former has a shallow root sys-

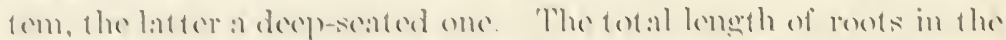

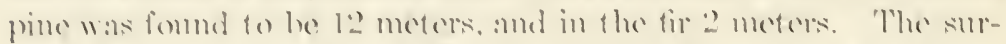

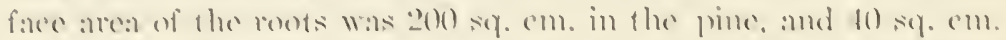
in the fir. "The esfimsted lometh of the root system of matme

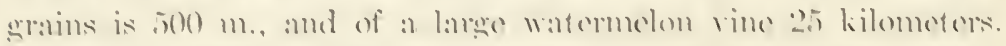

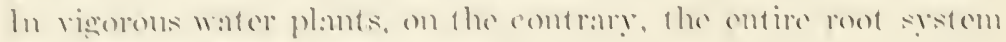

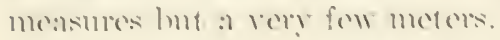

Experiment o. Structure of the root and formation of root hairs.

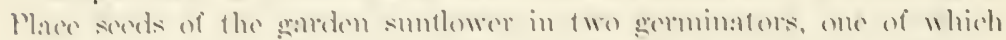

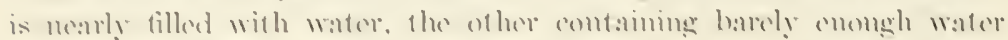

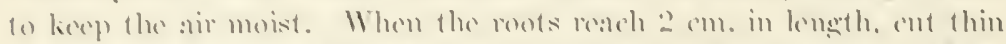

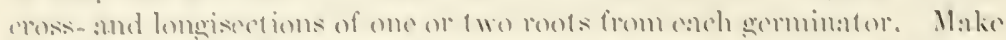

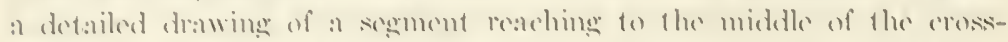

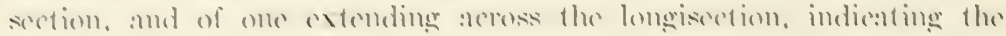

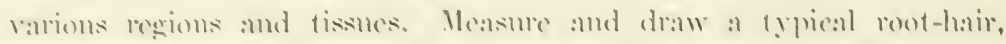

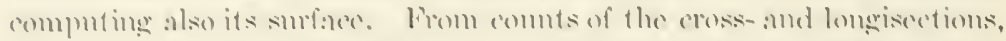

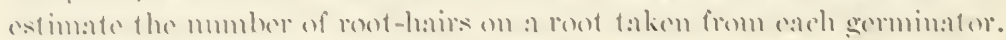

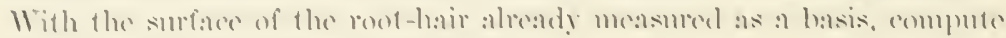

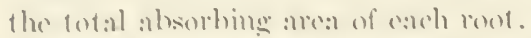

Experiment 7. Hydrotropism. Bmbed a porems tube ar a : 2 -inch pot. without a hole in the hottom, in the midetle of a s-imeh pot filled wish

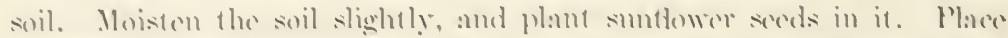

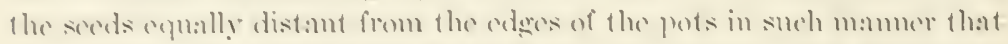

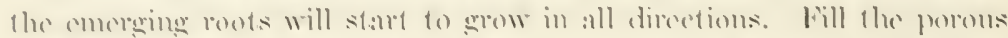
tube with watce. I fow dass after the ontyledoms:

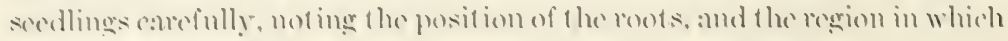
the tmoning oems.

57. Imbibition. This is the pouess that 1 alies place when a

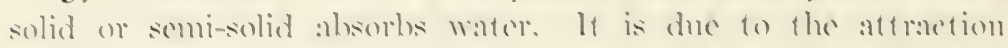
which the molerules of the two sulst:mess have for cate othere

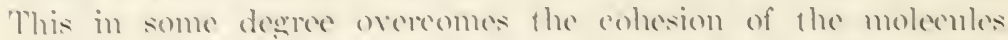

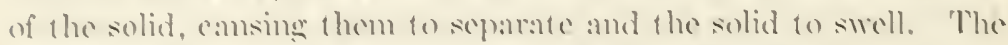

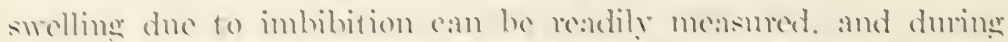

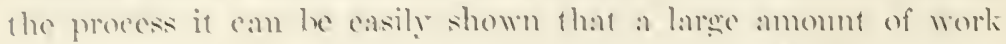

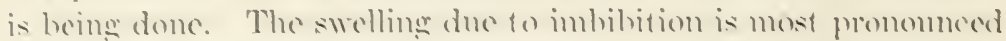

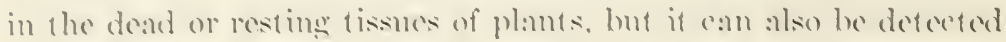
in living colls. 
Imbibition is a factor in alsomption, since it affects both the cellulose wall of the rorothair, and the lining mernbrane of protoplasm. It not only carrics the water into the plant by fillinge wall and protoplasm with it, but it also rendors both wall and protoplasm more porous by reason of the strelling due to the separation of the molecules. For this reason it is a most important. aid to the processs of osmosis, which controls the diffusion of liquids through plant membranes. Imbibition takes place more rapidly at high than at low temperatures. It is increased by the action of arids and alkalies, provided they are not ton strong. It is ereater in distilled water than in water eontaining salts in solution. The powerful foree exerter in imbibition is marle evident by the lifting power of swelling seeds or woord, as well as by the faret that heat is given off. This evolution of heat is apparently due: to the movement of the moleculess and also to the condensation of the water imbibed. The turning and twisting of awns when moistenced, as in stipa, is likewise an evidence of the energy of imbibition.

Experiment 8. Water of imbibition. Put 25 grams of dry peas and an erfual amourit of distilled water in a small cylinelrical jar with straight walls. Cover the pras with a close-fitting erork float, through the center of which is placeed a thermometer. Weight the cork down with seteral 10)-gram waights, at the same time marking its position. Winte the rise of the float as the poas swell, and also ermpare the temperature with that of the surrounding air. Determine the volume of a swollen and a dry pe:a hy means of calipers, and compute the percent of increas: due: $t$ or imbibition.

Cut small pieces of hard roord and of soft word to the same size. Ir:asure carefully, soak in distilled water, measure again, and compare the amount of swelling in the two.

58. Osmosis. 'Two solutions of unequal density when separaterl hy a perous membrane will grarlually pass through the latter, and mix with earh other. This purely physical process of diffusion is termed osmosis. It depends primarily upon the rlifforing density of solutions able to wet the limiting mombrane. Osmosis consists esseritially of two currents which set in opposite directions. The first current set up is troward the rlenser or stronger solution, but this is regularly compensated by at seement current passing from the donsor to the weaker solution. Tho. difference in density between the two solutions doetrmines the strength of the first eurrent, as well as the lengeth of interval that 
elapses before the second is set up. This is largely determined also by the affinity for water possessed by the substances in solution. For example, sugar has a comparatively slight affinity for water, and is much less active in osmosis than mineral salts or organic acids, which show a greater attraction for water.

59. Osmosis in root-hairs. The conditions presented by a root-hair embedded in a moist soil are apparently those found in ordinary osmosis. It offers a porous cellulose wall wetted within by a cell sap denser than the soil water which wets it throughout. A moment's reflection, however, makes it clear that in such event the root-hair would sooner or later lose as much water as it absorbs. The plant would then be unable to get water for its various functions, especially transpiration, and it would quickly wilt and die. Evidently, the root-hair must be enabled to modify ordinary osmosis in such a manner that it may take in more water than it gives out. This absolutely indispensable modification of osmosis is due to the presence of the protoplasmic membrane which lines the hair. This membrane, like all protoplasm, has a great attraction for water. Its effect is to increase the strength of the first current in osmosis (endosmose) and to decrease the return current (exosmose). The latter indeed becomes practically inperceptible. It is represented by the slow passage of a minute quantity of acid cell sap, indicated by the reaction of roots to litmus paper, or by their etching effect upon a marble surface. Osmosis in the root-hair differs from ordinary physical osmosis in that it consists practically of the inward current alone, the return current being prevented by the active properties of the protoplasm. Within the root, the normal process with currents in both directions takes place between the cells of parenchyma.

The osmotic properties of root-hairs are due to the fact that the density of the cell-sap is normally greater than that of the soil water. The substances in the hair capable of inducing osmosis are the sugars used as food, the mineral salts absorbed from the soil, and the organic acids and their salts. Of these, the sugars have little or no influence; the mineral salts play a relatively small part, since they ean be obtained only by absorption from without. The organic acids and salts constantly produced by the activities of the cell are by far the most active, and it is to them that osmosis is chiefly due. 
6o. Influence of soluble salts. The composition and density of the cell sap naturally varies in different plants. In all ordinary habitats the density is greater than that of the soil water, since this is one of the necessary conditions of endosmose. The density of the water content is determined by the amount of soluble salts present in the soil, and by the amount of water applied to it. The water content of ordinary soils contains from $0.01 \%$ to $0.1 \%$ of dissolved salts. In alkaline lands the soluble salts vary from $0.2 \%$ to more than $3 \%$. Up to $0.2 \%$, the action of such salts is not injurious, as indicated by the growth of ordinary field crops upon them. Beyond this point concentration becomes more and more injurious, owing to the difficulty of absorption. The limit for the most resistant cultivated plants is reached at about $1 \%$, and beyond this only such alkaline plants as the salt bush and the greasewood are able to grow. Soils containing much sodium carbonate and bicarbonate (black alkali) render osmosis and absorption much more difficult. The injurious effects of such salts become evident at a concentration of $0.05 \%$, while only the more resistant plants can withstand $0.1 \%$ to $0.2 \%$.

Experiment 9. Demonstration of osmosis. Tie a picee of parehment or dialyzer paper over the bulb of a thistle tube, taking pains to make it fit tightly. Fill the bulb with a $25 \%$ or $30 \%$ solution of eommon salt and allow the latter to rise a short distance in the tube. Place the butb in a beaker filled with distilled water and support it by means of a ring-stand. Follow the rise or fall of the column in the tube, and mark the various heights. Test the distilled water from time to time by means of a drop of silver ehloride to determine whether the salt has passed into it. When the column has reached the highest point, place the bulb in a eoncentrated salt solution, and note the behavior.

Experiment 10. The effect of soluble salts. Germinate sunflower seeds in three pots filled with sawdust, and after the seedlings are well established, water one with distilled water, the seeond with a nutrient solution, and the third with a $5 \%$ solution of eommon salt. Compare the behavior of the seedlings, and note also the effect of the solutions upon the root-hairs.

Treat a thread of pond scum with $1 \%$ solution of common salt colored with methyl blue. Note the effect, and after a few minutes replace the salt solution with distilled water. This slninkage of the protoplasm, whieh is known as plasmolysis, is essentially what occurs in the root-hairs in soil watered with the salt solution. 


\section{I. Effect of protoplasm upon the absorption of soluble salts.} The protoplasmic membrane of the cell is not merely a powerful factor in determining the absorption of water. It also exerts an extremely important action upon the amount of soluble material taken in with the water. The latter is not absorbed as it is found in the soil. The protoplasm has a different degree of attraction for the molecules of water and for those of the dissolvel salts. Moreover, it has a greater affinity for some salts than for others. In consequence, the soil water that enters the plant not only contains a changed amount of soluble salts, but the relative amounts of these are also different from the amounts present in the soils. The rule apparently is that proportionately more water than salt is absorbed when the solution is relatively concentrated, and proportionately more salt than water when the solution is dilute. An analysis of the ash of species growing in the same habitat not only shows that soluble salts exist in the plant in a different proportion from that found in the water, but also that this proportion is different in each species. This power of the protoplasm to take up water and soluble salts without strict regárd to their proportion is of very great importance to the plant. The plant is enabled to filter out as it were some of the dissolved salt when the concentration of the latter is higher, and it is unnecessary or injurious. On the other hand, the roothairs are able to absorb proportionately more nutrient material when the solution is dilute, thus avoiding the necessity of absorbing an excess of water in order to secure the necessary amount of salts. Furthermore, this property enables the protoplasm to absorb more of the salts that are being used most, and less of the others. Indeed, the property is probably to be ascribed to the difference in the demands of the plant.

62. Diffusion. The passage of absorbed soil water from the root-hair cell to a neighboring cell, and from this to the other cells of the root, takes place by virtue of osmosis. The absorbed water first passes into the cortical cell, and in return a certain amount of cell sap passes into the cell of the root-hair. This process of diffusion is continued throughout the cortical region until the water taken in by the root-hairs is finally brought to the fibrovascular region. Diffusion, however, is not due to osmosis alone. The attraction of protoplasm for water, as well as for other substances that it needs, doubtless plays a part. In 
addition, the entrance of soil water into the root-hair cell causes the elastic wall of the latter to stretch. The tendency of the stretched wall to recoil reacts upon the enclosed sap. Since the protoplasmic membrane prevents the escape of the water outward, the latter is forcel through into the adjoining cells, where the pull of one membrane is balanced by that of another.

There is no definite pathway for diffusion between the absorbing surface and the fibrovascular bundle. Diffusion may take place in all directions through a tissue. The general direction is determined, however, by the location of the region in which there is a lack of the diffusible substances. In the root the need for the water of absorption increases toward the fibrovascular bundles which are engaged in transporting it upward to the leaves. In similar fashion, the demand for the food materials brought down by the sieve tissue increases toward the outer layers. The general direction is determined by these two facts, and in the root diffusion is predominantly in a radial direction. It is not certain that diffusing substances follow the shortest route between surface and bundle, but this seems probable.

Experiment II. Diffusion in liquids and in tissues. Fill a 10-ce. cylindrical graduate half full of a $5 \%$ solution of common salt colored with methyl blue, and with a pipette carefully place 5 ce. of distilled water colored with tropæolin above the salt solution. Note the rate of diffusion.

Cut from a turnip a strip of tissue a decimeter long and a centimeter wide and deep. Place the strip in a $1 \%$ solution of common salt colored with methyl blue. Note the rate of diffusion by cutting off segments of $2 \mathrm{~cm}$. from time to time.

63. Turgidity. When water is absorbed by the root-hair, the increased pressure within the cell forces the protoplast still more firmly against the wall, and at the same time stretches the latter. The elasticity of the wall leads to a recoil against this force, and as a result the whole cell becomes firm and rigid. The same phenomenon, which is termed turgidity, takes place in all of the cells of the cortical parenchyma. It is necessarily absent in cells whose walls have lost their elasticity, such as the fibres and vessels of the bundles, and also in cells without protoplasm. The turgidity of each parenchyma cell renders the whole cortical region turgid. The turgidity which is thus given to the entire root is further emphasized by the tendeney of the 
more rigid bundle and epidermal layer to compress the swollen parenchyma and hence to increase its rigidity. In consequence, turgidity becomes a fundamental factor in support. This is particularly evident when stems and leaves are allowed to wilt. The water is removed from the cells more rapidly than it is supplied. The cells collapse, and with them the stem and leaves, in spite of the support of the fibrovascular bundles.

Turgidity is so intimately wrapped up with the absorption of water and its diffusion by means of osmosis that plants can function normally only while they are turgid. A temporary loss of turgidity is usually not fatal, but all the functions dependent upon water are necessarily brought to an abrupt stop. If the flaccid condition continues for a long period, the power of the plant to carry on absorption and diffusion is lost, and the plant dies. In this connection, turgidity renders the indispensable service of keeping the protoplasm firmly pressed against the cellulose walls, a condition necessary for keeping the wall filled with water. The latter in turn is absolutely necessary to the passage of water through the wall, and hence to diffusion. Turgidity is thus seen to furnish a ready clue to the condition of the plant. Turgid plants are normal, flaccid plants abnormal, i.e., in a pathological condition.

Experiment I2. Demonstration of turgidity. Cut a 3-inch section of dialyzer tubing and soak it in distilled water until softened. Carefully fold and tie one end, fill with a $10 \%$ solution of common salt, and tie the open end as closely as possible above the level of the liquid. Place this artificial cell first in distilled water, and, after it has become fully distended, put it in a $20 \%$ solution of common salt. Note the results. Place the cell in soil saturated with distilled water colored by erythrosin, and explain its behavior.

Allow two sunflower plants to wilt. Water one as soon as the leaves wilt strongly, and the upper part of the plant begins to droop. Water the second only after the whole plant has collapsed. Explain the results.

TRANSPORT

64. General nature. In all stemmed plants, the surface that absorbs water is separated by a greater or less length of stem from the leaf surface which loses water. Even in stemless flowering plants, practically the same condition exists, since a similar separa- 
tion of absorbing and transpiring surfaces is effected by the petiole. By far the greater bulk of the water absorbed nust be carried through the stem to the leaves. The rapid movement of the large amount of water which is lost by the active evaporation from the leaves makes the presence of a special pathway imperative. Such a pathway is found in the fibrovascular system, which has already been seen in the root to occupy a position peculiarly adrantageous with respect to the diffusing water. The fibrovascular bundle of the root connects directly with those of the stem, and the bundles of the stem are prolonged in the form of minute veins to all parts of the leaves. The fibrovascular system thus resembles a continuous series of water pipes, serving to collect the water absorbed by the roots, to carry it with relatively slight loss through the stem, and to distribute it to all parts of the leaf. This movement of the water, which is an essential function of stems, is transport. The details of transport will be more readily understood after a consideration of the structure of stems.

65. Types of stem structure. Among flowering plants, dicotyledons possess a stem essentially different in structure from that of monocotyledons. Though in less degree, woody stems also differ characteristically from herbaceous ones. All of these types are in fundamental agreement, inasmuch as each possesses the three primary regions corresponding to dermatogen, periblem, and plerome, though in monocotyledons the regions are confused. The essential differences between the three kinds of stem hinge upon the nature and arrangement of the fibrovascular bundles. The bundles of a dicotyledonous stem possess a layer of meristem, or cambium, and are able to increase their size. 'They are usually arranged in a more or less circular row placed about midway between the center and the surface of the stem. The bundles of monocotyledons have no cambium, and are consequently unable to grow after they are once formed. They are seattered more or less uniformly throughout the stem. The bundles of fern stems are also without cambium, and are solitary or scattered. Wroody stems are primarily dicotyledonous or monocotyledonons. They differ from herbaceous stems of the same type in the exresive development of woody tissues. This is shown in our common shrubs and trees, all of which are dicotyledons. In these the number of bundles is repeatedly augmented by the formation of new bundles from the ring of cambium, until the fibroviscular 
system is a closed ring, encircling the pith. The continued growth of this ring from year to year results in a stem consisting almost wholly of woody tissues.

66. Stem structure of an herbaceous dicotyledon. A section of the stem of an herbaceous dicotyledon reveals an epidermal, cortical, and fibrovascular region. The former is regularly a single layer of cells, as in the root. Its cells are often differentiated into epidermal cells, hairs, and guard-cells of stomata. The epidermal cell has its outer wall rendered impervious, and of ten also thickened, to prevent water loss. Hair-cells are epidermal cells elongated after the manner of root-hairs. They are usually many-celled, however, and their walls are cutinized, indicating that they are a protection against water loss. Guard-cells are indirectly a result of the cutinization of the epidermis. The latter renders necessary the presence of openings for admitting gases, and the consequent danger of water loss requires the development of guard-cells to regulate the opening. All of these modifications of the epidermis are really characteristic of the leaf, and they occur in the stem only in so far as it assumes some of the same functions.

The cortical region often consists of parenchyma alone. In many plants, however, a secondary supportive tissue, the collenchyma, is developed next the epidermis, and, more rarely, one or more rows of bundles of wood or stone fibers appear somewhere in this region also. Milk-tubes are likewise found here. The parenchyma is usually characterized by the presence of chloroplasts, though usually to a less degree than that of the leaf, and of intercellular spaces for the passage of air. In most cases, it does not show a differentiation of exoderm and endoderm, though the latter often occurs as an incomplete sheath about the fibrovascular bundles. The fibrovascular system is usually in the form of an interrupted circle of bundles strung like beads upon the ring of cambium. In older stems, or in robust species, such as the sunflower, the ring of bundles often becomes completely closed. In a few cases, such as the cucumber, there is a secondary outer ring. In many succulents, and in water plants, the fibrovascular bundles are greatly reduced, and their behavior exceptional. As in the root, each bundle has a phloem and a xylem portion, though their relative position is now changed. They are no longer radial, but the phloem has swung around so that it is opposite and outside of the xylem. In most herbs, the phloem 
or sieve area of the bundle consists of sieve tubes, companion cells, and thin-walled fibers. The sunflower and similar woody herbs possess in addition bundles of thick-walled fibers, or bast fibers, located on the outside of the sieve tissue.

Between the phloem and the xylem lie several or many layers of clear, thin-walled seriate cells, usually referred to as cambium. Properly speaking, the true cambium is but a single layer of active meristem, each cell of which by division alternately forms a xylem and a phloem cell. Since the latter are modified but slowly into the various parts of the bundle, there are always a number of layers which closely resemble the mother cells. The xylem romprises wood fibers and tracheary vessels, the latter of various types, ringed, spiral, reticulated, and pitted. Occasionally, also, large, pitted wood fibers occur here and there: these are called tracheids. The tracheary vessels are usually found in the middle of the xylem, surrounded and separated by the wood fibers. In the longisection it should be noticed that the vessels are continuous tubes of great length, while the wood fibers are single closed cells. Within the fibrovascular ring, and derived like it from the plerome, lies the pith, consisting usually of inactive parenchyma, sonetimes used for storage.

67. Stems of monocotyledons. A section of the stem of an herbaceous monocotyledon shows essentially the tissues found in the dicotyledon. The cambium, however, is found only near the periphery, and the bast is replaced by a sheath of stone fibers which surrounds each bundle. The irregular arrangement of the bundles likewise makes it impossible to distinguish a cortical region or the pith.

68. Structure of woody stems. A woody dicotyledon has essentially the grouping of tissues found in the herbaceous type. Wood and bast have been greatly emphasized at the expense of other tissues, and a new tissue, the cork, has been adrled. A section of a typical woody stem shows on the outside the cork, together with certain cambium cells which produce it. Beneath the cork are a few layers of collenchyma, followed by a broaler area of cortical parenchyma. Within the latter follow the bast bundles, parenchymatous cells, sieve tubes, and companion cells of the phloem. Beyond the latter is the cambium, and the rings of wood surrounding the pith. The wood consists chiefly of tracheids and wood fibers, together with a larger or smaller number 
of ressels, and short wood-parenchyma cells, usually filled with starch. Arising from the cambium and running radially through the bast and wood are the medullary rays. These consist of rows of parenchyma cells elongated radially. They serve as pathways for food solutions passing to and from the storage-cells of the pith, and as storage-cells for starch.

69. Functions of the stem. The stem is primarily an organ for support. Its most important secondary function is the transport of the water taken up by the root. The structural features peculiar to the stem are to be found in the arrangement and composition of the fibrovascular bundles. In the monocotyledons the need for increased support is met by the formation of new bundles. Dicotyledons can attain the same end by increasing either the number of bundles or the size of each bundle. Woody herbs, shrubs, and trees unite both methods, first increasing the number of bundles as well as the size, and later, after the ring becomes closed, increasing the size alone. In herbaceous plants practically all of the elements of the xylem play a part in the transport of water, but in woody plants the thick-walled fibers have little or no part in this function.

Experiment 13. Structure of stems. Cut thin cross- and longisections of sunflower, corn, and ash, the first two preferably by means of the paraffin method. Make a schematic drawing of the cross-section showing the fibrovascular system. Draw a segment from the cross-and longisection of each stem under the high power, and indicate the various regions and elements.

70. The upward movement of the water. When the water has been brought by diffusion to the radial bundle of the root, osmosis ceases. This is due to the fact that the elements of the bundle, fibers, tracheids, and ressels, are dead cells which lack protoplasm and for the most part have rigid and thickened walls. Under these conditions, osmosis and consequent diffusion become impossible, and imbibition and infiltration take their place. These in themselves are slow processes, and require to be emphasized in order that water may enter the bundle more rapidly. This emphasis is furnished by the cumulative action of the turgid cells of the cortical parenchyma. The constant absorption of water by the root-hairs, and its diffusion through the parenchyma, put an increasing strain upon the elastic wall of each cell and upon 
the epidermal layers. This strain greatly increases the imbibition and infiltration from the parenchyma cells adjoining the bundles, and explains how the water may enter rapidly enough to supply the constant evaporation from the leaves.

Infiltration occurs more easily and rapidly through thin walls. Consequently water passes readily into the vessels and tracheids through the thin areas and the pits of the wall. It enters the thickened walls of wood and stone fibers only with much difficulty or not at all. In addition, tracheids are separated by thin end walls, and ressels are continuous for long distances, while fibers are connected by thickened walls. From this it becomes evident that the movement of water upward must take place very largely in the ressels and tracheids, and to a very slight degree, if at all, in the thick-walled fibers. It will be seen later that the sieve tubes of the bundle have a special function, and hence are not available for carrying water to the leaves.

7 I. Causes of the movement. The force that arises from the turgidity of the cortical parenchyma is termed root pressure. The latter is often if not regularly sufficient, not only to force the water to filter into the tracheids and vessels, but also to cause it to rise some distance in them. Under exceptionally favorable circumstances, and with vigorous plants, this effect of root pressure may be demonstrated. A stem is cut off near the ground, and a glass tube of small bore is fitted over it tightly by moans of a rubber joint. If the plant is absorbing water strongly, the root pressure causes the latter to rise in the tube. Once within the tracheids and ressels, the water is subject to the effect of capillary artion. Capillarity, which is merely one form of attraction, is the foree which causes a column of water to rise in an extremely fine glass tube when the lower end is placed in water. Capillary action is due to surface tension, i.e., to the attraction between the molerules of the tube and those of the water. It is excrted in the cavity of the vessels, but attraction also causes water to rise in some degree in the walls of both tracheids and ressels. A lifting effect upon the water in the bundles is doubtless exerterl by the transpiration of the leaves. This effect is largely due to the active fore of osmosis arising from the increased osmotic pressure in the leafcells. The latter is brought about by the increasol density of the cell-sap caused by evaporation. A similar force is probably exerted by the osmotic pressure of the cells of the stem which are 
contiguous to the bundle. In part also this effect comes from the evaporation of water from cavity and wall, which facilitates the rise of water in both tracheid and vessel.

The principal cause of the upward movement of water is unknown. The most divergent views are held, not one of which has proved capable of satisfactory demonstration. In the account just given of probable factors in the movement, it is hardly possible to deny the existence of root pressure, capillarity, and the lifting power of evaporation and osmotic pressure. The relative importance of these, the manner in which theywork, and the existence of other factors are points that it is impossible to settle at present. It seems certain, however, that the so-called "vital properties" of the plant, apart from the physical forces already mentioned, have no part in the movement. The effect of transpiration upon the rate of movement would seem to bespeak great importance for this factor, though it is hard to prove this. In fact, while it is difficult to discover forces of strength sufficient to carry water to the tops of the tallest trees, the forces already discussed seem entirely adequate in the case of all herbaceous plants.

Experiment I4. Pathway and rate of movement. Cut three sunflower plants in such a way as to obtain three leafy stems $\frac{1}{2}, 1$, and $2 \mathrm{dcm}$. long respectively. Cut similar leafy shoots from the young growth of a tree or shrub. For use as a check, cut a $2 \mathrm{dcm}$. stalk from sunflower and tree, and remove the leaves. Fill a flat dish with a $1 \%$ solution of erythrosin, and place the lower ends of the cut stems in the stain. Arrange the sunflower stalks in one row, and the shoots in a second one to permit ready comparison. Note the time that elapses before the stain appears in the petioles of the uppermost leaves. Compare the rates in herbaceous and woody stems, and in the leafy and leafless ones. Cut cross-sections near the base and tip of stalk and shoot, and also across the leaf. Draw a stem bundle, shading the elements in which the stain moved. Make a diagrammatic drawing of stem and leaf section, showing the number of pathways.

\section{TRA NSPIRATION}

72. The structure of a representative leaf. The usual type of leaf is flat, broad, and thin, and is ordinarily more or less horizontal in position. The leaf is an organ peculiarly modified for the reception of light and the absorption of gases. Consequently, it becomes also the main seat of water loss or transpiration. The 
cross-section of a leaf shows the three primary regions, epidermal, cortical, and vascular. Each of these is modified in a manner characteristic of the leaf. In the epidermis this modification is the stoma, in the cortical region the differentiation of the green tissue or chlorenchym, and in the vascular region the great reduction and division of the bundles. The upper and lower epidermis of a leaf are very similar. In the vast majority of leares, they consist of a single layer of cells. Because of a difference of expcsure, the tendency of the upper epidermis is to develop cutinized

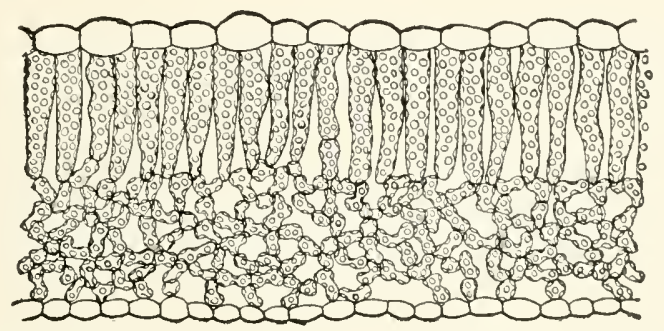

Fig. 14.-Cross-section of the leaf of the monks-hood, Aconitum columbianum, showing the palisade tissue above and the sponge tissue below.

hairs, and that of the lower to develop stomata. Thus while hairs and stomata often occur on both surfaces of a leaf, hairs are of ten more numerous upon the upper surface than upon the lower, while stomata are regularly more numerous upon the lower. In many leaves, hairs are found only upon the upper epidermis, while in others, stomata occur only upon the lower. The epidermal cells proper have their outer walls cutinized and usually thickened also. In these likewise the outer wall or cuticle is generally thicker on the upper surface than upon the lower.

73. The chlorenchym. As a rule, the eortical region of the leaf consists wholly of parenchyma cells filled with chloroplasts. From its nature, this tissue is called chlorenchym. The latter' comprises two distinct parts, viz, the palisade parenchyma and the sponge parenchyma. In the normal leaf, the palisacle tissue occurs in the upper half, and the sponge tissue in the lower half. The probable causes of this differentiation are discussed under Light. At present it is sufficient to point out that the position and development of these two tissues are directly conuected with differences in the degree of exposure to light and lumidity 
shown by the two surfaces. The palisade tissue consists of rectangular cells elongated at right angles to the surface, and packed so closely in rows that the intercellular air-passages are scarcely visible. The sponge cells, though usually irregular in outline, are more or less elongated in the direction of the surface. They are loosely connected, and their irregular forms permit the presence of numerous large air-spaces. The relative amounts of palisade and sponge tissue in the leaf are determined by water and light, and a further discussion of this matter will be found under Adaptation.

74. The reduced bundles. The repeated division of the fibrovascular bundles that enter the leaf is adapted to meet the increased need for support caused by its form. At the same time it serves to carry water to all parts of the leaf, which is the organ that needs water most. A close examination of a reduced bundle in section shows its intimate relation to the cells of the chlorenchym. The supportive elements of the bundle are greatly reduced. In many instances spiral ressels alone remain, thereby greatly facilitating the passage of water from the bundles into the cells of the chlorenchym.

Experiment 15. Structure of a leaf. Cut thin cross-sections of a sunflower leaf, preferably by the paraffin method. Under the high power draw in full detail a segment across the leaf at a point where a small bundle oecurs. Pay especial attention to the air-spaces and the number and position of chloroplasts in both palisade and sponge tissue.

Strip a bit of epidermis from each surface. Count the stomata in two or three fields, and compute the number for a square centimeter of each surface. Estimate the surface of a leaf by first weighing the entire blade, and then two or three piees of it a eentimeter square taken from different portions, and dividing the first weight by the average weight of a pieee. The quotient is the surface in square eentimeter's. Estimate the number of stomata on each surface of the entire leaf.

75. Diffusion in the leaf. The water absorbed by the roots is carried throughout the leaf by the reduced bundles. The water passes from the vessels into the cells of the chlorenchym by reason of the osmotic pressure of the latter reinforced by the attraction of the protoplasmic membrane. The latter effect is due to the fact that the vessel has no protoplasm to counteract this pull. The water passes from cell to cell by diffusion, exactly as in the 
root. Diffusion in the leaf is due to osmotic pressure, arising in part from the active production of organic acids and salts in the cells, but chiefly, it would appear, from the increased density of the sap caused by evaporation. The latter reason doubtless causes diffusion to set most strongly toward those areas in which evaporation is greatest. Here, as elsewhere in the plant, diffusion currents are always in the direction of greatest use.

76. Transpiring surface. In ordinary leaves, especially those found in the sunshine, the cutinized wall of the epidermal cells either entirely prevents transpiration from them or reduces it to an insignificant amount. The transpiring surface, therefore, is not the epidermis of the leaf, but it is formed by the cells that lose water rapidly and in relatively large amounts. It is composed of the aggregate cell surfaces that border on air-spaces, both in the sponge and the palisade tissue. At these places, the cell-sap, which fills the cell walls, passes into vapor whenever the air in the passages is not completely saturated. The moist air that fills the spaces gives up some of its moisture through the stomata to the drier air outside. It seems probable, howerer, that a more important factor in water loss is the passing of the moist air itself through the stomata, owing to the constant movement of leaves in the wind. In this case, drier air at once passes in to take its place. Consequently, while the number, size, and position of the stomata determine the ease and rapidity with which air and moisture pass out, the stomata do not form part of the transpiring surface. On the outside, the guard-cells are protected against evaporation in exactly the manner of epidermal cells, and the surfaces next the opening are also cutinized. The inner surface of the guard-cell next the air-chamber is usually exposed to the air of the latter, and consequently contributes very slight ly to the transpiring surface.

Experiment 16. Measurement of the actual transpiring surface. Find the linear extent of the air-spaces shown in the drawing of a sunflower leaf by attaching a needle-point to a thread, and allowing the threat to rum out as each side of an air-space is measured. If the result thus obtained is squared, it will represent roughly the area of transpiring surface for a square segment of the leaf of the width of the area studiecl. The two surfaces of this segment would represent the corresponting leaf surface. Determine the ratio between the actual leaf surface and the transpiring surface. 
77. Structure and position of stomata. The simplest form of stoma is a hole, which remains constantly open, and is surrounded by peculiar epidermal cells. In all vascular plants, however, the opening is regulated by two guard-cells. Below the opening regularly occurs an air-space of variable size, the air-chamber. The guard-cells vary considerably in different plants, but in all they agree in being oblong or cylindrical cells, bent in such fashion that they join broadly at the ends, but are free at the middle. The outer wall of each guard-cell is thickened, and in many cases the inner wall also. The wall next the opening is likewise more or less thickened, while that opposite the opening, i.e., touching the epidermal cell, is the thinnest. Guard-cells are almost invariably filled with chloroplasts which contain starch.

Stomata usually occur singly, scattered more or less uniformly over the epidermis, but in some plants they are found in groups.

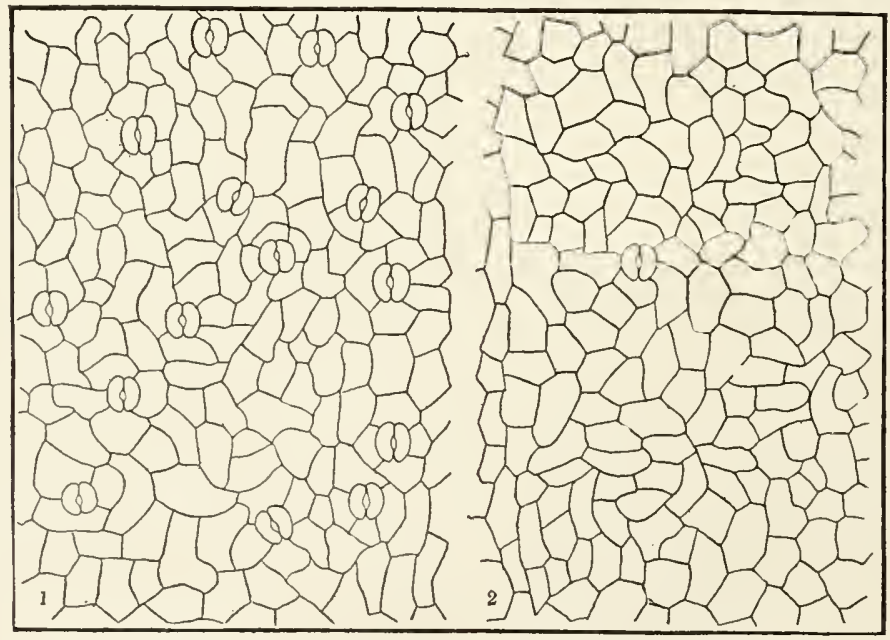

Fig. 15.-Distribution of stomata in the epidermis of an orchid, Calypso borealis. The lower epidermis (1) has 36 stomata per square millimeter of surface, the upper (2) but 2 per square millimeter.

Though commonly on a level with the epidermal cells, stomata are often sunken for protection, either singly, as in the century plant, or in groups, as in the oleander. Sunken stomata usually possess an outer chamber or court, formed by the over-arching of the epidermal cells. Their guard-cells usually exhibit one or 
two pairs of valves, though these are often found in other stomata also. As already indicated, stomata are ordinarily more abundant upon the lower epidermis of horizontal leaves, and in some species are restricted to this surface. In many aquatic and rosette plants, the stomata are more abundant upon the upper surface, and in floating plants they occur on this surface alone. The leaves of submerged plants normally lack stomata. In forms more recently submerged, the latter sometimes persist, but are functionless.

78. The functions of stomata. In their simplest form, stomata are for the purpose of permitting the ingress and egress of carbon dioxide and oxygen, though moisture must also pass out through them. In the thalloid liverworts, growing closely pressed upon moist earth, the danger of drying out through the openings alone would seem small. In leafy stemmed plants, this danger is greatly increased, and has necessitated the derelopment of guard-cells. The latter consequently have charge of the secondary function of stomata, which is to regulate the amount of transpiration. The movements of the guard-cells are regulated by light and by the interaction of humidity and water content. Stomata open in strong light and close in weak light; consequently they show a periodic movement, opening in the morning and closing at night. When transpiration tends to exceed absorption, as in the case of a great decrease in humidity, the guard-cells close. This checks transpiration, and usually enables the roots to meet the deficieney. When this occurs, or when the water supply is renewed, as by a rain, the guard-cells open.

79. Movements of guard-cells. The movements of the guardcells are brought about by changes in their turgidity. Stomata close when the plant becomes flaceid. i.e., when the plant is losing more water than it absorbs. They open again when the plant becomes turgid in response to increased absorption or decreased transpiration. Generally speaking, stomata are open for the exchange of gases, when the danger from excessive water loss is slight, and they remain closed when the danger is great. As a matter of fact, the closure is rarely quite perfect, so that some moisture escapes even when the stoma is closed.

The mechanism by which the stomata open and close is a simple one. It is most readily understood by comparing the top of a stoma with a cross-section of one. The thinnest wall of earh guard-cell is the one next the epidermal cell, the others. particularly 
the upper and outer, being more or less thickened. Since the guard cell is active, it has a relatively high osmotic pressure, and draw

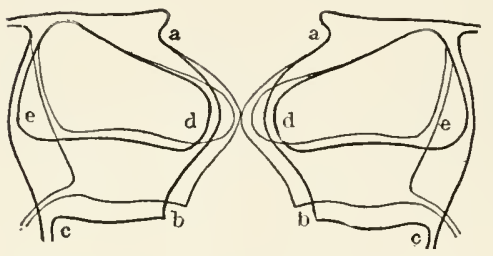

FIG. 16.-Diagram of the stoma of IIelleborus. 'The shape of the guardcells when the stoma is open is shown by the heavy lines. 'The thick outer and inner walls are shown at $a$ and cd. (After Sehwendener.) water readily from the adjoir ing epidermal cells. The resu' is to cause the inner walls of eac. guard-cell to become more an more convex. Since the guard cells are firmly joined to eac? other at the ends, the increaser turgidity forces them apart is the center, as though each wer pulled by a string attached to thr middle of the inner wall. A long as the plant remains full! turgid, the stomata stay open, except of course for the regula closing at night. When the water loss tends to become excessive or the water supply deficient, the osmotic pressure of the epiderma cells exceeds that of the guard-cells. Water is withdrawn from the latter, the inner wall becomes less convex, and releases the strain upon the two guard-cells, which close in consequence. Closure in its turn is maintained until the usual turgidity is restored. In many cases it is probable also that the epidermal cell: adjoining the stomata aid in this process by their shape and move ment.

Experiment 17. Movement of guard-cells. Strip a small piece o epidermis from the leaf of a turgid and of a wilted sunflower. Immerst the strips for a few minutes in a killing solution containing osmic acir (preferably Flemming's solution), wash and examine the stomata unde the high power. Remove fresh strips from the same sunflowers. Place the turgid epidermis in a $5 \%$ solution of common salt and the flaccio one in distilled water. Examine under the high power and explain the results. Nake a schematic drawing of a stoma when open and when closed.

Experiment 18. Position of stomata and water loss. Select four similar leaves of sunflower or, better, of a plant which has stomata only on the lower surface. Cover the upper side of one leaf with wax melting at a low temperature. Wax the lower surface of the second and both surfaces of the third. The fourth leaf is not coated, in order to serve as a check. Fix each leaf in a small vial filled with a known amount of water, in such fashion that the water lost is supplied through the petiole. Determine the loss from each leaf by weighing or measuring the water 
in the vial. Remove the leares from the vials and premit them to dry out, noting the time required in each case.

8o. The influence of physical factors upon transpiration. Three factors, humidity, water content, and light, affect transpiration directly. Their influence is seen not only in their ability to cause the stomata to open and close, but also in determining the rapidity of transpiration when the stomata are open, and. inderd, though in much smaller measure, when the latter are closed. We have already seen that light causes stomata to open in the morning and close at night, thus resulting regularly in less transpiration at night than during the day. In addition the greater part of the light energy absorbed by the chloroplast, usually more than $95 \%$, is converted into heat, and produces water loss or, as it is sometimes called, chlorovaporization. A marked decrease in humidity or in water content, as well as the two acting together, ordinarily causes the stomata to close, while subsequent increase tends to open them. It is usually impossible to distinguish clearly between these two factors in connection with water loss, since they practically always act together. For example, the stomata of water plants remain open even when the humidity falls to a minimum, and they likewise stay open in a saturated atmosphere, even though the water content be low. With reference to the amount or rate of transpiration, however, each factor has its own effect. Increased humidity checks water loss; decreased humidity promotes it. A reduction in water content decreases transpiration, and an increase tends to augment it. Transpiration is at a maximum when the water content is high or excessive and the humidity very low.

Temperature pressure, altitude, and wind affect transpiration only in so far as they change the humidity or, through the latter, the water content. These relations have already been discussed, and it is only necessary to state again the facts. High air temperatures increase water loss; low temperatures decrease it. Soil temperatures below freezing decrease transpiration by rendering water content less arailable. High altitudes, i.e., low pressures, promote transpiration; low altitudes, i.e., high pressures, reduce it. Dry winds increase water loss; moist winds decrease it. Apart from their humidity, winds increase transpiration hy removing the increasingly humid air above the leaf and by aiding in the morement of the air in the air-spares and through the stomat a. 
The effects of slope, exposure, and cover upon the amount of water loss are exerted through the factors already discussed.

$8 \mathrm{I}$. The measurement of transpiration. Of the many methods used to determine the amount of water lost from a transpiring plant, the most accurate and satisfactory is to weigh the plant in its own soil from time to time. This can easily be done in the case of plants grown in pots. A vigorous plant, growing preferably in a pot 1 or $1 \frac{1}{2} \mathrm{dcm}$. in size, should be chosen for study. The entire pot is covered with sheet rubber to prevent

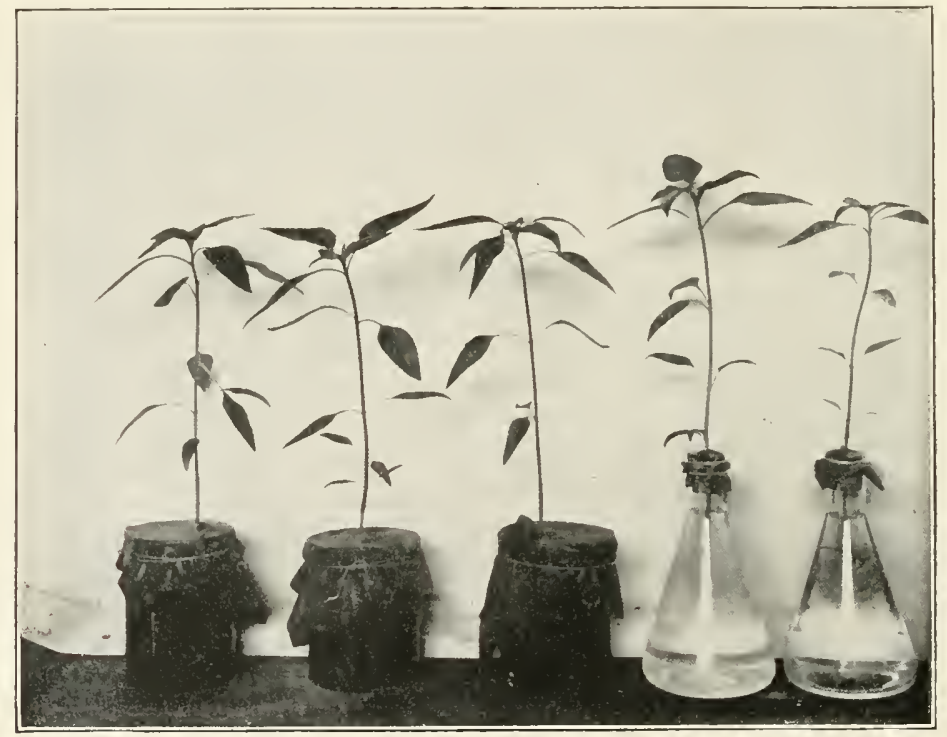

Fig. 17.-Treatment of plants for measuring transpiration. Three are rooted plants in pots; the other two are potometers, the one with a rooted plant, the other with the root removed.

the loss of moisture from its surface; or the outside of the pot may be waxed, and the top alone covered with rubber. The latter is tied closely about the stem, alongside of which a funnel tube is placed for the purpose of supplying water and air to the soil. The entire apparatus is weighed, and is then weighed again at the desired intervals. The plant should be kept under study for a week or two, being placed now and then in different conditions. Weighings are made at such times as to give the water loss for day and night, for periods of different length, and the 
total loss for the period of experiment. The plant will usually require watering only once or twice during the experiment, luit the soil should be aerated every day by blowing air through the thistle tube. When water is added, the amount must be carefully measured and recorded. For the sake of comparing different plants, and since the leaf surface varies on arcount of growth and the withering of old leaves, it is very desirable to express the amount of transpiration upon the basis of a square centimeter or decimeter of surface. The total leaf surface is found as indicated in Experiment 15; it is usually umecessary to allow for the stem surface. The transpiration for a square decimeter of surface is then found by dividing the water loss for the time concerned by the number of square decimeters of total area.

82. Measuring transpiration in the field. The measurement of transpiration in the field, i.e., of a plant in its own habitat, may be made in the same way. The inconvenience is greater only because of the need of taking the scales into the field, or of bringing the plant into the laboratory, and of seeing that the plant runs no risk of being disturbed or destroyed. 'The plants to be studied are carefully dug in the spring, when they are small, and transferred to pots of a size that will necessitate little or no repotting. The pots are sunken in the holes from which the plants are taken. Readings of transpiration may be made as soon as the plant is well established. The surface of the pot alone is covered with rubber, since the sides are protected by the soil. The plant is weighed and watered from time to time in the way already described. Care must be taken to free the surface of the pot from earth when it is taken from the soil for aach weigling. The transpiration is likewise expressed in grams per square decimeter of leaf surface. It is further rery desirable that the plants for experiment be located in the stations where physical factor readings are taken. This will make it possillele to discover the causes of the variations in the amount of transpiration shown by plants of different habitats.

Experiment 19. Influence of factors upon the rate of transpiration. Select five well-grown sunflower plants as nearly alike as powsible. Cover the pots with rubber as indicated above and weigh rach ome. Place one plant as a check in a sunny moist place in the plant-house. Alongside of it, place two dishes of measured surface, (ne containing a 
known amount of water, and the other moist soil of known weight. Of the remaining plants, place one in air as dry as possible, one in a cool spot, one in a windy situation, and one in darkness. Weigh each at the same intervals. Determine the day and night rate of loss, and the total loss for each plant, for the water surface, and for the soil surface, basing them upon a square decimeter of surface. Explain the results

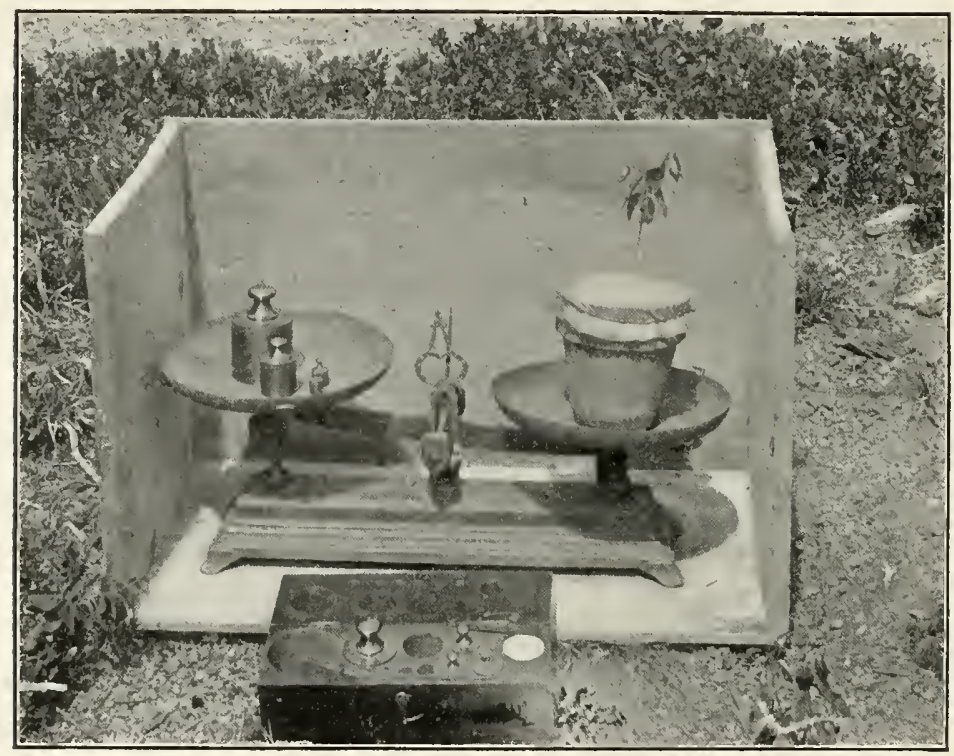

Fig. 18.- Portable box and balance for measuring transpiration in the field.

in the different situations. Compute the ratio of loss from one square decimeter of the check, from the water, and from the soil surface.

83. The amount of transpiration in plants. The amount of water transpired differs for the individual as well as for the species. Nuch of this variation arises from differences between habitats, but species of the same habitat differ widely. entirely apart from any variation in physical factors. This is due to the fact that species differ both in the amount and character of their transpiring and absorbing surface. The same is true, though to a much smaller extent, of plants belonging to the same species. Aside from distinguishable differences of structure or surfaces, plants of the same species lose water in varying amounts, some- 
times behaving as though each had an indivichality of its omm.

In the classical experiments of Hales (1727), the maximum transpiration of a sunflower was found to be $850 \mathrm{gm}$. in a twelvehour day, and $85 \mathrm{gm}$. at night. Sachs found also in the sumflower that the leaf surface lost water about half as rapidly as it evaporates from a water surface under the same conditions.

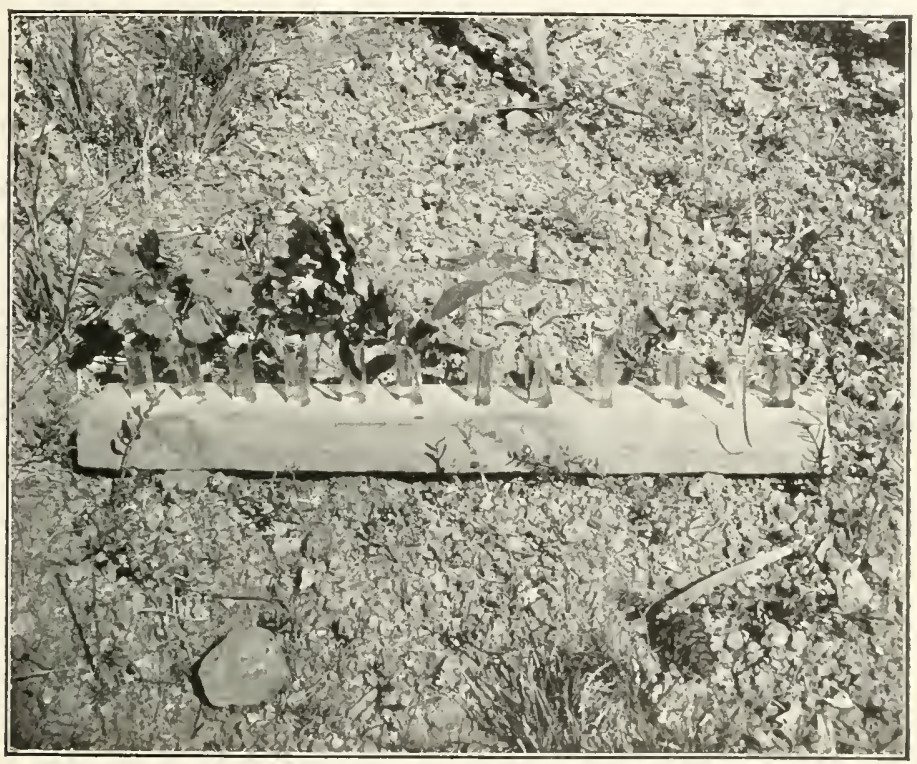

FIG. 19.-A battery of potometers for the ready comparison of the water loss of plants of the sime or different habitats.

According to Wiesner, the Indian corn loses per hour for each square decimeter of leaf surface $78.5 \mathrm{mg}$. in sunlight, $111 \mathrm{~m}$. in diffuse light, and $97 \mathrm{mg}$. in darkness, while orre of the woody mallows (Malca arborea) loses respectively 70 , 2S, and 23 mir. It has been found that a plant of Indian corn transpires $1+\mathrm{kg}$. of water during its period of erowth (17:3 (lays), and a hemp plant, $27 \mathrm{~kg}$. in a growing periol of 140 days. Haberlandt has estimated that the oat plants covering one hertare lost nure than $2,000,000 \mathrm{~kg}$. during their period of growth, while a similar number of barley plants transpired more than $1.0(0),(0)(x) \mathrm{ker}$. The transpiration of a large tree reaches an cnormoms total duriner one summer. Ton Iöhnel has estimated that a hecele frec tran- 
spired on the average $75 \mathrm{~kg}$. daily during the summer, while a birch tree possessing about 200,000 leaves lost nearly $400 \mathrm{~kg}$. during one hot day.

84. Relation between transpiration and absorption. It has been previously shown that transpiration and absorption are necessarily reciprocal, or compensatory. The amount of water absorbed determines the amount that can be transpired, and, conversely, the rate of transpiration reacts forcefully upon absorption. Leaves that bear stomata cannot avoid transpiration, but under ordinary conditions this is beneficial instead of harmful. The growth of a plant depends upon the amount of water absorbed, and the amount of nutrient material dissolved in it. Where the water supply is sufficient, plants that transpire the most obtain the greatest amount of water and salts, and grow the best. Under the usuaconditions, the water absorbed by the roots contains about .01\% of dissolved salts. In other words, a plant must absorb and transpire $10 \mathrm{~kg}$. in order to obtain 1 gram of nutrient salts for use. In the case of many water plants, the nutrient content is much less, and the amount of water that must be transpired is correspondingly greater. Thus, while transpiration is an inevitable process for all plants with stomata, it is more significanl for some than for others. Its significance depends upon absorpt tion, i.e., upon water content. For plants in dry soils, transpiration is more or less injurious, and it must be prevented in so far as possible. Transpiration is beneficial to plants of moist habitats because it promotes their growth. This benefit is still more pronounced in amphibious plants, where the movement of a large amount of water through the plant is necessary to its welfare.

85. Compensation for increased transpiration. From what has just been said, it is clear that the effect of increased transpiration is determined by absorption: the converse is equally true though much less important. Such compensation is naturally possible only when the water supply is adequate to meet the new demand. Consequently, when the water loss is greatly increased, the final adjustment of the plant is determined by the amount of water available at the root surface. As indicated, the compensation merely results in increased transpiration when the absorption is entirely adequate to the demand. When the water supply is inadequate, the stomata close. If this condition is but temporary, the stomata open as soon as absorption is able to restore the normal 
turgidity. When the drouth is continued, the plant first wilts and then dies. Plants often find themselves in conditions where the drouth is sufficiently severe to render the temporary closing of the stomata more or less ineffective, though not fatally so. Such conditions result in modifications of various sorts, most of which decrease water loss, though some are for the purpose of increasing the water supply.

86. Details of the adjustment. The water evaporated from the cells bordering air spaces is supplied by osmosis from the adjacent cells. The latter in turn draw upon cells nearer the transporting bundles, until the demand for more water reaches the bundles themselves. The vessels of the leaf meet the demand, and the water given up is replaced in consequence of an upward movement through the bundles of the stem and root. The deficit thus caused is met by the movement of water into the root bundle, and is consequently passed along until it reaches the root-hairs. The last step in the process of replacement is taken by the latter, which absorb the necessary amount of available water. As a matter of fact, the root-hair is taking in water at the same time that it is passing by diffusion into the adjacent cells.

If the demand for water reaches the root-hair at a time when it can not obtain an equivalent amount by absorption, it yields some water to the adjacent cell, but not as much as is needed. This is due in part to differences of osmotic pressure in the two cells, but in a large degree also, it would seem, to the strong attraction of protoplasm for water. Apparently as long as this attractive power of the protoplasm of the root-hair is met by absorption, water is permitted to pass readily into the adjacent cells. But in case this affinity is only partially satisfied, the protoplasm of the absorbing cell counteracts in a measure the pull exerted by the adjacent cell, and insufficient water passes into the latter. As a consequence, both cells become less turgid, and, if transpiration continues without compensating absorption, finally lose their turgidity entirely. A similar readjustment oceurs throughout the parenchyma of the root, the innermost cell drawing water from the bundle. This loss is met by taking water from the leaf-rells along the bundles, and the consequent loss of turgiclity passes throughout the leaf, finally reaching the epidernal cells. The latter withdraw water from the guard-cells, which consequently close. 
Experiment 20. Pathway of adjustment. From the cross-section of leaf and root, and the longisection of the stem, construct a schematic drawing in such manner as to show a strip of the cortical tissue of the root in contact with the lower end of the bundle, and a segment of the leaf in contact with the upper end. Indicate upon the drawing the course by which the change due to increased evaporation through a stoma reaches the root-hair, and the course of the return adjustment when water is lacking for absorption. 


\section{CHAPTER IV}

\section{ADJUSTMENT TO LIGHT}

87. Relation of the plant to light. As the source of energy or the food-making activities of the plant, light is scarcely secondry to water in importance. It is unnecessary only in the case f molds, mushrooms, etc., which do not make their own food, ut use that made by other organisms. The primary response f green plants to light is the production of chlorophyll by the lastid. Under the influence of light, the chloroplast is able to ecompose carbon dioxide and water to form sugars or elaborated oods. A large amount of the light absorbed is converted into eat in the plastid, and produces evaporation. The number and rrangement of the chloroplasts are determined by the intensity f the light. The latter also regulates the movement of the guardells, causing the stoma to open in strong light and to close in arkness. The direction of the light produces a turning or bendig of the plant, which is termed phototropism. The normal position leaves is due in large measure to the action of light, and the me is true of the day and night positions taken by many of nem. Finally, the form of the leaf is probably due more to light ian to any other factor. The effects of light may be summarized follows:

1. Production of chlorophyll.

2. Decomposition of carbon dioxide and water to form sugar.

3. Loss of water from the chloroplast.

4. Changes in the number and position of chloroplasts.

5. Daily opening and closing of the stomata.

6. Turning of stems and leares.

7. Day and night position of leaves.

s. Changes in the form and strueture of the leaf. 
88. The nature of light stimuli. The stimulatory action of light is exerted primarily upon the chloroplast. To this are probably to be traced all of the effects just enumerated, though it is impossible as yet to establish this connection in the case of the turning of stems and leaves, and the periodical changes in the position of the latter. In these the effect of the stimulus does not appear in the chloroplast, or the cell containing it, but is transmitted to a more remote part of the plant, where it becomes evident. Since such movements occur only in green plants, and apparently result in placing the leaves in more favorable positions, it seems extremely probable that they are due in the first place to the reaction of the chloroplasts to light.

Stimuli result from a change in the intensity, direction, or quality of the light. In nature, the quality of the light is very little if any different in various habitats. Even in dense forests, the diffuse light is white, not green. The direction of the light is of little importance, except where the illumination is strongly one-sided. This is the rule in horizontal leaves, though the position really results in a difference in intensity. Plants on the edges of forests and thickets are often bent toward the sumshine, but within a particular habitat such movements are lacking, except in the case of a few plants, as the sunflower. The change in light intensity necessary to produce a response varies for different species, and it is also influenced by the intensity in which the species normally grows. The normal extremes of intensity are full sunshine, represented by 1 , and a diffuseness of .002, i.e., light 500 times weaker than sunlight. The food-making activity of the chloroplast is so fully dependent upon the light that it is affected by very slight differences of intensity. On the contrary, such responses as the movement of the chloroplasts, changes in leaf structure, and phototropism are produced only by much greater differences.

89. Measurement of light. Determinations of light intensity are made by means of the photometer. This is a tight metal box containing a central wheel upon which a strip of photographic paper is fastened. The wheel is revolved past an opening $6 \mathrm{~mm}$. square, which is closed by means of a slide working closely between two flanges. The disk or the wheel is graduated into twenty-five parts, which are numbered. A line just beneath the opening coincides with the successive lines on the disk, and indicates the 
number of the exposure. The movement of the wheel is regulated by a click. The metal case is made in two parts in such way that the bottom may be readily removed and the strip placed in position. The photographic paper used is the kind called "solio." The photometer must be filled in the dark room, or at night in weak light. A strip $6 \mathrm{~mm}$. wide is cut lengthwise from the $S \times 10$ sheet, and $\frac{1}{4}$ of an inch is cut from one end in

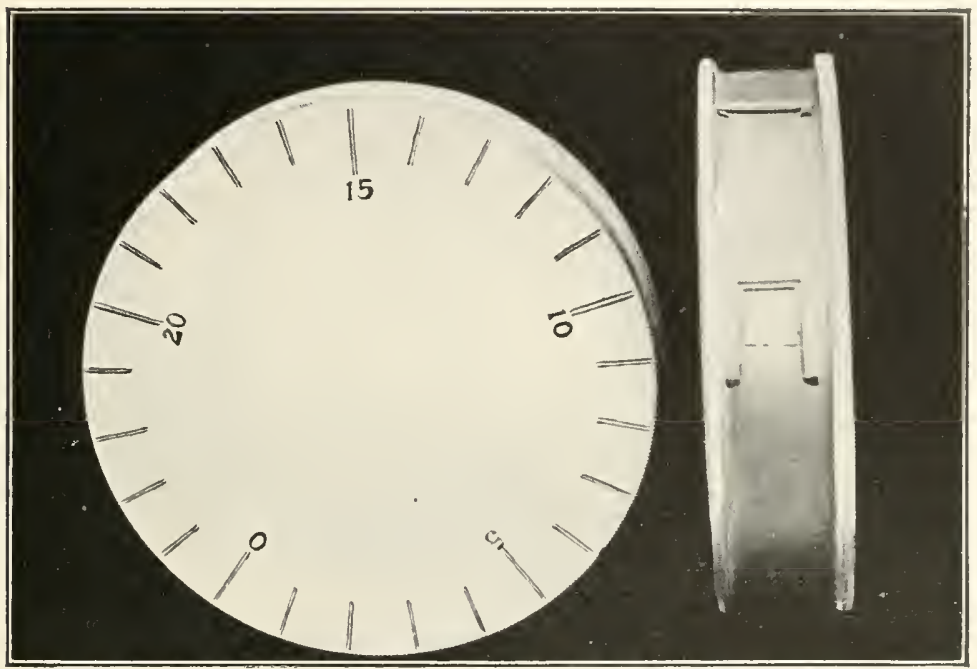

Fig. 20.-A new form of the simple photometer, showing the numbered face and the slit for making exposures.

order to secure the right length. A crease is carefully made $\frac{1}{4}$ of an inch from each end to prevent the breaking of the paper when the cork plug is put in place. The strip is then placed upon the wheel, great care being used not to touch the coated surface with the fingers. It is fixed in position by using a piece of cork to hold the creased ends in the slit of the wheel. The latter is then placed in the case, the zero turned until it is opposite the index line, and the photometer is ready to be used.

9o. Making a standard. An exposure is made by moving the slide quickly, in such a way as to uncover the entire opening. Care must be taken not to pull the slide completely out of the groove, as it is impossible to replace it with sufficient quickness. The length of exposure is determined by means of a watch. A 
stop-watch is especially raluable for this purpose, but a watch of the usual type is satisfactory. After a little practice, it is a simple task to hold the watch with the one hand against the photometer in the other, in such fashion that the slide may be moved without taking one's eyes from the second-hand. Immediately after each exposure, the disk should be turned to the next line: this should be made an absolute rule. Except in the case of readings made for special purposes, the instrument is held with the edge toward the south, with the opening uppermost in the usual position of the leaf.

Standards and ordinary readings are made in practically the same manner. There are various kinds of standards, but the most satisfactory for ordinary purposes is a temporary or proof standard bearing a series of exposures. This is obtained by exposing a strip to full sunshine at noon upon a clear day. Exposures are made for $1,2,3,4$, and 5 seconds successively, the greatest care being taken to make the time of exposure exact. Frequently it is advisable to make a second series to serve as a check upon the first. After it is completed the standard is removed and placed in a light-tight box, such as is used for photographic plates. It should be used only in gaslight or in ruby light. The former permits much more accurate comparison. When kept in a cool place and handled carefully, the standard and the solio strips may be preserved for several months without appreciable change. Ordinarily, a single standard is sufficient for an entire growing period, though it is sometimes desirable to make a new one from time to time to serve as a check upon the original.

9I. Making readings. The best practice in making readings is to secure a decided tint that falls between the extremes of the standard. It is practically impossible to obtain a sunshine equivalent for very faint tints, and equally difficult to match the very deep ones obtained by long exposure. The most satisfactory method consequently is to expose until a good tint is secured, but one that is not stronger than the 5 -second tint of the standard. In deep shade, this often requires a long time, and in such places it is usualiy more satisfactory to stop the exposure with a lighter tint, approximating the 1- or 2-second exposure of the standard. In taking readings, the date, time of day, station, number of instrument and of exposure, and the length of the latter in seconds, must be rarefully recorded. As a rule, readings are 
made only on clear days, except where the light values of clourly days are desired for special purposes. After a strip has been completely exposed, it is removed in the dark, and a new one is put in place. The former is carefully labeled, and dated upon the back, and is then filed with the same care as the standard.

92. Comparison with the standard. The light intensity denoted by each exposure is ascertained by comparing the latter with the standard. The strips are placed alongside of each other in gaslight of fair strength, and the exposure is moved along the standard until the tint that matches it is secured. With a little practice this may be readily done. Skill and certainty in making the tints match are obtained by comparing the exposed strip with the standard a second time. If this is done without reference to the first results, the two comparisons serve as a valuable check upon each other. When the proper match is secured for a particular exposure, the comparative light intensity is found by dividing the length of exposure in seconds by the length for the standard tint. Thus, if an exposure in deep shade for 180 seconds matches the 2-second standard, the light is 90 times more diffuse or weaker than the sunlight. The latter is taken as unity, and the light intensity of the shade is written in the form .01.

93. Causes of variation in light intensity. The primary object of light readings is to determine the amount of light in various habitats, as a basis for explaining the differences shown by the plants in them. The real differences between habitats arise from the presence or absence of a primary layer, as well as from the character of the latter. In striving to measure such differences, it is absolutely necessary to avoid errors arising from the condition of the sky, or from time or place. Clourls have a marked effect upon the amount of light, almost invariably by rerlucing it. This difficulty, as already indicated, is entirely climinated by taking readings upon clear day's alone, avoiding even those when the sky is shightly hazy.

94. The effect of time. The intensity of the light raries throughout the day and the year. The daily maximum occurs at noon "sun-time," a point which itself moves back and forth through the year. The annual maximum falls on June 2"2, the minimum upon December 22. The daily minimum is reached at nightfall, and it lasts until dawn. In both cases the greatest light intensity occurs when the sun is at its highest altitude, i.e., 
when the angle that it makes with the surface of the earth is greatest, and the lowest when this angle is the least. At equal distances from either maximum, e.g., at $\mathrm{S}$ A.M. and 4 P.M., or on March 21 and September 23, the angle is the same. The effect of angle upon light intensity is due to the absorption of the light rars by the earth's atmosphere. This absorption is greatest near the horizon, where their pathway is the longest, and it is least at the zenith. In other words, the absorption is greatest at sunrise and sunset, least at noonday; greatest in December, least in June. Considering the two at the same time, maximum sunlight occurs at noon on June 22, minimum sunlight at sunrise or sunset on December 22.

From the foregoing it is clear that the variation in light due to time must be taken into account. In critical investigation, it is desirable to compute the error arising in this way, and to eliminate it from the reading. For ordinary purposes, it suffices to make readings directly comparable by restricting the times at which they are made. In a growing period of six months beginning March 21 and closing September 23, the noon intensities are respectively .98 and $.93{ }^{1}$ Between 9 A.M. and 3 P.M. during this period, the range would be from.$\$ 2$ to .95 , a difference that is practically negligible. Hence, in all ordinary study, the value of readings taken in full sunlight between 9 A.M. and 3 P.M. from March 21 to September 23 may be regarded as unity. Consequently, readings made in shady habitats during the same period may be compared with them directly without making allowance for the slight error. Naturally, when readings are taken simultaneously, no error exists, and the same is practically true of readings made between 10 A.M. and 2 P.M.

95. The effect of altitude. Altitude affects the amount of light by decreasing the distance which the rays must travel through the atmosphere, and thus decreasing the absorption. This influence is much smaller than has been commonly supposed. It is estimated that $20 \%$ of a light ray is absorbed before it reaches sea-level. At the top of Pike's Peak (4267 meters high), the absorption is $11 \%$. In the one case the light is $80 \%$ of that which enters the atnosphere, in the other $\$ 9 \%$. Consequently the maximum intensity at sea-level and at the summit of Pike's Peak is .9S and 1.09 respectively. The difference between them

${ }^{1}$ Research Methods, 57. 
altogether too small to have any important effect. The amount f light received by a slope differs from that received by a level rea of the same extent. Since the leaf position is the same in oth cases, this difference is of no significance.

Experiment 21. Measuring light intensity. Make a standard beween $10 \mathrm{a} . \mathrm{m}$. and 2 p.m. on a sunny day, and then take a reading in he open, one in the plant-house, and one in each shade-tent. Repeat he series at the same time upon a cloudy day. Remove the strip, nd find the value of each reading. Is the ratio of intensity in the arious places the same for cloudy and for sunny days?

96. Reception and absorption of light. Plants possess no pecial structures for the reception of light. The latter falls alike pon all aerial parts, the characteristic form of the leaf being hiefly to increase the surface. The epidermal cells, which reeive the light, merely transmit it, and the stimulus is first felt $n$ the chlorenchym beneath. The general effect of the epiclermis 3 to reduce the amount of light that enters the leaf. This is due artly to reflection and partly to absorption. Leaves with a mooth or shining cuticle reflect the light, while a thick cuticle $r$ a dense coating of hairs absorbs much of it. In some cases he shape of the epidermal cells is such that the light passing hrough the cuticle is more or less concentrated before it reaclies he chlorenchym. This is a rare occurrence, however, and of ttle importance. The rule is that by far the greater amount f the light that enters the leaf passes through the epidermis and absorbed by the chlorenchym. Some light passes entirely arough the leaf, but ordinarily this is slight. Thick or fleshy aves absorb practically all the light that falls upon them. Thin aves placed in sunshine transmit considerable light, but it must e remembered that such leaves are usually confined to sharly abitats, where the light is very diffuse and the absorption relavely complete.

97. The amount absorbed. The amount of light actually used the leaf is ascertained by determining the amount that passes rough the epidermis, and by taking from this that which passes arough the entire leaf. The amount of light available for the hlorenchym is measured by stripping a piece of epirlermis from te leaf. This is placed over the opening of the photometer, and nexposure made. After the strip is removerl, another exposure 
is made to obtain the light intensity at the time. The epidermis print, as it is called, is compared with the standard, using the second exposure as a check upon the latter. A leaf print is made in similar fashion and at the same time by placing the leaf closely over the opening. The value of the epidermis print less that of

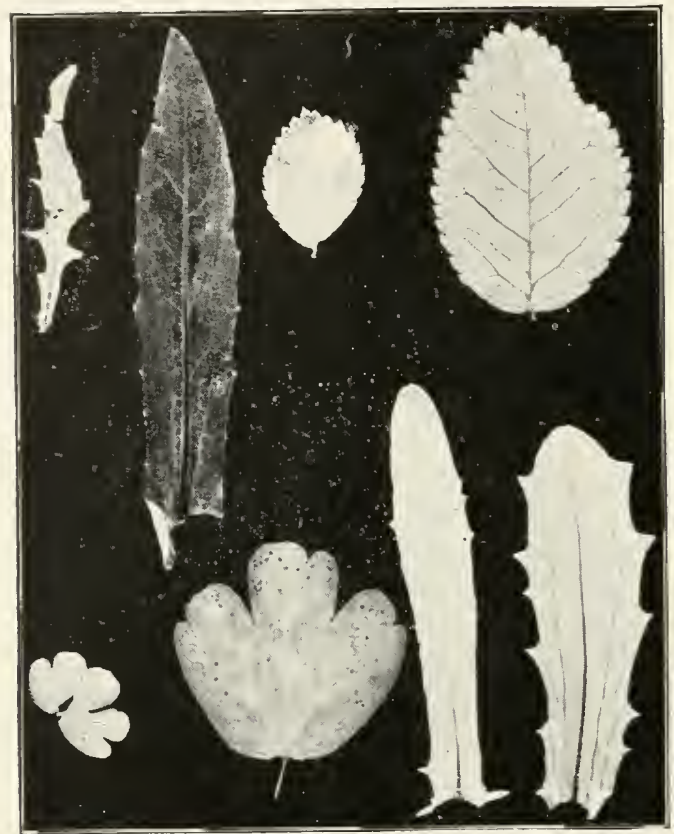

FIG. 21.-A leaf print of the sun and shade leaves of four species which show both sun and shade forms, or varieties. In each the shade leaf is the darker.

the leaf print is a measure of the absorption of the chlorenchym, i.e., of that part of the leaf sensitive to light. In the sunflower the value of the epidermis print is .1 approximately, that of the leaf print .003 , and the light absorbed by the leaf is consequently .097 .

Experiment 22. Epidermis and leaf prints. Strip from the upper surface of a sunflower leaf a piece of epidermis sufficient to cover the opening of the photometer. Make an exposure beneath the strip, and with the same or a similar leaf make a leaf print. Take a third reading to obtain the full light intensity. Compare the results with the standard, and determine the amount of light screened out by the epidermis, absorbed by the chlorenchym, and transmitted through the entire leaf. 
98. The production of chlorophyll. The primary response of the plant to light is the production of chlorophyll. This response does not occur in plants, such as the bacteria, mushrooms, broomrape, etc., in which the power to make chlorophyll has been lost in consequence of parasitic or saprophytic habits. On the other hand, a few plants, conifers, ferns, and cacti, are able to make chlorophyll in darkness, though it probably cannot be formed continuously under such conditions. The rule is that plants with plastids produce chlorophyll only in the light. Conversely, their chlorophyll disappears in darkness. The light intensity necessary for the production of chlorophyll varies in different species. This pigment is formed in shaded habitats with light values as low as .001 , even though very few flowering plants can function at all under such conditions. For the majority of plants, sunshine presents the best conditions for the formation of chlorophyll. If the sunlight becomes too concentrated, it tends to decompose the chlorophyll more rapidly than it can be built up. Although this rarely occurs in nature, chlorophyll undergoes constant decomposition by light, and it persists only because it is built up at the same time.

99. The nature of chlorophyll. Chlorophyll is a complex pigment, or a mixture of several pigments. It is produced by

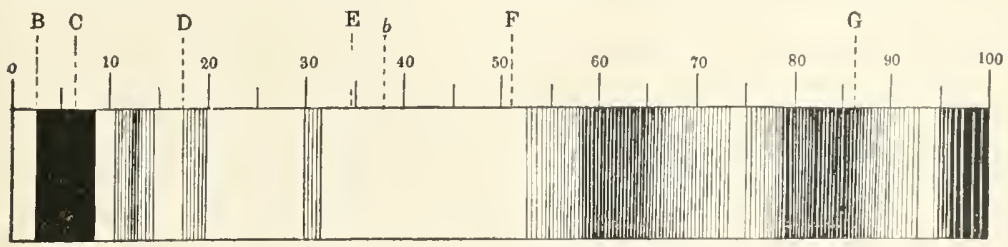

Fig. 22.-Absorption spectrum of chlorophyll removed from the leaf by solution in alcohol. The letters $B-G$ indicate the position of Framhofer's lines. The groups of dark lines from the red to the vioket rnd indicate the seven alsorption bands of chlorophyll, i.e, those parts of the spectrum in which the light is alsorbed by the chloroplyyll. (After Sachs.)

specialized bits of protoplasm, the plastids. When the necessary conditions are met, i.e., the presence of light, water, carbon dioxicle, and a trace of iron salts, the plastids of actire tissues are always green, i.e., they are chloroplasts. The latter lose their color in the dark, or, ordinarily, when carbon dioxide is absent. The pigment is broken down in ripening fruits and in flowers, and also 
in autumn leaves. Chlorophyll is a product of protoplasmic activity, formed during the complex processes of nutrition. Apparently it is not a part of the protoplasm, but is held in solution in it. It is produced most actively in white light, but it has been

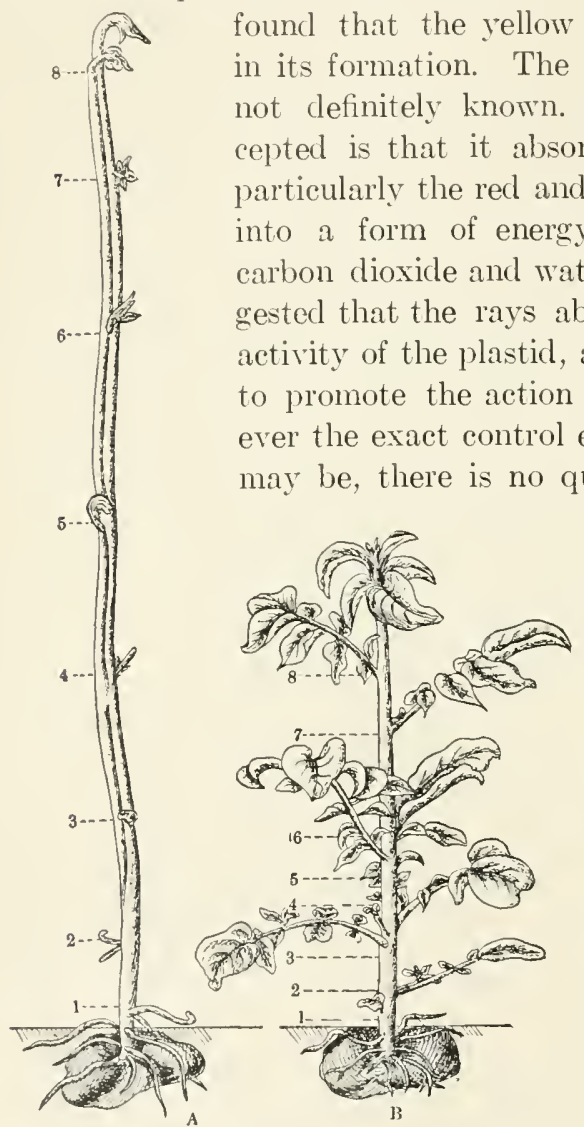

FIG. 23.-Potato-plants grown in darkness $(A)$ and in light $(B)$. The elongation of corresponding internodes may be compared by reference to the figures. (After Pfeffer.) yellow rays are the most active in its formation. The function of chlorophyll is The view commonly accepted is that it absorbs certain rays of light, particularly the red and the blue, converting them into a form of energy capable of decomposing carbon dioxide and water. It has also been suggested that the rays absorbed are harmful to the activity of the plastid, and are eliminated in order to promote the action of the other rays. Whatever the exact control exerted by the chlorophyll uestion of its necessity for the formation of elaborated food by the decomposition of carbon dioxide and water.

Iоo. The influence of darkness. Disregarding the exceptions already noted, seeds germinated in the dark produce plants that are whitish or yellowish in color. The same result occurs in green plants which are placed in darkness. An examination of the plastids shows that they are more or less yellow in color, due to the presence of a pigment called ctiolin. The latter is apparently convertible into chlorophyll, since a yellowish plastid becomes green upon exposure to light. Plastids which occur regularly in the dark, viz., leucoplasts, are also capable of turning green in light, as is well known in the case of the potato tuber, but the existence 
of an etiolin-like substance in them is unknown. The vellowish or colorless plants produced by darkness are said to be etiolated. Etiolation affects not only the color of the plant, but its form and structure as well. Stems usually become thin and elongated, and their branching is reduced. The size and number of the leaves are decreased, and the latter are often reduced to mere scales. There is a corresponding reduction in their structure, the distinction between palisade and sponge tissues disappearing as a rule.

Experiment 23. Influence of light and darkness. Plant sunflower seeds in four small pots. Place two pots in the dark, and leare two in the light. After the seedlings have grown to a few inches, exchange a green plant and a colorless one. After a few days note the behavior of the chlorophyll. Make a drawing of the plant that has been constantly in the dark, and of the one kept in the light. Make a crosssection of the stem and leaf of each, and illustrate the important differences by a drawing.

I0I. Photosynthesis. The decomposition of carbon dioxide and water by the action of light, and the combination of the products into sugars, is termed photosynthesis. It is the special duty of the chloroplast, and can take place only in light. It is most active in sunlight, decreasing with a decrease of light intensity, though at a varying rate for different species. For flowering plants, photosynthesis becomes practically impossible, even for shade forms, when the light intensity reaches .001 . In the case of many sun plants, the minimum is reached long before this, depending upon the stability of the species concerned. In nature photosynthesis is always due to the presence of white light. By experiment it may be shown that certain colors of the spectrum are more active than others in this process. It is found that the greatest activity occurs in orange-red, somewhat less activity in the blue, and little or none in other portions. These regions are those in which the absorption of light by the chlorophyll is greatest, a fact which gives support to the riew that it is this absorption which furnishes the energy necessary for photosynthesis.

I02. Absorption and diffusion of carbon dioxide. Photosynthesis depends, moreover, upon the presence of the crule materials with which it is concerned, viz., carbon dioxicle and water. We have already seen how the water absorbed by the roots 
reaches the leaves, and consequently the chloroplasts. The carbon dioxide required is absorbed by the leaves through the stomata. With the air it enters the chamber below the guard-cells, and then finds its way throughout the leaf by means of the air spaces. The degree of photosynthetic activity depends in a large measure upon the rapidity with which carbon dioxide enters the leaf and diffuses through it. This is due to the fact that, while the supply of this gas is practically unlimited, the amount actually present in the air is very small, usually about $0.04 \%$ by weight. In consequence aeration, i.e., the movement of gases into and through the leaf, becomes a very important function of the latter. It depends in the first place upon the number of the stomata, the size of their pores, and the length of time they are open. The advantage of having the stomata open in the light thus becomes evident, as well as that of placing them chiefly upon the lower surface, or of sinking them, so that the chances of water loss closing them are reduced. Ease of diffusion within the leaf depends upon the thickness of the leaf and the number and size of the air spaces. The rapidity of diffusion is chiefly determined by the rate at which the carbon dioxide is being used. Thus, active sun leaves absorb and use much more carbon dioxide than the less active shade leaves, although the latter regularly possess larger air spaces. Gases penetrate the walls of the chlorenchym cells only in solution. This is brought about by the cell-sap which fills the wall, and in consequence carbon dioxide and water reach the chloroplast together.

I03. Chemical changes during photosynthesis. The precise changes that take place during photosynthesis are in doubt. It is definitely known that the carbon dioxide and water are broken down, and that oxygen is set free and escapes from the leaf. In fact, the evolution of oxygen from the plant is the usual test of photosynthetic activity. The first visible product of the latter is the starch formed in the chloroplast. It is evident, however, that a number of changes must occur before starch can appear. The number and nature of these changes are not known with any degree of certainty. The formation of grape sugar, or glucose, precedes that of starch, and it is probable that glucose is formed from a simpler carbohydrate, formaldehyde. The probable stages in photosynthesis may be indicated by the following series of formulæ. 
(1) $\mathrm{CO}_{2}+\mathrm{H}_{2} \mathrm{O}=\mathrm{CH}_{2} \mathrm{O}_{3}$, carbonic acid;

(2) $\mathrm{CH}_{2} \mathrm{O}_{3}=\mathrm{CH}_{2} \mathrm{O}+\mathrm{O}_{2}$, formaldehyde and free oxygen;

(3) $6 \mathrm{CH}_{2} \mathrm{O}=\mathrm{C}_{6} \mathrm{H}_{12} \mathrm{O}_{6}$, glucose;

(4) $\mathrm{C}_{6} \mathrm{H}_{12} \mathrm{O}_{6}-\mathrm{H}_{2} \mathrm{O}=\mathrm{C}_{6} \mathrm{H}_{10} \mathrm{O}_{5}$, stareh.

Experiment 24. Dependence of photosynthesis upon aeration and light. Place two vigorous sunflower plants in darkness for twenty-four hours in order to bring about the disappearance of the starch. Use wax or vaseline to coat the upper surface of one leaf, the lower surface of a second, both surfaces of a third, and allow a fourth leaf to remain uncoated. Place this plant in full sunshine, leaving the other in the dark. This experiment should be started as early in the morning as convenient. During the afternoon of the same day, cut cross-sections from each of the four leaves of the plant in sunlight, and from one of the leaves in darkness. Note the relative amount of starch in each as well as its distribution.

104. Measurement of photosynthesis. The intensity of photosynthetic activity in different plants, or in the same plant under different conditions, is best measured by the quantity of starch produced. This is not an exact measure, since much of the glucose formed is removed at once instead of being converted into starch. However, since the amount of glucose produced can not be measured, the degree of activity can only be based upon the starch formation. This can be done by treating entire leaves with iodin, as in the method employed by Sachs. ${ }^{1}$ A more accurate method is to cut sections of the leaves to be studied, and to count the starch grains, and in some cases the number of plastids. The count is made for a segment $100 \mu$ wide across the entire section. Two such segments are counted in different parts of the leaf, and the result is multiplied by five to give the number of starch grains for a unit segment $1 \mathrm{~mm}$. in width.

Experiment 25. Relation of photosynthesis to sun and shade. Remove the starch from two sunflowers by keeping them in darkness for twentyfour hours. Place one plant in sunshine and one in a shade-tent of known light intensity. After six or eight hours, cut sections of a leaf from each, and determine the starch content for a unit scgment. Compare the results in the two leares with respect to the light intensity for each.

105. Translocation. A part of the glucose made by the chloroplasts is used by the leaf itself, while a large amount is carried

${ }^{1}$ Research Methods, 137. 
away to the stem, flowers, and roots. Starch appears in the chloroplasts only when the glucose is formed more rapidly than it is removed. This is usually the case in the sunlight, and starch accumulates throughout the day. When photosynthesis ceases at night, the starch in the plastid is converted into glucose by the chemical addition of a molecule of water to each molecule of starcli, and the glucose is transported in solution to the different parts of the plant. The removal, or translocation, of the glucose normally takes place during day and night, but, since this substance is usually made about ten times faster than it can be removed, translocation is most active at night. This movement of the soluble food is largely caused by differences in osmotic pressure between the various cells. Its direction is determined by the greatest use, the movement in general being toward the organ or tissue that is most actively assimilating or storing the food. In the chlorenchym as well as in the parenchyma of the stem and root, the glucose moves by ordinary diffusion. In its passage from the leaves to the other organs of the plants, it follows a more definite pathway. This is regularly constituted by the sieve tissues of the fibrovascular bundle, though it is not impossible that glucose should reach the root by diffusion through the parenchyma of the stem. This is a slow process, however, and by far the greater amount of glucose must reach the various organs by way of the sieve tissue. Thus, the fibrovascular bundles constitute a complete system for the transport of the foods made by the leaves, as well as for that of the water and solutes absorbed by the roots.

Experiment 26. Translocation. Select a vigorous sunflower that has been in the sunshine all day. Cut a leaf from it and put the leaf away in a moist chamber. Sever the midrib or primary veins of a second leaf, cutting through almost to the upper epidermis. Early the next morning, remove the severed leaf and an uninjured one from the plant. Cut cross-sections of the three leaves, and explain the differences in starch content.

ro6. Storage of food material. The storage of glucose in the form of starch may take place in practically any part of the plant. Except for the temporary formation of starch in the chloroplasts, storage in the green leaf is rare. It oceurs very often in seedleaves, and frequently in seeds, stems, and roots. In all cases the method by which the material is stored is the same. It is 
accomplished by the leucoplasts, and hence can occur only in living cells. The sugar solution is taken up by the lencoplasts, which remove by chemical action a molecule of water from each molecule of the glucose, and deposit the resulting starch in their own substance. This deposition of starch takes place rapidly at night, and slowly, if at all. by day. In consequence, the starch grains of storage tissues regularly show layers corresponding to this periodical activity. As the starch grain grows, the leucoplast is stretched thinner and thinner until it becomes invisible. It never disappears, however, since, at the time when the reserve material is to be used, it must dissolve the starch by again combining water with it to form sugar.

Starch is stored to serve as food material for starting new growth and continuing it until a constant supply of food can be furnished by the new leaves. In the seed, it nourishes the young plant until the latter strikes root and carries its leaves into the light and air. The stored material of root or rootstalk gives a new shoot, while that of the woody stems enables the buds to burst and to send out leaves and flowers. In seeds the reserve material is stored in the endosperm about the embryo, as in the grasses, or it is stored in the leaves of the embryo itself, e.g., in the bean, pea, etc. In perennial plants, storage often occurs in the stem. In herbaceous perennials, the underground stem, rootstalk, tuber, bulb, or corm serves this purpose; in trees and shrubs, the pith and medullary rays of the woody stem itself are used for storage. True roots serve more rarely as storehouses, but in certain biennial and perennial herbs they have this function.

Experiment 27. Storage tissues. Make cross-sections of a wheat kernel, a bean, a woody stem, a rootstalk or tuber, and a root. Stain lightly with iodin, and look for leucoplasts. Make a diagram of each section showing the extent and the location of the storage tissues.

107. Influence of light upon the number and position of chloroplasts. Only a small amount, usually less than $5 \%$. of the light that reaches the chloroplast is used in photosynthesis. The remainder is converted into heat, and produces a raporization of the water in the plastid. The effect is less pronounced in the sharle owing to the lower light intensity. In consequence, chloroplasts arrange themselves in the sunshine in line with the light 
rays, so that they screen each other from the full effect of the light, and thus reduce the amount of water they lose. This arrangement is not a necessary protection against over-illumination, for the chloroplasts of the guard-cells receive stronger light without serious harm, but it appears to be a device to prevent injurious water loss from the chloroplasts while they are active. In the
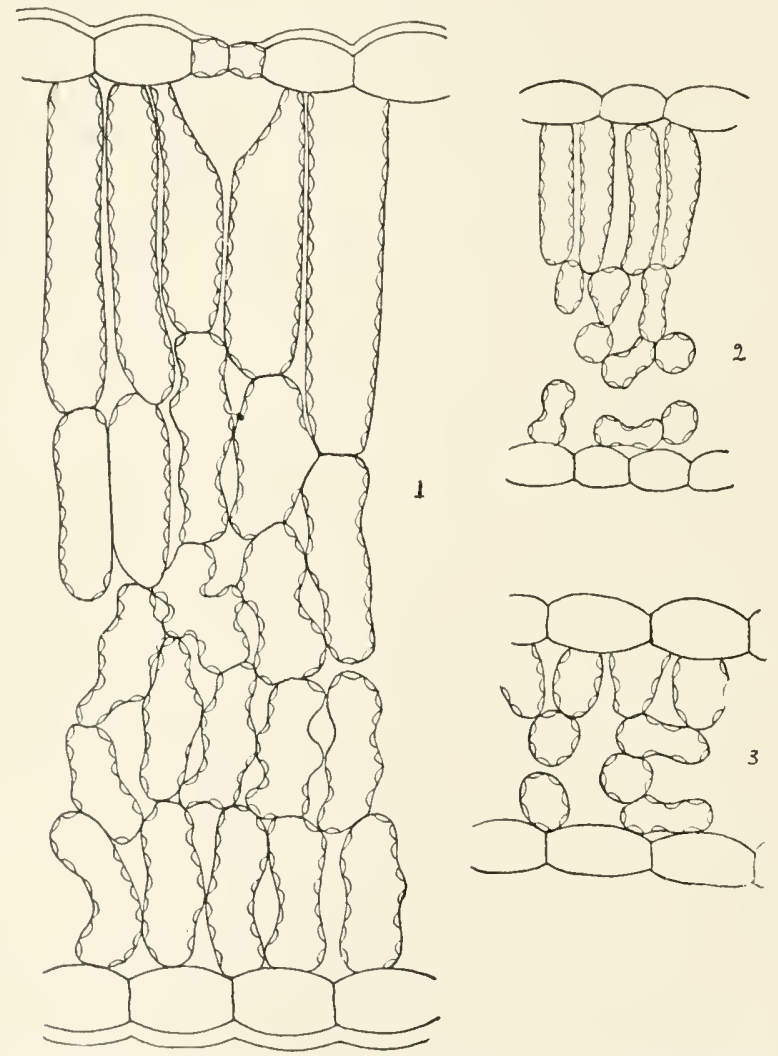

F1r. 24.-Position of chloroplasts in sun leaf (1) of Allionia linearis, in a leaf of the shade form (2), and in one found in very deep shade (3).

shade the danger of excessive water loss is slight, while the need of obtaining all the light possible is imperative. Accordingly, the plastids arrange themselves at right angles to the light ray, thus increasing the surface for light absorption. This arrangement of the plastids is found not only in sun and shade leaves respectiveiy, but it is also typical of horizontal leaves. In fact, the latter 
owe the differentiation of the chlorenchym into palisade and sponge tissues to this fact. The upper part of the leaf receives full sunlight, and the plastids place themselves in line with the light rays. The lower portion receives only the light that is not absorbed by the upper. It is just as truly shaded as a leaf growing in a forest, and the chloroplasts spread out in such fashion as to receive as much light as possible. This arrangement is the rule, but it is not absolute, owing to local modifications due to the position of air passages, and the necessity of diffusion from cell to cell. The position of the plastids influences the form of the cells, so that, while both palisade and sponge cells are more or less elongated, the palisade cells are placed at right angles to the leaf surface, and the sponge cells are parallel to it. This relation is doubtless connected with the fact that sun leaves are generally narrower and thicker in comparison with shade leaves, which are thinner and broader. The influence of light upon the form and structure of the leaf is considered under Adaptation.

Experiment 28. Arrangement of chloroplasts. Fix one of a young pair of leaves of a sunflower with the lower surface uppermost and the other in an erect position. After they have become fully grown, cut cross-sections of each, and compare with the cross-section of a leaf in the normal position. Make drawings of changes in the number and arrangement of the chloroplasts, as well as in the shape of the cells.

I08. Movement of stems and leaves. Through the longcontinued action of light, the stems and leares of plants have acquired certain habits of growth or position. A change in the normal relation results in an attempt upon the part of the plant to assume a corresponding position. Stems usually place thenselves in line with the light rays, while leaves tend to stand at right angles to them. If the direction of the light is changed, either by shutting it off from all sides but one, or by changing the position of the plant, the stem tries to bend in such a way as to keep the same position with relation to the light. Leares when inverted or otherwise changed from the normal position twist and turn in an endeavor to resume it. In somewhat similar fashion, roots, which are organs habituated to the absence of light, in some plants at least bend away from the light, if they are free to do so. Finally, light produces certain continuous periodical changes in the position of the leaf. 
I09. Phototropism. Seedlings exposed to light from one side alone regularly bend in the direction of the light. 'This reaction is perceptible even with low light intensities. It occurs in adult plants as well as in young ones, but it is usually more noticeable in the latter. In most cases the stimulus is received by the tip of the stem, though in some plants the cotyledons are the part stimulated. In either erent the stimulus is transmitted to the zone in which growth is most rapid, and the response first

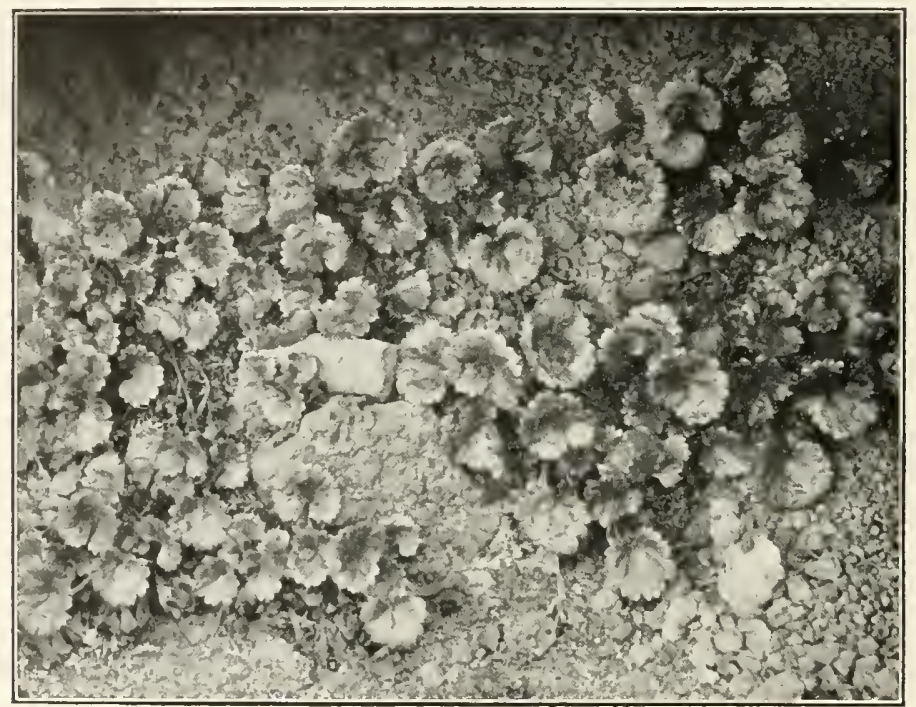

FIG. 25.- Rosettes of a saxifrage, Teleonyx jamesii, growing under an overhanging rock. The leaves are turned squarely to the north.

becomes evident there. Stems that bend toward the light are termed prophototropic, while roots and those stems that bend from the light are spoken of as aphototropic. Horizontal leaves endeavor to maintain a position at right angles to the incident light, and are consequently termed diaphototropic. All phototropic movements have a common purpose in that they serve to place and keep the leaf surfaces in the most farorable position with respect to light. A few plants such as the sunflower often respond to the direct rays of the sun by turning the crown in the direction of the latter. These plants may be termed heliotropic. The leaves of certain plants, chiefly leguminous ones, seem to possess a similar property. 
Experiment 29. Phototropic movements. Select four sunflower seedlings in which the plumules have not yet unfolded. Remove the cotyledons from one. Wrap the stem of another with black paper or tinfoil from the base to the cotyledons, and wrap the tip of the stem of the third in similar fashion. Use a thread moistened with ink to mark the upper part of the stem of the fourth at $2 \mathrm{~mm}$. intervals. Place the plants in a light-tight box at equal distances from a small hole in one end. Remove them after a few days, and explain the results noted in each.

I 10. Nyctotropism. Many plants change the position of their leaves at night. This is particularly true of plants with compound leaves, such as the bean, clover, oxalis, sensitive plant, and others. The leaflets of these plants close at night, and the entire leaf of ten changes its position, usually by drooping. This phenomenon is called nyctotropism. It is thought to be due to the influence of light, but it seems that temperature plays at least as active a part in bringing it about. The movement occurs at night and morning, when the changes in light intensity are the most rapid, but at this time the changes in temperature are marked also. The opening and closing of many flowers takes place at these times also. These have likewise been supposed to be influenced by light, but it is now known that they are due to heat.

Experiment 30. Nyctotropic movements. Grow sensitive plants, beans, clover, and oxalis. Compare the position of the leaves at night and in the daytime. Change the plants from sunlight to darkness, and the reverse, and note the results. 


\section{CHAPTER $V$}

\section{ADJUSTMENT TO TEMPERATURE}

III. Relations of plants to temperature. In its action upon plants, temperature is like water, but unlike light in that it has more or less to do with nearly every function. It is not only a necessary condition for the chemical changes that occur everywhere in the protoplasm, but it also furnishes the energy for some of them. As a stimulus it differs from both water and light, since the responses to it are not localized in a particular organ, but are found throughout the living tissues. It has, moreover, no formative effect upon the plant, i.e., it cannot change its form or structure, except in so far as growth has a bearing upon these. As in the case of all factors, habitat play's a very important part in determining the influence of temperature upon each species. The latter has been accustomed for countless generations to certain extremes of heat and cold, as well as to certain seasonal sums. Temperatures beyond these extremes check the plant's activity, and the same is true of a deficiency in the total heat available during the growing period. The effect of habit is well shown by many seeds and spores, which are merely plantlets securely protected against drouth. These have accommodated themselves to a long period of cold, in consequence of which it is often impossible to cause them to germinate without subjecting them to cold, either naturally or artificially.

Temperature is directly concerned, either as a necessary condition or as energy, with every function of protoplasm. In a large measure, moreover, it controls the movement of the protoplasm. It is especially requisite in all the changes that have to do with the assimilation of elaborated food, and in a general way, at least, may be said to control growth. Lnder certain conditions, plants show changes of position which are caused by heat and may be 
termed thermotropic. The opening and closing of flowers and flower heads are due to temperature, and to some degree doubtless the drooping of leaves at night and the movements of some fruits arise from the same cause. While all functions, absorption, photosynthesis, etc., owe much to temperature, certain ones, digestion, respiration, growth, and reproduction, are particularly dependent upon it. This is likewise true of the germination of the seed, which combines the first three functions. In connection with germination, temperature has a profound effect upon ecesis, or acclimatization, and consequently upon the development of vegetation.

II2. The measurement of temperature. With the aid of the thermometer, the determination of temperature becomes one of the simplest of tasks. Since temperature is an extremely variable factor, it is often convenient to use automatic thermometers, or thermographs. When thermographs are not available, their lack may be partially met by maximum-minimum thermometers, which are used to record the extreme temperatures during day and night. In all ordinary work, however, the use of the simple thermometer in connection with simultaneous readings gives satisfactory results. The thermometers used should be standard or standardized instruments reading accurately to one degree, or, better, to one fifth of a degree. As these are both delicate and expensive, they must be used with great care, particularly in the field. In making readings of air temperatures, precautions are necessary to expose the bulb to the full effect of wind or sun, when these are present, and to keep it away from the hand or person. Moreover, in taking readings in rapid succession, the instrument must be left in each position until the mercury becomes stationary. In some cases, as when the wind blows fitfully, the mercury rises and falls constantly. In simultaneous readiness this fluctuation may be ignored, and the precise position at the time of the signal is the one taken. Otherwise the mean of the fluctuation is taken as the proper reading. Readings at the surface of the soil are made in the same way. In all cases the bulb must touch the surface and not lie separated from it by at stratum of air. The temperatures are different for the soil surface ancl for dead or living vegetation lying upon it. Consequently this fact must be taken into account in comparative readings makle in different stations. 
I 3. Soil temperatures are determined by means of the instruments used in the air, or by means of thermometers specially constructed for the purpose. The latter are thermometers possessing a very long tube, the whole instrument being encased in a wooden jacket for protection. The soil thermometer is placed in the ground with the bulb at the desired depth. The scale is then above the surface, where it may be read directly. Such thermometers, however, are relatively expensive. Their placing requires considerable time and trouble, and their use is restricted to the few places where they would be entirely free from disturbance. Soil temperatures are relatively constant, especially at depths greater than three or four decimeters. In consequence, frequent readings of them are unnecessary, and the simplest thermometer yields satisfactory results. Soil temperatures are usually measured in connection with water content, the hole from which the soil sample is taken serving for the temperature reading. Unless the latter is made as soon as the sample is removed, the hole is stopped with a cork to prevent any change in temperature. In making the reading, the thermometer is lowered carefully into the hole, the cork is put in place, and the instrument allowed to remain for several minutes to make sure that the mercury indicates the proper temperature. In the case of holes deeper than the thermometer is long, a cord is tied to the top of the latter to assist in raising or lowering it. In obtaining the temperature, the thermometer is not lifted out of the hole, but is raised in the latter until the upper end of the column can be read. With a little practice, this can be done very easily before the column begins to rise or fall. When several soil readincs are made in one station on the same day, the use of the cork as a stopper makes it possible to use the same hole without appreciable error. If readings are made on different days, it is desirable to bore a new hole.

I 4. Plant temperatures. Unlike the warm-blooded animals, plants do not possess temperatures that are independent of the surrounding medium. Certain plant activities, notably respiration, bring about an evolution of heat, but in the vast majority of cases this is so slight as to have no appreciable effect upon the plant. As a consequence, plants and plant parts tend to assume the temperature of the medium, viz., air, soil, or water, in which they are found. In other words, they behave essentially as non- 
iving matter does. The temperature of the plant, especially n the case of aerial parts, is not always the same as that of the nedium, for several important reasons. The temperature of the lant responds more or less slowly to that of the air, and in the case of a sudden change it is for a time greater or less than that f the air. In fact, the temperatures of the plant behave more ike those of the soil than of the air. The plant lags in the change n proportion to its mass and to the character of its surface. Transpiration probably has some effect upon the leaf surface. his effect does not seem to be great, since the leaves of rosettes ften have a temperature as high as that of the surface of the oil upon which they are found, and, in mountain regions at least, he temperature of sun leaves is higher than that of the surroundng air.

In taking internal temperatures of plants it is desirable to use thermometer with a bulb as small as possible. In the case of thick tems and roots or other fleshy parts, a slit is cut or a hole is nade with a cork-borer, and the entire bulb sunken in the tissue. emperature readings are obtained less easily in the case of ordinary eaves. Fairly satisfactory results have been secured by rolling he leaf while in position tightly about the thermometer bulb. Vhen it is possible, the thermometers are left in place, in order hat readings may be made at various times, thus showing the onnection between the temperature of the plant and of the nedium.

Experiment 3I. Temperatures of plant and habitat. In addition to he temperature readings in the field outlined in Experiment 5, make imultaneous readings of air, soil, and plant temperatures. This can be one most conveniently in the plant-house, although it is desirable to nake similar observations out of doors in the spring. ${ }^{1}$ A plant witlr a eshy root, such as the beet, is the most satisfartory. Bore a hole of he proper size in the root, and sink the thermometer bulb well below he surface. Roll the tip of a leaf elosely about the bulb of a second hermometer, folding in the edge of the leaf in such a manner as to over the bulb entirely. Hang one thermometer in the air alongside he leaves but in the sun, and place another in position for making soil eadings. Finally sink another bulb in dead or inactive tissue, such s that of an apple or potato. Read the five thermometers as nearly imultaneously as possible at various times during the day. The best esults are obtained by making readings early in the morning, at noon,

${ }^{1}$ Research Nethods, ss 
in the evening, and at night. Compare and explain the temperatures obtained.

I 15. Variations of temperature. As in the case of light, there is a daily and an annual fluctuation in temperature. The amount of heat received depends upon the angle of the sun's rays and their consequent absorption. The actual temperatures at the surface of the earth are greatly modified by radiation, conduction, and convection. In consequence the maximum daily temperature does not occur at noon "sun-time," as in the case of light, but several hours later, usually about $4 \mathrm{p} . \mathrm{m}$. The minimum is not reached at nightfall, but just before sunrise upon the following morning. The maximum temperatures for the year do not occur at the June solstice, but a month or two later. Similarly, the minimum falls a month or more after the December solstice.

The variation of temperature with latitude and altitucle is well known. Northern latitudes receive the sun's rays at a greater angle than southern ones, and the absorption of heat by the atmosphere is correspondingly greater. In so far as absorption is concerned, high mountains receive more heat than lowlands. The loss by radiation, however, is so much greater that mountain regions are uniformly colder than plains or lowlands lying on the same parallel. This is due to the extreme rarity of the air, which allows heat to pass through it readily. Although the air on mountain tops is colder than that of the plains, the surface temperature of the soil is often considerably higher. This difference, however, is far overbalanced by the rapid radiation at night. Temperature also varies with the slope. This is due to the fact that a square decimeter of sunshine covers this amount of surface only when the rays strike the latter at right angles. As the angle diminishes, the rays are spread over more and more surface until at $10^{\circ}$ a square decimeter receives but $17 \%$ as much heat as at $90^{\circ}$. It has already been indicated that this has slight importance, owing to the fact that stems and leaves have the same position upon a slope that they do upon the level. Furthermore, temperature differs at various levels in the air and the soil. Air and soil temperatures naturally affect each other. The highest temperatures are usually found between the two, i.e., at the surface of the soil. In both directions the temperature rapidly decreases. In the air this is due to the fact that radiation becomes imperceptible a short distance above the ground, while the influence of the wind be- 
comes more and more noticeable. Heat penetrates the soil slowly, either on account of poor conductivity or because of the capacity of the water content for latent heat. The temperature of the soil decreases rapidly in the first few decimeters, and at the depth of a meter often remains constant throughout the growing season. The air is ordinarily warmer in the daytime than the soil, especially on sunny days. It loses heat more easily, however, and after a sudden change or at night the soil is for a time warmer than the air. On account of the high specific heat of water, dry soils are regularly warmer than wet ones.

I 6. The influence of other factors. Clouds and winds are among the most important factors that modify temperature. During the daytime clouds decrease temperature by absorbing the sun's rays, while at night the effect is exactly opposite, on account of the hindrance they offer to radiation. Winds raise temperatures when they blow from a warmer region, and lower them when they come from a cooler one. Humidity acts after the manner of clouds, a humid air increasing the amount of heat absorbed. Soil temperatures are affected not only by the amount of water present, but by the character of the soil. Sand and gravel are more easily heated than clay and loam, and the air above them is also warmer because they lose heat more rapidly by radiation. The effect of exposure is closely connected with slope. Slopes that face the south and west receive the most sunshine, and are regularly warmer than north and east slopes. Cover, whether clead or alive, reduces day temperatures by screening out the sun's rays, and increases night temperatures by retarding racliation.

II7. Favorable and unfavorable temperatures. It is hardly necessary to point out that the temperatures of a plant's orn habitat are ordinarily the most favorable to it. It is likewise clear that the plant is subjected to a consilerable range of temperature during the growing period. The point within this range at which the plant functions best is the optimum. This varies much, the optimum temperature for the seedling being lower than for the fruiting plant. It is never a mere point, but is a space of several degrees at least. In fact, for plants in their own habitats it is largely hypothetical. This is not true for the extremes of heat and cold which a plant can withstand and live. These are the maximum and minimum respectively, and are actual points heyond 
which the plant dies. Naturally, maximum and minimum temperatures vary widely for different species, and to a small extent also for different individuals of the same species. Furthermore, a plant can withstand extremes of heat and cold much better in some stages than in others. It is least resistant in the active condition when the tissues are filled with water, and most resistant in the resting state typical of spores and secds. Nearly all flowering plants are killed by exposure to temperatures below $0^{\circ} \mathrm{C}$. and above $45^{\circ} \mathrm{C}$. Their seeds, however, may resist temperatures of $-250^{\circ} \mathrm{C}$. and $100^{\circ} \mathrm{C}$. The resistance of seeds depends in a very large degree upon the absence of water. Seeds when quite dry have been found to survive when exposed for an hour to $110^{\circ} \mathrm{C}$., while an exposure to water vapor at $70^{\circ} \mathrm{C}$. killed them in one fourth the time. The maxima and minima of natural habitats during the growing period practically always fall between $0^{\circ} \mathrm{C}$. and $45^{\circ} \mathrm{C}$. In hot springs the maximum for many algæ and bacteria rises to $\$ 5^{\circ} \mathrm{C}$. or higher. The bacteria are capable of withstanding much higher temperatures, and, in the spore condition, are able to resist temperatures of $120^{\circ}-130^{\circ} \mathrm{C}$.

I 8 . Freezing. The injury arising from exposures to low temperatures depends primarily upon the amount of water that the plant contains. For example, the watery leaves and stems are usually killed by exposure to $0^{\circ} \mathrm{C}$., while the drier seeds and underground parts resist the long-continued action of temperatures from $-30^{\circ}$ to $-40^{\circ} \mathrm{C}$. Dry seeds, moreover, are capable of germination after exposure to $-25^{\circ} \mathrm{C}$, , but soaked seeds lose this power under such conditions. The reason for this difference of behavior resides chiefly in the protoplasm, though it is impossible to go further than the statement that active protoplasm is more sensitive to cold than is the resting form. The small amount of cell-sap in resting tissues is also much more concentrated than that of living cells, and this of course increases the power of resistance.

Frost, i.e., freezing temperatures, kills plants by withdrawing water from the cell-sap and forming ice crystals, usually upon the outside of the cells. When the freezing is extreme, the cells are ruptured by the formation of crystals within them. It is very probable that the chemical constitution of cell-sap and protoplasm is changed in a manner harmful to the plant. Such a result seems to be clearly indicated by the behavior of many plants 
which are seriously injured or killed by temperatures several degrees above the freezing-point. If allowed to become warm very gradually after freezing, many plants remain turgid in place of wilting, and thus survive. This result appears to be due to the gradual absorption of the melting crystals by the cytoplasm, and there is in consequence no loss of turgidity. When the thawing takes place rapidly, the protoplast is unable to do this, and the ice crystals melt and fill the intercellular spaces. The cells become flaceid, and the plant wilts and dies. In the same habitat, plants differ much in their ability to resist frost, and this is also true of different parts of the same plant. Aerial parts naturally freeze first, but among these the newest and most active tissues, i.e., those containing the most water, succumb first. Flowers are most easily damaged, then the leaves, next the stems, and last of all the roots, which are more or less protected by the soil. Upon high mountains, where frosts may occur at almost any time during the summer, plants become unusually resistant, and able to withstand repeated freezing and thawing.

Experiment 32. Effects of freezing. Soak peas in water for twentyfour hours. Expose ten soaked and ten dry peas for twenty-four hours to temperatures below freezing. Flace the two sets of peas in moist chambers, and compare their power to germinate. At the same time place several sunflowers of different ages out of doors, together with plants of a more woody species. Note the effect upon each. Transfer some plants quickly to a warm room, and others more grachually. Cut a section of a frozen leaf or stem, and compare with a section made of a part that has thawed out.

II9. The sum of temperatures. The greater number of speries and of individuals pass through their entire life cycle without being exposed to maximum or minimum temperatures. Extremes of temperature have little significance for them. Their effect is confined to the plants that appear very early in the crrowing period, and those that linger toward the close. The activity and growth of any plant depend upon its recriving the requisite amount of heat during the growing period. Although temperature has no power to change the form and structure of plants, its influence upon size is very great, owing to its control over growth. The sum of the temperatures which act upon a plant is of the first importance in determining its general appearance. The effect 
may be produced either by temperatures that are more or less constantly too low, or by shortness of season, which is equally effective in reducing the total amount of heat available for the uses of the plant. As a rule, these two factors act in unison, producing marked reduction in size. Such reduction is characteristic of the vegetation of alpine regions, although the dwarf habit of alpine plants is due chiefly to adjustment to water. The gen-

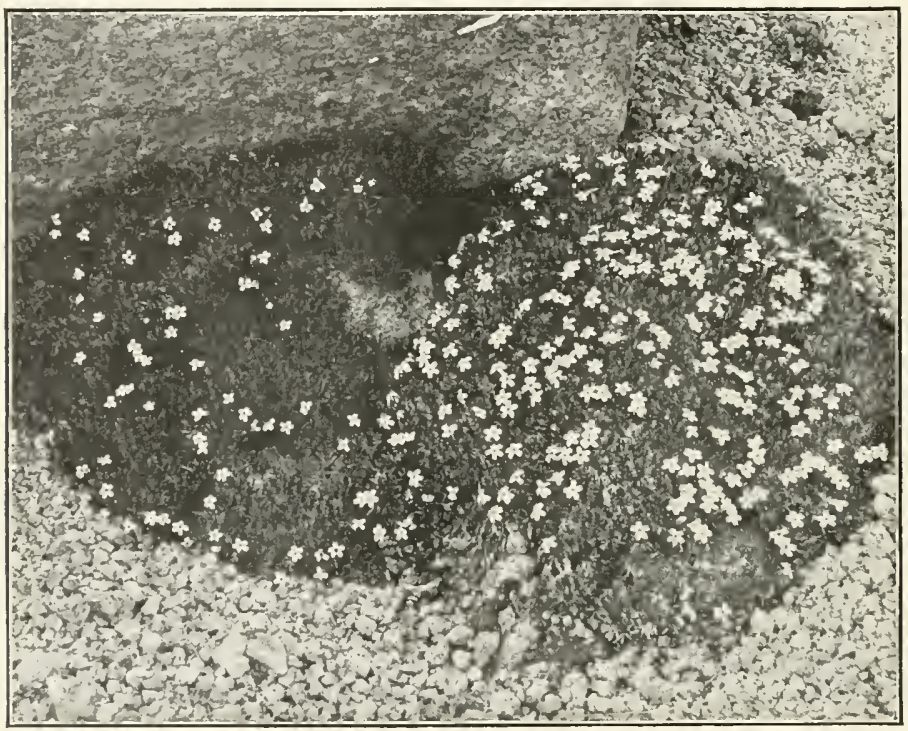

FIG. 26.--Alpine mats of silene acaulis growing on the north sicie of a rock. The effect of different temperature sums is shown by the number of flowers.

eral effect of low temperatures may often be seen in field crops during seasons in which the temperatures are largely below the normal. This effect may readily be demonstrated by growing seedlings of the same species in warm and cold compartments of a plant-house. The resistance of plants to low temperatures, especially those of winter, depends upon the relation between the available water, which is reduced by freezing, and transpiration, rather than upon the actual cold.

120. Influence upon vegetation. Temperature has no effect upon the movement of plants, i.e., migration into new habitats, but it has a profound influence upon the establishment, or ecesis, 
of the migrants. Seeds, fruits, etc., will move equally well in all directions, provided the proper agents are at hand for carrying them. Consiclering temperature alone, their er esis is more certain if they move to the east or west than if they move southward or northward. Generally, also, the chances of establishment are greater southward than they are northward. In the first case, migration to the east or west does not essentially change the relation of the plant to temperature. Migration southward means that the plant must accustom itself to higher temperatures as well as to a greater ammual sum. While this is taking place, the plant may be at a disadvantage in competition with other plants already well established. Plants that migrate northward, in addition to a corresponding adjustment to lower temperatures and a lower sum, run an increasing risk of encountering a fatal minimum. This risk is greatly increased by the fact that southern plants require a longer period for their life eycle than northern ones, and in a northern habitat are often unable to reach maturity before the regular appearance of fatal frosts. So far as the controlling influence of temperature is concerned, plants spread readily to the east and west, less easily to the southward, and least easily to the north. The same fundamental rule applies to mountains, the increasing cold upward making ecesis more uncertain than it is downwarr. The grouping of species, which forms vegetation, is in accordance with this fact. In consequence, vegetation exhibits zones extending east and west upon continents, and lengthwise along mountain ranges, which are due largely to temperature. The disturbing influence of other factors and the discussion of vegetation zones is considered under Zonation.

I2 I. Digestion. The complex materials, starch, cellulose, oils, and proteids, stored as reserve fool in various parts of the plant, must be dissolved or otherwise chemically changed before they can be used. This process is digestion. It is carried on by the protoplasm or by certain peculiar products of it, callerl cnzymes or ferments. In chlorophyllous plants, digestion takes place within the living cells, except in certain insectivorous forms where the secretion is poured out upon the surface, as in the pitcherplant and Venus' fly-trap. Fungi, on the contrary, rewnlarly carry on digestion outside of their own cells, either digesting the food before it is absorbed, as in many saprophytes, or making use of the enzyme to permit their entrance into the tissues of host- 
plants. Every living cell of the plant possesses the power of digestion, but this is often localized in particular areas. It is inherent in chloroplasts and leucoplasts, and is present to a marked degree in the scutellum and aleurone layer of grains, in the outer cells of embryos surrounded by endosperm, in the digestive cells of insectivorous plants, etc.

Enzymes possess the characteristic property of acting upon and changing an amount of stored food greatly in excess of their own bulk. The way in which they are formed by the protoplasm is unknown, but the production of a granular substance termed zymogen seems to be an essential step in the process. As a rule, each enzyme is able to digest but a single reserve material, or at most it is able to act upon only a few related materials. No enzyme known at present can act upon a carbohydrate and also upon oils or proteids. The enzymes which digest starch and related substances are termed diastases; that which attacks cellulose is called cytase. Invertase changes sucrose or cane-sugar into a simpler sugar. Lipase decomposes fats and oils, while pepsin and trypsin are the chief substances concerned in the transformation of proteids. The chemical changes that take place in digestion are highly complex and still largely obscure. Solution is a characteristic step in the case of all solid food materials. Starch and cellulose are converted into sugars, which in their turn may be further changed before use. Starch is dissolved by the action of two enzymes, termed diastase of translocation, and diastase of secretion. The former occurs throughout the plant as well as in the germinating seed. The latter is largely confined to the seed, appearing in it only after germination has begun. Diastase of translocation attacks the starch grain uniformly, while diastase of secretion corrodes it in such fashion as to give it an irregular outline.

I22. Chemosynthesis of digested materials. Food material may be used in different ways by the plant, or even by the same cell. Sugar, for example, may be changed into a proteid and used to make additional protoplasm; it may be used to free energy by means of respiration, or to form cell wall, or it may be converted into various carbohydrates. While almost any soluble carbohydrate may be used directly to release the energy stored in it, it can be assimilated by the protoplasm, i.e., used in the construction of new living material, only through the chemical 
addition of nitrogen to form proteids. Like nearly all chemical changes in the protoplasm, this process is little understood. Although it occurs regularly in the chloroplasts, it is not confined to them, nor indeed to green plants. It is not dependent upon light, and is termed chemosynthesis because the necessary energy is supplied by chemical action. The plant is unable to take nitrogen from the air, but secures it from the soil in the form of ammonia or of nitrates. The latter are combined with glucose or with maltose to form amides, diffusible nitrogenous compounds convertible into proteids. This action takes place in the presence of potassium, calcium, and magnesium, usually in the form of sulphates and phosphates. While all of these seem necessary, potassium alone appears to take part directly, though sulphur and phosphorus appear ultimately in the protoplasm. The calcium is apparently for the purpose of neutralizing oxalic acid or other injurious compounds arising during the process. The probable reaction has been represented by the following:

$$
\begin{aligned}
& \text { glucose }+\begin{array}{c}
\text { potassium } \\
\text { nitrate }
\end{array}=\text { asparagin } \\
& \mathrm{C}_{6} \mathrm{H}_{12} \mathrm{O}_{6}+2 \mathrm{KNO}_{3}=\mathrm{C}_{4} \mathrm{H}_{8} \mathrm{~N}_{2} \mathrm{O}_{3}+\mathrm{K}_{2} \mathrm{C}_{2} \mathrm{O}_{4}+2 \mathrm{H}_{2} \mathrm{O}+\mathrm{O}_{3}
\end{aligned}
$$

123. Respiration. Light is the original source of energy for all chlorophyll plants, and indirectly for all hysterophytes, with the exception of a few nitrogenous bacteria. The energy of light is, however, available only at certain times. Consequently the plant has been obliged to find a way of storing it, so that it can be used at night as well as in parts of the plant deprived of light. This is brought about in the formation of complex food materials which represent a certain amount of stored or potential energy. In such forms energy may be carried or translocated to various parts of the plant, and stored as starch, oil, or proteid to start the plantlet, so that it can again reach the light and obtain its energy directly. Translocation, storage, and digestion are all as much concerned with the distribution and use of energy as with that of food material that is to be assimilated. This is evident when it is called to mind that a sugar, oil, or proteid serves both as a supply of energy and as a constructive material.

The liberation of energy stored in various compounds, which are originally soluble or rendered so by digestion, takes place 
during the process of respiration. The latter is aerobic when it takes place in the presence of oxygen, and anaerobic when oxygen is absent. Aerobic respiration is characteristic of green plants, though these are to a certain extent anaerobic during germination. Anaerobic respiration occurs chiefly in fungi. During respiration in flowering plants, oxygen is taken up from the air, and carbon dioxide is evolved, accompanied by the production of heat. The process is one of oxidation, in which the living substance or the elaborated foods in it serve as fuel for the production of energy. It occurs in every living cell, but is most pronounced in regions of greatest activity, especially so in meristem. It is at a minimum in resting cells, and is practically absent in seeds and other propagative organs during the low temperatures of winter. Respiration is directly dependent upon temperature, but is little affected by light. The minimum temperature for the process is about $-15^{\circ} \mathrm{C}$. Its activity increases with the temperature, and appears to reach an optimum in the neighborhood of the maximum for flowering plants.

I24. Fermentation. Bacteria, yeasts, and molds obtain the neressary supply of energy by decomposing the greater part of the food upon which they grow into alcohol or various organic acids. This process, which is called fermentation, may be carried on by both aerobic and anaerobic plants, and is merely a kind of vigorous respiration. The power to carry on fermentation is small or absent in many fungi. It is especially characteristic of yeasts, and the consequent action is well illustrated by the common yeast. The latter decomposes sugar into alcohol and organic acids, with the evolution of carbon dioxide. Yeast ferments sugar and other carbohydrates normally in the presence of oxygen, but it may manifest this activity for some time without oxygen. Yeasts may act upon fats, but not upon proteids, while bacteria and molds produce fermentation in sugars, oils, or proteids.

125. Germination. Seeds owe their ability to germinate under the proper conditions to the energy stored in the reserve food contained in them. This energy is released by the processes of digestion and respiration. The reserve food of seeds is usually in the form of starch, oil, or proteid, and in many seeds two of these occur together. It is either stored in the cotyledons or packed about them as endosperm. In both cases its digestion 
is brought about by the cotyledons, which likewise absorb the digested material. When a large amount of food is stored in the cotyledons, the latter usually remain in the ground, or, if carried above it, they rarely become functional leaves. When the food is packed about the cotyledons, they act as the first leaves of the seedlings, except in the grasses. Here the single seed-leaf is transformed into a special organ of absorption, the scutellum. The digestion of stored material is carried on chiefly by the cotyledons, though the cells of the endosperm also play a part when the latter is present. The conversion of starch into sugar is effected by diastase, largely secreted by the cotyledons. The latter often produce other enzymes as well, though these do not always seem necessary to the removal of proteids. The foods digested by the cotyledon are translocated to all parts of the embryo, and vigorous respiratory action is set up to secure the energy necessary for assimilation and growth. Such respiration is regularly aerobic, though under abnormal conditions it may for a time be anaerobic. Digestion continues until the food material has been removed from the endosperm or the cotyledons, by which time the seedling is provided with roots and leaves and is again able to obtain its food and energy directly from photosynthesis. Respiration, on the other hand, is a continuous process. Once actively begun in the embryo, it continues throughout the life of the plant, disappearing only when the latter passes into the seed stage or other resting condition.

Experiment 33. Digestion and respiration in seeds. Germinate seeds of the bean, sunflower, and Indian corn in a moist chamber or a germinator. As soon as the radicles appear, cut a median section of each seed to show the relation of the various parts. Note especially the condition of the reserve food as compared with that of the food in the dry seeds. Remove a few of the corn embryos, and place them upon moist potato-starch in a moist chamber. After some time, note the action upon the starch grains.

Place a number of peas in a bottle, cover them with water, and close the bottle with a rubber stopper containing two holes. Insert a thermometer in one of the latter, lowering the bulb to the water. Bent a piece of glass tubing so that one end will fit in the second hole of the stopper without reaching the water below, and pass the other end into a stoppered bottle containing a $10 \%$ solution of lime-water or of barium hydrate. Explain the precipitate that is formed. Compare the temperatures of the germinating peas with those of the air outsicle. 
126. Nutrition of hysterophytes. Plants that possess chlorophyll are holophytes, those that lack it, hysterophytes. From the standpoint of nutrition, plants that make their own food by photosynthesis are autotrophic, i.e., self-nourished, while colorless plants are heterotrophic, i.e., nourished by material traceable more or less directly to green plants. A few flowering plants are mixotrophic, i.e., while they absorb most of their food in organic form, they are still able to make more or less sugar by photosynthesis. Some of these, such as the mistletoe, seem to show normal photosynthesis, the parasite taking nothing but water and inorganic salts from the host-plant. Others, such as the dodder, are green only until they become attached to the host-plant, after which the chlorophyll disappears. Hysterophytes are usually grouped as parasites and saprophytes, although a large number of fungi may be parasitic or saprophytic, either by choice or by necessity. Many parasites are able to grow on a number of different host-plants, and certain of the saprophytic molds can flourish on almost every organic substratum. Other parasites, on the contrary, are confined to a single host, and occasional saprophytes are similarly limited in habit.

A hysterophyte is nourished in practically the same way as the embryo which receives its food from the endosperm, or as the colorless tissues of a green plant, which are supplied with nutriment by the chloroplasts. The deep-seated cells of a wheat stem depend upon the leaves for food just as the rust upon it does, and the processes of digestion and of respiration are essentially the same in both. The saprophyte, though less directly, is similarly dependent upon the activity of green leaves for the sugar, starch, cellulose, oil, or proteid which it digests and absorbs. The respiration of many saprophytes is likewise similar to that of rootcells and of parasites, but in a large number, especially yeasts, mokds, and bacteria, respiration implies fermentation. For this reason, saprophytes often grow readily in solutions containing organic acids, which are the products of fermentation.

127. Kinds of parasites. The type of parasitism in which the presence of the parasite benefits the host-plant in some measure is commonly distinguished as symbiosis or mutualism. Such a relation is found between certain fungi and the roots of many trees, the beech, oak, pine, spruce, etc., in Monotropa, and in the root-like stems of the coral-root, Corallorrhiza. The root with 
its associated fungus is termed a mycorhiza. A similar relation exists between the roots of Leguminosce and the nitrogen bacteria which form tubercles upon them. Symbiosis occurs likewise between many of the simpler algæ, such as Pleurococcus and Nostoc, and many cup-fungi and black fungi, constituting the forms termed lichens. In all of these cases the fungus is parasitic upon the host-plant, deriving from it all of its food, or in some cases the larger part of it. Its position in or about the host is of such a nature that it compensates the latter for the loss of food by some beneficial action upon it. The lichen surrounds the algal host with filaments in such fashion as to shield it from heat and drouth, though this relation was first established merely to withdraw carbohydrates from the algal cells. In Leguminosce the bacteria of the root tubercles make it possible for the plant to avail itself of the nitrogen of the air, while without the tubercles, as in the case of all other green plants, this substance can only be obtained from compounds in the soil. In return for the nitrogen fixation, the bacteria take their food supply from the host-plant. In the case of mycorhiza the fungus is probably a saprophyte originally, living upon humus in the soil. After finding its way into the loot, it lives more or less parasitically, drawing all of its food, or much of it at least, from the host-plant, and in return aiding the latter in obtaining nitrogen compounds.

Experiment 34. Nutrition of representative hysterophytes. Prepare cultures by half filling two small Petri dishes with a $2 \%$ sugar solution, and two with a thin flour paste. In a third pair place a layer of butter, and in a fourth a piece of moist cooked meat. Sprear compressed yeast (Saccharomyces) over the various substrata in one series, and dust spores of blue mold (Penicillium) or black mold (Ascophora) over the material in the second series Place the cultures in a water-bath regulated for a constant temperature of $30^{\circ} \mathrm{C}$, and note the growth from day to day. Compare the rate and amount of growth on the various substrata. Care must be taken to keep the cultures moist.

Germinate sunflower seeds, and after the seedlings have appeared sow seeds of dodder (Cuscuta) in the same pot. Note the behavior of the dodder seedlings, and study the green thread-like stem in crosssection. After it has become attached, cut a section through parasite and host at the point of union, and study the relation of the tissures of the two.

Cut longisections of the root-like stems of Corallorrhiza, and note the position and relations of the fungal filaments. Cut cross-sections of 
a lichen thallus, and note the arrangement of the host-cells. Carefully dissect the section in order to determine the connection between the fungal filaments and the individual aglal cells.

I28. Growth. The growth of any plant is marle possible only by the growth of the individual cell, and, in multicellular plants especially, by the division of the latter. The absorption of water by a protoplast causes the stretching of the elastic cell wall, and the accompanying assimilation of food results in an increase in the amount of cytoplasm. The activity of the cytoplasm brings about a deposition of cellulose particles in the stretched wall, and keeps it at its normal thickness. In a meristem cell that has stopped dividing and has begun to stretch in consequence of the absorption of water, the vacuoles of cell-sap increase in bulk more rapiclly than the cytoplasm. The nucleus, moreover, shows a marked decrease in size, doubtless due to the withdrawal of material from it as it loses the power of active division. Thus, while the meristem cell contains a large nucleus surrounded by much cytoplasm filled with many small racuoles, a single large vacuole is the most conspicuous feature of a parenchyma cell. The cytoplasm, while it has increased somewhat in quantity, is now a thin layer closely applied to the inner surface of the wall, and the nucleus has become more or less inconspicuous. In addition to the reinforcement of the cell wall by the placing of new cellulose particles among the original ones, the cytoplasm may add new layers of cellulose in those cells especiaily destined for mechanical support. These thickening layers may be added almost uniformly, as in stone cells and fibers; at the angles, as in most thick-angled tissue; or in various forms, as in ringed, spiral, and reticulated vessels or tracheids. The first layers usually consist of cellulose, but in the later ones this is generally replaced by lignin in supportive tissues, and by cutin in protective ones, as in the cuticle of the epidermis. The growth of the cell becomes impossible after the wall is thickened or its substance changed, since mechanical stretching is no longer possible.

129. Growth of tissues and organs. The continued growth of a mass, i.e., a tissue, is possible only when the individual cells increase in number as well as in size. Since inerease in number is the regular consequence of the growth of the cell, the two always occur together. Increase in the size of a cell is limited not only by mechanical laws, but also, and esperially, by the relation 
between surface and volume. The volume grows so much more rapidly that the surface becomes unable to furnish adequate food material, and division becomes necessary as a temporary remedy for this condition. In all cells, division is brought about by a preceding indirect division of the nucleus, i.e., mitosis, though in a number of cases the nucleus divides directly without affecting the cell. All the cells of the embryo, for a time at least, are capable of active division, i.e., they constitute meristem or dividing tissue. Even in the seedling, the greater number of the cells have lost this power, which is confined to a few special regions during the further development of the plant. Practically all vascular plants maintain meristem at root-tips and stem-tips throughout the life period. With the exception of monocotyledons, woody spermatophytes and many herbaceous ones retain in the stem a special meristematic layer, the cambium. The ordinary shrubs and trees possess meristem in their buds and in the layer which produces the protective cork. In roots the pericycle is persistently meristematic, and the inner layers of the cortical cylinder sometimes possess the same property. The parenchyma of both stem and root for a long time possesses the power to produce meristem, and it regularly serves this function in producing the cambium which connects the bundles of the stem. In flowering plants the meristem of all growing tips proceeds from one or more groups of apical cells, while in the mosses, liverworts, and ferns it is derived from the division of a single apical cell.

In all plants higher than the simple algae, the stimulus of fertilization produces growth. In the carpophytes the action is exerted both upon the egg-cell and one or more of the adjacent cells; in mosses and ferns the resulting growth is usually ("onfined to the egg-cell. In the spermatophytes, fertilization initiates the development of the endosperm as well as that of the embryo, and likewise often produces a striking growth of calyx, receptacle, or other portion of the fruit axis. Both propagation and reproduction are consequently to be classed as phenomenil of growth, and to be considered in connection with it.

Experiment 35. Regions of growth. Sow fern spores on clean, moist sand, and after they have germinated, observe them from time to time, noting the behavior of the apieal eell. Germinate secels of the horsebean (Vicia faba), and after the seedlings appear, cut off the root and stem tips, as well as some sections of the upper part of the radicle. 
Embed and cut on the microtome. Study the origin and structure of the meristematic regions Cut eross-sections of a woody stem for the study of cambium, and the cork meristem or phellogen. Cut crosssections of a flower bud and note the meristem.

I30. Conditions that influence growth. In most one-celled plants, growth takes place equally in all directions. In filamentous and massive forms, growth is greatest in one direction, and division is correspondingly modified. The cell and the plant become more or less drawn out, as though influenced by two poles. Although this phenomenon, which is called polarity, is all but universal among plants, its cause is obscure. The polarity so characteristic of stemmed plants is largely a matter of the control exerted by gravity, but in the case of thallophytes, e.g., liverworts, lichens, and algæ, other factors, light, water, etc., enter in. Gravity is the most important of all forces in determining the direction of growth. Broadly speaking, the main axis of vascular plants is in line with the pull exerted by gravity, while the secondary axes, branches, leaves, etc., are more or less at right angles to it. The growth of the root is with the pull due to gravity, that of the shoot against it. The relation of growth to gravity will be further discussed under geotropism.

I3r. The amount and rate of growth are determined by the physical factors of the habitat. Growth is directly affected by the condition of the plant, especially its turgidity and nutrition, but these are under the control of the physical factors. The supply of oxygen is an important factor, though its effect is observable only when the usually adequate supply is greatly reduced, as in the case of many water plants and humus plants, particularly certain saprophytes. Water is, for many reasons, of the first importance in growth. It is necessary for the mechanical stretching of the cellulose wall, which is a prerequisite for the growth of all tissues. It is not only necessary for the formation of carbohydrates, but also for the absorption of nitrogen compounds and other necessary salts. It serves as a vehicle for the translocation of elaborated foods, and is indispensable in maintaining the turgidity of the plant. Temperature is equally important in growth. Apart from the indirect effect which it exerts through its influence upon absorption, photosynthesis, etc., it controls growth directly through digestion, assimilation, and respiration. Indeed, heat and water may be termed the two requisites for 
growth. Light apparently exerts only an indirect effect through the dependence of growth upon the food supply furnished by photosynthesis. Strong sunlight has been supposed to exert a retarding influence upon growth, but this is very doubtful. In diffuse light and darkness, plants grow taller than in sunlight, but this result seems to be due to other causes, and only indirectly to light. Humidity acts indirectly but powerfully upon growing plants by controlling transpiration, and through it affecting absorption. Soil influences growth by its control of water content, air content, and nutrient salts. Except for its occasional mechanical action upon the growth of woody plants, wind, like the remaining physical factors, affects growth only through other factors.

132. Regions of greatest growth in various organs. The growth in length of roots, stems, and leaves is normally due to

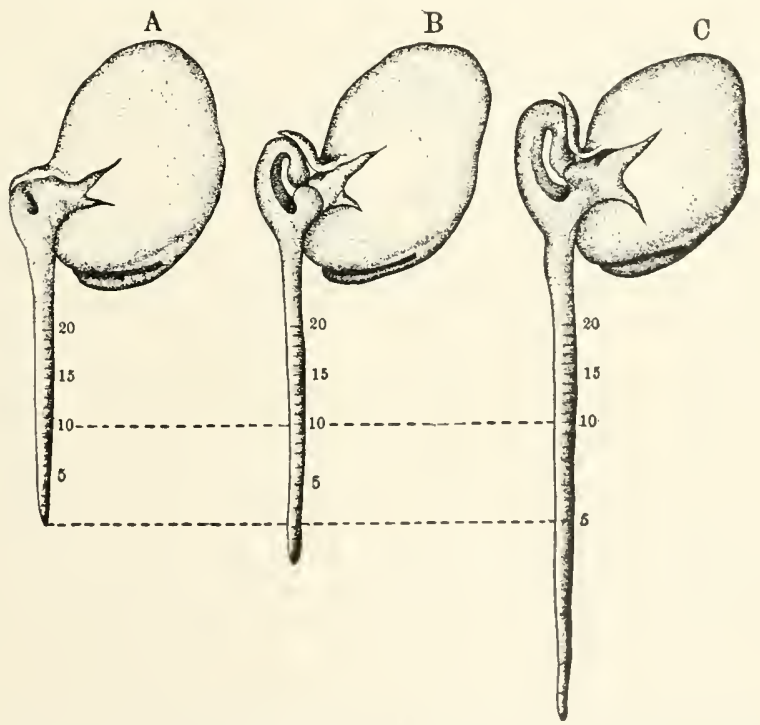

FIG. 27.-Seedling of the horse-bean, Vicia faba, showing the amount and location of the growth in $A$ after 6 hours $(B)$ and after 24 hours $(C)$. (After P'feffer.)

the apical meristem. In some cases layers of cells at one end of the internodes of the stem or near the bases of the leaves retain the power of growing, and thus produce intercalary growth. In all regions of growth, and especially so in apical ones, there are two more or less distinct zones. In one the cells divide actively, 
but grow little; in the other division is greatly diminished or altogether lacking, and the stretching of the cells pronounced. The former consists almost wholly of meristem and may be called the zone of division, while the latter consists of cells more or less modified into parenchyma, and may be termed the zone of elongation. The zone of division is regularly much shorter than that of elongation, the ratio often being greater than $1: 3$. The zone of division occupies the tip of stem or root, and the zone of elongation extends back from it for a distance several times greater. Elongation is greatest just back of the meristem, and it decreases gradually toward the permanent tissue of the organ. In the intercalary growth of an onion leaf, elongation is greatest at the apex of the sheath, and it decreases less rapidly upward into the blade and more rapidly downward. The length of the growing region varies for different plants. In roots it may vary from one to several centimeters. The growing region of the stem is normally much longer, ranging from 5-40 centimeters and in rare cases even more. It may consist of one to several internodes, and in certain water plants growth may extend over as many as fifty internodes or rarely over the entire stem.

Experiment 36 . Influence of temperature, water, and light upon regions of growth. Germinate seeds of Vicia faba in a moist chamber, and as soon as the roots are a centimeter long, mark several carefully with an inked thread at intervals of a millimeter. Put one or two in a warm place and as many in a cool spot Determine the region of greatest growth, and note the differences due to temperature.

Select four sunflower seedlings that show three internodes, taking pains to choose plants as nearly alike as possible. Mark the stem of each at $5 \mathrm{~mm}$. intervals, and mark one of the youngest leaves of each transversely at intervals of $2 \mathrm{~mm}$. Place one plant in a warm sunny place and keep it well watered, marking the other leaf of the upper pair longitudinally at intervals of $2 \mathrm{~mm}$ Place the second plant along sirle the first, but do not water it. Put the third plant in darkness, and the fourth one in a cool spot. Follow the growth in each from day to day. After several days or a week determine the total growth of stem and leaf under each condition, as well as the region of greatest growth for stem and leaf.

133. Rhythm of growth. The rate of growth is by no means uniform throughout the day or the year. It exhibits a certain rhythm or periodicity, in accordance with which the growth fluc- 
tuates greatly at different times, or ceases at the end of a certain period. The division of the year into a growing period and a resting period is the most striking evidence of the law of growth. Variations in growth probably arose originally from the fluctuation of the controlling factors, heat and water. They have become so firmly impressed upon the plants through the action of similar fluctuations upon countless generations that they are more or less firmly fixed as habits which persist under changed conditions. In consequence, rhythm appears to depend as much or even more upon the habitual development of the plant as upon the physical factors of its habitat.

The daily growth of a plant shows a maximum and a minimum, the latter sometimes falling to zero. The maximum usually occurs late at night, apparently after translocation becomes less active, and the minimum falls near noon, not far from the period of greatest photosynthetic activity. Between the two the rate of growth falls and rises more or less gradually, though abrupt changes often occur. During the growing period growth begins slowly, but after a certain period, the length of which varies for different plants, it rises rapidly and uniformly, as a rule, to the maximum. The latter rate is maintained for a short time only, after which it first falls rapidly and irregularly to a point near the minimum. Growth is then maintained at a very low, irregtilar rate for some time and finally stops altogether. Cessation of growth may occur but once in the lifetime of an individual, as in the case of annual plants and most thallophytes, or it may occur at fixed intervals, as in perennial herbs and woody plants. In the latter the rhythm shown in a single period of growth and of rest lasts throughout the entire year, although unusual conditions may cause an interruption of growth at any time. Changes or conditions of the plant which are connected with the resting period become fixed habits, owing to their constant recurrence. This is equally true of the adult plant and of the embryo in the seed. Woody plants which shed their leaves at the hegimming of an annual period of cold or drouth often retain this habit after the cause is removed. Seeds which have been regularly exposed to winter conditions have acquired the habit of remaining dormant during this period. When brought under the usual ennlitions they may refuse for a long time to germinate unless they are subjected to cold naturally or artificially. The daily rhythm 
of growth or movement also becomes fixed, and is often exhibited by plants in the absence of the usual causes.

I34. The age of a plant, i.e., the total period of growth, depends very largely upon its size and complexity. A unicellular plant, such as a bacterium or an alga, may pass through its life cycle in a few minutes, for, while it does not die, its individuality is lost in consequence of division into two new cells. At the other extreme are found the trees, many of which live for centuries, and a few for more than a thousand years. Practically all vascular plants require at least one season to complete their development, and the majority of them live for many years. The death of plants which have but a single period of growth is ordinarily due to unfavorable physical factors, or to the fact that all the tissues of the parent plant have taken the permanent form, leaving no meristem to initiate growth during the following season. Woody plants might well seem to be immortal, except perchance for accidents, but even in them the great accumulation of material sets a mechanical limit to the size that can be attained. The approach of this limit is furthermore hastened by the inevitable decay of the dead tissues of the trunk, resulting in the fall of the tree while growth is still possible.

135. Reproduction. The earliest division of labor in plants produces a nutritive or vegetative part and a reproductive one. The two are absolutely interdependent: they are connected by growth, which is the result of nutrition and the cause of reproduction, or at least the means by which it is brought about. The simplest case of reproduction is that shown in fission, where the production of two new plants from the parent cell is the direct outeome of growth. Multiplication must have been originally at least merely a consequence of this process, by which a plant was enabled to continue growth by becoming two. Since growth is characteristic of all plants, reproduction in direct consequence of growth is found in practically all groups of plants. This process is ordinarily termed asexual reproduction or propagation, and the cells or parts by which it is carried on are propagules. The formation of propagules can take place only during the period of growth, and these serve, as a rule, for multiplication under favorable conditions. A large number of propagules, however, pass into a resting condition by the formation of a protective covering, and thus serve to carry the plant or a portion of it through drouth 
or cold. The last, however, is the usual task of sexual reproduction or generation.

The fusion of two sexual plasms or gametes produces a sporophore. In the phycophytes the latter is one-celled and is usually spoken of as a resting spore. In all cases the sporophore or some part of it is well protected, to avoid drying out during unfavorable conditions, usually those of winter. It is also stored with food, or contains chloroplasts to enable the protoplasm or plantlet to burst the covering and to obtain a good start when favorable factors return. In some alga and fungi the entire sporophore assumes this rôle, but in the majority of these, and always among the mossworts and ferns, this task is assigned to the spores produced by it. Among flowering plants it is the seed that serves this purpose. In the following brief discussion of the methods of reproduction, it is not feasible to consider all of these, and only the more important are indicated.

136. Propagation. Fission is the almost universal method of propagation among the unicellular plants. Budding is merely a kind of incomplete fission, and the internal division of the protoplasm in forming macrozoogonids is practically fission within the cell wall. After plants became multicellular, however, fission merely increased the number of cells in the plant, except in those cases where the cells fall apart to form conidia. Filamentous forms consequently came to break their threads into pieres or hormogones by the modification or death of a cell. Among the multicellular phycophytes the propagules are usually asexual zoospores, while among the carpophytic fungi the latter have become colorless and aerial, constituting conidia. In both cases ther are the direct consequences of growth. and are designed for immediate germination under favorable conditions, as well as to bring about distribution. Conidia, however, have acquired more or less resistance, since a long time may often elapse before they reach proper conditions for germination.

Among the liverworts and mosses the propagules are usually special bits of the plant body or ganetophore. which are ralled gemmix. These are usually formed upon the thallus or the stem, though they are also developed from other parts. W'hen detarhed they ordinarily grow at once into new plants. In a few cases specialized leaves may serve the same purpose. The fermworts and ferns have placed their stems underground in most cases, 
and propagation is largely carriect on by the latter. In consequence, other kinds of propagules are rare. Buds, bulbils, or bud-like bodies serve for propagation in some ferns.

137. Propagules of flowering plants. In the spermatophytes, root, stem, leaf, and flower are all capable of producing meristematic tissues that may serve as the essential part of a propagule. Probably no plant has the power to levelop buds upon all of these organs, and in most cases this ability is restricted to one or two parts. It is a common characteristic of the stem and is often found in roots. It occurs rarely in leaves, at least under natural conditions, and is altogether exceptional in flowers. Root buds, i.e., the use of roots as propagules, are very common in woody plants, both trees and shrubs, such as the aspen, cottonwood, lilac, rose, raspberry, etc., and it occurs also in herbaceous plants e.g., milkweeds, dock, toadflax, and certain composites. The development of plants from root buds often takes place under normal conditions, but it is a regular occurrence when the trunk has been cut down.

Buds occur on foliage leaves, especially those that are thick or fleshy. They spring usually from the margins, but are also formed upon the surface. Such leaves are regularly used for artificial propagation by florists and gardeners. In nature leaf buds occur regnlarly on only a few plants, though they have been occasionally observed upon a number of herbs, chiefly among the mustarl and lily families. Although some are able to form plantlets upon the leaf while it is still in position, it is evident that propagation by this method would rarely prove successful in nature, except perhaps in wet habitats. The production of buds from floral leaves occurs in but a few genera, and such buds are incapable of propagation without the artificial removal of the carpels. Flowering branches are often replaced by propagative buds in many grasses, in the onion, saxifrage, etc.

138. Stems as propagules. Bud-bearing stems are variously modified to constitute propagules, of which they are by far the most important source. According to the form which the stem takes, such propagules are termed stolons, offsets or rumers, rhizomes, corms, bulbs, and bulbils. The stolon is a descending or trailing leafy branch which forms roots and a shoot where it touches the ground; it is found in many bushes, currants, gooseberries, ete. The runner is a prost rate or decumbent slender leafless 
stem, which forms roots and leaves at its outer end, either before or after the latter touches the ground. Offsets are short runners, but there is no real difference between the two. Runners are found in the strawberry, certain species of erigeron, saxifrage, etc. Rhizomes or rootstocks are the underground stems or branrhes so characteristic of perennial herbs, e.g., most grasses, mints, iris, Solomon's seal ete. They persist from year to year, forming new buds and carrying the successive generations further and further from the original home. A tuber is a greatly thickened rootstock, or a thickened portion of one, such as is found in the potato. The corm is really a short tuber. often broader than long, and usually upright in position. Roots are produced from the lower surface and buds from the upper, though they may spring from the sides also. Corms are found in the rocus, jackin-the-pulpit, etc. Bulbs resemble corms in shape, but they are not solid. They are greatly shortened subterranean stems, made up largely of thickened scale-like leaves. Bulbs are the characteristic propagules of the lilies and their relatives. Bulbs and corms sometimes form underground offsets which produce new bulbs at the end. Bulbils or bulblets are small aerial bulbs, produced in the axils of leaves, as in the lily, or in flower clusters, as in the onion.

Experiment 37. Propagules. Note the development of the perennial herbs and the shrubs in the spring. Determine the method of propagation in as many as possible. Prepare a list for grassland and forest of the plants thus studied. Arrange the species according to the type of propagule, and note the distribution and importance of the various types.

139. Sexual reproduction. In its simplest form sexual reproduction is merely the fusion of two protoplasts or gametes. There is no differentiation of the gametophore, and fertilization has no effect apart from the two cells concerned. In the beginning, sexuality seems to be little more than a device by which a double quantity of protoplasm is secured for the resting spore. In the carpophytes, and especially in the bryophytes, the gametophore is considerably differentiated. Fertilization produces a sporophore of increasing complexity, in which spore production, though still the principal function, is not the only one. step ly step the sporophore assumes the functions of the gametophore, until 
the latter is left only its characteristic task, the production of gametes. During this time a division of labor occurs by which each gamete is developed upon a special gametophore. With the appearance of the flowering plants, the primitive relation in which the sporophore is dependent upon the gametophore is reversed. The macrospore is retained upon the sporophore, and the male gamete is no longer able to reach the egg-cell by swimming through the water to it. The sporangia in which microspores and macrospores are produced are further protected and nourished by being enclosed within the sporophylls that bear them, giving rise respectively to stamens and pistils. A further step in the increase of parental care leads to the loss of the power to produce sporangia by some of the sporophylls, which thereby become sepals. The need of insuring the transfer of pollen grains from stamens to pistils has apparently produced a further division of labor. The innermost sepals have become brightly colored in the majority of cases, and as petals serve as organs of attraction for insects, as well as for other animals that bring about pollination. The flower is hence to be explained as a reproductive device, by which the sporophore secures better protection and nutrition for its spores and gametes, and insures the fusion of the latter in spite of changed conditions and the loss of motility in the male gamete.

The immediate task of the flower is to bring about pollination and consequent fertilization, by means of which seeds and fruits are produced. To secure the proper discharge of these functions, the flower has undergone innumerable modifications. All of these may be grouped with respect to: (1) the production of pollen, (2) its protection, (3) the disposition of stamens and petals, (4) source and destination of pollen, (5) relation to the agent concerned in dispersal.

I40. Production of pollen. Pollen grains are commonly exposed to the double risk of injury by weather and of loss in transit, particularly in transfer by winds. Furthermore, they often serve as food for the insect agents of pollination, and a large number of grains are thus sacrificed in order that a few may be carried. As a general rule, the amount of pollen produced increases with the danger of loss. There are few if any definite modifications for this purpose, doubtless because it is most easily accomplished by increasing the number of stamens in each 
flower, or of stamen-bearing flowers. A large production of pollen is secured in many open flowers, such as the buttercup, anemone, strawberry, cinqfoil, etc., by a large number of stamens, and doubtless compensates for the great loss arising from the ease with which many insects may reach the pollen and eat it. Among wind-pollinated plants the greatest loss occurs in the diœcious trees, such as the cottonwood and ash, and the monœcious conifers, e.g., pines, spruces, and firs, in which the pistillate cones are
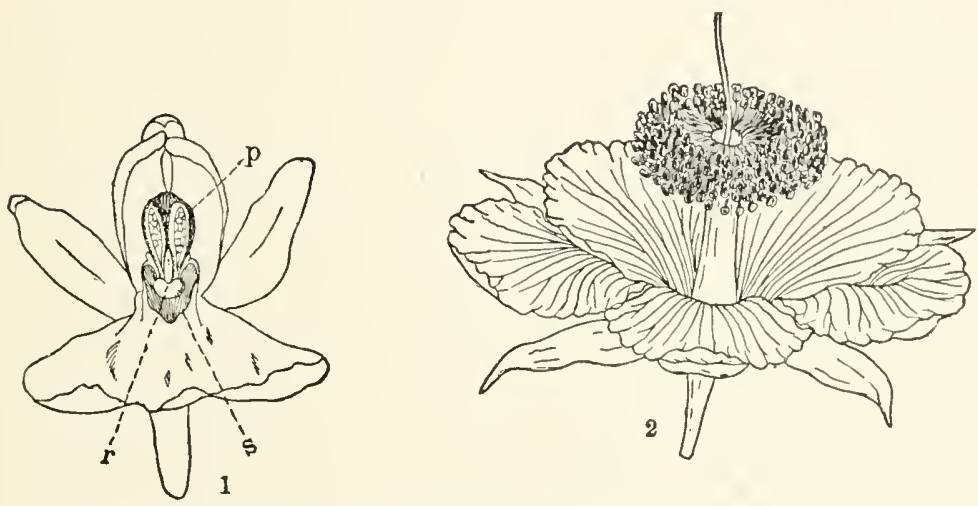

FIG. 28.-Extremes of pollen production. 1, an orchid, Orchis sp.; p, pollen mass in anther cell; $r$, retinaculum; $s$, stigma; 2, a baobab flower (Adansonia) with a column of stamens. (1 after Le Maout and Decaisne, 2 after Baillon.)

usually above the staminate ones. The need of compensation in such cases is very great, and the amount of pollen necessary is enormous. Indeed, in many coniferous forests, nothing is found so universally scattered as pollen grains that have miscurried. In many trees the great loss of pollen is offset by the development of a large number of flowers, especially of imperfect ones in which the material ordinarily available for sepals, petals, and pistils is used for stamens. This is the case in polygamous flowers, such as those of the maple. Not all wind-pollinated flowers produce a large amount of pollen. In the grasses and sedges, for example, the number of stamens is usually 1-3. This is probably to be explained by their habit. They are low-growing and usually densely associated, in consequence of which the pollen is carried through the whole group of individuals before it is blown away.

As would be expected, the number of stamens and hence the 
amount of pollen produced decreases as the method of pollination becomes more and more perfected. Moreover, accessory staminate flowers disappear, and the number of flowers is often greatly reduced also. In practically all zygomorphic flowers, i.e., those that apparently owe their irregular form to insect-pollination, such as the mints, snapdragon, orchids, etc., the number of stamens is regularly reduced to four or two. In certain orchids the number of pollen masses, or pollinia, is reduced to two or one, so certain has pollination become.

Experiment 38. Amount of pollen. Make a comparison of various species with respect to the number of flowers, and the number of stamens in each flower Estimate the number of pollen grains in an anther and determine the total pollen production of a plant of each type.

I4 I. Protection of pollen. Flowers protect their pollen against injury from rain or dew by means of the most diverse modifications. In many instances the protection afforded is secondary, the structure or modification having been developed chiefly for other reasons. The most striking devices, especially those involving a movement of the plant or its parts, serve primarily for protection. A number of plants, particularly wind-pollinated ones, seem to have no protection against injurious moisture. In many of these it will probably be found that the protection, though obscure, is effective. The period of flowering and the time of flowering, when more thoroughly investigated and understood, will suffice to explain why some flowers seem unprotected. It is probable that plants in which the pollen is not protected from harm in some way do not occur, since the existence of a species is proof of such protection. In some plants indifference to the effect of rain or dew apparently constitutes an ample protection.

The damage that results from wetting is not the same for every plant. In some, moisture causes premature germination; in the majority it interferes seriously with the transfer of the pollen. In all these cases the protection afforded the pollen serves also for the nectar. In some instances it is possible that the derice has really been developed for the latter purpose.

Pollen must be protected against dryness as well as against moisture. This is usually accomplished so effectually by the structure of the grain itself that other modifications for this purpose are obscure, if not altogether lacking. In the case of desert plants 
it is possible that the period or time of flowering, the structure or position of the flower, may result in a certain degree of protection. The stigma, while in a receptive condition, must be guarded against excessive dryness, and also perhaps against rain. This is usually brought about by the same devices that insure the protection of the pollen. Finally, the pollen must be guarded against those insects which would devour it without effecting its transfer. This result is usually obtained as a secondary consequence of modifications for insuring pollination.

I42. Structural protection. The derices which serve to protect pollen are of three sorts: (1) morphological, (2) mechanical, (3)

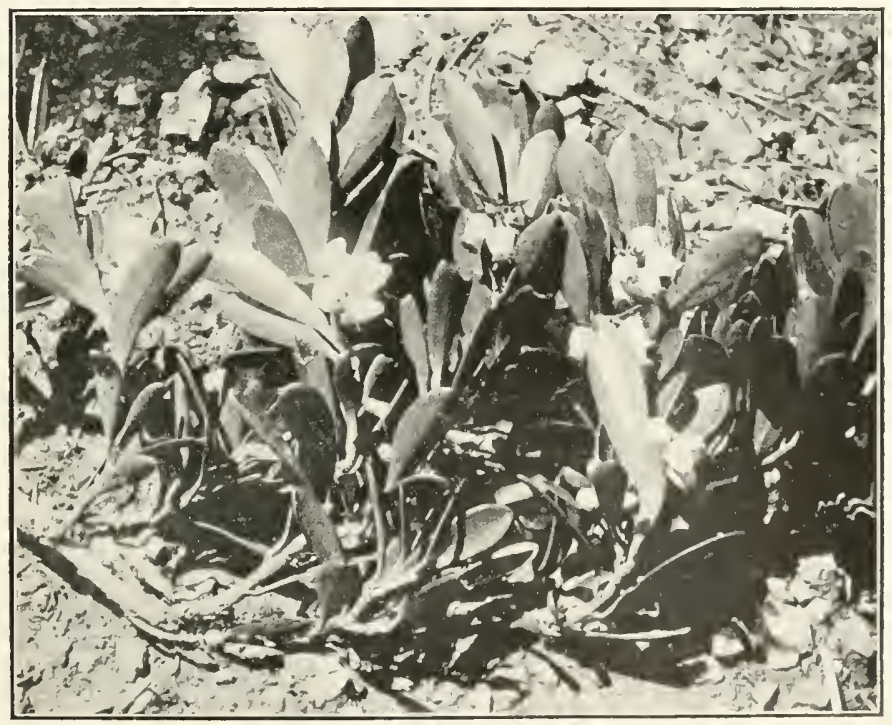

FIg. 29. - Structural protection of pollen in the hearherry, Aretostaphylus uva-ursi, by means of the inverted flask-shaped corolla.

seasonal. The first and third, as a rule, accomplish protection incidentally. Structures of the second class probably owe their very existence to the necessity for protection of the pollen. Morphological contrivances are purely structural or positional. T'o the first class belong all flowers in which protection results from the structure or shape of the flower, of the flower parts, or of the flower cluster. Protection of this sort may arise from the structure 
or sculpturing of the pollen grain itself, or from the form of stamen, pistil, corolla, calyx, bract, or inflorescence. The thick wall of the pollen grain is a very considerable protection, often increased by oil or viscin, as in Onagra, Circaca, etc. Protection is also brought about by the position of the anther, or throngh the location of the pore by which the latter opens. In conifers the swelling of the staminate scales when moist closes the way to the pollen grains. Iris covers the stamen with a broad petaloid stigma. Instances of protection by means of the shape of the corolla occur abundantly among flowers with united petals, e.g., Androsace Gentiana, Lithospermum, etc., and sometimes among those with separate petals, such as Aconitum, Bicuculla, and Delphinium. Certain cleistogamous, i.e., closed, flowers, also belong here. More rarely the calyx serves the same purpose, as in some species of Clematis. In Ariscma and other Aracec, protection is brought about by the form of the spathe. In certain eatkin-bearers, Populus especially, some shelter is afforded by the large bracts. Protection as a result of the position of the flower or inflorescence occurs in a large number of species in which the flowers are turned toward the earth, and in flowers with tubular corollas which deviate even slightly from an upright position. To this class belong Erythronium, Pentstemon, Teucrium, species of Gilia, etc. In Tilia the flower clusters are placed in such a position that they are sheltered by the leaves, a derice which also occurs in some species of Impatiens.

I43. Protection by movement. Nechanical devices comprise movements of the flower or its parts, or of the flower cluster. The movement is one of closing or of drooping. In most cases protection takes place by the closing of the corolla, more rarely by the closing of other parts of the flower. This is especially well shown in day-bloomers and night-bloomers, particularly those that are ephemeral, i.e., that wilt shortly after opening. Dayblooming and night-blooming serve to protect the pollen during the time when it is not being remored and may be injured, although this habit was probably first acquired with relation to insect visitors. The sepals sometimes close for protection in apetalous forms. The swelling of scales in pine cones and the closing of pores in some anthers should be mentioned here, though they are not due to a definite movement. The protection which is obtained in some flowers by a pendulous or ascending position is secured in 
many erect ones by the bending or drooping of the flower-stalk. This is notably the case in Campanula rotundifolia and to a less extent in $C$. aparinoides, in which the bud is erect but the flower is drooping. In Oxalis, Anemone, etc., the bending takes place more quickly and lasts overnight only, or, more rarely, throughout cloudy or rainy days. In some cases the entire flower cluster

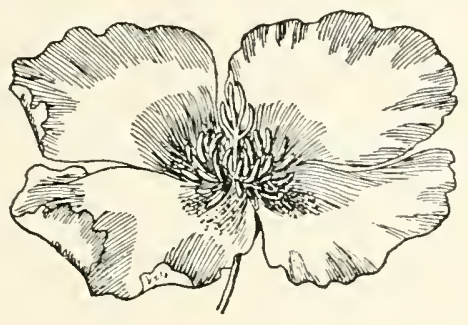

a

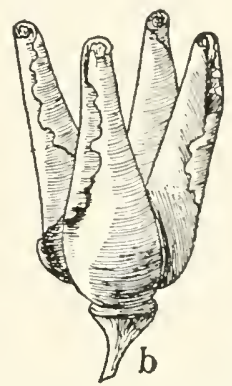

Fig. 30.-Protection of pollen in the California poppy, Eschscholtzia californica, by the rolling of the petals in wet weather $(b)$. (After Kerner.)

droops, as in rertain geraniums, umbellifers, and composites. In some radiate and ligulate flowers of the last family, protertion is afforded by the upward or inward movement of the ligules. In radiate flowers, such as the asters, the protertion of the disk florets by the rays is only partial, but in species of the Liguliflore each floret is protected by its own ligule and by the longer ligules of the florets nearer the margin.

The movements of the flower and its parts are usually referred to as anthotropism. The mechanism by which the movement is produced is not well understood in most cases. The opening and closing of the flower, as well as the bending of the rays in composite heads, is now definitely known to be caused by variations in temperature, and not in light, as is commonly supposed. The precise nature of the response to heat is not known, hut it seems to be a direct reartion of the protoplasm. The bending of flowerstalks may be due to more rapid growth upon one side than the other, or to the attraction exerted by gravity.

144. Seasonal protection. The seasonal protertion exhilhiter by many flowers is concerned with the time or period of flowering. This is shown in plants such as I pomoa, Taraxacum, ete., which open their flowers in bright sunshine and close them upon the approach of rain or at nightfall, thus effertively sheltering the pollen. 
Ephemeral flowers, e.g., Tradescantia, Portulaca, Onagra, etc., open only under farorable conditions, and wilt after a few hours, thus reducing the chance of injury to a minimum. The blooming of flowers at particular times during the growing period doubtless has some connection with the presence or absence of definite protective devices. Many species have formed the habit of flowering at the season in which there is least danger from rains. Seasonal protection sometimes occurs along with morphological or mechanical devices, producing a double protection.

Experiment 39. Protection of pollen. Make careful field observations upon the spring flowers, and note whether the pollen is sheltered or not. Study and sketch some of the ways in which protection is brought about, and arrange the species in groups according to the method employed.

145. Disposition of the stamens and pistils. Since the pollen must be transferred from the anthers to the stigma in some way in order to insure fertilization, the relative position and development of the stamens and pistils become matters of the greatest importance. They not only affect the method of transfer, but they also ketermine the kind of fertilization that results. The arrangement by which stamens and pistils occur in different flowers is termed diclinism, and plants which possess staminate and pistillate flowers are said to be diclinic. Diclinic species are monocious when the staminate and pistillate flowers occur upon the same plant, and divecious when the staminate flowers grow upon one plant and the pistillate ones upon another. Plants with stamens and pistils in the same flower are said to be monoclinic. The presence of monoclinic and diclinic flowers in the same species is called polygamy. In monoclinic or perfect flowers the rule is for stamens and stigmas to mature at different times, in order to increase the chance of cross-pollination. This condition is termed dichogamy. Dichogamous flowers are protandrous when the anthers shed their pollen before the stigma becomes receptive, and protogynous when the stigma matures first. The stigma has been termed short-lived when it is receptive for a short time, and long-lived when it remains receptive, i.e., capable of causing pollen to germinate, for several days or more. When the anthers and stigma mature at the same time, the flower is termed homogamous. 
Flowers usually open before or upon the maturity of anthers or of stigma, but sometimes they remain completely or partly closed and are called cleistogamous. Homogamous flowers, which open, may have the anthers and stigma so placed that self-pollination is impossible, or these parts may be contiguous in such fashion

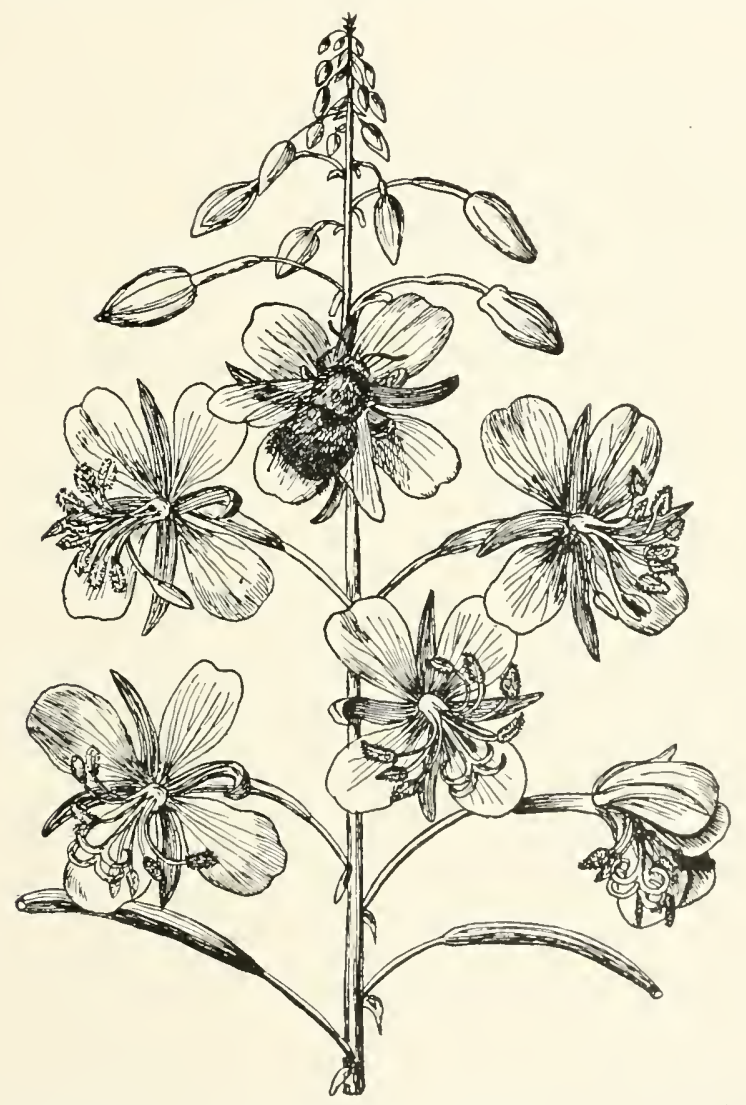

FIG. 31.-Dichogamy in the fireweed, Chamonerium angustifolium, in which the anthers mature before the stigma. (After liermer.)

that self-pollination may occur. Flowers that may be self-pollinated sometimes have the stamens, or the stamens and the styles, in two or three sets of different lengths, in a measure decreasing the disadvantage of self-pollination.

Experiment 40. Grouping of stamens and pistils. Note the relations of stamens and pistils in various flowers of the spring florit. Make 
sketches of several flowers representing different types, showing the flower in longitudinal section.

146. Source and destination of pollen. When a stigma receives its pollen from the anthers in the same flower, the flower is selfpollinated. If the pollen comes from a different flower, the flower is cross-pollinated. Self-pollination is also called autogamy, and cross-pollination, allogamy. The latter is the rule among plants, though autogamy is a frequent occurrence. A great number of plants that are modified for allogamy and are regularly pollinated in this way are so arranged that they may be self-pollinated in case cross-pollination does not occur. Darwin was the first to show conclusively that cross-pollination tends to produce stronger and more vigorous plants, thereby furnishing an adequate explanation of the preference which plants have for this method. The numerous modifications of diclinism and dichogamy seem to be for the purpose of preventing self-pollination, while the innumerable devices for dispersing pollen, attracting insects, etc., are to insure cross-pollination. All diclinic plants and many dichogamous ones can be pollinated in this way alone, while alloautogamous species, i.e., those capable of pollination in either way, are self-pollinated only after the failure of cross-pollination. Iany flowers belonging to different varieties, or more rarely to different species, may cross-pollinate each other. Although the crossing of related forms has been an invaluable method in plantbreeding, it does not seem to be a frequent process in nature, apparently being limited to a few genera, such as the willows, verbenas, etc. Cross-pollination of this sort is termed hybridization.

Cross-pollination between two flowers of the same plant is called geitonogamy, i.e., pollination by a neighboring flower; between flowers of different plants it is xenogamy, i.e., pollination by a distant flower. Either may occur in species with perfect or monœcious flowers, but xenogamy alone is possible in dinecious plants. In single-flowered plants xenogamy is alone possible, but in manyflowered ones an insect will carry strange pollen only to the first few that are visited on each plant. As would be expected, geitonogamy is apparently less beneficial to the species than xenogamy, although in plants where both are possible it is usually much more frequent. Geitonogamy is of greater advantage to the plant than 
autogamy. This fact explains the large number of allo-autogamous plants.

147. Cross-pollination. The benefits arising from the transfer of pollen from one flower to another, as well as the necessity for such a transfer in diclinic species, have led to the production of numerous devices for bringing it about. These have been developed

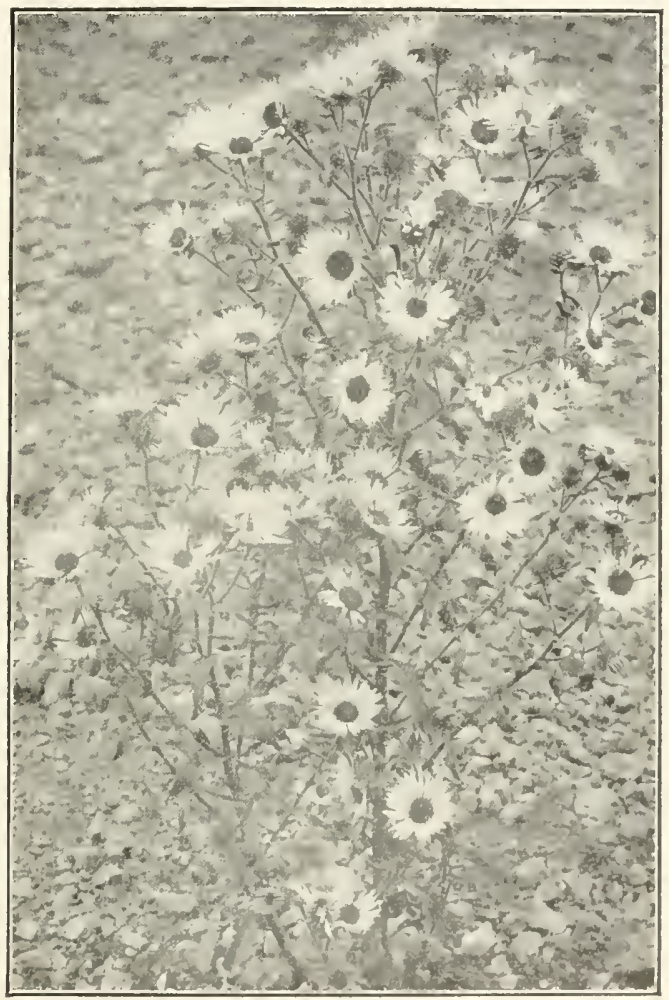

Fig. 32.-Geitonogamy in an aster, Macheranthera aspere, in which pollinibtion regularly oceurs between neighboring flowers or heads.

in relation to one of three factors, water, wind, and animals, especially insects. With reference to the agent concerned, crosspollinated species are aceordingly termed hydrophilous, anemophilous, or zoophilous. Hydrophilous species mat be pollinated under water, as in Zostera or C'cratophyllum, or more often the pollen is borne on the surface of the water, as in Ruppiu, ('alli- 
triche, etc. Anemophilous flowers may lack stigmas, as in the gymnosperms, or, more commonly, possess them, as in the angiosperms. Among the latter, five types of flowers are recognized with respect to the way in which the pollen is exposed to the wind. These are (1) the catkin-bearers, Salix, Populus, Betula, etc.; (2) species with hanging flowers, Acer negundo, Rumex, etc.; (3) flowers with long slender filaments, Plantago, Graminacex, Cypera-

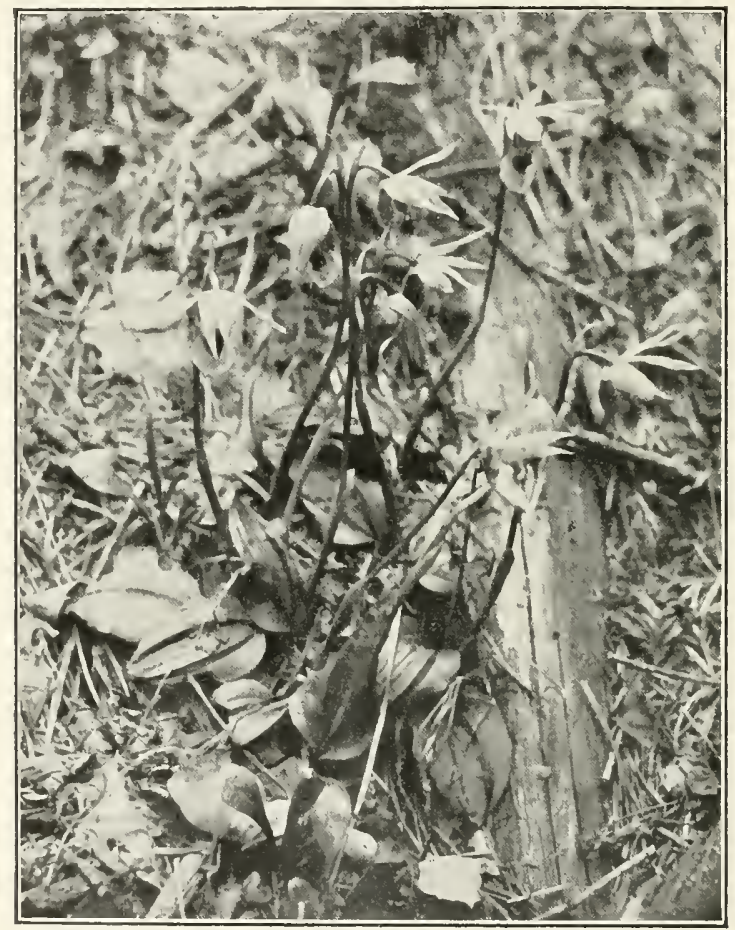

FIG. 33.-An orchid, Calypso borealis, with one-flowered scapes, thus making xenogamy alone possible.

ceœ, etc.; (4) flowers with explosive anthers, Urtica, Parietaria, ete.; (5) species with fixed flowers, Typha, Potamogeton, Sparganium, etc.

148. Pollination by insects. Zoophilous species may be pollinated by birds, as in Bignonia, Impatiens, and Lonicera; by snails, as in Ariscoma; or even by bats, as in the case of a few tropical plants. Plants that are pollinated by insects are by far the most 
important, and are very many times more numerous than all other zoophilous species. Indeed, more species are pollinated by insects than by all other agents combined. It is highly probable that all flowers with corollas owe the development of the latter to insect-pollination, and this is true also of many species which possess sepals alone. The form, color, and frarrance of petaloid flowers in particular seem to be due almost wholly to insects. They have modified their form to afford landing-places for welcome visitors, to enable the latter to find their way quickly to the nectar and pollen, and to confuse or repel unwelcome risitors. As would be expected, those flowers which have been most strikingly modified, such as the mints, figworts, orchids, and many composites, are the ones which are dependent for pollination upon insects of a certain type.

Insects are attracted by color or fragrance, and in many flowers both methods of attraction occur. Inconspicuous flowers which are scentless are nevertheless often visited by insects for the sake of the pollen they afford, and the pollen is the real attraction in brilliant scentless flower's. These are termed pollen flowers; in them a part of the pollen is sacrificed to insure the transfer of the remainder. In nectar flowers, nectar constitutes the attraction, and the removal of the pollen is incidental. Flowers have produced a great many devices to effect the sprinkling or loading of insects with pollen, and to insure the deposition of the pollen in the proper manner. Furthermore, the opening of the flower at a certain time of the day or season is an adaptation to the habits of the insects upon which it depends for pollination.

149. Self-pollination. Autogamy exists as the alternative method of pollination in the majority of plants that are regularly cross-pollinated. It is the sole method in cleistogamous flowers and in those whose size, structure, or position makes them little adapted to cross-pollination, or whose habitats present conditions unfavorable to the latter, as in the case of many arctic and alpine plants. Autogamy is direct in inost cleistogamous flowers, and in those where contiguity of stamens and pistils, or the position of the stamen above the pistil, permits the pollen to fall directly upon the stigma. It is indirect when the transfer of pollen is the result of movement or growth, as in the majority of autogamous plants. Indirect autogamy is brought about by various nuethods, of which the movements of stanens or style, their elongation or 
contraction, the closing of the perianth, and the falling of the corolla are the most frequent.

Experiment 4I. Pollination. Select five flowers of different types, representing preferahly such divergent forms as the willows, grasses, legumes, roses, mints, composites, etc Determine by a series of ob-
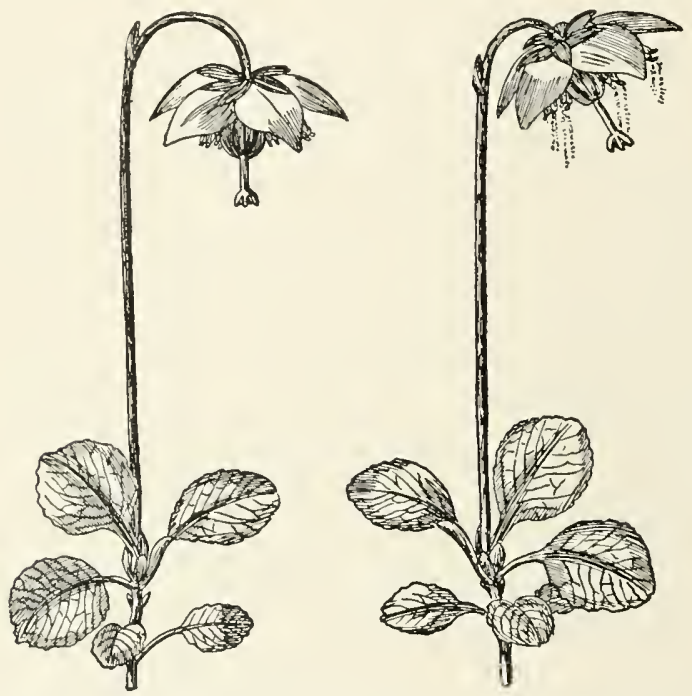

Flg. 34.- Self-pollination in Moneses uniflora by the combined movement of pedicel and stamen filaments. (After Kierner.)

servations the kind of cross or self-pollination which each shows, the agent concerned, and the exact manner in which the agent works. In those that are pollinated by insects, point out the various devices for attraction and transfer.

150. The period of flowering. The time at which a plant opens its flowers and matures its fruits is the result of long-continued endeavor on the part of the species to adjust itself to the climatic factors of its habitat. Since all the factors are highly variable, especially heat, which is the most important in this connection, the time of flowering varies slightly from year to year. In a very abnormal season the variation becomes pronounced. Flowering occurs when the amount of growth, which is chiefly determined by temperature, reaches a certain stage. The necessary sum of temperature is reached more slowly in a cool year 
than during a warm one, and the flowers consequently appear later. This sum is likewise obtained later as one goes northward or ascencls mountain ranges, and the time of flowering is correspondingly delayed. The period during which a species remains in flower is similarly though less evidently dependent upon temperature. In the rast majority of species the period of flowering is largely a fixed habit. This is especially eviclent in many annuals, and in species that flower early in the spring. In nearly all cases its

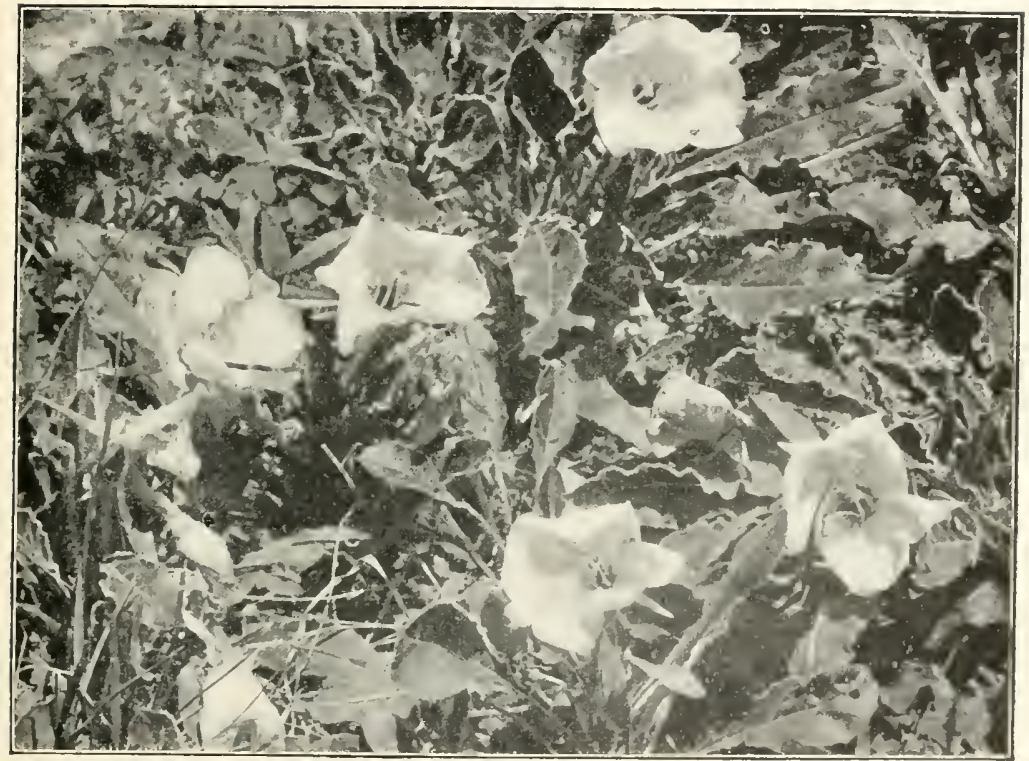

FIG. 35.-Ephemeral night-blooming flowers of an evening primrose, Puchylophus hirsutus. The flowers open at sundown; they close at $7-8$ a.m. the next day and quickly wither.

position and length have been determined by the necessity of rendering it possible for the seeds to mature before the time of killing frosts. Species with relatively small and simple fruits, such as the grasses and composites, may flower late, while those with large or complex fruits, many loses, legumes, etc., usually flower much earlier.

Since flowering is so intimately connected with temperature, flowers may be most conveniently classified in accordance with the season in which they appear, or in which the period of flowering 
chiefly falls. A few species, such as the dandelion, bloom throughout the growing period, and are termed aianthous or ever-blooming. By far the greater number of plants complete their flowering within a certain period. Consequently, flowers may be grouped as prevernal, vernal, æstival, and serotinal, corresponding to early spring, spring, summer, and autumn. Prevernal flowers are the first few that appear before spring has really begun. Vernal bloomers flower from about the middle of April to the middle of June. The astival period closes about the middle of August, and the serotinal period lasts until the time of killing frosts. There is naturally no fixed limit for each period, but during each the general nature of the vegetation is characteristic.

I5I. Time of daily flowering. The time of day at which the flowers of each species open, and the life period of a single flower,

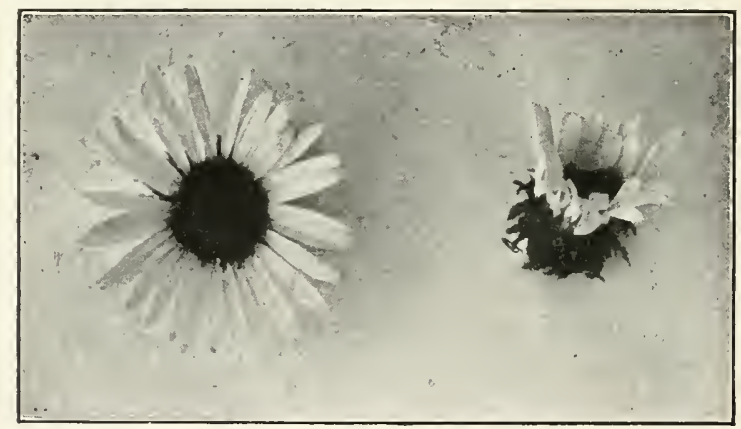

FIG. 36. - Head of an aster, Macharanthera aspera, showing the position of the rays during the day, and at night or in cloudy weather.

are habits that are more definitely fixed than the seasonal flowering. Flowers begin to open as early as 3 a.m. The majority of daybloomers open before $S$ a.m., and practically all are open before 10 a.m. Night-bloomers open between 4 p.m. and $s$ p.m., the latest usually blooming just at twilight. Many species do not close their flowers at all, the latter merely withering and dying at the end of the life period. Hemeranthous and nyctanthous flowers open and close daily, with the exception of ephemeral ones in which the life period is less than one day. These movements, which are controlled by temperature, ordinarily occur at stated times. The dependence upon temperature is so absolute that opening or closing may be hastened or delayed by artificial 
means. Oftentimes hemeranthous flowers do not open at all on unusually cool days, and nyctanthous ones fail to close. The majority of nyctanthous species are ephemeral, while only about one half of the day-bloomers are of this type. Flowers that open and close daily may live for two days only, as in Erigeron and Claytonia, or for two weeks, as in Crocus. Flowers that remain open are long-lived as a rule. Many of them live for several weeks, the maximum period being eighty days for Odontoglossum, an orchid. The minimum period, three hours, is found in the "flower-of-an-hour," Hibiscus trionum, which is the most ephemeral of all flowers. The study of the period of flowering and of the time of opening and closing constitutes what is commonly called phenology, i.e., a study of the phenomena of appearance. While this is a fascinating field, its importance at present is secondary.

Experiment 42. Time of flowering. Select ten species which inchude ever-blooming, day-blooming, night-blooming, and ephemeral plants, and keep a tabular record during the spring of the time of day when the flowers open and close, of the life period of a single flower, of the time when the first flower appears, the maximum of the flowering period, and its close.

152. Fructification. The normal consequence of pollination is the fertilization of the egg-cell of the ovule, and the development of the latter into the seed. In the majority of flowering plants, the ovary and its contents are alone concerned in the changes of growth which follow fertilization. The ripening ovary of this type becomes a simple fruit. In some cases, fertilization is followed by a modification of the end of the flower-stalk, producing. a complex fruit, such as that of the apple, strawbery, blackberry, rose, pine, pineapple, Osage orange, etc. Fruits are usually classified with respect to their texture as (1) fleshy funits, including stone fruits, and (2) dry fruits, and, with respect to their behavior when ripe, as dehiscent or indehiscent. Meshy and stoue fruits are indehiscent; dry fruits may be dehiscent or indehiscent.

153. Fleshy fruits are characterized by a thickening aud softening of the wall of the ovary, by which it becomes juicy or fleshy. They comprise the berry, diupe, pepo, poule. and such multiple fruits as the fig and pineapple. In the herry, e.g.. the currant, grape, gooseberry, tomato, ete, the whole tissue of the 
ovary is soft. In the drupe or stone fruit, apricot, cherry, peach, etc., the outer part of the wall becomes fleshy, while the inner hardens into stony tissue. On the other hand, the pepo has developed a hard rind upon the outside, while the inside is pulpy. The pome of the apple and pear resembles a berry, but the flesh is the modified calyx, the pistil being represented by the papery core.

I54. Dry fruits are leaf-like, papery, membranous, or hard in texture. Indehiscent dry fruits, i.e., those that do not split open at maturity, are the achene, the nut, the samara, and the grain. The achene is a small seed-like fruit, such as is found in the buttercup, st rawberry, sunflower, thistle, dandelion, etc. The nut is a fruit which possesses a hard stony wall, such as is found in the acorn, hickory, and walnut. The samara is an indehiseent fruit provided with a wing, e.g., the ash, elm, and maple. A grain is an achene in which the wall of the ovary is completely fused with the seed, as in corn, wheat, and other grasses. Dehiscent dry fruits, or those that split open at maturity, comprise the utricle and the pod, the latter being subdivided into the follicle, legume, loment, capsule, silique, silicle, and pyxis. A utricle is an achene with a loose, dehiscent pericarp, such as is seen in the amaranth and goosefoot. All other fruits which split open at maturity are grouped under the general term pod. The follicle is a simple pistil which splits along the inner suture, e.g., columbine, larkspur, and milkweed. The legume is a follicle which opens along both sutures, thus splitting into valves, as in the bean, pea, vetch, etc. The legume is called a loment when divided into one-seeded joints that separate at maturity. The capsule is the pod of a compound pistil. The pod of the mustard family, or silique, is two-celled in consequence of a false partition which stretches between the valves. The silicle is a short, broad silique, such as that of the shepherd'spurse; while the pyxis opens circularly by means of a lid, e.g., the plantain and the purslane.

I55. Movements of fruits. The way in which fruits and seeds are scattered about is chiefly determined by the nature of the fruit, as will be shown in detail under Migration. Certain movements are also concerned in this to some degree. These so-called carpotropic movements result from the bending of peduncle or pedicel, by which the position of the fruit is changed, or from the growth of the peduncle, by means of which the flower cluster 
is raised. Changes of position are shown in Allium, Campanula, Chamanerium, etc., where the drooping or horizontal flower becomes erect after fertilization, largely owing to the action of grarity. The upright position appears to promote the ripening of the fruit

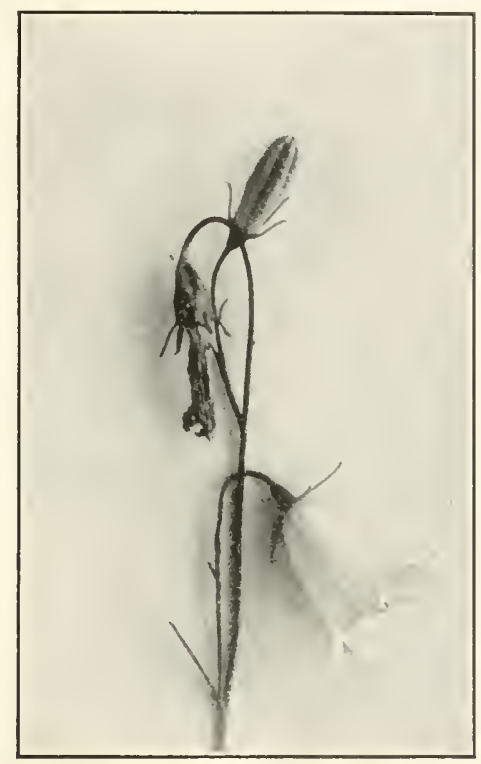

FIG. 37.-Inflorescence of the bluebell, Campanula petiolata, in which the bud is erect, while the flower and fruit are turned downward by the movement of the pedicel.

and to place the seeds in a more advantageous position for dissemination. The elongation of the scape in consequence of growth after flowering, such as occurs in the dandelion and other stemless composites, seems to be for the purpose of lifting the achenes above the surrounding plants, in order to increase the chances that they will be borne away by the wind.

Experiment 43. Kinds of fruits. Since relatively fow fruits mature in the spring, the study of the kinds oi fruits and their relation to migraltion should be made early in the antunn. The number of fruits at this time is very large, and the opportunities for observation unusually favorable. A field trip should be made through prairic and woodland in early fall, the various kinds of fruits noted, and the species grouped 
accordingly. This work may well be combined with the study of dissemination and migration indicated on a later page.

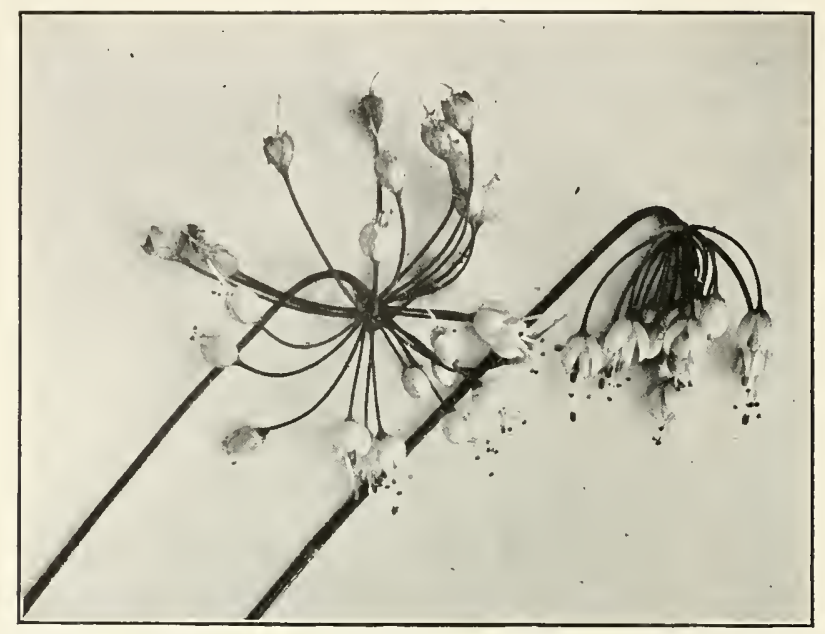

Fig. 38.-Umbels of a wild onion, Allium recurvatum. The buds and flowers droop, but the pedicels begin to curve upward after fertilization, and the capsules become erect.

Grow plants of Campanula rotundifolia or Chamcnerium angustifolium. Trace in detail the movements of flower and capsule, and sketch the characteristic positions. 


\section{CHAPTER VI}

\section{ADJUSTMENT TO GRAVITY, CONTACT, AND SHOCK}

I56. The relation of the plant to gravity. Gravity differs from all the factors previously considered in being constant and in affecting all plants essentially alike. Although it occurs in every habitat, exerting a profound control upon the relation of root, stem, leaves, and flowers, no essential differences between stemmed plants arise from its action. This is an immediate result of its constancy, and consequently under normal conditions gravity has no power to produce modification. In fact, the control exerted by it is stabilizing rather than modifying. The first terrestrial plants in all probability possessed flat thalloid bodies. Through the action of two opposite media, air and soil water, the thallus became differentiated, a change further emphasized by the different light intensity at the leaf and the root surface. Any tendency upon the part of the leaf surface to grow upward, or to become upright, tended to increase the light energy available, and the downward growth of the hair-like roots increased the water supply. Plants that thus became polarized were placed at a great advantage over the thalloid forms. They were doubtless the ancestors of the vascular plants. It does not seem probable that gravity played a considerable part in producing the polarity shown by stemmed plants. As this habit became more and more fixed, however, it necessarily acquired a constant relation to gravity. The roots grew downward in line with the pull exerted by it, while stems grew constantly in opposition to it. After countless generations, the relation has become so firmly established that the control exercised by gravity is much greater than that of light.

I57. Geotropism. The relations of plants to gravity are comprised in the term geotropism. The actual bending or turning of an organ in response to gravity is evident, only when the normal 
position is disturbed. Geotropism is equally characteristic of the normal position, since the latter is maintained only in consequence of it. Stems are negatively geotropic, i.e., they grow away from

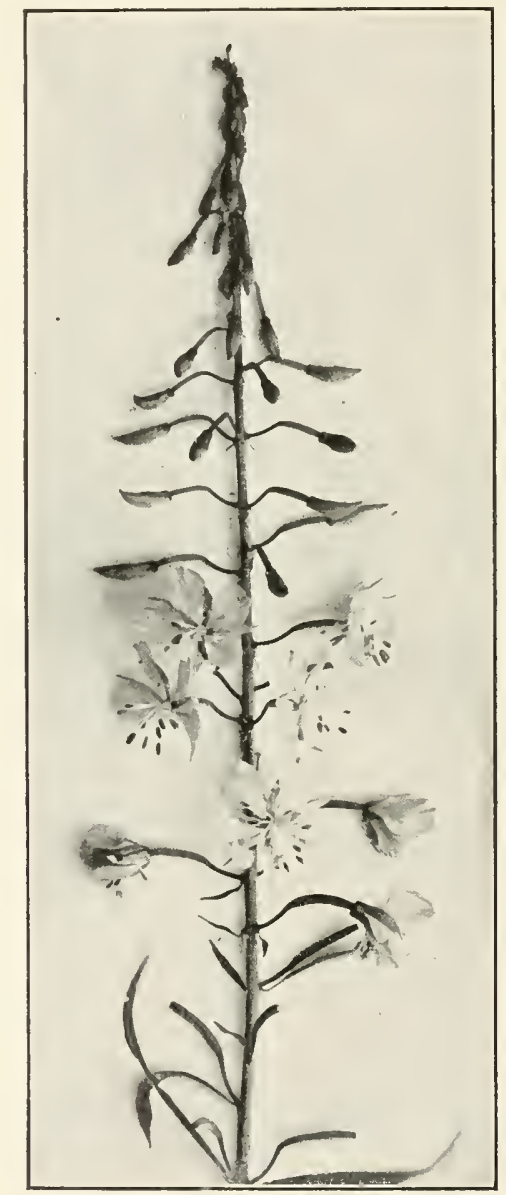

Fig. 39.-Inflorescence of the fireweed, Chamænerium angustifolium,showing the movements of the pedicels and the position of bud, flower, and fruit.

the attraction of gravity. Roots are positively geotropic, i.e., they grow in accordance with the pull of gravity. Leaves of the dorsiventral type place themselves more or less nearly at right angles to the stem and are hence termed diageotropic. In addition 
to maintaining this angle, leaves also tend to keep their surfaces horizontal. Flowers and fruits are sometimes diageotropic also. In certain species they change their relation to gravity, as is regularly the case in anthotropic and carpotropic movements. For example, the bud of Chamanerium angustifolium is positively geotropic, the flower diageotropic, and the fruit negatively geotropic. Branches of the stem and root are usually diageotropic, though they are capable of changing this relation in considerable measure.

158. Cause and reaction. The exact way in which the stimulus of gravity is perceived by the plant is not known with certainty.

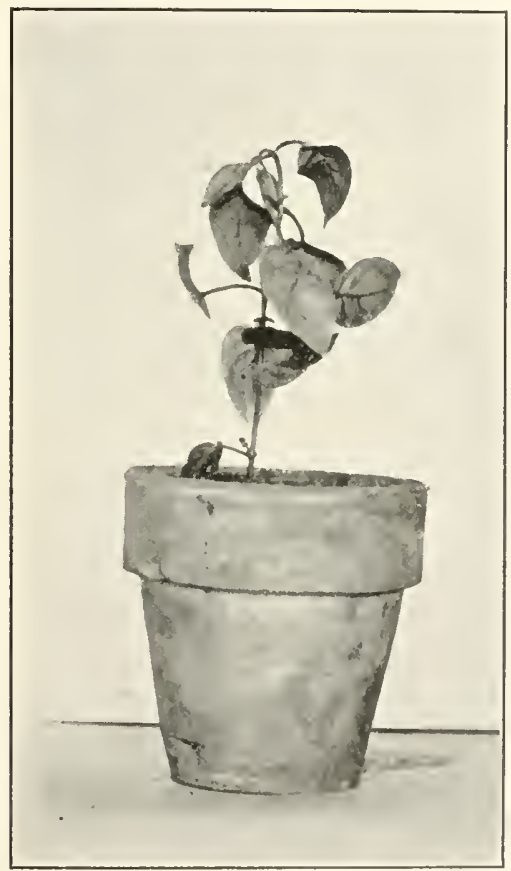

FIG. 40.-A young plant of Fuchsia sp., showing the effect upon leaf position when the control exerted by gravity is destroyed by growing the plant under the action of centrifugal force.

It has been suggested that the fall of starch grains or other inclusions to one side when the position of the plant is changed sets up a stimulus in the protoplasm, but this does not explain all cases of geotropism. It seems more proballe that protoplasm 
possesses a specific sensibility to gravity, just as it does to light. When a change in the position of the plant occurs, the normal relation of the cytoplasm to gravity is modified, and changes are set up in it that tend to restore the normal. The perception of the stimulus of gravity by the root and the stem takes place largely in the meristem of the tip. In the root the sensory zone is scarcely more than a millimeter wide, comprising the tip alone. This zone in the stem is less restricted, the entire meristem of the apex being sensitive. In addition, the cells of the cortical parenchyma, and sometimes those of the pith, are capable of perceiving the stimulus. In the case of leaves and flowers, it is probable that the power of perception resides in all the living cells.

The length of time for which a plant must be changed from its normal position before a response to gravity becomes evident is termed the reaction time. It is a curious
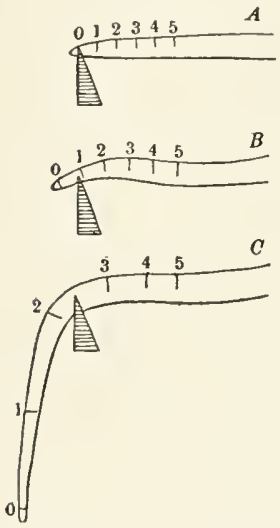

Fic. 41.-'l'he region of eurvature in the primary root of the horse-bean, Vicia faba. In $A$, the root was marked into five areas of $2 \mathrm{~mm}$. eaeh; $B$ shows the growth and eurvature at the end of two hours, and $C$, at the end of twenty-three hours. (After Sachs.) fact that only a part of this time is necessary for the perception of the stimulus. If a plant is put in a horizontal position for a quarter of an hour, and then placed upright, geotropic curvature will still occur. Consequently, reaction time consists of two periods, one necessary for perception, the other for reaction.

I59. Region of curvature. The geotropic curvature of the root is effected in a zone scarcely wider than the sensory zone and lying just behind it. The manner in which the stimulus is transmitted from the one to the other is unknown. The actual bending is due to the elongation of the cells upon the upper or converse side, and is accompanied by the compression of those upon the concave surface. The region of curvature in the stem is much more extensive than that of the root. The reason for this difference is apparently to be found in the fact that the major portion of the root is held firmly by the soil, while the stem is free to curve. The curvature of the stem is first apparent in the region of rapid growth just below the tip. It travels downward in such a manner that, as it ap- 
proaches the base, the tip is carried beyond the vertical. Finally, the tip swings back and is held in the normal position by the fixing of the curvature in the base of the stem. In leaves the region of curvature normally lies in the petiole, but if the leaf is reversed and held firmly in some part of the blade, the free area will attempt to twist into the normal position. In the case of flowers, curvature normally takes place in the peduncle.

I60. Ecological significance of geotropism. Apart from the fundamental action of gravity in maintaining the position and form of plants, geotropism is of great value to plants in remedying the effects of accidents due to wind, snow, animals, etc. In many trees, especially conifers, geotropism brings about the replacement of a broken or injured apex by one of the branches. Trees that have been blown down sometimes regain an upright position, in part at least, by means of geotropism, and they often convert the branches of one side into upright stems. Herbs that have been blown down by the wind or trampled by animals regularly regain an upright position, at least in the new growth. Inflorescences, flowers, and leaves that have been bent or caught in a mass of leaves and branches, turn and twist to resume their normal position. One not infrequently finds a stem hanging in such fashion that the usual relations of the flowers are exactly reversed, and in consequence the flowers, as well as the fruits, have curved about to take their normal position. Finally, geotropism is a powerful factor in the successful germination of seeds in nature by virtue of its action in carrying the radicle into the soil.

Experiment 44. Geotropism. Plant sunflower seeds in a pot, placing some flatwise, and others with either end downward. Cover the pot with a wire netting to hold the soil in position, and invert it upon a tripod, using a bell-glass to cover both. Explain the behavior of the seerllings, and note the relation of the curvature to the original position of the seed.

Transplant a sunflower seedling to each of six 2-inch pots. After they are well established, place one in darkness in a horizontal position, and one in the same position in light. For four suecessive mornings put one of the remaining pots in a similar position. In the ase of the last two pots, restore the last plant to its normal relation after a halfhour and note results. Remove the seedlings from the pot and sketch them in order, showing the position of stem and root. Compare with the plant grown in darkness Restore the last seedling to an upright 
position, and note the time that elapses before it reaches the perpendicular.

Select three plants of Chamenerium that are beginning to flower. Reverse a flower and leaf of one, fixing the base of the stalk so that the

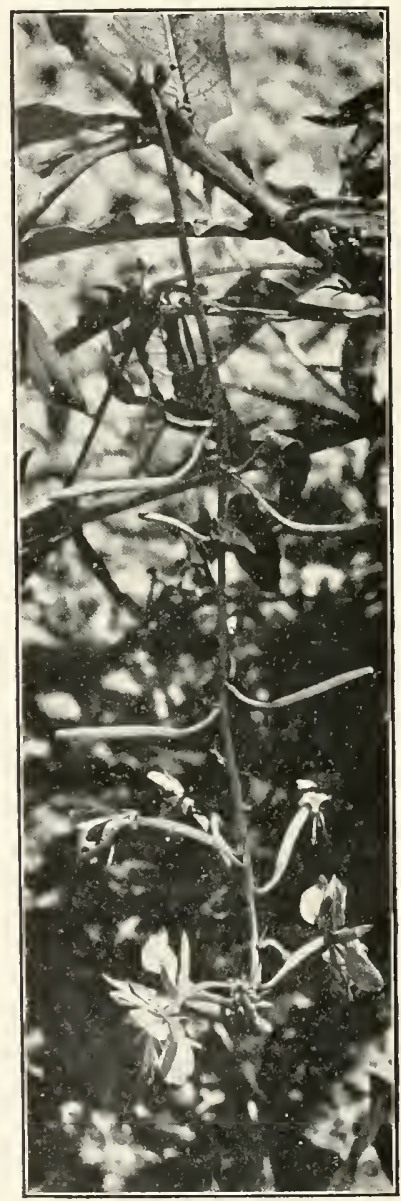

FIG. 42.-A flowering branch of the fireweed, Chamanerium angustifolium, accidentally broken and inverted. The pedicels are curving to place the flowers and fruits in the usual position.

blade and flower are free to turn. Turn the other plants upside down, placing one in darkness. Make sketches of the resulting changes, and explain them. 
I6 I. Response to contact. Many climbing plants have developed organs called tendrils, by means of which they cling to their supports. Tendrils are characteristic of climbers, Micrampelis, Sicyos, Vitis, etc., in contrast to the twiners, such as the bindweed, morning-glory, etc. Tendrils are specialized branches or leaf parts which have become especially sensitive to contact. Similar sensibility in a less degree seems likewise to occur in the stems of twining plants. The growing point of roots is also sensitive to contact, and is consequently enabled to pass a hard substance which lies in its path.

The sensory area of a tendril is usually restricted, though in a few cases it extends over the major portion of it. As a rule, the basal portion is scarcely or not at all sensitive, and the sensory area is confined to the concave side of the curved or hooked tip. A few tendrils respond to contact upon any side, while other's respond only to lateral contact, in addition to that upon the lower side. Generally speaking, they are not sensitive when either very young or very old, but react only while they are growing and showing circumnutation, i.e., the constant movement of the tip in a circular manner. The value of circumnutation in bringing the tip in contact with a possible support is evident. When the sensory area is brought into contact with a stimulus of the proper kind, the tip begins to curve. The curving may begin in less than a minute after the contact, or several hours may elapse before it becomes evident. Sensitive tendrils respond to a momentary slight touch, but for the majority a stronger stimulus is necessary. The size and surface of the support have much to do with the presence and nature of the response.

In certain plants the stimulus affects only the point of contact, but in the majority of cases it is also transmitted, and results in the spiral coiling so characteristic of many tendrils. This reaction usually begins near the sensitive tip and travels toward the base. Its advantage is evident in that it lifts the stem and serves to hold it firmly, but not so rigidly that it may be easily torn away. The curvature which produces attachment as well as the spiral coil is the result of unequal growth. The cells of the sensory sicle either do not elongate at all after contact, or they do so more slowly than the cells of the opposite side. The coil becomes fixed in consequence of the development of the tissues into a more permanent form. 
Experiment 45. The behavior of tendrils. Experiment with the tendrils of Cucurbita or Micrampelis to determine the sensory zone as well as the period during which the tendril is sensitive. Find the length of time necessary for contact to produce curvature in the tip, and for the transmission of the stimulus as shown by the formation of the coil. Note the behavior of tendrils that fail to reach a support, and of recently formed coils from which the support is removed. Sketch a tendril in various stages. Ascertain by sectioning the behavior of the cells on the convex and concave surfaces.

162. Response to shock. While all protoplasm possesses in some degree the power of response to mechanical shock, this reaction is readily seen only in moring or streaming protoplasm, and in certain specialized organs or plants, such as the stamens of some cacti, and the leaves and stems of sensitive plants. The best illustration of response to shock is afforded by the common sensitive plant, Mimosa pudica. The normal reaction consists of the folding of the leaflets and the drooping of the whole leaf at the point of union between petiole and stem. A slight shock merely causes the leaflets to close, and it is quite possible to touch the leaves so lightly that it does not constitute a stimulus. At least, no visible reaction takes place. The vigor of the plant also has much to do with the response. The healthy leaves of plants that had at one time been subjected to drouth and cold responded but feebly to heavy blows, merely moving the leaflets slightly, while those of a normal plant reacted fully to a gentle touch.

The perception of shock by the sensitive plant is scarcely if at all localized. Nearly all the epidermal cells of stem and leaf have the power of perception, except certain cells of the base of the petiole, i.e., the pulvinus. When the leaf or stem is struck vigorously, the stimulus probably acts directly upon the pulvinus, the leaflets folding, and the petiole drooping almost at once. The perceptive power of any leaflet may be readily shown by striking it gently. The impulse travels down the axis, closing the leaflets as it goes, until it reaches the pulvinus, when the whole leaf droops. The manner in which the stimulus is transmitted is not certainly known. It is supposed to take place through rows of turgid tubular cells, which lie near the bundles, by means of disturbances in the cell-sap.

The movements of leaflets and leaves are due to changes in the pulvinus, a mass of swollen tissue at the base of the petioles 
of leaflet and leaf. The pulvinus consists chiefly of turgid parenchyma, surrounding a fibrovascular bundle sheathed in collenchyma. In consequence of a stimulus, the protoplasm of the cells upon the lower side of the leaf pulvinus contracts, forcing a small amount of cell-sap out into the air spaces. This destroys the turgidity of the lower cortex, and at the same time shortens the cells. This releases the tension upon the cells of the upper side, and allows them to expand, thus causing the leaf to bend downwards. This action is emphasized by the pull of the leaf itself. In the pulvini of the leaflets, the contraction must occur upon the upper side, allowing the lower cortex to expand, and to raise the leaflets in direct opposition to gravity. After a response, the contractile cells gradually absorb the excreted water and regain their turgidity, thus restoring leaf and leaflets to their normal position.

Experiment 46. Response to shock. Grow several plants of Mimosa. Make various experiments to ascertain what regions are sensitive, as weil as the strength of stimulus necessary to produce a response. Strike the end leaflets of two leaves at the same time, one forcibly, the other gently, and note the time necessary for the transmission of the impulse to the pulvinus of each leaf. Note when leaves regain the normal position, the effect of repeated blows upon a leaf that has reacted, and how long a time it requires to resume its normal condition. 


\section{CHAPTER VII}

\section{ADAPTATION TO WATER}

\section{$\rightarrow$ I63. The relation of structures to water. The functional}

responses of the plant to water content and humidity may produce modification of form, of structure, or of both. This may take place in root, stem, or leaf, or, under intense conditions, may occur in all of these. Modification is greatest in the leaf as the organ of greatest activity, and of greatest exposure of surface to the changing factors in the air. It operates upon the stem in the degree that the latter carries on the functions of a leaf. The root is changed least, owing to the greater uniformity of conditions in the soil, as well as to its fewer activities. Under extreme conditions, either organ may be lost. As would be expected, the root is frequently lost when it is no longer needed for absorption, and the leaf when the water supply is reduced to a minimum.

I64. Adaptation to a small water supply. A low water supply threatens the functions of the plant, and consequently its growth and existence, whenever the water loss is increased. The effect of a deficiency in the supply must be met by changes in structure which decrease the demand arising from water loss, or by those that increase tr supply by adding to the absorption or storage rapacity of the root. These changes affect the form and size of the various organs as well as their structure. Modification in the form and size of leaf or stem lessens transpiration by reducing the amount of surface exposed to the air. Changes of structure, on the other hand, bring about the protection of epidermal cells and stomata, as well as the internal tissues, from the factors that promote transpiration. They also forestall the effects of excessive water loss by storing water in specialized cells or tissues against periods of low humidity. In a few extreme cases the epidermis may be modified for absorbing water rapor from the air. 
The modifications of the plant which serve to decrease water loss may be grouped under the following hears: (1) position of the leaf; (2) rolling of the leaf; (3) reduction of the leaf or stem surface; (4) epiclermal modifications, $(a)$ of epictermal cells, (b) of stomata; (5) changes in the chlorenchym.

165. Decrease of water loss through leaf position. Horizontal leaves, as a rule, transpire more than those which take a vertical or oblique position. Since the light energy is greatest when the sun is highest, those leaves transpire least which make the smallest angle with the rays of the sun during the middle of the day. A leaf at right angles to the rays of the sun receives almost ten times as much light and heat upon the same surface as one placed

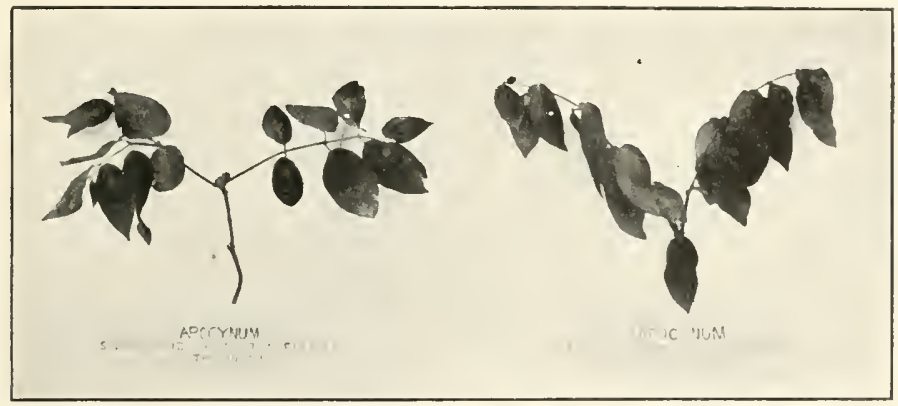

FIG. 43.-Plants of the dogbane, A pocynum androsamifolium. The horizontal position of the leaves at night or early morning changes toward midday to the vertical, thus protecting the leaves from the direet rays of the sun as well as from the strong radiation from the gravel soil.

at an angle of $10^{\circ}$. Reduction of water loss by means of the vertical or oblique position of the leaves is a frequent occurrence in the erect or hanging leaves of many tropical trees. A similar means is found in "compass plants," such as Sil pulum laciniatum, Lactuca scariola, ete., and in all species with more or less erect, hanging, or equitant leaves. The effect, however, is just opposite in the sunflower and other heliotropic species, since the turning of the crown tencls to maintain a position at right angles to the rays. In the case of plants that grow in mats, the agdregation of stems brings about the mutual protection of the leaves. In adrlition, mats often have erect or oblique leaves.

166. Decrease through the rolling of the leaf. In a laren number of plants, the amount of leaf surface exposed to dry air is reduced hy the rolling or folling of the leaf. Rolling occurs in many 
plants merely as a temporary compensation. Water loss takes place more rapidly, as a rule, from the surface bearing the larger number of stomata. In consequence, the edges are usually rolled up with the lower side inward, chiefly by reason of the greater turgidity of the upper. The furrowed leaves of monocotyledons, especially the grasses, are well adapted to changes of this nature. The leaves of many grasses and heath plants are permanently

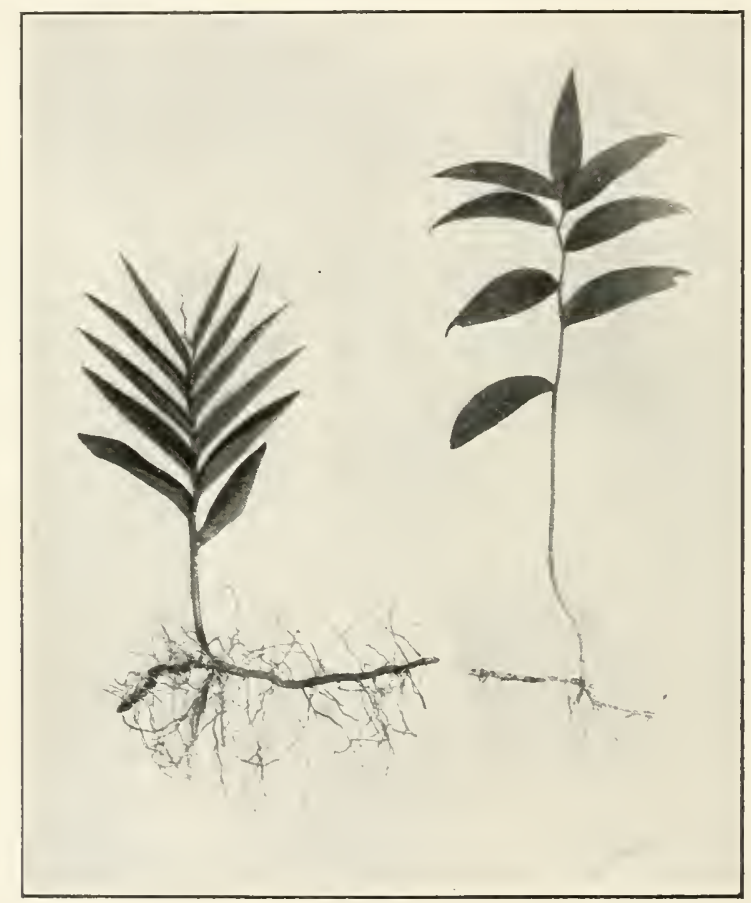

FIG. 44.--Sun and shade forms of Wagnera stellata. The leaves of the sun form are folded or rolled together, while the shade leaves are flat.

rolled or folded. In these the protection against drouth is very effective. It arises not only from the reduction of surface, but also from the fact that the stomata lie in a chamber that is permanently and more or less completely closed. Many mosses roll and twist their leaves when threatened by drouth, but in these the rolling merely reduces the leaf surface exposed.

167. Reduction of leaf or stem. Plants reduce their surface, and thereby the amount of transpiration, by decreasing the number 
of leares, by reducing the size of each leaf, or by a change in its form. Among herbaceous plants, a decrease in the size or a change in the shape of the stem brings about a similar result. In extreme cases of reduction, the leaves are completely lost, and in some instances the same fate overtakes the stem. Such a marked decrease in the amount of surface exposed is found only in intense xerophytes, though it occurs in all deciduous trees and shrubs as a temporary adaptation. Changes in leaf form regularly produce a decrease of surface. The scale, the linear or cylindrical leaf, and the succulent leaf are the most striking examples of reduced leaf forms. Lobed or divided leaves usually show a tendency to reduce the size of the lobes or divisions when they are grown under drier conditions.

I68. Changes of the epidermal cells. The cells of the epidermis are protected against evaporation by a coating of wax or other

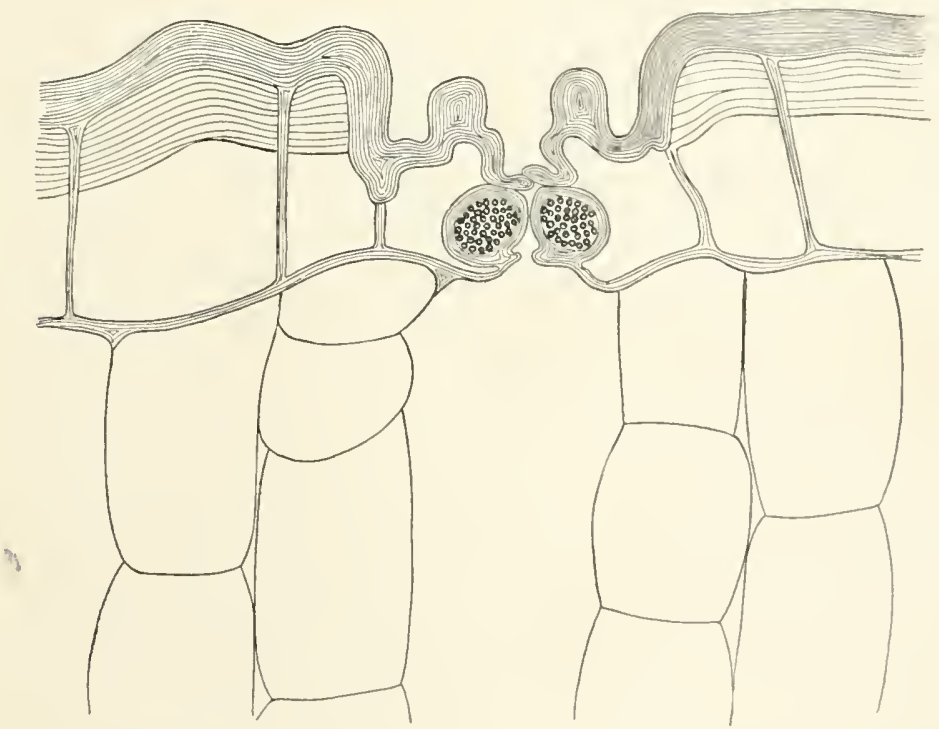

Fig. 45.-Portion of a cross-section of a leaf of the century-plant, lgate americana. 'The outer wall of the epiderm is modified to form a very thick euticle, and the stomatia are smomen helow the surface.

material, by means of a thickened outer wall or cuticle, or by the development of hairs. The first two sometimes oc'ur upon the same leaf, but the formation of a hairy covering is ustrally preclucled 
by the presence of either of these. It often occurs, however, on the lower side of a leaf that is cutinized above. Excretions of wax or of salts render the epidermis highly impermeable, and correspondingly reduce the loss of water through the epidermal cells. The thickening of the outer wall of the epidermis to form a cuticle is the most perfect of all devices for decreasing permeability, and thus reducing transpiration. In many desert plants the greatly thickened cuticle completely prevents all transpiration except that which occurs through the stomata. In these the cuticle is also regularly developed in such a way as to protect the guard-cells. Some species have an epidermis that comprises two or more layers of cells. While this is an effective protection against water loss, it is not frequent.

A coating of hairs decreases transpiration by screening the epidermis so that the amount of light and heat is diminished, and the access and movement of dry air impeded. A few scattered hairs are of little or no value for this purpose, but a uniform compact layer is of the greatest service, since it protects the stomatal openings as well as the epidermal cells. Hairs are of the most various sizes and forms, but all hairy coverings serve the same purpose, even when they are primarily for water storage, as in a few plants. The fact that hairs protect the stomata as well as the epidermal cells explains the occurrence of a hairy covering on the lower surface, even when it is absent from the more exposed upper side. In some cases, hairs are developed only to serve as screens to the stomata.

169. Modifications of the stomata. Since the great bulk of the water lost under ordinary conditions passes through the stomata, the changes of the latter are of the utmost importance in reducing transpiration. Their modifications for this purpose are many, but practically all of them are concerned with number or position. Species growing in dry places have fewer stomata to the same leaf area than those in moist habitats. The number on both surfaces decreases as the danger of excessive water loss increases. The decrease is usually more rapid upon the upper surface, which finally loses its stomata entirely. Stomata are usually more numerous on the less exposed or lower surface of the leaf. Exceptions occur in many shade plants where the exposure of the two surfaces is equal, and in aquatic plants, in which water loss is beneficial instead of harmful. The change in the number of 
stomata is well illustrated by Ranunculus sceleratus, a species of wet places, in which the stomata are more abundant upon the upper surface. Plants grown in water with the leaves floating, and in soils containing $40 \%, 30 \%, 15 \%$, and $10 \%$ of water, showed respectively the following results with respect to the stomata of the two surfaces: upper 20 , lower 0 ; upper 18 , lower 11 ; upper 11 , lower 8 ; upper 10 , lower 6 .

Reduction in the number of stomata gives sufficient protection only under moderate conditions of dryness. Where dryness is intense, the guard-cells are usually found sunken below the epidermis, either singly or in groups. Sunken stomata are generally

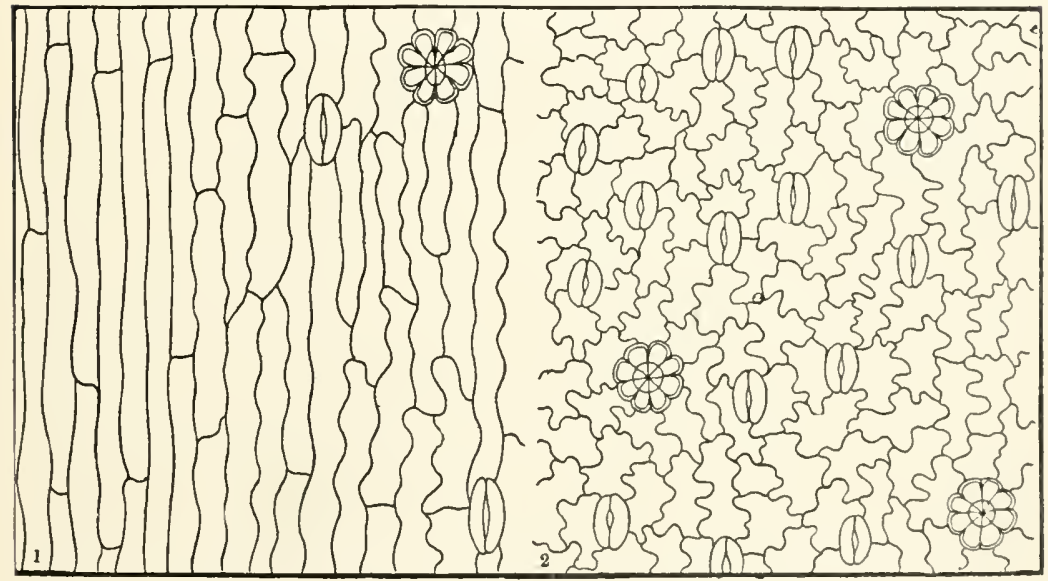

Fig. 46.- Upper epiderm of a submerged (1) and an aerial leaf (2) of a plant of Callitriche bifila, showing the decrease in the number of stomata.

found at the bottom of chimney-like openings, which are sometimes almost completely closed above. When the stomata are sunken in groups, the carities are commonly filled with protective hairs, or closed by them. In both eases the protection is very effective. The guard-cells are screened from the intense action of light and heat, and from the dry air. The rays of the sun can enter the chimney-shaped chambers only for a few minutes each day, and are practically exchuded from the stomatal hollows, which are filled with hairs. The influence of dry winds is likewise almost wholly eliminated. This is true in a less degree for stomat a which are arranged in furrows protected by intervening ridges. The cuticle often forms valve-like projections upon the gruart-cells 
or above them, which serve to reduce the size of the opening. In some cases, moreover, the size of the pore formed by the two guard-cells is permanently reduced. In a few plants the effect of intense drouth is almost completely prevented by closing the pore by means of a waxy excretion.

I70. Changes in the chlorenchym. The rapidity with which water escapes from the tissue of the leaf is largely determined by the size and number of the air passages. Water-laden air reaches the stomata most easily when the air spaces are large and continuous, and least readily when they are small and scattered. Consequently, leaves exposed to the danger of excessive water

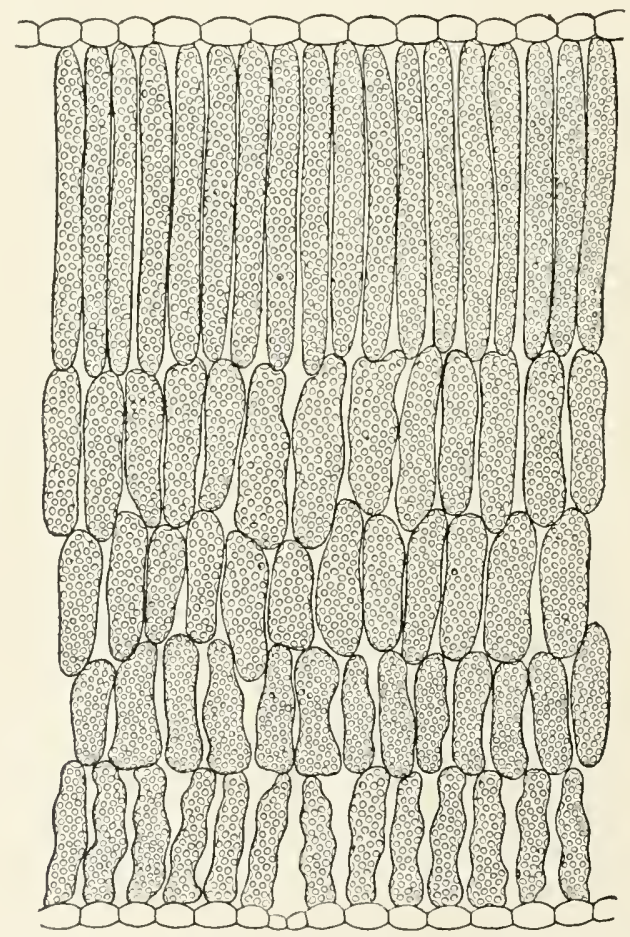

FIG. 47.-Leaf of a plains species, Bahia dissecta, in which the chlorenchym consists entirely of palisade tissue.

loss usually have the size of the air spaces reduced, and especially the size of the passages that connect them with the pores of the stomata. An increase of palisade tissue reduces many of the air 
spaces to mere lines, and thereby greatly decreases the amount of transpiration. The conversion of sponge tissue into palisade tissue further diminishes water loss by placing the chloroplasts in such a position that they mutually shield each other, and thus reduce the transpiration caused by light. The development of layers or masses of stone fibers, or sclereids, beneath the epiclermis, though primarily for support, likewise hinders the escape of moisture. Such modifications are frequent in needle leares, especially those of evergreen trees, pines, spruces; etc. The cell-sap sometimes plays an important part, by holding water in cells which have a high salt content, or contain more or less mucilage.

I7 I. Increase and storage of water supply. The amount of water supplied to the leaves by the roots can be increased only by increasing the area of the absorbing surface, or by changing its location. The production of more root hairs, accompanied by the growth and branching of the roots, is the usual response of plants to moderate drouth. Plants of dry habitats ine rease their absorption by extending the absorbing surfaces of the root into the deeper portions of the soil, as well as by their branching within this area. Water loss from the root surfaces in contact with the dry upper soil is prevented by means of a well-developed cortex. For these reasons xerophytes are often characterized by the possession of tap roots. Some plants, chiefly epiphytes, ahsorb rain water and dew by means of their leaves. A few desert plants seem able to condense the moisture of the air by means of hygroscopic salts, or in other ways, and to absorb it through the epidermis of the leaf. For all plants with roots, however, the amount of absorption by stem or leaf is inconsiderable, and can play no important part in increasing water supply.

There is a limit to the increase of water supply by the extension of the root surface. In consequence, many xerophytes hare developed structures for storing water. Modifications for water storage are occasionally found in roots and stems, such as those of many fleshy plants. Storage devices oceur chiefly in the leares. where they are of great importance. They increase the water supply by storing the surplus of absorbed water against a time of need. Noreover, they of ten retain the stored water with great tonacity, and thus tend to offset the pull exerted loy exaporation. The epidermis is frequently modified to form reservoirs for watcr. 
These may consist of the epidermal cells proper, of layers of water cells just below the epidermis, or of swollen cells found upon its surface. Cells of the chlorenchym are often transformed into large clear water cells, which may be scattered singly or arranged in groups. The groups of water cells are sometimes scattered, but they usually occur in transverse bands, or in horizontal layers. Such layers lie between the palisade and sponge tissues, and connect the bundles. A few plants possess tracheid-like cells which serve to store water. In the case of succulent leaves, practically the whole chlorenchym is used for storing water. Such leaves retain their water tenaciously by virtue of mucilage or other substances.

I72. Adaptation to excessive water supply. Plants which grow in water but have their leaves exposed undergo changes

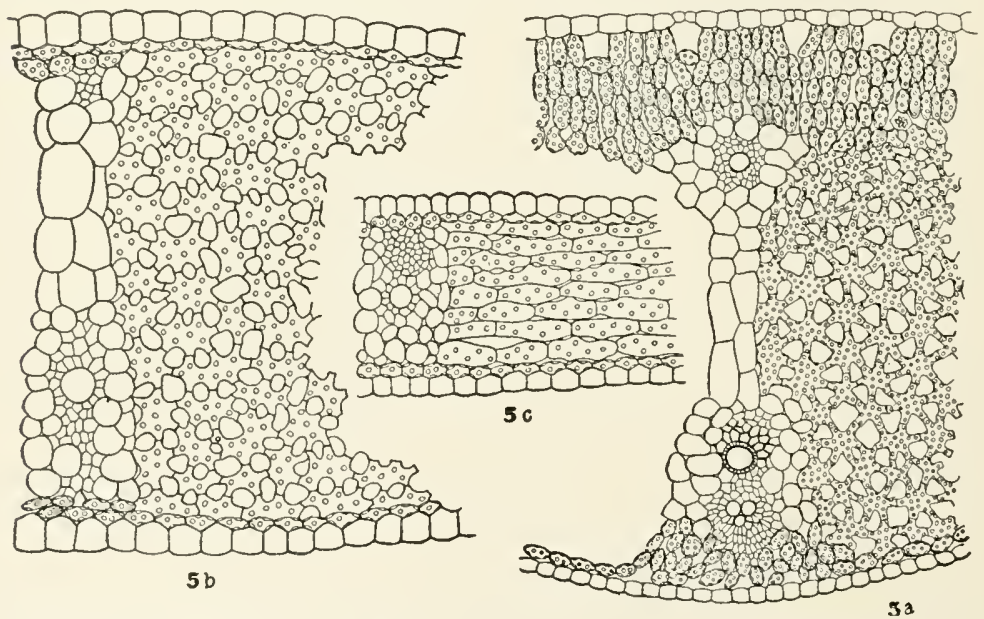

Fig. 48.-Cross-sections of floating ( $5 a)$, submerged ( $5 b)$, and deeply submerged leaves (5c) of Sparganium angustifolium. The palisade tissue of the floating leaf is replaced by a single row of sponge cells in the submerged one and the air-passages correspondingly increased. The deeply submerged leaf lacks palisade tissue and the air-passages are much reduced.

that increase the water loss and decrease the water supply. The absorbing surface is much reduced by the uniform lack of root hairs, and the relatively small development of roots. In a few extreme cases the roots become mere vestiges or are entirely wanting. The leaves of water plants show a marked tendency to increase the exposed surface. This is clearly shown by the 
experiments with Ranunculus sceleratus, in which the latter was grown under varying conditions of water content. The leares of the mud and floating forms were found to be larger than those of the drier soils, but they had changed little or not at all in thickness. The lobing of the leaves was also found to be reduced, or the lobes often came to overlap. Water plants rarely show any modifications of epidermis or stomata, which could serve to hinder transpiration. Stomata are usually more numerous upon the upper surface, where they are completely exposed. In the same species their number is greater in the forms grown in wet places. The air spaces are extremely large, and, in connection with the abundant stomata, permit of very rapid transpiration. The increase in the amount of air space is accompanied by a reduction of palisade tissue, and a decided increase in the sponge tissue. The result is to expose the chloroplasts more completely to the sunlight, and to augment the consequent loss of water. The complete absence of storage tissues is a further indication that the leaves of water plants are adapted to promote water loss.

Experiment 47. Experimental adaptation to water. The most satisfactory plants for experiments in adaptation are found in plastic species, such as Ranunculus sceleratus, and the so-called heterophyllous ones, e.g., Ranunculus delphinifolius, Roripa americana, ete. These are amphibious, i.e., capable of growing in water or on land, and are consequently able to undergo adaptation in both directions. Seeds of these plants may be collected in the field, or the plants may be transferred to the greenhouse and allowed to mature there. Ranunculus sceleratus is especially suited to work of this sort, since it grows and reproduces with the greatest readiness in the plant house.

The seeds are germinated under the usual conditions beneath ghass or sphagnum. After the plantlets have developed four or five leaves, thirty or forty are transplanted into 2 -inch pots. The transfer to 4 -inch pots is made about the time the leaves reach ten or twetre in number. The plants are still kept under miform conditions for a few days until they are well established. They are then subjected to different eonditions, ranging from soil as dry as possible for growth to submeryence beneath the water. Four pots are watered in such amount that the plants are just able to make a slight growth. The proper amount "an only be found by trial: it is usually from $25-50 \mathrm{cc}$. per day. A second series is watered with twice this amount, approximately $100 \mathrm{ce}$. and a third one with $200 \mathrm{ee}$. for each plant. The fourth series is grown in mud covered with a thin layer of water, and the fifth in water, the level 
of which is raised from time to time so that the leares are kept floating. These two series are handled most conveniently if the plants are grown in a deep tub or a half-barrel. The last series should be grown in a large barrel or in a deep box, one side of which is replaced by glass. Six inches of soil are placed in the bottom and a faucet is inserted in the side just above the soil. This is to aid in the aeration of the water from time to time, as well as to make it possible to draw it off readily in case it becomes stagnant. The water level is kept just above the leaves as they stretch up. In case the leaves begin to turn yellow, they are allowed to float on the surface until they regain the normal color.

All the series should be grown in the same house where heat, light, humidity, etc., are the same. In this event all the modifications obtained can be referred with certainty to water content as the cause. In the three series, mud, floating, and submerged, the soil is saturated and it is unnecessary to measure the water content. The latter should be determined several times during the course of the experiment for the three series in soil. The growth and the behavior of the plants of the various series should be carefully followed and compared throughout the experiment. In connection with growth, it is sometimes desirable to compare the soil temperatures with those of the water. When the instrument is accessible, a water photometer should be used to determine the light intensity for submerged leaves, and for the under side of floating ones.

As the plants come into full flower, an individual from each series should be carefully sketched, or photographed, to a fixed scale showing the branching of roots and stem, leaf and flower production, etc. A typical leaf should be drawn in like manner, and its area and thickness carefully determined. The relative water loss should be determined by placing a leaf from each series in a vial of water in the manner already employed in a previous experiment. If the number of leaves on each plant is counted, this will make it possible to approximate the evaporation for the whole plant. Careful counts of stomata should be niade for both surfaces of a representative leaf of each series, the actual transpiring surfaces, i.e., the air spaces, estimated, and a table of comparisons made. Finally, microtome sections should be made of similar leares and a segment of each sketched in the proper sequence to show differences of thickness, structure, etc.

I73. Types of plant body. The plant regularly bears the impress of its habitat in the form or structure of some or all of its organs. This impress is usually recognizable at a glance, and can be referred at once to water or light stimuli. Since it is the product of the present habitat, the plant which bears it is called 
a habitat-form, or eead. Thus, there are water ecads, and light ecads, i.e., plants whose character has been determined by adaptation to water, or to light. The same species may show sereral ecads, in case it grows in habitats sufficiently different, a fact well illustrated by the various forms of Ranunculus sceleratus. In addition to the impress which a species owes to the water or light of its habitat, it possesses other characteristic features, which can be referred only indirectly or not at all to these. Such are the forms termed trees, shrubs, grasses, etc. These are characteristic of great areas of vegetation, and are hence termed vegetation forms or phyads. The causes that produce them lie hidden in the history of each species, and at present they can only be grouped with respect to form.

I74. Types produced by adaptation to water. Plants which grow habitually where the water supply is low show one or more of the characteristic modifications due to the latter. They are consequently termed dry-land plants or xerophytes. Those found in habitats with an excessive water supply show corresponding modifications, and are ealled water plants or hydrophytes. Nerophytes and hydrophytes represent more or less extreme conditions of habitat and structure. Habitats which are neither dry nor wet produce plants intermediate between these two types. Such intermediate plants, or mesophytes, show no characteristic modifications. As a rule, definite structures for increasing water supply or decreasing water loss are either slightly developed or completely absent. As would be expected, certain mesophytes approach the xerophytes, while others are more or less hydrophytic in nature. The plants of forests, meadows, prairies, and cultivated fields are usually mesophytes. Those of high prairies, tablelands. plains, sandhills, deserts, alpine peaks, ete., are xerophytes, and the dwellers in wet meadows, swamps, ponds, streams, and of her bodies of water are hydrophytes. Generally speaking. xcrophytes grow in dry soils, mesophytes in moist soils, and hydrophytes in wet soil or in water. Partly on account of the influence of hmmidity. and partly because many habitats shade very gradually into each other, it is impossible to establish an absolute correspondence between each group and the water content. Jerophytescommonly grow in soils whose holard is less than $15 \%$, and with a rhresind of $5-10 \%$, while hydrophytes grow in saturated soils or in watrr. Sands and gravels are saturated at about $20 \%$, and hence rontain 
hydrophytes at a percentage which in a finer soil suffices only for mesophytes. This is largely due to differences in the amount of available water. Such differences serve also to explain the apparent lack of correspondence in alkaline soils, etc.

175. General features of xerophytes. Most xerophytes possess a deep-seated root system, which is able to draw water from the lower moist soil, and to conserve it from loss in the dry upper layers. Reservoirs for water storage are rarely developed in the root. The stem usually shows modifications more or less similar to those of the leaf. The stem is often reduced and sometimes disappears, though not all stemless plants are xerophytes. The stem is most modified as a rule when the leaves are greatly reduced or absent.

The organ which is most strikingly modified in xerophytes is the leaf. This exhibits a large number of variations in size, form, texture, and structure. Several of these are often combined in the same leaf, though as a rule one alone is characteristic. The most satisfactory grouping of xerophytes is upon the basis of the leaf, since it is the organ most directly affected. Hence, those plants on which the leaves are present and properly modified may be termed leaf xerophytes, and those in which the stem has been modified in the absence of the leaves, stem xerophytes. Various groups of xerophytes have also been distinguished with respect to certain factors which reduce the water supply. Thus, species of saline and alkaline soils have been termed halophytes or salt plants, those of aretic habitats, polar xerophytes, and those of many bogs and swamps, bog xerophytes. The latter are probably not xerophytes at all, while the other two show no essential differences from the ordinary types. They are due to the lack of available water, and exhibit most of the common xerophytic modifications.

176. Types of leaf xerophytes. In these, adaptation has acted primarily upon the leaf, while the stem has remained normal, or has changed but slightly in most instances. In some cases the leaves have been reduced to seales, but even then they persist. throughout the growing season, and continue to take the primary part in photosynthesis. Leaf xerophytes may be arranged in groups based upon the form of the leaf or its structure. Since the same leaf sometimes shows two or more structural modifications, a grouping with respect to form is the most satisfactory. The 
following types may be distinguished: (1) the normal form; (2) the succulent form; (3) the dissected form; (4) the grass form; (5) the needle form; (6) the roll form; (7) the scale form. In many of these, subgroups based upon the structural protection, viz., cuticle, hairs, and water cells, may be recognized.

I77. Normal leaf xerophytes. The leaf is normal in size and shape, and of the usual dorsiventral character. The necessary decrease in transpiration is brought about by structural modifications, rather than by a reduction in size. Three well-defined subtypes may be recognized with respect to the structure used to

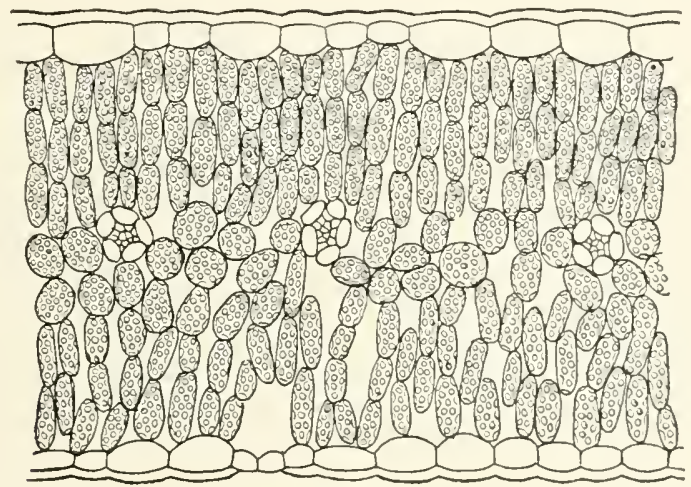

Fig. 49.-A normal leaf xerophyte, Arabis fendleri, in which water loss is decreased by a cuticle, and the conversion of the sponge tissue into a loose palisade tissue.

secure protection. These are the cutinized, the lanate, and the storage leaf. The cutinized leaf compensates for a low water content by thickening the outer wall of the epidermis and rendering it impervious by the addition of cutin. The cuticle thus formed sometimes becomes very thick, filling half or more of the cell cavity. It is usually thicker upon the upper surface of horizontal leaves, but is more uniformly developed upon upright or oblique ones. The cuticle is often reinforced by a marked (levelopment of palisade tissue. Cutinized leaves are usually leathery in texture; and in addition, they are often evergreen. Practically all xerophytes with smooth leaves of the normal form belong here, though many of them have storage cells as well. Ciool examples of this type are found in the hearberry, Arctostaphylus und-ursi, in species of Allionia, P'entstemon, ete. 
I78. Storage leaves are distinguished by the water storage cells, or tissue developed in the chlorenchym. They usually show a welldeveloped cuticle, with several rows of palisade tissue, and may consequently be regarded as a special modification of the cutinized leaf. The storage cells maintain a reserve supply of water, which
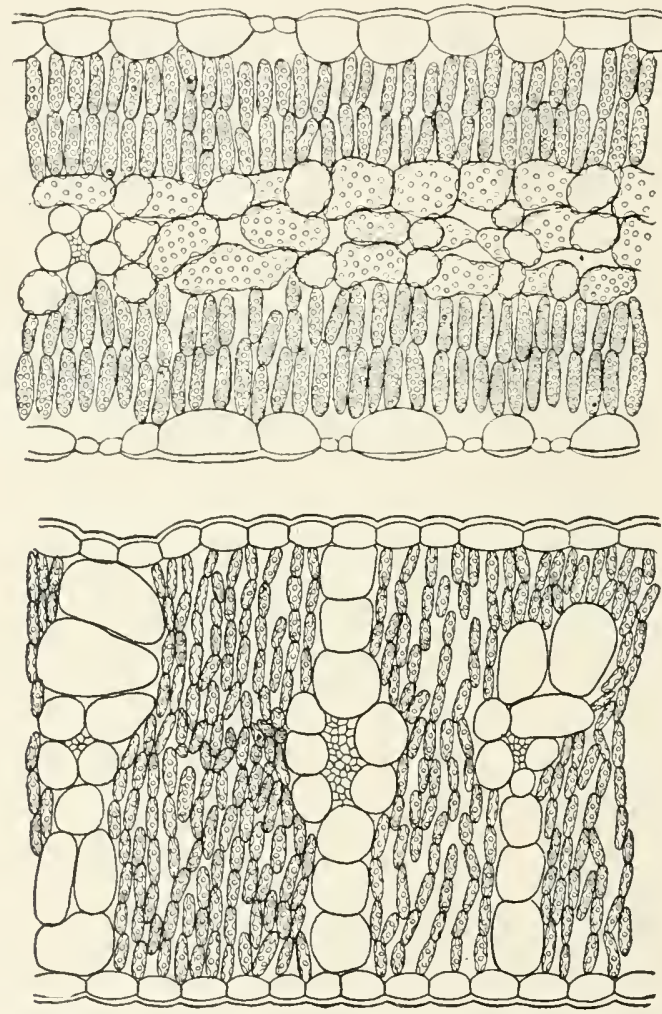

FIG. 50.-Cross-section of the two types of storage leaves. The storage layers are transverse in Mertensia linearis, and vertical in Grindelia squarrosa.

is slowly yielded to the other cells in time of extreme drouth. They differ from the cells of palisade or sponge in size and shape, but their origin from these is indicated by the fact that in some species chloroplasts are still present, though reduced in number. Water cells usually occur in plates or layers, which may be at right angles to the surface of the leaf or parallel with it. Xerophytic species of Mertensia, Erigeron, etc., illustrate the more fre- 
quent arrangement in which the water tissue forms horizontal layers, while certain species of Helianthus, Grindelia, Psoralea, etc., have this tissue disposed in transverse bundles or rows.

I79. Lanate leaves are those with dense hairy coverings upon one or both surfaces. The form of the hairs varies widely in different species, from short, often glandular ones to those that are repeatedly branched or curved in various ways. An epidermis covered with a dense layer of hairs regularly lacks a cuticle. Moreover, the protection against water loss is so perfect that the chlorenchym often assumes the loose structure found in shade leaves. A very large number of plants, e.g., Antennaria, Artemisia, Tetraneuris, etc., obtain their protection against drouth by means of hairs. In a few cases, the latter are confined to the upper surface, but as a rule they are nearly or quite as abundant upon the lower surface also.

Experiment 48. Study of normal leaf xerophytes. Cut crosssections, preferably by means of the microtome, of the three types of the normal leaf. Make a careful drawing of a segment across each, and in addition outline the entire leaf. Compare the three types critically, especially with respect to the various protective devices. This comparison is most striking when the three species concerned can be found in the same habitat.

I80. Other leaf xerophytes. Species that have lost the normal form of the leaf in response to dryness have often found it also necessary to employ additional protection. Consequently, they may show a thick cuticle, a hairy covering, or storage tissue. In all of the following types, reduction of the leaf surface is the characteristic feature, though this result may be arriver at in various ways, e.g., by thickening the leaf, by lobing, by rolling, cte.

1. The succulent form. Many succulent leaves are normal in shape and size, though they are always thicker than orlinary leaves. Usually, however, they are reduced in size, and more or less eylindrical in form. The necessary decrease in transpiration is secured by reducing the surface, and by storing water uniformly throughout the leaf. The latter is usually covered with a waxy coating, and often possesses a very thick cuticle. The character of the leaf arises from its unusual ability to store water, which forms the chief protection of the plant. The stored water is lick very firmly in opposition to the pull of evaporation. This property 
is doubtless due to the protoplasm in part, but it arises chiefly from a dense or mucilaginous cell-sap. Common examples of leaf succulents are the century plant, Agave, the ice-plant, Mesembryanthemum, and the stone-crop, Sedum, Senecio, etc.

2. The dissceted form. In these the reduction of surface is brought about by the division of the leaf blade into narrow linear

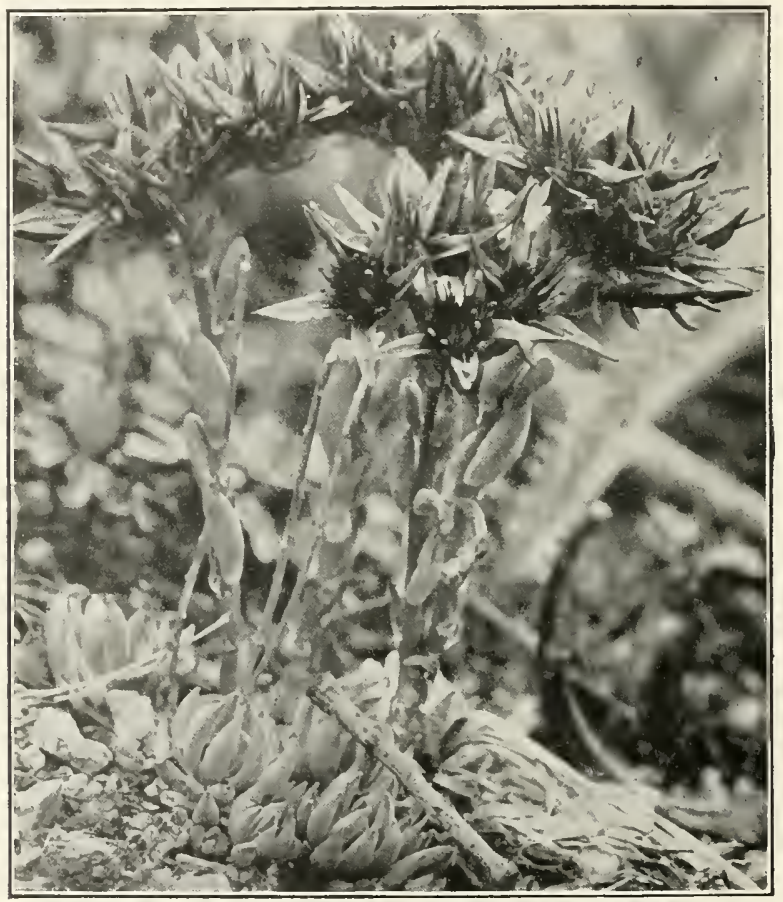

Fig. 51.-A leaf succulent, Sedum stenopetalum.

or thread-like lobes which are widely separated. The resulting decrease in exposed surface is considerable, in some cases exceeding nine tenths of the gross outline. The lobes or segments are themselves protected by a hairy covering or a thick cuticle, which is often supplemented by many rows of palisade tissue, or by storage tissue. Artemisia, Gilia, and Senecio contain xerophytic species that are good examples of this type.

3. The grass form. Terophytic grasses and sedges have narrow filamentous leaves with longitudinal furrows which serve to protect 
the stomata. The furrows are sometimes filled with hairs as an additional protection, and the leaves often further reduce their surface by rolling up into a thread-like shape. The leaves contain also a large amount of sclerenchyma which renders water loss difficult. The elongated awl-shaped leaves of Juncus and certain

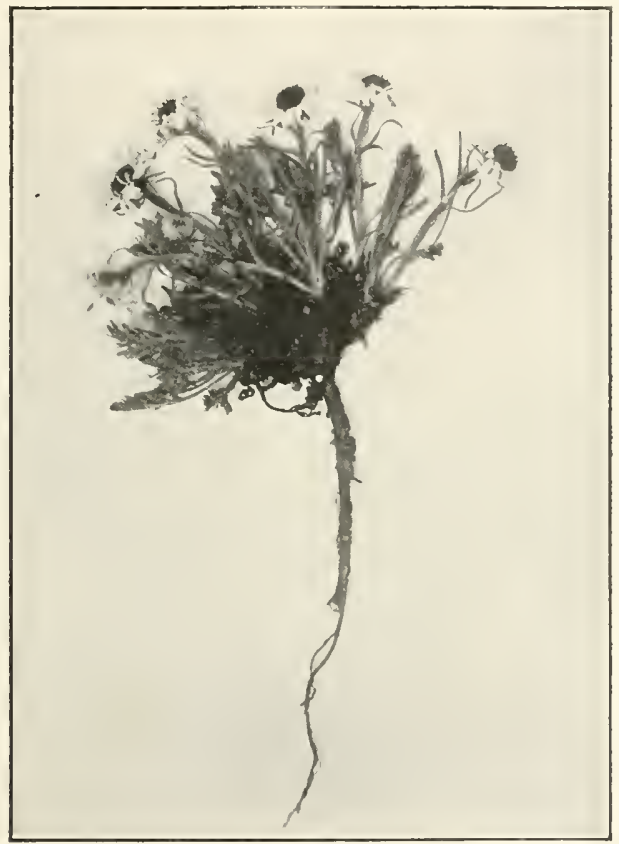

FIG. 52.-A xerophytic mat plant with dissected leaves, Erigeron pinnatisectus.

Cyperacece are essentially of the grass type, though they are usually not furrowed.

4. The needle form. This is the typical leaf of pines, spruces, and other conifers. It is the result of a sweeping reduction of leaf surface made necessary by the persistance of the leaves during winter. The leaves continue to transpire at a time when the available water is low on account of freezing, and scrious injury from drouth is prevented only by greatly reducing the amount of surface exposed. The relatively small water loss from the neelle leaf is further decreased by a thick cuticle, and usually by layers of sclerenchyma just below the epirdernis. 
5. The roll form. Roll leaves are frequently small and linear. Their characteristic form is produced by the rolling in of the margin on the under side. This forms an almost completely closed chamber for the protection of the stomata, which are regularly confined to the lower surface of the leaf. The upper epidermis has a thick cuticle, and the lower one is often covered with hairs. The roll type is found especially among the genera of the Ericales, but it also occurs in a number of other families.

6 . The scale form. The reduction of leaves to scales represents the extreme modification of the leaf under xerophytic conditions. The next step results in the loss of the leaf and the assumption of its functions by the stem. Scale leaves are short and broad, leathery in texture, and closely appressed to the stem, as well as often overlapping. They are characteristic of many trees and shrubs, e.g., Cupressus, Tamarix, Thuja, etc.

Experiment 49. Study of xerophytic leaves. Species representing the above types of leaf xerophytes should be grown in the greenhouse in so far as possible. Agave, Sedum, and Bryophyllum serve well for the succulent leaf, Artemisia and Gilia for the dissected form, Sporobolus, Muhlenbergia, Stipa, and Juneus for the grass form, Erica and Calluna for the roll type, while conifers with needle or scale leaves are readily found out-of-doors. Sketch a representative leaf of each type, and estimate the total surface in square centimeters. Make cross-sections and draw a segment from each leaf.

I8I. Stem xerophytes. These are characterized by the absence of leaves. In some plants the leaves are present at first, but fall early in the season. In many cases the leaves are reduced to functionless scales or are entirely absent. The functions of the leaf are transferred to the stem, which assumes many of the structural modifications of the former. The stem or some part of it often becomes so changed that it is readily mistaken for a leaf. The following kinds of stem xerophytes have been recognized, although not all plants of these types are now xerophytes: (1) the phyllode form, (2) the virgate form, (3) the rush form, (4) the cladophyll form, (5) the flattened form, (6) the thorn form, (7) the succulent form. 182. Types of stem xerophytes. 1. The phyllode form. The petiole is broadened into a leaf-like structure or phyllode. It replaces the leaf blade which is entirely lacking. In other cases the stem is flattened or winged and takes the place of the whole leaf. This type occurs in Acacia, Baccharis, Genista, etc. 
2. The virgate form. The leaves either fall off early or are reduced to functionless scales. The stems are thin, erect, and rod-like, and are often greatly branched. They usually possess a thick cuticle and much palisade tissue, and the stomata are often sunken in longitudinal furrows. This type is characteristic of Genista and many of its relatives. It is found also in Ephedra, many species of Polygonum, Lygodesmia, etc.

3. The rush form. In many species of Juncus, Heleocharis, Scirpus, and other Cyperacew the stem is nearly or completely leaf-

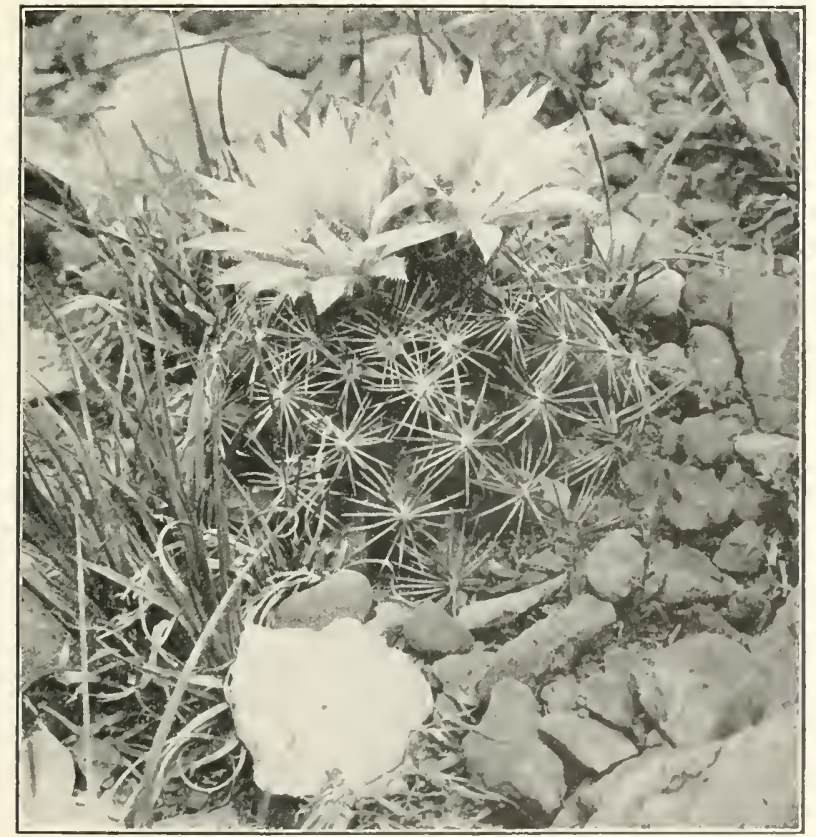

Fig. 53.-A stem succulent, Cactus viviparus.

less, and it is cylindrical and unbranched. It risrally possesses a thick cuticle and several rows of dense palisade tissue.

4. The cladophyll form. In Asparagus the leaves are redned to mere functionless scales, and their work is assumed by the small needle-shaped branches.

5. The flattened form. This is a variation of the preceding type. The place of the scale-like leaves is taken hy cladopluylls, which are more or less flattened and leaf-like branches. Ruscus is a familiar example of this form. 
6. The thorn form. This is typical of many spiny desert shrubs, in which the leaves are lost very early, or are reduced to mere functionless scales. The stems have an extremely thick cuticle, and as a rule the stomata are deeply sunken and protected by valves. Colletia and Holacantha are good examples of this type.

7. The succulent form. Plants with succulent stems such as Euphorbia, Stapelia, and the Cactacece have decreased water loss both by the extreme reduction or loss of leaves, and by reduction of the stem surface. In addition they guard against excessive transpiration by means of water-storage tissues containing a mucilaginous sap. The cuticle is usually highly developed and the stomata sunken. Thorns and spines are also more or less characteristic, though they serve only slightly and incidentally against water loss.

Experiment 50. Form and structure of stem xerophytes. Draw in careful outline and to scale the stem or shoot of a representative plant of each type. Make a drawing of a cross-section of the stem of the virgate, or the rush form, and compare with the needle leaf.

183. Mesophytes. Mesophytic species grow in habitats that are neither extremely dry nor wet, and consequently they show no striking response to water supply or loss. They possess a form or structure that is more or less characteristic by reason of



FIG. 54.-Cross-section of the leaf of a mesophyte, Pedicularis procera.

the absence of distinct modifications. As their name indicates, mesophytes are middle plants, i.e., they stand midway between xerophytes and hydrophytes. For this reason, they pass on the one hand into dry land plants, and on the other into water plants. More than this, the less intense xerophytes and hydrophytes have 
often found themselves in conditions that have changed them into mesophytes. Many of the latter have in consequence retained characters of leaf, stem, or root which are to be regarded as ancestral rather than as the result of adaptation to the present habitat. All of these facts make it unprofitable if not impossible to arrange mesophytes under various types. Although they show a large variety of forms, these are likewise found in the other two groups. Such vegetation forms cannot serve as a basis for separating mesophytes into groups based upon the kind or amount of adaptation to water.

Mesophytic species fall naturally into the two groups, sun plants and shade plants. This is due chiefly to the fact that shade in large measure offsets xerophytic conditions, and also generally retards the development of hydrophytes. The factor concerned here is no longer water content, but light. 'The characteristic changes are due to the latter, and sun and shade forms are types of adaptation to light. Consequently they are considered under the latter.

Experiment $5 \mathrm{r}$. Comparison of mesophyte and xerophyte. Make a careful comparison between the form and leaf structure of a mesophytic and a xerophytic species of the same genus, e.g., Artemisia, Helianthus, Muhlenbergia, Pentstemon, etc.

184. Hydrophytes. The forms and structures of water plants stand out in sharp contrast to those of xerophytes. On the other hand, they grade insensibly into mesophytes, and it is impossible to draw a sharp line between them. Typical hydrophytes grow in water, in soil covered by it, or in saturated soil. With respect to their relation to water and air they may be arranged in three fairly natural groups, viz., amphibious, floating, and submerged plants. In the amphibious form the leares show the usual relation. They grow in the air, while roots and stem are under water to a greater or less degree. Floating plants hare leaves in which the upper surface is in contact with the air, and the lower with water. In submerged forms the leaves are usually below the surface of the water, i.e., carbon dioxide and oxyen are obtained from the water and not from the air. J Both surfares of the amphibious leaf and the upper surface of the floating leaf are of such a nature as to permit as much transpiration as possible. This function is entirely lacking in the leares of sulmerod plants. 
The development of air passages for aeration is great in amphibious and floating forms, but they are normally absent from submerged plants, in which they persist occasionally as vestiges. Submerged plants grow in light that is more or less diffuse, owing to the absorption of rays by the water, and their photosynthesis is much like that of shade plants, while the other forms are sun plants. The fibrovascular system, which is only moderately well developed in the amphibious type, is considerably reduced in floating plants, and is little more than a remnant in submerged ones.

185. Amphibious plants. The species of this group are closely related to mesophytes: they are the least specialized of water

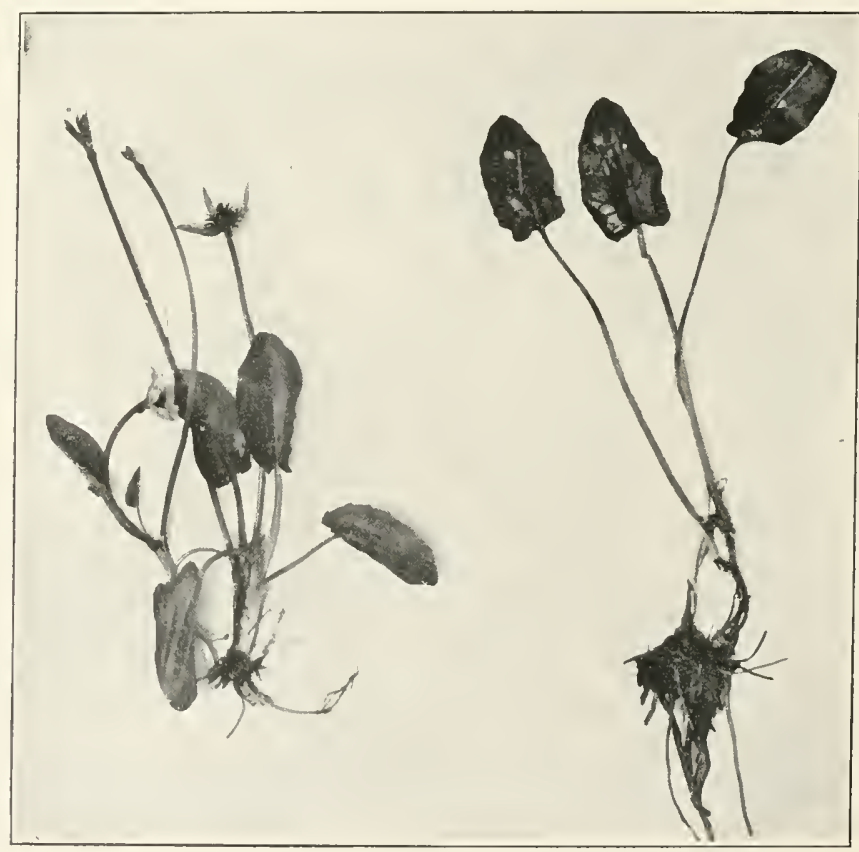

FIG. 55.--An amphibious plant, the white marsh-marigold, Caltha leptosepala. The floating form with long petioles was produced by the change of the marsh into a lake.

plants. As a rule, they grow in saturated soil or in shallow water. Owing to their frequent occurrence at the water's edge, many amphibious plants have a wide range of adjustment, and may grow for a time as mesophytes, or partially submerged. In the 
majority of cases the leaves are constantly above the water. The lower leaves of some species are covered, either normally or by a rise in level, and take the form and structure of submerged leaves. In Callitriche autumnalis and Hippuris vulgaris, the submerged leaves show changes of size and structure, while in the heterophyllous species, Ranunculus delphinifolius, Proserpinaca palustris, Roripa americana, ete., they differ from the aerial leaves in being greatly dissected.

The leaves of amphibious plants, with the exception of those just mentioned, are usually large and entire, the stem well developed, and the roots numerous and spreading. The epidermis has a thin cuticle or none at all, and is destitute of hairs. The stomata are numerous and usually more abundant on the upper than on the lower surface. The palisade tissue is represented by one or more well-developed rows, but this portion of the leaf is regularly thinner than the sponge part. The sponge tissue contains large air passages, or numerous large air chambers, usually provided with thin plates or diaphragms of cells. The stems are often palisarled, and are provided with longitudinal air chambers crossed by frequent diaphragms.

Experiment 52. Structure of amphibious plants. Draw in outline a representative amphibious plant, such as Alisma, Ranunculus, or Sagittaria. Outline an aerial and a submerged leaf of Callitriche or Hippuris, and of a heterophyllous species, such as Ranunculus delphinifolius. Draw a segment from a cross-section of the aerial and submerged leaves of one of the foregoing.

I86. Floating plants. In the form and structure of the upper portion, floating leaves are essentially similar to those of amphibious plants. They are usually coated with wax to prevent the clogging of the stomata by water. Stomata are found only on the upper surface, with the exception of a few cases where they persist with loss of function upon the lower side. The palisale tissue of the leaf is much less developed than the sponge tisisue, which is filled with enormous air chambers. The stems or the petioles are much elongated, and the aerating system is ureatly developed, while the supportive tissues, i.e., the fibrovisculat bundles, are reduced. In the Lemnace, the leaf and strm are represented by a tiny thallus. The roots are in the process of disappearing; for example, spirodela has several, Lemmu one, and Wolffia none. 
Experiment 53. Structure of floating plants. Make an outline drawing in which Nymphcea and Lemna are contrasted. Draw a cross-section of the floating leaf and compare it with a similar section of a Lemna thallus.

187. Submerged plants. Stem and root are both greatly reduced in submerged forms. This is due to the fact that absorption
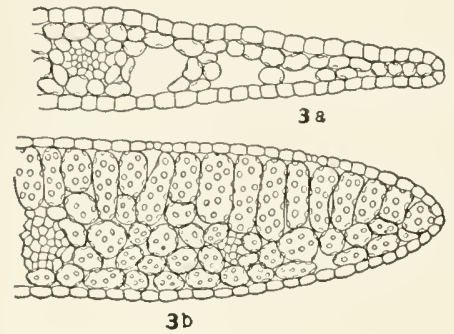

Fig. 56.-Cross-section of a submerged $(3 a)$ and an aerial $(3 b)$ leaf of Callitriche bifida. is no longer carried on solely by the root, but by the whole stem and leaf surface as well. The greater density of water as compared with air also renders support less necessary, and the stems are unusually long and slender, with poorly developed bundles. The leaves are greatly reduced in size and thickness, and in form they are ribbon-like, linear, cylindrical, or finely dissected. These changes seem chiefly to serve the purpose of increasing the surface for absorption, especially of gases, and for receiving the diffuse light rays. Stomata are sometimes present, but they are always functionless. The chlorenchym is essentially that of a shade leaf. In the few cases where palisade and sponge tissues are present, they are doubtless relics of a former structure. The air chambers are either much reduced or entirely lacking. When present, they probably serve as reservoirs for air obtained from the water.

Experiment 54. Structure of submerged plants. Make an outline drawing of the shoot and root system of Ceratophyllum, Myriophyllum, or Philotria. Draw the entire leaf in cross-section.

Make a detailed comparison by means of a table of the form and leaf structure of the various types of hydrophytes.

I88. Bog plants. Many plants of bogs, ponds, banks of streams, etc., have the appearance of xerophytes, in spite of the fact that they grow in water. Their leaves are more or less reduced, and are sometimes lacking. The cuticle is thickened and the palisade tissue well developed. The usual explanation of "bog xerophytes" is that they are caused by humic acids in the water, which hinder the absorption and aeration of the roots. In other words, the available water is thought to be small, though the 
total water content is excessive. It has been shown, however, that the presence of acids increases the absorption of water. Consequently, it seems absolutely impossible for small quantities of humic acids to proluce xerophytes in ponds and bogs. Their influence would tend to make water plants even more hydrophytic. Moreover, in many ponds and swamps where leafless sedges and

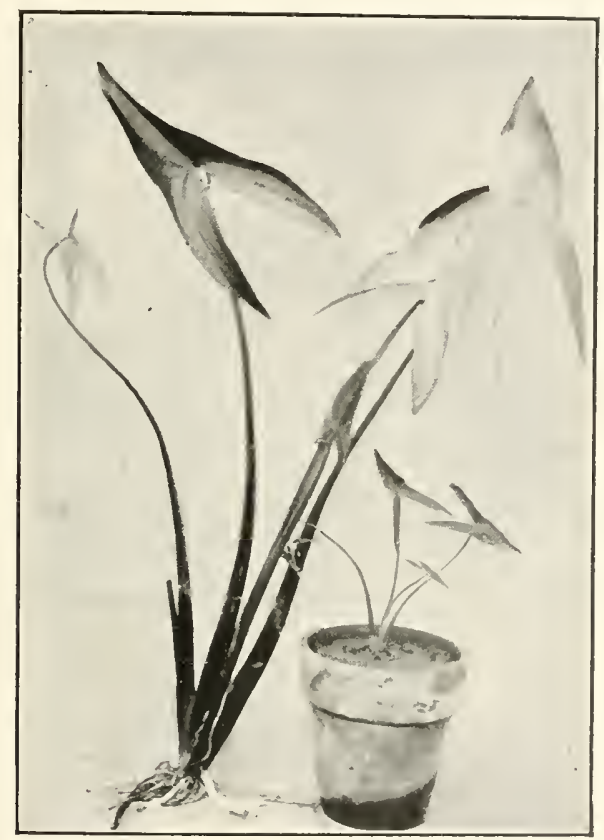

Fig. 57.-A bog plant, Sagittaria latifolia. 'The large plant represents the normal form, while the small one in the pot is a xeroplyytic form artificially produced to prove that the normal form is not at xeroplyyte.

rushes grow, not a trace of acids can be discoverel. Furthermore, plants which are typical hydrophytes throughout, such as Cullha, Ludwigia, Ranunculus, and Sagittaria, are regularly found srowing alongside of these apparent xerophytes. It is impossible for the same habitat to produce both hydrophytes and xerophytes. Many of the so-called bog xerophytes possess structures, such as air passages, diaphragms, ete., which are peculiar to hydrophytes. This is especially true of the form and structure of the root system. 
In consequence, it is incorrect to refer to bog plants as xerophytes. In spite of the superficial evidence, they are hydrophytes.

The presence in bog plants of modifications characteristic of xerophytes seems to be explained by the stability of the species concerned, i.e., by their ability to adjust themselves to changed conditions without undergoing a corresponding change in structure. It has recently been shown that certain sun plants undergo no material change in structure when grown in the sharle. This was likewise found to be true of some species growing in two or more habitats of very different water content. Hence it is probable that the xerophytic features found in some amphibious plants are due to the persistence of stable structures. The latter were developed when these species were growing in xerophytic situations, and not by the hydrophytic habitat in which the plants are found at present. The monocotyledons, and especially the grasses, sedges, and rushes, are extremely slow in adapting themselves to new conditions, i.e., they are very stable. Thus it is readily seen how certain ancestral characters may have persisted in spite of a striking change of habitat.

Experiment 55. Study of water-content types. Classify the various species found in the field as xerophytes, mesophytes, and hydrophytes, and arrange them under the proper types. 


\section{CHAPTER VIII}

\section{ADAPTATION TO LIGHT}

189. The relation of organs to light. Light stimuli call forth functional responses which produce changes in form or structure, or in both. The latter is the rule, since changes in structure really lead to changes in form, as will be seen later. As would be expected, the leaf undergoes by far the greatest modification, and distinctions between sun and shade plants are based almost wholly upon it. The stem shows more or less modification in response to light, owing to the fact that it usually contains chloroplasts, as well as to the fact that it bears the leaves. The root is withdrawn from the action of light and naturally shows only indirect effects, such as might result from differences in growth, etc. The loss of the leaf or even of the stem or root may occur in very diffuse light or in darkness. This is more directly connected, however, with the assumption of a parasitic or saprophytic habit.

I90. Influence of the chloroplasts. The clue to the effect of light upon the form and structure of leaves is found in the position of the chloroplasts. It has already been pointed out that the arrangement of the latter varies with the intensity of the light. Sunlight causes the chloroplasts to form rows in line with the light rays, while diffuse light leads them to take a position at right angles to the ray. The three principles upon which the structural response of the leaf to light rests are: (1) the numlier of chloroplasts increases with the intensity of the light; (2) in diffuse light, i.e., in the shade, chloroplasts arrange themselves in such a way as to increase the number exposed to liglit; (3) in sunny habitats, chloroplasts place themselves so that they decrease the exposure and the consequent transpiration.

The chloroplasts lie in close contact with the layer of protoplasm which lines the cell wall. The latter is itsolf elistic and 
extensible, and it surrounds a fluid and semi-fluid mass. The shape of the cell is in consequence very easily changed. The movement of the chloroplasts into lines or rows throughout the cell doubtless causes it to elongate in the direction of the rows. In the sun the cell thus becomes lengthened in line with the light rays, and perpendicularly to the surface of the leaf. It becomes a rertical palisade cell, and is termed prolate, since it is drawn out in the direction of the poles. In the shade the cell is elongated at right angles to the light ray, and parallel to the surface. It develops into a horizontal sponge cell, which is flattened contrary to the poles, and is hence termed oblate. The form of the sponge cell is further modified by the development of air spaces. The chloroplasts of some species, especially monocotyledons, do not appear to respond to varying light intensities by arranging themselves in rows. In such plants all the cells of the leaf remain more or less globose, and there is no distinction into palisade and sponge.

The palisade cell is the normal result of the response of the chloroplasts to sunlight. The sponge cell is due to the action of diffuse light, or shade, upon the chloroplasts. Palisade cells are usually converted into sponge cells in the shade, and sponge into palisade in the sun. The latter is illustrated by leaves more or less illuminated from below, in which palisade tissue appears on both sides. The formation of sponge tissue in diffuse light is a characteristic result when plants grow in the shade of others. This is equally true of leaves deeply shaded by others of the same plant, as is the case in trees and shrubs, and of those which grow in the diffuse light of ponds or other bodies of water. The upper half of a horizontal leaf shades the lower, producing the typical differentiation of the leaf into palisade and sponge. A thick covering of hairs shades the palisade tissue, converting it into sponge tissue.

I91. Modifications of the chlorenchym. The conversion of the chlorenchym into the two tissues, palisade and sponge, is the direct result of the unequal illumination of the leaf surfaces. This is the normal oceurrence in the usual horizontal type of leaf. Exceptions occur only in the monocotyledons already noted, in which the leaf tissue consists throughout of sponge-like cells. In certain stable species, also, which are now found in diffuse light, the palisade tissue has not been developed by the 

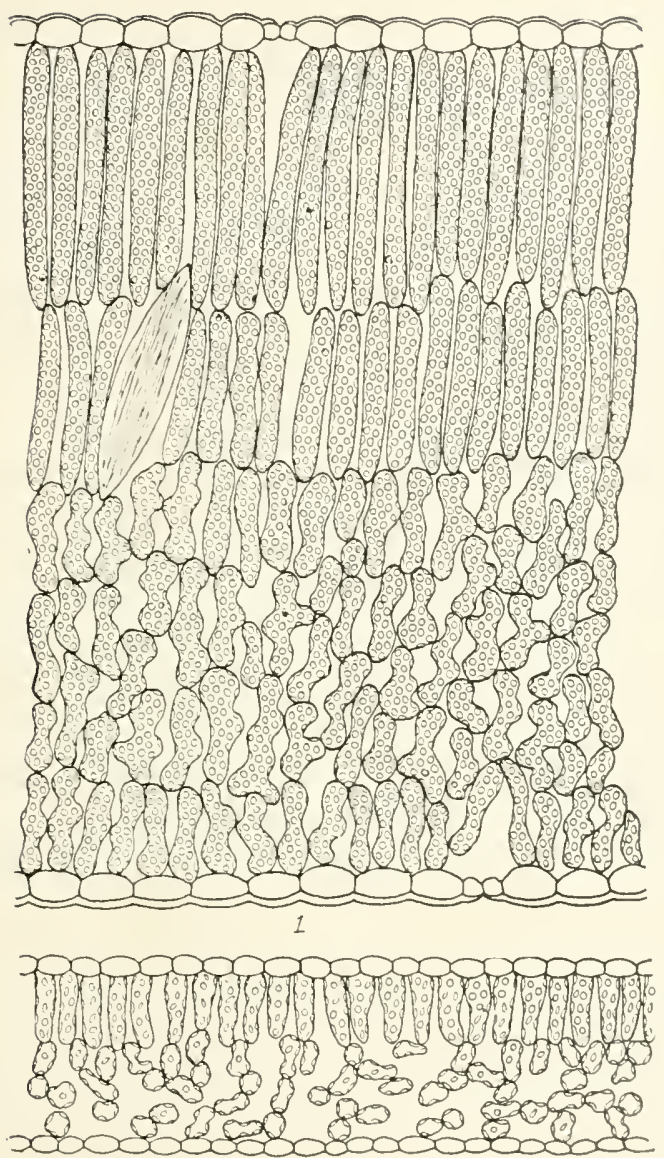

2

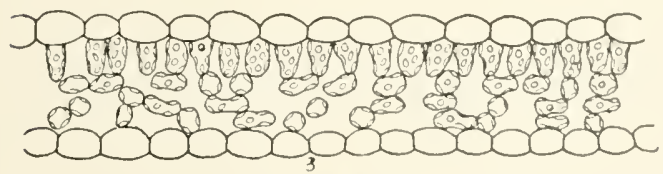

FIG. 58.-Cross-sections of leaves of Allionia linearis, showing the changes which the chlorenchym of the sum form (1) undergoes when growing naturally in moderate shade (2) with a light value of .012, and in deep shade (3) with a light value of .003. 
shade, but represents an ancestral feature that has persisted in spite of the change. The difference in the amount of light received by the two surfaces is determined by the position of the leaf. Leaves that are erect, or nearly so, usually have both sides about equally illuminated, and may in consequence be termed isophotic. Leaves that stand more or less at right angles to the stem usually receive much more light upon the upper than upon the lower surface. They really receive two intensities of light, and may accordingly be termed diphotic. Certain horizontal or dorsiventral leaves, however, absorb nearly or quite as much light on the lower side as on the upper. This is true of sun leaves with a dense hairy covering, which screens out the greater part of the light falling upon the upper surface. It occurs in some degree also in xerophytes which grow in light-colored sands and gravels that serve to reflect the sun's rays upon the lower side of the leaves. In deep shade, moreover, there is little or no difference in the strength of the light received by the two surfaces, and shade leaves are often isophotic in consequence. Isophotic leaves are typical of shaded habitats, but they occur also in the sun. Diphotic leaves are found chiefly in sunshine, but the diphotic structure often persists in shade that is not too dense. It should also be noted that the isophotic sun leaf consists chiefly or entirely of palisade tissue, while the isophotic shade leaf is similarly composed of sponge tissue. Thus, while the direction of the light determines whether a leaf shall be isophotic or diphotic, its intensity determines the kind of tissue formed.

I92. Sponge tissue. All of the cases just cited make it fairly clear that sponge tissue is dereloped primarily to increase the light-absorbing surface. It is found practically without exception in all leaves where the light is diffuse, regardless of the cause of the latter. The leaves of shrubs and herbs which grow regularly in forests consist largely or entirely of sponge tissue. The interior leaves of the foliage of trees and shrubs contain much more sponge than the leaves of the same plant which are exposed to the sun. Sun species transferred to the shade usually change much or all of their palisade tissue into sponge. This is also true of the leaves of amphibious or floating species that become submerged, while the leaves of submerged plants consist entirely of sponge or sponge-like cells. Further evidence of the development of sponge tissue in consequence of reduced light intensity 
is furnished by diphotic leaves and those with hairy coverings. In ordinary diphotic leaves the absorption of sunlight by the chloroplasts of the palisade cells reduces the intensity to such a degree that the plastids of the lower half of the leaf are in diffuse light. In consequence, the cells that contain them become elongated or oblate, and form sponge tissue. In this case the latter is just as truly an adaptation to diffuse light as in the preceding, where the whole chlorenchym is in the shade of other leaves or plants. A cover of hairs reflects and absorbs the greater part of the light which falls upon the leaf, and thereby changes

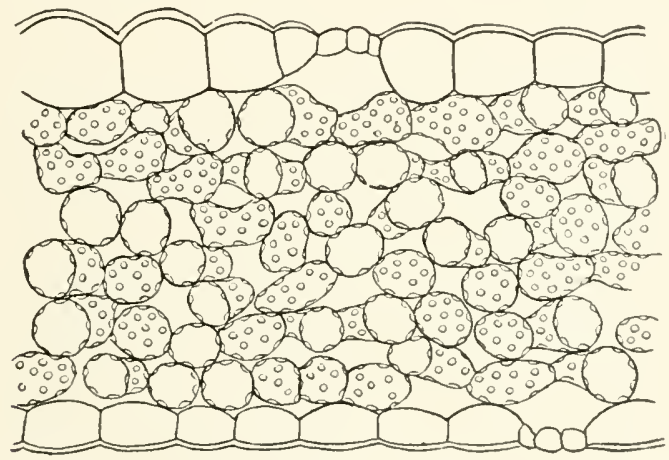

FIG. 59.-Leaf of a bog orchid, Gyrostachys stricta, in which the chlorenchym consists wholly of sponge cells.

the interior into sponge tissue. Consequently, lanate sun leaves usually possess chlorenchym essentially like that of shade leaves.

From the preceding it seems clear that sponge tissue serves primarily to increase the light-absorbing or chlorophyll surface under all conditions that make such an increase beneficial. In addition, it is intimately connected with aeration, largely owing to the fact that it is in contact with the lower epidemis, which usually contains the larger number of stomata. Indeed, the spongy nature of this tissue is due to the presence of air spaces. which are the means of carrying on effective aeration. This point is nicely brought out by submerged leaves, in which the form of the cells and the arrangement of the plastids are those of sponge tissue. The usual air spaces are altogether lacking, however. since the air is now obtained in solution in the water. Finally, the abundance and size of the air spaces in the sponge makes the latter subject in some degree to the modifying influence of tran- 
spiration. The fact that light is the most potent factor in producing sponge tissue is proved by the uniform occurrence of the latter in the lower half of the leaf, when the stomata are more numerous upon the upper surface.

193. Palisade tissue. The formation of paiisade tissue is brought about in response to sunlight or to low water content. In very many cases the two act together and produce a striking

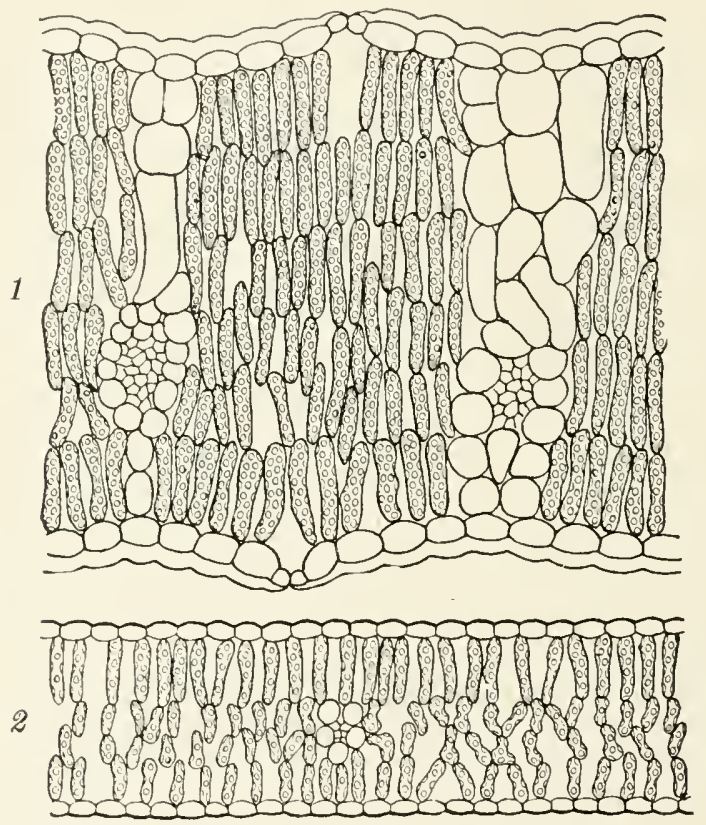

Fig. 60.-Cross-section of leaves of the sun (1) and shade (2) form of a sunflower, Helianthus pumilus, in which the chlorenchym consists entirely of palisade tissue.

modification. In amphibious and floating plants, and in many mesophytes where the water supply is adequate, the palisade is due to the action of light. On the other hand, it is possible to increase the number of rows of palisade cells in the leaves of most sun plants by growing them in drier conditions. As a consequence, it is a difficult task to decide which factor is the more important in producing this tissue. When it is recalled that the light energy is almost entirely used in causing evaporation from the plastids, 
it is evident that palisade tissue is primarily, if not wholly, a protection against water loss. Since the latter is due to light or to water, palisade may be developed chiefly by the one or the other aceording to conditions.

Protection against water loss in consequence of sunlight is brought about by the arrangement of the chloroplasts in vertical rows so that they screen each other. Palisade cells greatly decrease the transpiration due to low humidity by being so closely placed that the outward movement of the moist air is hindered. The air passages between them are usually reduced to the narrowest of chambers, and often to mere lines. The truth of these statements is not affected by the fact that leaves with much palisade tissue, i.e., sun leaves, sometimes transpire twice as much as shade leaves of the same size. This is explained by the much greater activity of chloroplasts in the sunlight. As a result, sun leaves require a larger supply of carbon dioxide, and the number of stomata is correspondingly increased, often being dloubled. In consequence, the loss of water through the stomata is necessarily increased. The small size of the air passages in palisade tissue would seem to prevent the rapid movement of carbon dioxide to the chloroplasts. This is apparently compensated by the fact that the greater demand for this gas causes it to move most rapidly toward those points where it is being used in the largest quantities.

194. Changes of the epidermis. The appearance of the chloroplasts in the epidermal cells of plants growing in diffuse light is the only change directly traceable to light. Chloroplasts are regularly present in the epidermal cells of woodland ferns and of submerged plants. They are also found in those shade forms of sun species in which the outer wall of the epidermis has become thin enough to admit carbon dioxide. The absence or slight development of hairs in shade plants is an advantage, because it prevents the further weakening of the already diffuse light. The value of arched epidermal cells and of epidermal papilla in controlling the absorption of light by shade plants seems to be slight. The factor that has called forth these modifications and the primary purpose they serve must still be regarded as unsettled. The increasel size of the epidermal cells in many shade forms seems to be for the purpose of increasing translocation and water loss, and to bear no direct relation to light. The extreme size of these cells in certain mono- 
cotyledons growing at the edge of shaded brooks is probably a contrivance to increase water loss.

The number of stomata for an equal area of the epidermis is greater in sun leaves than in shade leaves. This is generally true of all sun and shade plants, but it is most clearly shown by the different habitat forms, or ecads, of the same species. The sun leaf of Allionia linearis has 180 stomata, and the shade leaf 90 stomata per square millimeter. In Scutellaria brittonii, the 100 stomata per sq. mm. of the sun leaf are reduced to 40 in the shade leaf. However, in a stable species such as Erigeron speciosus, the number of stomata remains unchanged in those plants that have moved into the shade. The presence of the larger number of stomata in the sun plant, which is exposed to the greater water loss, has already been explained.

195. The form of leaves. The form of the leaf is largely determined by the action of light upon the chloroplasts and the consequent change in the form of the cells that contain them. Oring to the direction in which they elongate, sponge cells tend to produce an extension of the leaf at right angles to the light rays. On the other hand, palisade cells extend the leaf in line with the falling rays. In consequence, leaves which contain an excess of sponge tissue are relatively broader, while those in which palisade is preponderant are relatively thicker. Since plants economize material and energy in so far as possible, the broadened leaf tends to be thin, and the thickened leaf to be narrow. In accordance, shade leaves, i.e., those that consist largely or wholly of sponge tissue, are broader and thinner, and often larger, than sun leaves of the same species. Sun leaves, on the contrary, are thicker, narrower, and often smaller than shade leaves. What is true of the sun and shade forms of the same species holds for sun and shade plants generally.

196. Changes of outline, size, and thickness. The outline of shade leaves is more nearly entire than that of those in the sun. This is easily proved by comparing the sun and shade forms of a species with lobed or divided leaves, though the rule is not without exceptions. In Fig. 21 the outline of the shade form is more entire in Bursa and Thalictrum, but less entire in Machoranthera. Leaf prints of this kind serve more satisfactorily to illustrate the increase in size and decrease in thickness produced by the increase of surface in the shade leaf. In all such comparisons, however, 
the relative size and vigor of the sun and shade plants must be taken into account. The relation between surface and thickness is shown by the following species, in all of which the leaf is larger in the shade than in the sun. In Allionia linearis, the thickness of the shade leaf is one fourth that of the sun leaf, i.e., the ratio is $3: 12$, and in Capnoides aureum $6: 12$. The ratio in Thalictrum sparsiflorum is $9: 12$, and in Macharanthera aspera $11: 12$. The ratio of thickness of the shade and sun forms of Bursa bursa-pastoris is

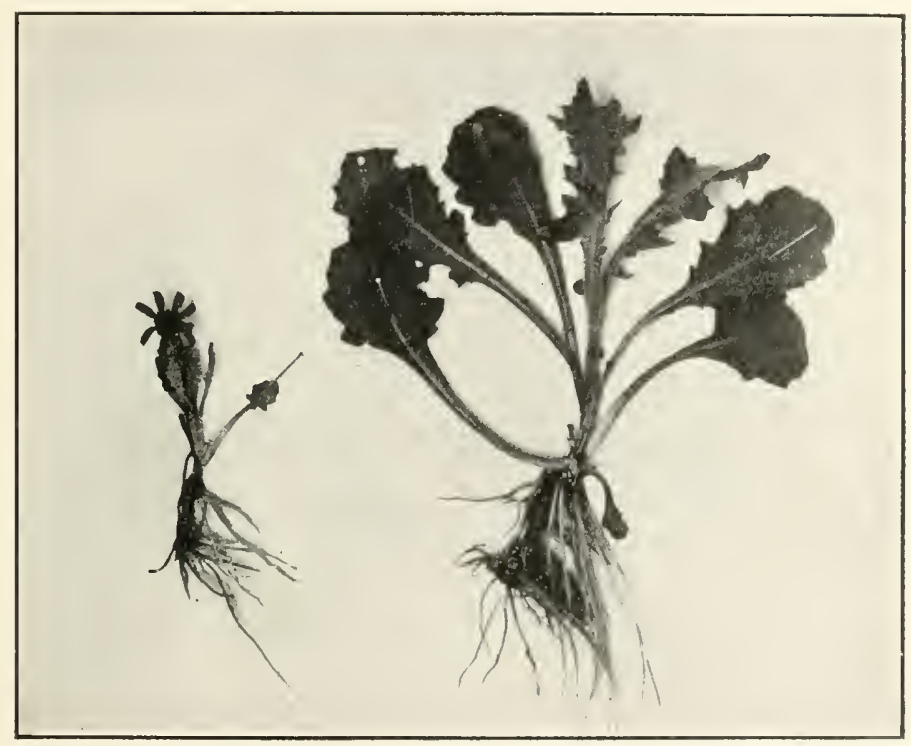

Fig. 61.-Sun and shade torm of Senecio taraxacoides. The leaves are larger, thinner, and smoother in the shade plant, and usually more entire.

14:12, but the greater thickness of the shade leaf is explained by the fact that this plant is ten times larger than the sun form. Upon the basis of size, the thickness of the shade leaf is scarcely one ninth that of the sun leaf. Some species show no change in thickness, and but little in size or outline. This is doubtless to be explained by the fact that the form is so fixed in the sun plant that the decrease in light intensity has little or no effect upon it.

197. The form of stems. Shade ecarls are regularly taller and often more branched than the corresponding sun form. In general, this statement is true of all sharle plants as compared with sun 
plants. The effect of diffuse light in causing stems to stretch upward has been known for a long time, but the way in which it is brought about is still unexplained. It is often stated that the stem elongates to obtain more light, but the only basis for this is that the stem grows in the direction from which the light comes. This elongation is much more marked in the case of plants grown in the dark, in which the height of the plant has no bearing upon the amount of light that it can obtain. It has been shown that the stretching of the stem is due to the excessive

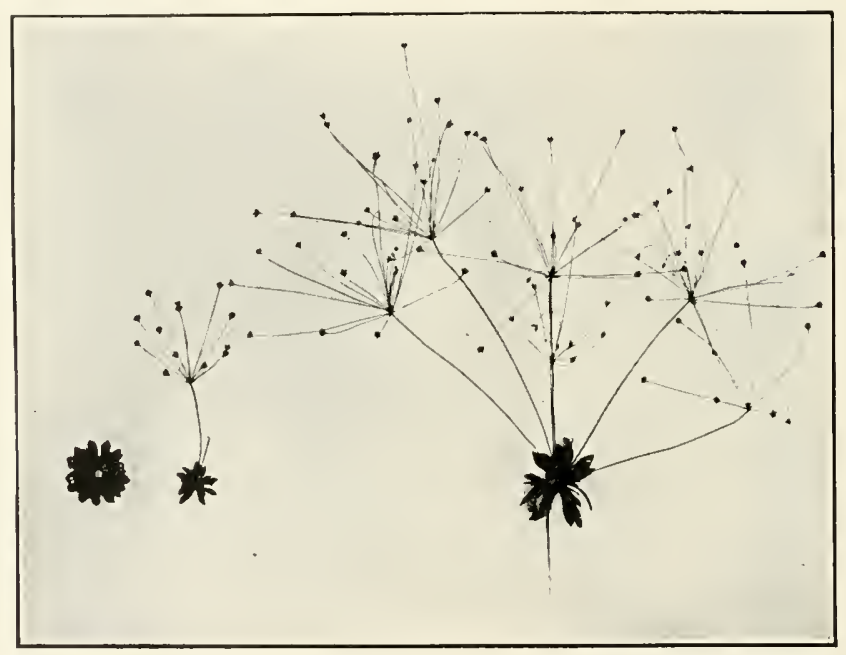

F1G. 62.-Modifications of the stem in several forms of Androsace diffusa. The rosette is an alpine plant growing at $3800 \mathrm{~m}$.; the middle plant grows in the open gravel at $2600 \mathrm{~m}$. and the branched plant in the shade at $2600 \mathrm{~m}$.

elongation of the parenchyma cells, but the cause of the latter is in doubt. It is generally thought to be the absence of the usual action of sunlight, which is assumed to be a retarding of growth in sun plants. The evidence in favor of such a view is far from conclusive. It seems probable that the elongation of the parenchyma cells takes place under conditions which greatly promote the mechanical stretching of the cell wall, but prevent the normal growth of the latter by intussusception. The fact that photosynthesis, and hence the amount of constructive material, is greatly reduced in shade plants favors such an explanation. What- 
ever the cause may be, it is evident that the elongation of the stem is an advantage to plants that grow in diffuse light. This holds for submerged as well as for shade plants. Upon a stem with elongated internodes, the leaves interfere less with the illumination of those below them. This is also true of the branches, which serve further to carry the leaves away from the stem and from each other in such a way that the plant obtains the greatest possible exposure of its leaf surface.

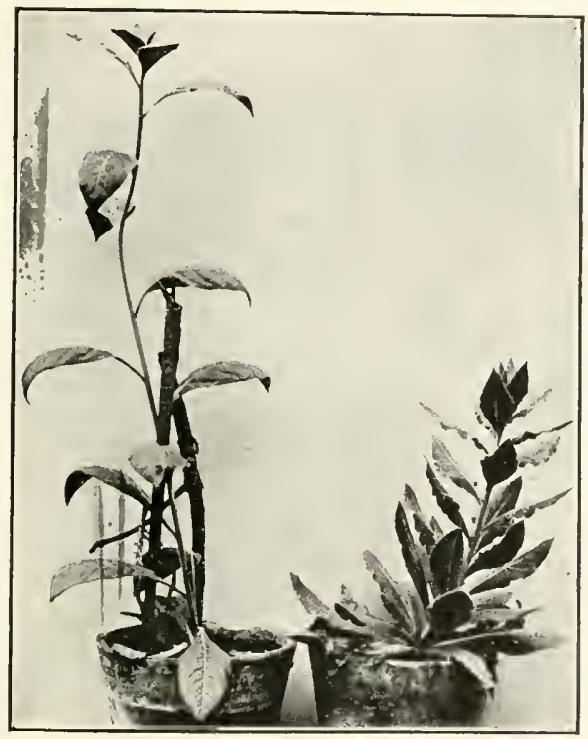

FIG. 63.- Shade and sun plants of Gaura parviftora, the former produced in a shade tent.

Experiment 56. The production of adaptations to light. Construct a series of shade tents 1-2 meters square and high. This may be clone in the greenhouse or out-of-doors by using wooden strips of $3-5 \mathrm{~cm}$. to make a framework of the size desired. The latter is divided into three parts, and each is covered with cloth of the proper texture to give the light intensity sought. It is desirable to lave a series of tents with light intensities $0.1,0.05$, and 0.01 of the normal sunshine out of doors. These values may be approximated by cheese-cloth, muslin, and luek, and after a few trials may be secured almost exactly. Each tent is coveresl by tacking the proper cloth upon it. The interior walls are usually made of the eloth belonging respectively to the second and the third tent. On one side the cloth is not tacked, but is arranged to button closely 
on the framework in order to serve as an opening. Ordinarily it is not necessary to ventilate each tent, but, if the humidity within becomes too high, this is effected by means of hoods at the top or sides.

Practically all flowering plants will show some adaptation to the different light intensities of the shade tent. Helianthus, Allionia, and Taraxacum have been found especially suited for this work, though a number of others, Bursa, Galium, Onagra, ete., are equally good. Helianthus annus (wild form) illustrates fairly well the behavior of a stable species, and Allionia linearis or A. nyctaginea that of a plastic one. Taraxacum taraxaeum shows the effect of shade upon divided leaves and the form of the rosette. Both Bursa and Onagra are especially good to show the stretching of the petioles and internodes. It is best to start the seedlings under normal conditions and then to place 4-6 of each species in each tent as soon as they begin vigorous growth. A set should likewise be left in normal light to serve as checks.

During the growth of the plants make occasional readings of light intensity for the three tents, and make one determination of the starch content of a representative leaf of each species for each tent. Follow with care the differences in the growth and behavior of each species in the three tents and in the sunlight. When the plants are well grown, make an outline drawing of the leafy plant of each species for the four conditions and a similar outline of a representative leaf of each, drawing all stems as well as leaves to the same scale. Select a representative leaf from each form, and make a leaf print for the four forms of each species. Kill a similar set of leaves from each species and make a study of the structural modifications as shown by microtome sections. A similar study of modifications in the number of stomata may well be made by stripping the epilermis from the fresh leaves. Prepare a concise account of the adaptation of the species concerned to different light intensities.

198. Types of leaves as determined by light. Isophotic leaves are equally illuminated on both surfaces, or nearly so, and possess a more or less uniform chlorenchym. Diphotic leaves are unequally illuminated, and show a division into palisade and sponge tissue. The ordinary horizontal or dorsiventral leaves are usually diphotic. Leaves of this type contain both palisade and sponge, though the relative importance of the two varies considerably in different species. Diphotic leaves are characteristic of sunny swamps, meadows, prairies, etc., and are frequent in xerophytic habitats. Floating leaves, in which the light is almost completely cut off from the lower surface, are also diphotic. This type of structure is often found in the leaves of shady 
forests, in which it is a relic of the structure of the ancestral sun leaf.

- Isophotic leaves fall into three types, based upon the intensity of the light. The palisade leaf, or staurophyll, is a sun leaf in which the chlorenchym consists wholly of rows of palisade cells. It is produced by nearly equal illumination of both surfaces, due to

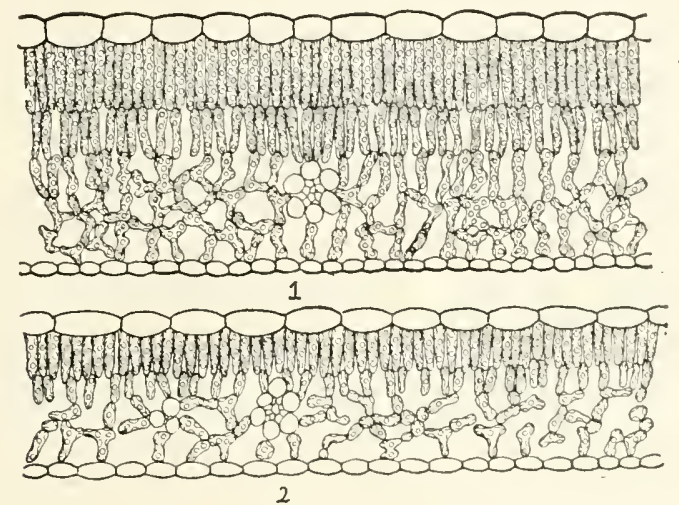

FIG. 64.-Isophotic leaf (1) of an oak, Quercus novimexicana. The shade leaf (2) is of the same type, though one row of palisade tissue is lost and the leaf is thinner.

its upright position or to reflection from a light-colored soil. In a special form of this type, the diplophyll or double leaf, the intense light does not penetrate to the middle of the leaf. In consequence, the upper and lower palisade areas are separated by a central sponge-like tissue, which is used for the storage of water. The sponge leaf, or spongophyll, includes all shade leaves, except those in which some palisade persists from the ancestral sun form, and practically all submerged leaves. Its chlorenchym consists of sponge-cells alone. Certain monocotyledons, which grow in the sun but lack palisade, may also be referred to this type for the present.

199. Sun plants and shade plants. Sun plants are also termerl heliophytes and shade plants sciophytes. The former comprise practically all xerophytes, prairie and mearlow mesophytes, and amphibious and floating hydrophytes. Shade plants include the mesophytes of thickets and forests and submerged hydrophytes. The differences in the form of stem and leaf shown lyy these two types have already been cliscussecl. The greater number 
of sun plants are diphotic, as represented by Pedicularis procera (Fig. 54). Plants with isophotic leaves are found frequently in xerophytic places, though erect leaves of this type occur in

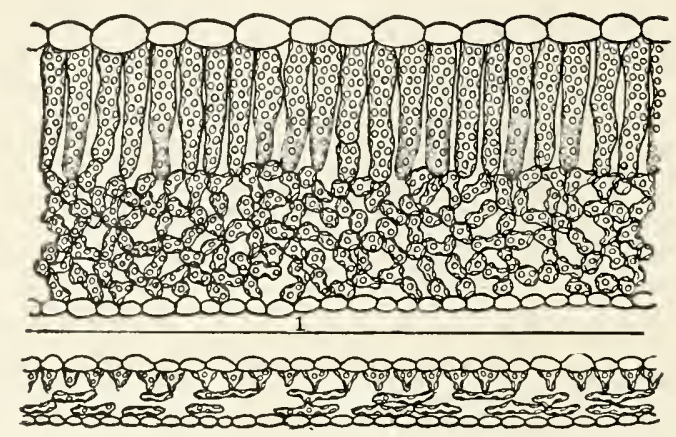

FIG. 65.-Isophotic leaf (1) of Bidens bigelovii, which in the shade form (2) becomes practically a spongophyll by the reduction of the palisade layer.

most sunny habitats. The staurophyll, in which protection is due to the extreme development of palisade tissue, is illustrated by Allionia linearis (Fig. 58) and Bahia dissecta (Fig. 47). The diplophyll, which is characterized by a central band of sponge tissue or storage cells, is found in Mertensia linearis (Fig. 50). The spongophyll is frequent among plants of deep shade, but, as the leaf sections of Allionia (Fig. 58) and Quercus (Fig. 64) show, the diphotic leaf is equally common among shade plants. The form of sun spongophyll found in certain monocotyledons is shown in Gyrostachys stricta (Fig. 59).

Experiment 57. Sun and shade forms in nature. Nake a list of all the genera of the local flora in which sun and shade species occur, and make a general comparison of the latter.

Make a thorough search for sun and shade forms of the same species. Such species, called polydemics, are especially apt to be found near the border of grassland and woodland, where species may wander easily into either habitat. Make a study of the sun and shade forms of a polydemic by means of outlines and leaf prints. 


\section{CHAPTER IX}

\section{THE ORIGIN OF NEW FORMS}

200. The law of evolution. Evolution is the production of a new plant form out of an existing one. It is commonly spoken of as the origin of species, but this expression is far from exact. All plant groups, forms, varieties, species, genera, etc., regardless of their rank, are products of evolution. The term species, moreover, has become so vague that it no longer has definite meaning from the standpoint of evolution. Properly speaking, the latter is the origin of all new forms. The existence of such a universal process is now beyond question. The exact ways in which new forms arise and the factors which control their origin are still imperfectly known. Evolution has scarcely entered the experimental stage. There has been a surplus of works and papers upon this subject, but with few exceptions they have added nothing to our real knowledge of it.

20I. Stability and plasticity. Evolution is the process in which organisms are changed by the immediate or remote action of their environment. The exact connection between many changes in plants, for example, and their habitat has not yet been male, owing to the extremely small amount of experimental study. The feeling that all changes can be traced sooner or later to the factors of the habitat arises from the belief that every form has descended from the primitive protoplasm, solely in consequence of changes wrought in the latter by the habitat. The most convincing evidence in favor of this belief, which naturally can never be proved or disproved, is found in the fact that every form uset for experiment can be changed in response to changing fartors. Consequently we are justified in assuming as a working hypothesithat all plants can be changed by means of the habitat. 'T's 
obtain the proof of this and of the manner in which it occurs is the task of experimental evolution.

Forms which grow for a long time in the same habitat seem to fix more and more those functions and structures which are the responses to it. They may be said to acquire habits which become more fixed the longer the causes act. Of this tendency to fix characters, there is as yet no definite and complete experimental proof. Sufficient evidence to warrant its use as a working hypothesis is found in the behavior of plants in nature and in experiment. Some forms or species show little or no change when grown in greatly changed conditions, while others respond to slight differences in habitat. The former are said to be stable, the latter are termed plastic. The great majority of plants are neither extremely stable nor extremely plastic. Some are more stable, others less so. Some clue to this may be obtained from observations made in the field, but the final test of a plant's stability must be made by growing it under changed conditions.

The amount of stability shown by a plant determines to what degree evolution or change is possible for it. In other words, the form and structure inherited by the plant from its ancestors not only constitutes the material acted upon by evolution, but it also determines how far the change may go. This is the historical or ancestral factor in evolution. The change which the plant undergoes is the result of a change in the habitat, which is the physical factor in evolution. The amount of change or modification in the plant depends upon the intensity of the change in habitat, i.e., upon the stimulus as well as upon the degree of stability. Evolution is thus seen to be the result of two opposite tendencies, stability and change. When the former predominates, evolution is either very slow or very slight. In extreme cases it may be impossible. When the second tendency is stronger, evolution is rapid, and a new form appears in response to each change in habitat. In consequence, while we shall see that evolution may be brought about in several ways, every instance of it is at bottom a question of the relation between the antagonistic tendencies, stability and change.

202. Constant and inconstant forms. New forms that arise by evolution produce offspring similar to themselves as long as the offspring remain in the home. If the offspring invade new and different habitats, they may retain the characters of the parent 
or they may be modified under proper conditions, returning to the form from which the parent sprang. Forms which remain true to the parent type under different conditions are said to be constant, while those that revert to the type preceding the parent are termed inconstant.

For a great many years species were supposed to be constant, but varieties and forms inconstant. Constancy was rarely made a matter of experiment, however, and was practically never used in connection with the naming of new species. In consequence, many species of the manuals are not constant, and many varieties and forms are. The distinction between these three disappears accordingly. It has slight meaning to distinguish one new form as a species and another as a variety. The use of either term in any exact scientific manner is difficult until the present so-called species are thoroughly examined experimentally, and new criteria are established as a result. The common usage of descriptive botany is to term new forms species, regardless of the way in which they originate or the amount of difference they show. It is necessary to distinguish different kinds of species, or to make a definite distinction between species and other forms. The basis for either procedure must be experiment and not observation merely, though the latter is often an aid.

Constancy is in nowise a test of evolution, though it plays an important part in the arrangement of the new forms that arise. The way in which new forms originate determines whether they shall be constant or not, i.e., constancy is itself a result of evolution, wather than a factor in it. Moreover, it seems very probalole that constancy is directly influenced by the habitat. A shacle form that has sprung from a sun plant usually reverts at once to the original form if the sceds of the first generation are grown in the sun. This reversion seems to take place more slowly after a number of generations, and it is probable that it would be slower or more incomplete after a hundred or a thousand generations.

203. Origin by descent before Darwin. Before the appearance of Darwin's "Origin of Species" in 1859, it was commonly believed that genera and species were the result of special creative acts. Varieties, on the contrary, were supposed to arise from species through the influence of external eonditions. 'This was the view held by Linnaus, whose authority was such as to cause 
its almost universal acceptance. Bacon ${ }^{1}$ in his "Natural History" (1658), seems to have been the first to state that one kind of plant may change into another through transmutation. Among the causes of the latter he mentions drouth especially, further pointing out that it does not act if the earth be moist. His greatest achievement, however, was in anticipating in definite though crude fashion the methods of experimental evolution, as shown by his six rules for making one plant change into another. One of these was "to take marsh herbs and plant them upon the tops of hills and champaigns, and such plants as require much moisture upon sandy and very dry grounds." Another was "to make plants grow out of the sunshine, since this was a great change in condition, and might bring about a change in the seed." Bacon's ideas, though many were necessarily crude and incorrect, indicate clearly that he had observed the origin of new forms by adaptation to the habitat, and believed that such forms could be produced experimentally.

The first writer whose views on evolution attracted serious attention was Lamarck.2 His ideas were first advanced in 1801, and further enlarged and revised in 1809 and 1815 . He was the first to point out clearly that all species have descended from other species. Lamarck believed that new forms arose in three ways: by the direct action of the habitat, in consequence of the use and disuse of parts, and through crossing of existing forms. He held, moreover, that evolution takes place in conformity with the law of progressive development, and, to explain the universal presence of simple forms, he assumed that these are arising constantly out of non-living material. Within recent years, many of Lamarck's views have been widely adopted by biologists, who are accordingly known as Neo-Lamarckians. Saint-Hilaire ${ }^{3}$ in 1828 reached the conclusion that the species of to-day have descended from earlier ones through the modification of the latter. He regarded the habitat as the cause of change, as is clearly shown by his statement that "specific characters remain fixed for each species as long as the latter grows under the same conditions: they are modified in case the habitat undergoes a change."

204. Darwin and the Origin of Species. The preceding account

${ }^{1}$ Bacon, Francis. Sylva Sylvarum or a Natural History, 110, 1658.

${ }^{2}$ Philosophie Zoologique, 1809.

${ }^{3}$ Sur le Principe de l'Unité de Composition Organique, 1828. 
makes it evident that Darwin was not the discoverer of the law of evolution, contrary to what is often assumed. In an historical sketch of the progress of opinion on the origin of species previous to the appearance of his own book, Darwin himself summarizes the views of twenty biologists who gave entire or partial support to the idea of evolution. The action of natural selection as a factor in evolution, the discovery of which has been commonly attributed to Darwin, was first suggested by Wells in 1813. Natthew in 1831 and Naudin in 1852 held the same view of the importance of natural selection as that advanced independently by Darwin and Wallace in 1859. Nevertheless, while it is incorrect to ascribe the discovery of evolution and natural selection to Darwin, he must receive the fullest credit for bringing about the final acceptance of origin by descent. His twenty years of painstaking study of evolution left no doubt of its being a universal process, even though he was unable to prove the exact way in which it acts.

Darwin recognized that new forms arose through the direct action of the habitat and through the production of sports. $\mathrm{He}$ considered that the action of the habitat led to definite or indefinite variation, while it was impossible to connect the origin of sports with external causes. Definite variation occurs when all or nearly all individuals respond in the same way, while indefinite variation, called also fluctuating variability, takes place when the individuals are sliqhtly modified in all directions. While Darwin believed that definite variation, i.e., adaptation, as well as sports, i.e., mutation, occasionally produced new forms, he held that species ordinarily arise in consequence of indefinite variation. The minute variations of individuals were assumed to be preserved and accumulated through natural selection, or the survival of the fittest. The latter, moreover, was supposen to be due entirely to the competition between individuals and not to the direct action of the physical factors of the habitat. Darwin's conclusions were based chiefly upon the study of domesticaterl plants and animals, and upon observation instead of upon experiment. These two facts serve to explain why he fouml it possible to put the greatest emphasis upon origin by variation and natural selection, which is, of the three methods recomnized by him, the only one not experimentally proven.

205. Evolution after Darwin. As frequently happens after the appearance of a great work, the "Origin of sipecies" usheres in at 
period of theoretical discussion of slight value. This was especially unfortunate, since it almost completely obscured the fact that the value of Darwin's hypotheses could be tested by experiment alone. Hence in this period it is necessary for us to consider only the conclusions of Henslow and De Vries. The former obtained much new material from a field neglected by Darwin, viz., the origin of adaptations in nature, while the latter by means of careful experiments placed beyond question the origin of new forms through mutation. Henslow ${ }^{1}$ believes that Darwin was wrong in assuming that "indefinite variability is a much more common result of changed conditions than definite variability." His own opinion is that "in nature variations are always definite and not exceptionally so: the consequence is that 'all or nearly all the individuals become modified in the same way' (and) the result is that a new variety and thence a new species "would be produced without the aid of natural selection." His final conclusion is that "the origin of species is due to the joint action alone of the two great factors of evolution-variability and environment-without the aid of natural selection."

De Vries ${ }^{2}$ states that while "the current belief assumes that species are slowly changed into new types, in contradiction to this conception, the theory of mutation assumes that new species and varieties are produced from existing ones by sudden leaps." His conclusions are based chiefly upon the experimental study of an evening primrose, Enothera lamarckiana. He found that out of a hundred or more species in nature, this was the only one that suddenly produced new forms, i.e., mutations. From it he obtained in the field and in garden cultures twelve mutations or "new elementary species." These arose suddenly from the parent stock, without any connection with the habitat, and came true from seed. A careful examination of De Vries' results leaves no doubt that mutation is proved to be one of the methods by which new forms originate. That it is the only method of origin is certainly not true. Moreover, it is perfectly evident that De Vries' experiments upon Enothera are quite inadequate to prove it the chief method, as he would have us think. It is difficult, more-

${ }^{1}$ Henslow, George. The Origin of Plant Structures by Self-adaptation to the Environment, IX, 1895.

${ }^{2}$ De Vries, Hugo. Die Mutationstheorie, 1901; Species and Varieties, their Origin by Mutation. 1905. 
over, to accept his statement to the effect that his work is "in full accord with the principles laid down by Darwin." The latter held that new forms arise regularly from indefinite variations; De Vries derives them from mutations; Darwin regarded natural selection as a necessary agent in originating new forms by variation, while to De Vries it is merely a process that acts after origin is complete.

206. Fundamental methods of evolution. From the foregoing it is evident that new forms probably originate in one of three

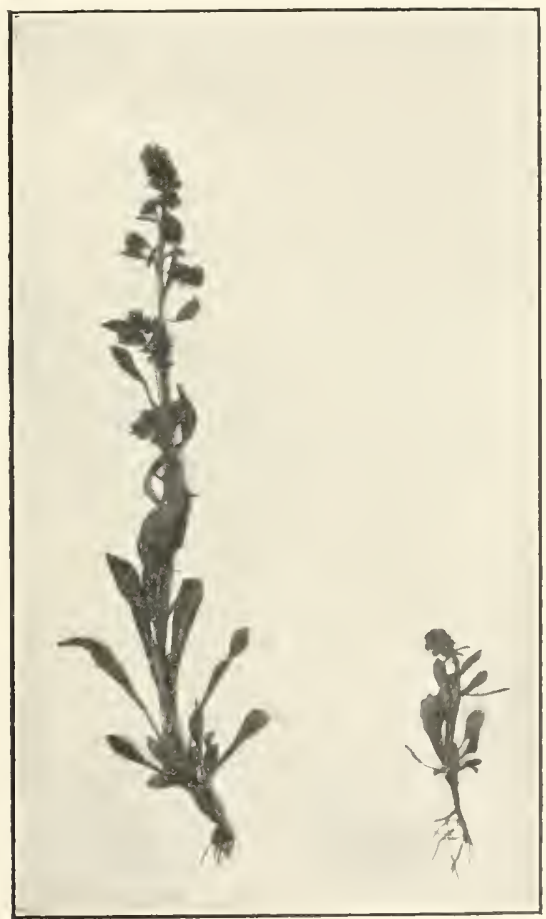

FIG. 66.-Solidago oreophila and its alpine form, Solidago decumbens. The latter is due to dwarfing, arising from low temperature and from the increased water loss eaused by decreased pressure at high altitudes.

different ways, i.e., by indefinite variability or variation, by definite variation or adaptation, or by mutation. New forms arise also by crossing or hybridization, which has usually not beell accounted a method of evolution. It is interesting to note 
that Bacon, Lamarck, and Saint-Hilaire held that evolution proceeded chiefly from adaptation. Darwin, while recognizing the occurrence of both adaptation and mutation, was led to think that variation was the common method of origin. Henslow and many other Neo-Lamarckians held that adaptation is the universal method, refusing to accept variation and neglecting mutation. De Vries, on the other hand, eliminates adaptation as unable to produce constant forms, points out that variation has never been proved to originate new forms, and consequently regards mutation as the universal process. In these extreme views there is both truth and error. Adaptation, mutation, and hybridation have been proved by experiment to be able to produce new and distinct forms. While similar proof is lacking in the case of variation, it seems probable that it is because no careful experiments have yet been made in regard to it.

207. Origin by adaptation. New forms may originate in nature by adaptation to the physical factors in consequence of invasion into a different habitat, or of a marked change in the same habitat. It is equally clear that they may be produced artificially. In either case the chances that a new form will arise depend almost wholly upon the stability of the original form. An extremely stable form remains essentially the same in all habitats in which it can grow. A very plastic one gives rise to a new form whenever it enters a new habitat or has its own changed. Origin by adaptation occurs universally in the case of plastic species whenever they are placed under different physical factors. The factors that control origin of this sort are the direct ones, water and light. The ways in which plants respond to them by changes in form and structure have already been discussed in the two chapters preceding. A new form arising from adaptation is called an ecad. For example, the seeds of a plastic sun plant that has entered a forest develop into a shade ecad, while a prairie species carried into a bog may give rise to a water ecad. A species able to invade successfully two or more different habitats will produce a corresponding number of ecads, provided it is not too stable.

Since plastic species are the only ones that give rise readily to new forms, it is to be expected that such forms will respond with similar readiness to new conditions. A shade ecad can be made to return to the parent form by transferring its seeds to the sun. 
That all ecads will do so upon being returned to the original habitat can not be told until each one has been placed under experiment. This appears to be probable, but preliminary results indicate that the longer an ecad remains in the habitat that produced it the more difficult a change becomes. This is in accord with the general opinion that stability is merely fixed habit. Hence the longer a plant is in the habit of carrying on its functions or pro-

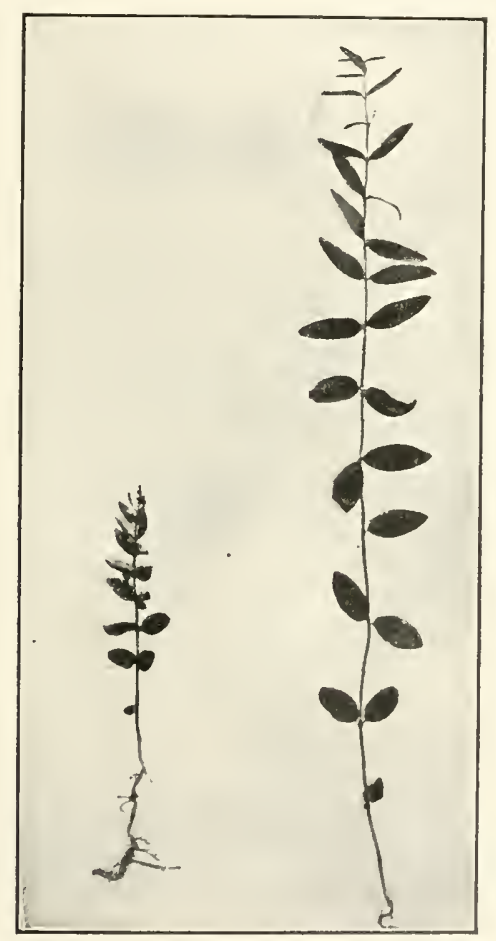

FIG. 67.-The sun form of the mountain skulleap, Scutellaria brittonii, and the new form which arises from it by adaptation to deep shade.

ducing its structures in a certain way the more stable it beromes. In nature ecads are frequent, occurring more or less commonly wherever distinct formations touch each other. While they may wander back at any time to the original home and revert, they ordinarily persist for years, often doubtless for centuries, as dist inct new forms. In amount of difference they are as distinct as many new species and have often been describerl as such. W'hether they 
are species or not depends entirely upon the meaning given to this term. For the present it is elearer to use the term ecad for all new forms arising by adaptation.

Adaptation is closely related to variation. Both are probably equally due to response to the habitat, but they differ in amount and direction of responce. The latter is definite in the one case, indefmite in the other. Origin by adaptation, like mutation,

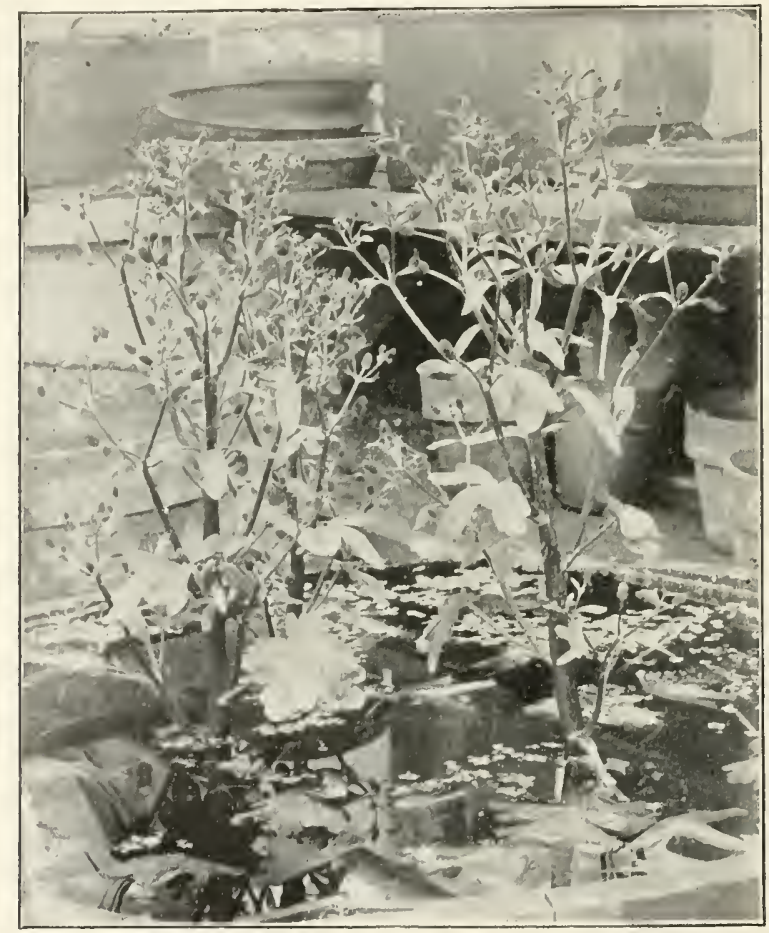

FiG. 68.-A floating form of a crowfoot, Ranunculus seeleratus, produced by artificial adaptation.

takes place quickly, usually in a single generation. Variation must work slowly through many years, in consequence of the heaping up of minute differences. In this process natural selection is the essential factor; in adaptation while present it is much less evident. Moreover, while origin by variation is still a doubtful factor in evolution, it is probable that origin by adaptation is the most frequent method found among plants. 
represented by a larger number of individuals, the unfavorable ones by fewer. This process by which competition, the factors of the habitat, or the two acting together, pick out certain plants to the disadvantage of others is called natural selection. Essentially the same thing occurs in artificial selection, when the florist selects for propagation plants that have a desired feature, and neglects or destroys the remainder. Darwin felt, moreover, that favorable variations tended to grow more and more marked with each succeeding generation. As a consequence, the individuals showing these would become more and more numerous and distinctive, while those with other modifications would decrease and finally disappear. After many years, probably after several centuries, a form sufficiently distinct to be called a variety or species would be produced. Forms arising in such a manner are termed variants.

The critical point in the theory of origin by indefinite variation is the action of natural selection in preserving and accumulating minute differences. The presence of selection in nature is universally recognized. The tendeney for a habit to become fixed is generally conceded. Yet it must be stated that there is no experimental proof that natural selection acts in the way assumed by Darwin. Until such evidence is obtained from careful experiments, it must remain doubtful whether new forms can be produced by variation and natural selection.

209. Origin by mutation. Mutation takes place when one or more individuals of a form show a sudden and more or less marked departure from it in one or more features. Differences of this sort are extremely rare in nature, at least in comparison with adaptations and variations. Sports are more frequently seen among cultivated plants, probably owing to the intensive action of cultivation. In nature one may expect to find a white-flowered sport of any species with red, blue, or purple flowers, but the most minute search reveals few other mutations. When the latter occur they are ordinarily represented by very few individuals. A new form arising by mutation is termed a mutant.

A mutant can rarely be traced to the direct action of the habitat. It is probable, however, that it is the result of delayed or latent response to some change in factor, or of a series of responses set up in the plant by a factor. A species may show mutation in any direction, just as is true of variation. In fact, mutation seems to be merely the appearance of variations 
accumulated within the plant. The difference between a variant and a mutant is apparently one of degree and not of kind. In the one case, however, natural selection plays a necessary part in the process, while with mutants it merely determines whether they shall persist. The features of a mutant may be unfavorable as well as favorable. In addition, a mutant crosses readily with the parent form. In consequence, it runs many chances of disappearing or of being merged with the original form. When the

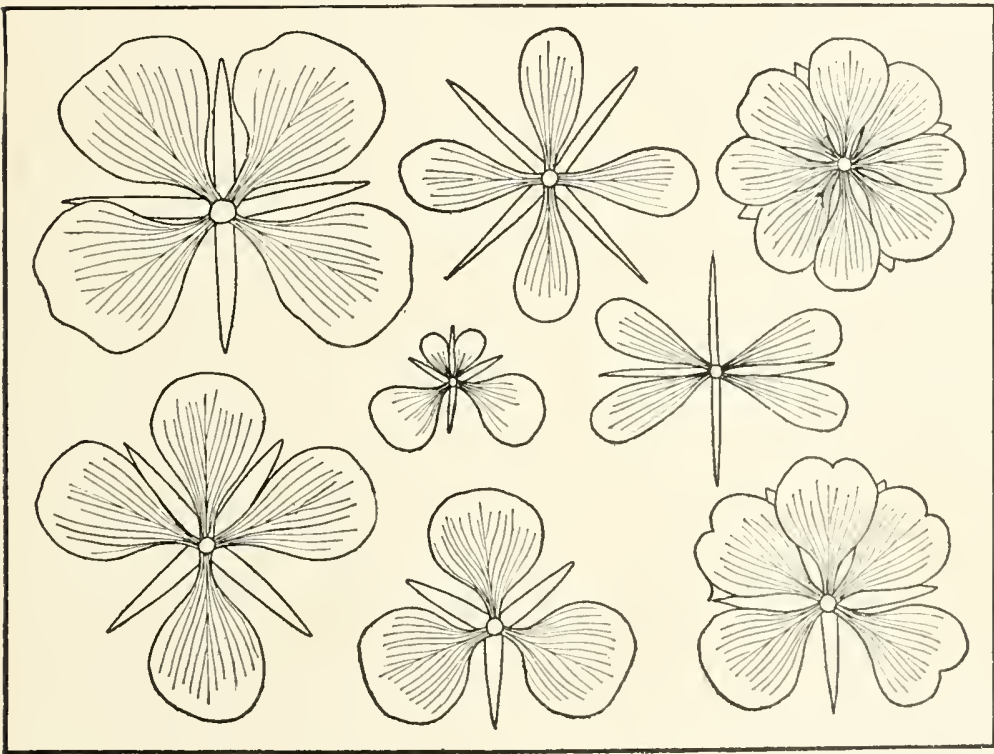

FIG. 70.-Diagrams of flower "sports" or mutations in the fireweed, Chamanerium angustifolium.

infrequence of mutants is taken into account in connection with these facts, it seems probable that origin by mutation plays but a minor part in evolution.

2 ro. Origin by hybridation. When two individuals more or less unlike are cross-pollinated, the result is a hybricl. When the parent individuals belong to the same form, crossing merely produces ordinary fertilization. If the plants are quite different, i.e., if they belong to distinct genera, the foreign pollen is as a rule mable to produce fertilization. Hybrids ordinarily arise between related species, between a species and its varieties, or rarely between varieties. In the first case crosses are said to be unisexual, i.e., 
a certain character found in one parent does not occur in the other. In the second case the cross is termed bisexual, certain characters of the parents combining in pairs. In unisexual crosses the hybrid may show all the characteristic features of both parents, some individuals resembling one more than the other. The hybrid individuals may resemble one parent more than the other, even to the extent of being scarcely distinguishable from it. In bisexual crosses between a species with a certain character present or dominant and a variety of it, in which this character is latent or recessive, hybridation takes place in accordance with Mendel's law. All of the first generation of hybrid individuals show the dominant character of the species. If these plants are self-fertilized, approximately three fourths of the second generation show the dominant character, while one fourth exhibits the recessive character of the variety. If the flowers are again self-pollinated, the recessive individuals are found to come true to type. The dominant group splits, some of the plants remaining dominant while the others show the hybrid character of the preceding generation, i.e., their progeny will contain recessive, dominant, and hybrid forms.

The production of new forms by hybridation occurs only when the resulting hybrids are in some degree a mixture of the characters of the parents. It seems not to be a frequent source of evolution in nature, though a few distinctive forms are known to have originated in this manner.

Experiment 58. The occurrence of new forms in nature. Make a careful scrutiny of the species of the flora for the purpose of discovering ecads, variants, mutants, and hybrids. Note the differences between the parents and the new forms discovered. Estimate the chances the new forms have of surviving, using number, vigor, kind of modification, etc., as a basis for this.

2II. Natural selection. The success of some individuals and the handicapping or destruction of others in the process of natural selection is due either to the action of physical factors or to competition. Since the latter really operates through the reaction upon the habitat, natural selection rests finally upon the ability of a variation or change to cause a form to thrive in a particular habitat. In both mutation and hybridation, the new form appears suddenly, and selection can have nothing to do with its origin. 
It merely determines whether the new form can persist in the place where it arises or to which it may be carried. In adaptation, natural selection and the process of adaptation go hand in hand and selection is obscured. Since an ecad is the direct product of a habitat, it can not arise in a place unfavorable to it, while mutants and hybrids originate regardless of their fitness for the habitat. Natural selection consequently plays no part in producing new forms by either of these two methods of origin. On the other hand, it furnishes the only means of accumulating and preserving minute indefinite variations, and it plays a part in adaptation. The question of its value in evolution must rest chiefly upon experimental evidence that new forms originate by variation.

212. Isolation. As already indicated, the fate of any new form is determined not only by competition and the physical factors of the habitat; it depends also upon the chances of crossing with the parent form or related forms. If forms do arise by variation and selection, the possibility of origin depends largely upon the absence of repeated inter-crossing. Forms which are prevented from crossing with each other are said to be isolated. Isolation may be due to physical or biological barriers, to distance, or in short to any condition which prevents the access of strange pollen.

Isolation has often been thought a necessary condition for the origin of species. This can be true only of such forms as originate through variation. Minute differences between the various individuals would be constantly leveled, and the cumulative action of selection would be effective only upon individuals cut off from the main group. In origin by adaptation and mutation, isolation naturally can take no part. Yet it does directly affect the persistence of either ecad or mutant by preventing crosing and consequent merging with the parent form. In so far as origin by hybridation is concerned, it is evident that isolation renders it impossible, owing to its complete dependence upon cross-pollinat ion as a cause.

213. Polygenesis. The origin of a form at two or more distinct places or times is known as polygenesis. Apecies were long sup)posed to have been created but once and in a single place. This idea of a single origin for all species was carried over into evolution, and Darwin maintained it vigorously against the doctrine of multiple origin. For many years after the general acceptance 
of evolution, the theory of single origin was retained. This was in spite of the fact that almost insuperable difficulties were often found in trying to explain through migration the presence of the same species in two or more remote and isolated regions.

The riew that the same species may arise at different places or times has recently been maintained by several ecologists. ${ }^{1}$ It is

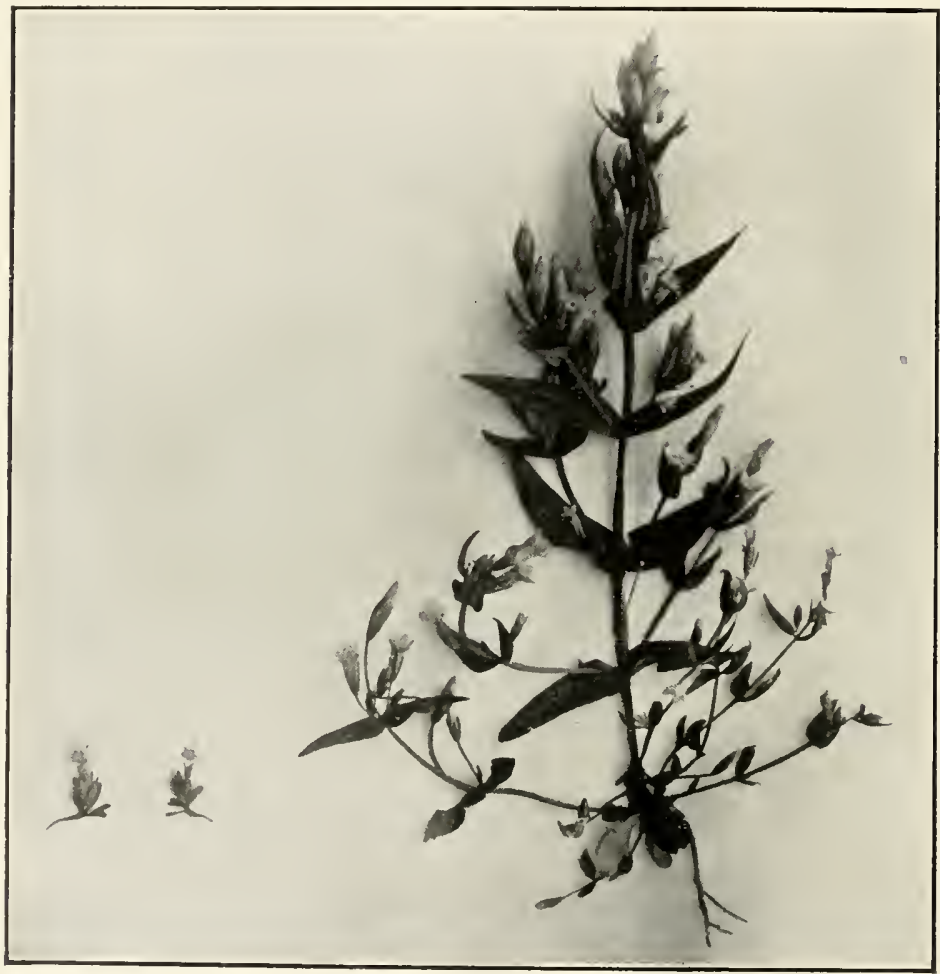

FIG. 71.- The mountain fringed gentian, Gentiana amarella, illustrating polygenesis. The first dwarf grew in alpine gravel at $3700 \mathrm{~m}$, the second in subalpine gravel at $2800 \mathrm{~m}$. and only a few inches from the normal many-flowered form.

at once evident that this may occur in the case of hybridation whenever the parents are spread over a wide area. The experiments of De Tries and his followers upon Enothera have proved that the same mutant may arise at remote places as well as at

${ }^{1}$ Research Methods, 230. 
different times. The writer's own studies have demonstrated that this is equally true of ecads. In consequence, the conclusion is unavoidable that it holds equally well for variants, since the conditions that bring about variation and selection would recur at various points in the area of a species widely distributed.

A form that arises in two or more places is called polytopic, one originating at different times, polychronic. Contrasted with these are monotopic forms which originate but once. On account of migration, it is practically impossible to determine whether a species is polytopic or monotopic except by experiment. It is equally impossible to tell at present which method is the usual one, though it is probable that most forms are monotopic.

214. Experimental evolution. Three fundamental methods form the basis of the experimental study of evolution, ${ }^{1}$ which alone can yield trustworthy results. The first makes use of the actual experiments in adaptation, mutation, hybridation, and variation which are found in nature. The second produces similar experiments in nature, either by changing the habitat in which the form concerned is found, by transferring the plant to new and different habitats, or by actual crossing. The third method is a modification of the last, by which plants are brought into the greenhouse and subjected to known factors, which are kept under control. While these methods of experimental evolution seem simple, they are out of place in an elementary study of ecology. The origin of a new form is so complex and sucli thorough and painstaking study is required, that experiments of this sort must be left to the specialist.

${ }^{1}$ Research Methods, 149. 


\section{CHAPTER X}

\section{METHODS OF STUDYING VEGETATION}

215. The study of vegetation. It is desirable to study the effect of physical factors upon regetation with the same care and thoroughness that are used in the case of the plant. As is shown more clearly later, vegetation responds to the habitat by means of changes and structures, which correspond in a general way to the functions and structures of the individual plant. It accordingly exhibits both adjustment and adaptation. In other words, it is possible to trace the development of vegetation and to study and record its structures. In order that these primary tasks may be carried out with accuracy and thoroughness, it has been necessary to invent methods which yield definite and detailed results. The latter are just as necessary for vegetation as for the plant. In fact the careful study of the habitat and plant loses much of its value if it is not also extended to the regetation.

Methods suited to the study of vegetation must make it possible to discover and follow the smallest changes and to recognize the innumerable details of structure. In addition they must be of such a nature that they furnish a complete and detailed record of all the changes and structures found. The quadrat method, with its modifications, meets all these requirements, and in connection with maps, photographs, and formation herbaria forms a complete system for the exact study of regetation. ${ }^{1}$

216. The quadrat. As the name indicates, the quadrat is a square area of varying size marked off in the formation, i.e., one of the many units that make up vegetation. In its simplest form, it is used to count the individuals of each species, and to determine the relative abundance and importance of the species of a forma-

${ }^{1}$ Research Methods, pp. 160-198. 
tion. In doing this, one discovers many points commonly overlooked, and gains a fair idea of the minute structure of a bit of vegetation. The quadrat is also used to follow the changing aspects of a formation during the growing period and to show the exact differences between diverse areas of it. In the chart quadrat the position of each plant is noted and recorded upon the chart, which thus becomes an indispensable record of structure, and a starting-point for making out future changes. Permanent and

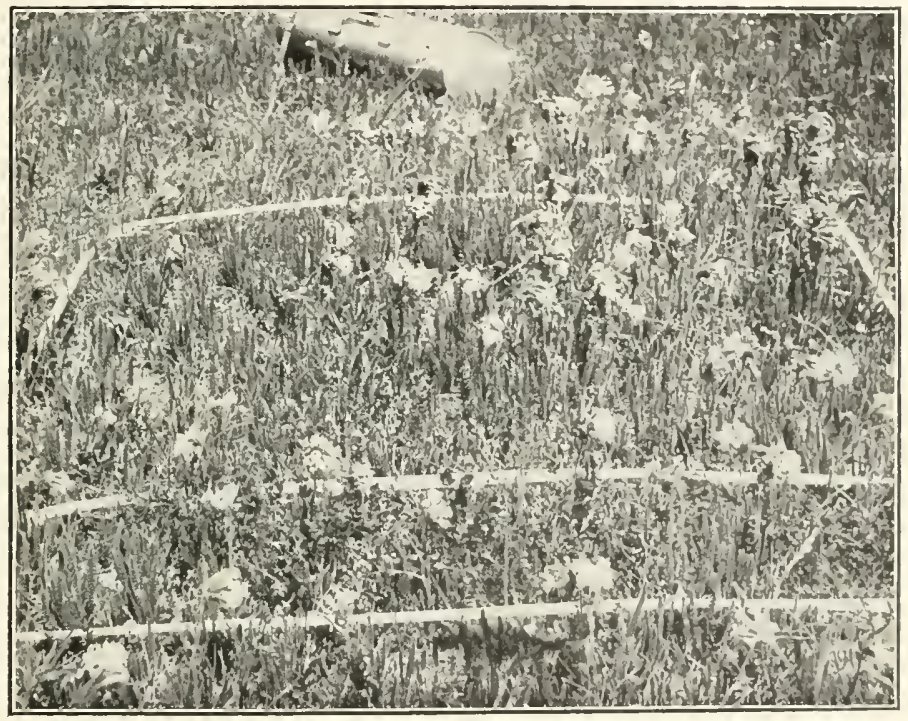

Fig. 72.-A quadrat with charting tape.

denuded quadrats are modifications by which the exact study of an area is extended over a term of years.

While a quadrat is but a small bit of a formation, it shows the exact structure of this bit. It is impossible to study the entire area with the same thoroughness, but a number of quadrats located with eare in those places which appear different at a crlance will reveal the entire range of structure. The quadrat, like any other method, must be used with discrimination, and 1not located at random.

217. Kinds of quadrats. The unit size of the quadrat is a meter and this is the size of the quadrat commonly used. For 
the sake of convenience, larger quadrats are square also. A major quadrat is a square of four units, and a perquadrat one of sixteen units, i.e., it is four meters square. Quadrats are also named with respect to the use made of them. A list quadrat is one in which the species are listed, and the number of individuals of each is counted. Chart quadrats are those in which the position of each plant is accurately indicated upon the chart of plotting paper. Permanent quadrats may be of either sort, though they are nearly always charted. They are distinguished by the fact that they are marked in a way to permit of study from year to year. The denuded quadrat is a permanent one, from which the plants have been removed in order that the manner in which they re-enter may be followed.

218. Marking out quadrats. The tapes used in establishing quadrats are one or two meters long and a centimeter wide. They are divided into decimeter intervals by means of eyelets, and the intervals are numbered from left to right as conspicuously as possible. The tapes are held in position by means of wire stakes which hold the tape close to the ground, and have loops by which they are readily moved.

In staking a quadrat the end tapes are always placed so that the numbers read from left to right, and the side tapes so that they read downward. In making a chart a fifth tape is stretched parallel to the top tape and a decimeter from it. When this strip is charted, the upper tape is moved to the next interval, and so on, thus permitting the rapid and accurate mapping of the whole quadrat. In all cases care must be taken to stake quadrats in such a way that they are square.

219. The list quadrat. This is used when it is desired merely to obtain the number of individuals, i.e., abundance, usually in connection with the chart quadrat. The size of the list quadrat depends chiefly upon the nature of the vegetation. In herbaceous formations the usual size is the major quadrat which is two meters square, but when the plants are small and crowded the meter quadrat is used.

In listing a quadrat, i.e., counting the number of individuals of each species, the smaller, less conspicuous plants are listed first, since these are apt to be tramped down. When the outside tapes and the taller species afford sufficient landmarks, a single species is counted at a time. Otherwise a fifth tape is used to 
mark out each decimeter strip, and the plants are checked off as they are found. Except in cases of unusual difficulty, plants should never be broken or pulled as they are counted. Clusters and bunches of stems from the same root are counted as single plants, and the number of stems indicated by an exponent. In the case of bunch-grasses, each bunch is counted as one plant.

220. Abundance. Species are arranged in the quadrat list upon the basis of their abundance, i.e., number of individuals. They are also divided into groups which correspond to the various degrees of abundance. Two types of abundance are recognized, owing to the fact that the individuals of some species occur in groups, while those of others are more or less uniformly arranged. The former are said to be gregarious, the latter copious. The species counted are classified with respect to the following table of abundance:

Social exclusive, no other species of vascular plants present.

Social inclusive, more than 100 in the quadrat.

$\begin{array}{llrll}\text { Gregarious }^{1} & \mathrm{gr}^{1} & 100-50 & \text { Copious }^{1} & \text { cop }^{1} \\ \text { Gregarious }^{2} & \mathrm{gr}^{2} & 50-25 & \text { Copious }^{2} & \text { cop }^{2} \\ \text { Gregarious }^{3} & \mathrm{gr}^{3} & 25-10 & \text { Copious }^{3} & \text { cop }^{3} \\ \text { Subgregarious } & \mathrm{sg} & 10-5 & \text { Subcopious } & \mathrm{sc} \\ \text { Vixgregarious } & \mathrm{vx} & 5-1 & \text { Sparse } & \mathrm{sp}\end{array}$

While the number of plants per quadrat gives a much clearer idea of the relative importance of the species than the usual terms abundant, common, rare, etc., height and width have much to do with the question of importance. The part which a speries plays in giving character to vegetation and its relation to the halbitat can be determined only by taking into account the space it occupies, as well as its abundance. This may be done with sufficient accuracy, after finding the average height and width of the plant body of any species, by means of the formula, height $\left(\pi R^{2}\right) \times$ abundance.

22I. The chart quadrat. Whenever it is desired to obtain an exact record of changes of structure, the chart quadrat is used. The meter quadrat is preferable on account of the labor involved in charting. The location must be decided by the area to be studied and by the facts to be brought out. Chart quadrats are used chiefly for comparing representative areas of clifferent formiltions or diverse areas of the same one, as well as the spring, summer, and autumn aspects of the latter. 
222. Making quadrat charts. The quadrat is stakerl out in the manner already describer. The chart is made to the scale of 10:1. A square decimeter is outlined on centimeter plotting paper, and the centimeter squares are numbered at the edges to correspond to the intervals of the quadrat. The upper and lower lines are numbered from left to right, and the side lines from top to bottom. Mapping is always begun at the upper left-hand corner of the chart. The position of the plants in the first decimeter of the quadrat is indicated in the first centimeter of the

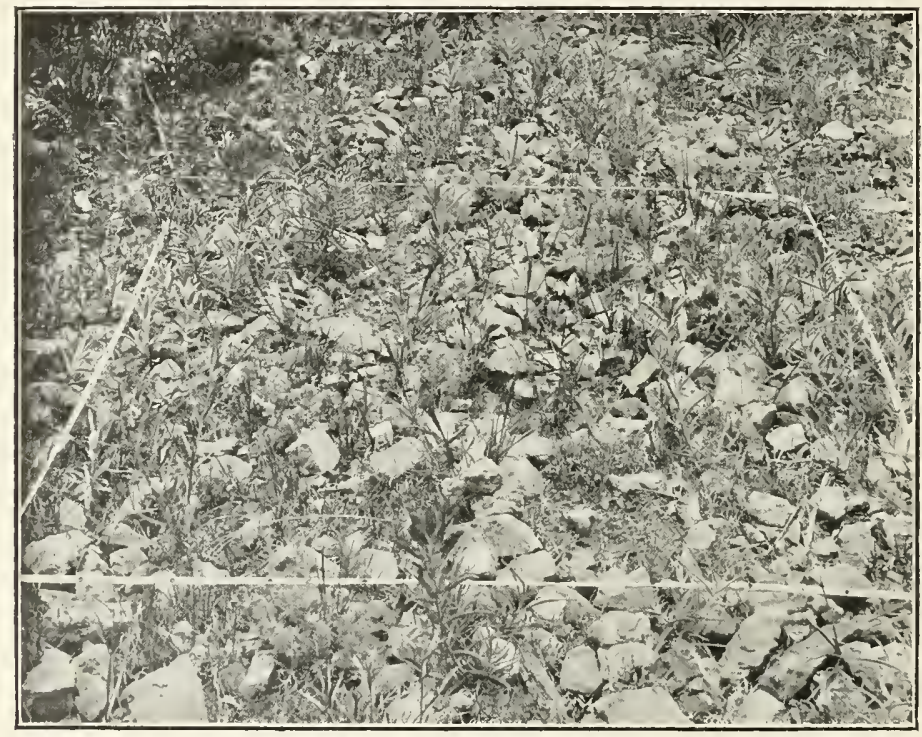

FIG. 73.-A quadrat in the foothill thicket formation near MIanitou. The principal species is the painted-cup, Castilleia integra.

chart, the small squares aiding in determining the exact location. As soon as the first decimeter strip is plotted, the upper tape is moved to outline a new strip, and this is repeated until the quadrat is finished.

Each plant is put down whenever possible, but mats, turfs, and mosses are merely outlined in mass as a rule. This is usually done with large rosettes and mats also, even when they are single plants. Each plant is represented by the initial letters of the name. The first letter of the generic name is used, if no other genus found in the quadrat begins with the same letter. If two 
or more genera begin with the same letter, e.g., Agropyrum, Allium, Anemone, the one most abundant is indicated by $a$, and the others by the first two letters, as al, an. In case two species of the same genus are present, the species initial is combined with the generic one, e.g., ac and ar for Agropyrum caninum and A. richardsonii respectively. When a similarity in names would require three or

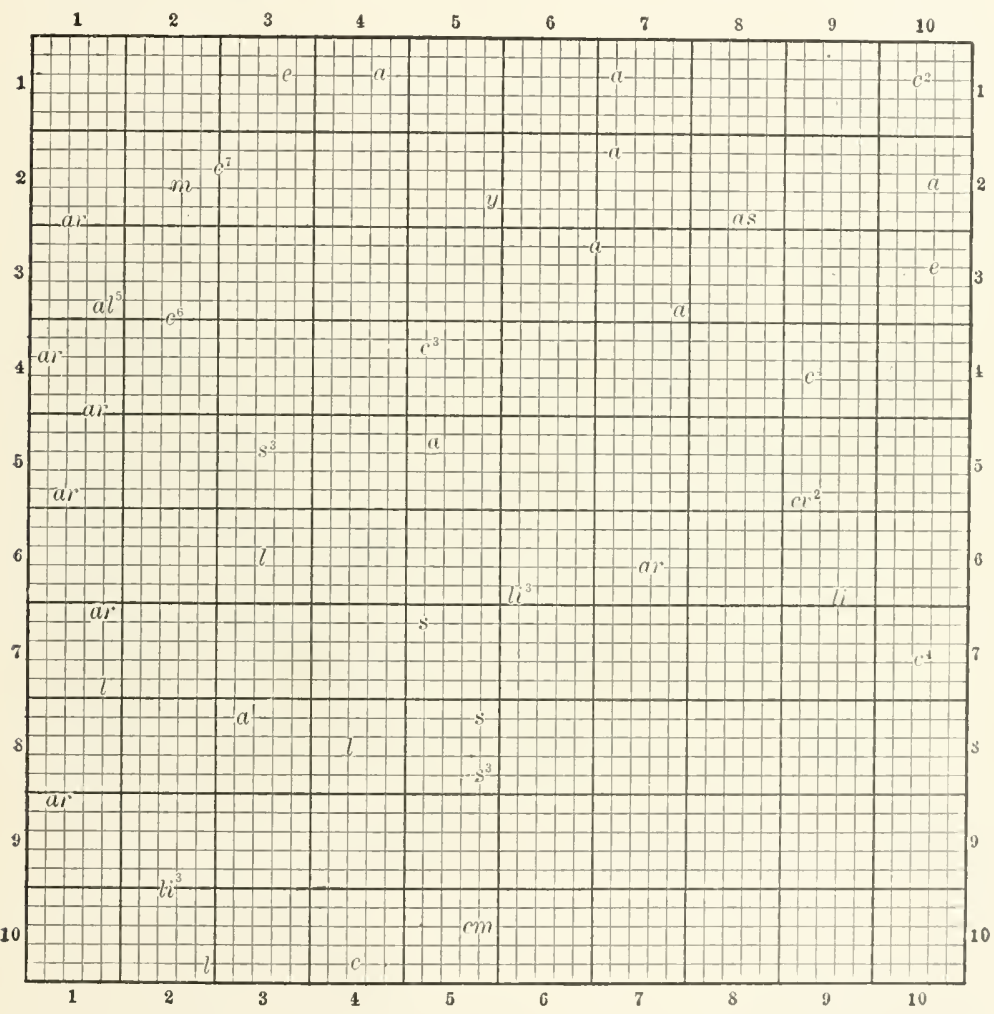

Fig. 74.-Chart of the quadrat shown in Fig. 73. The principal syereies are Castillcia integra $(c)$, Artemisia frugida $(a)$, and Aragallus lamberti (ar).

more letters, e.g., Androsace, Anemone, Antenuaria, this is aroided by fixing an arbitrary sign for one, viz, at. The number of stems from one root is indicated by an exponent with the proper initial, viz., $a^{3}$. Seedlings are represented by a line drawn horizontally through the letter. Plants in flower or fruit are distinguishel by a line drawn vertically through them. In charting the seasonal 
aspects, however, the rule is to indicate only the characteristic species, i.e., those that flower at the time concerned. The legend giving the list of abbreviations and species is placed directly below the chart. Each chart is numbered, and the formation, place, and date indicated. When physical factors are determined for the quadrat, these are recorded upon the chart in so far as possible.

223. The permanent quadrat. Chart quadrats which are marked so that they can be visited and studied from year to year are permanent quadrats. The latter are indispensable for follow-

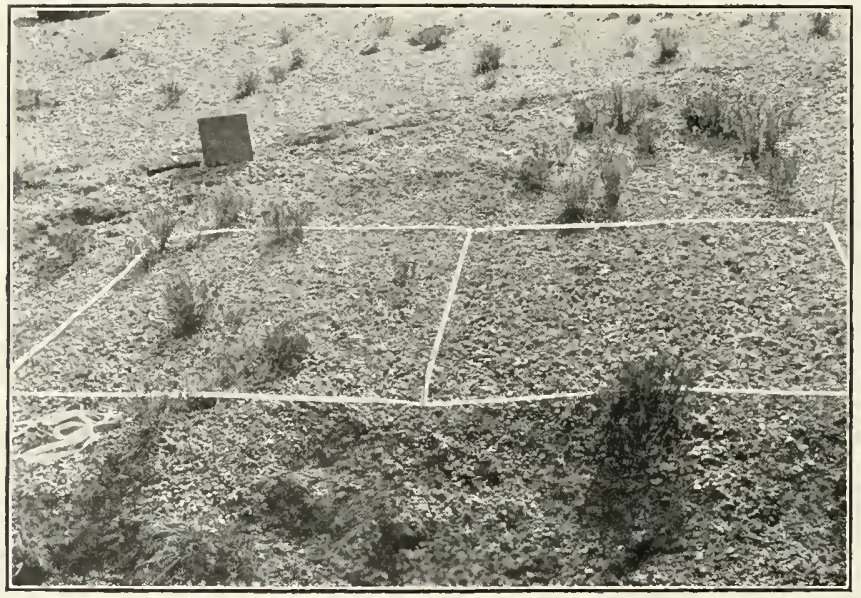

FIf. 75.-A permanent and a denuded quadrat in the gravel slide formation. Both quadrats were charted and one then denuded.

ing the changes of aspects with the season and the slow yearly changes which formations undergo in their development. Since they record the existing structure as well as its subsequent changes, permanent quadrats are used almost exclusively in preference to list and chart quadrats. Practically all formations are constantly undergoing more or less change, much of which is so slow or obscure that it can be discovered only by the permanent quadrat. New plants are entering through invasion, others are disappearing in consequence of it. The extent and rapidity of such changes can be ascertained only by the minute and repeated study of a definite area. This is especially true where one formation is being replaced 
by another, i.e., in the process called succession, in which the use of the permanent quadrat is imperative.

The permanent quadrat is a meter square. It should be located in a station where readings of physical factors are taken. If such quadrats are established elsewhere, readings should be made in them in so far as possible. Permanent quadrats are staked and mapped in exactly the same way as chart quadrats. The quadrat is fixed by driving a labeled stake at the upper left-hand corner, so that its edge indicates the exact position of the quadrat stake. A smaller one is placed at the opposite corner to facilitate the task of setting the tapes accurately in later readings. The label stake bears merely the number of the quadrat and the date when it was first established. It is driven in firmly and is allowed to project just enough to enable it to be re-located with readiness. The use of natural or artificial landmarks is necessary in order that the stake may be found easily upon successive visits. At each subsequent visit the tapes are placed with reference to the stakes, and a chart is mapped in the usual manner. These are labeled and dated like the original ones, but they are numbered to indicate both the quadrat and the visit, e.g., $15^{2}$ is the second chart made of quadrat 15 .

224. The denuded quadrat. This is ordinarily a permanent quadrat, from which the plant covering has been removed after a chart and photograph have been made. Practically the same thing is obtained by staking a permanent quadrat in a new soil or in one recently laid bare. The clenuded quadrat is of the usual size, 1 meter. It is especially adapted to the stuly of invasion and the resulting competition, and throws a flood of light upon the development of formations in the course of succession.

Permanent quadrats may be denuded at any time that seems desirable. The best practice is to establish two side by side, and then denude one of them, the other serving as a control. A quadrat which is to be denuded is first mapped, photographed, and labeled exactly like a permanent one. The regetation is then destroyed, usually by removing it with a spade. Ordinarily the aerial parts alone are removed by paring the surface of the ground. When it is wished to trace the consequences of a greater disturlance, the upper seed-bearing layer of soil is removed and the undereroumd parts dug up. Quadrats are usually denuded in the fall, at or near the close of the growing period, though it may also he done 
in the spring. In this case invasion is ordinarily delayed, owing to the removal of accumulated seeds and propagules. The treatment of denuded quadrats upon succeeding risits is the same as for permanent ones. Since denuding practically makes a new habitat, the factors which control invasion can be found only by taking readings within the denuded area. Such readings are of the greatest value when they can be compared with those of an adjoining permanent quadrat.

225. Transects. The transect is a cross-section of vegetation. It is practically an elongated quadrat, extending through a station, a formation, or a series of formations. Unlike the quadrat, it is designed to show in a graphic manner the differences in structure between two or more contiguous areas. While the quadrat is always located in a homogeneous area, the transect traverses areas more or less unlike, and is plotted with especial reference to topography. The transect is principally used to bring out the differences between zones, and between those groups of individuals called societies, communities, and families. With respect to dimension, transects are distinguished as line, belt, or layer transects. Belt transects are permanent and also denuded. The last belongs properly to investigation and hence is not discussed here.

226. The line transect. This is the form employed when only the more striking differences in structure are sought. It is especially adapted to elementary study, on account of the relative ease with which it may be run. It is ordinarily used for an entire formation or for a series of them. A simple line transect is made by establishing the desired points and then recording the plants pace by pace along the line between them. A more accurate method is commonly used to give detailed results. In this tapes exactly like quadrat tapes but 10,50 , or 100 meters long are used. The transect is located in the area to be studied by running the tape from one landmark to another, and fastening it here and there by quadrat stakes. When the topography is not level, it is necessary to obtain the length and angle of the slopes in order that an exact outline map may be constructed. In noting the plants that occur along the tape, every second vertical line on the centimeter plotting paper is taken to correspond with the tape. The individual that touches the latter is recorded to the right or left respectively, and within the centimeter square that corresponds to the particular decimeter interval of the tape. When 
it is desirable to save the time, the plants are noted on either side alone. The species are indicated by initials as in quadrat mapping. In plotting, the topography is carefully drawn to scale, and the rows of initials transferred from the field record to the outline, centimeter by centimeter. A 10-meter transect can thus be recorded on a meter sheet upon the seale of $10: 1$. Transects longer than this are drawn to a scale of $100: 1$ or $1000: 1$, and the details must be correspondingly reduced. When both detail and length are desired, they may be secured by clividing the line into 10-meter parts and assigning one part to each sturlent.

227. The belt transect. This is a belt instead of a line, and its width consequently permits a more detailed and aceurate record of the arrangement of the plants. The wirlth of a belt transect is determined by its length and by the character of the vegetation. The usual width is one rlecimeter in herbaceous formations and one meter in woodland formations, when only the trees and slirubs are taken into account.

In staking a belt transect two tapes are employed to mark out a strip just one

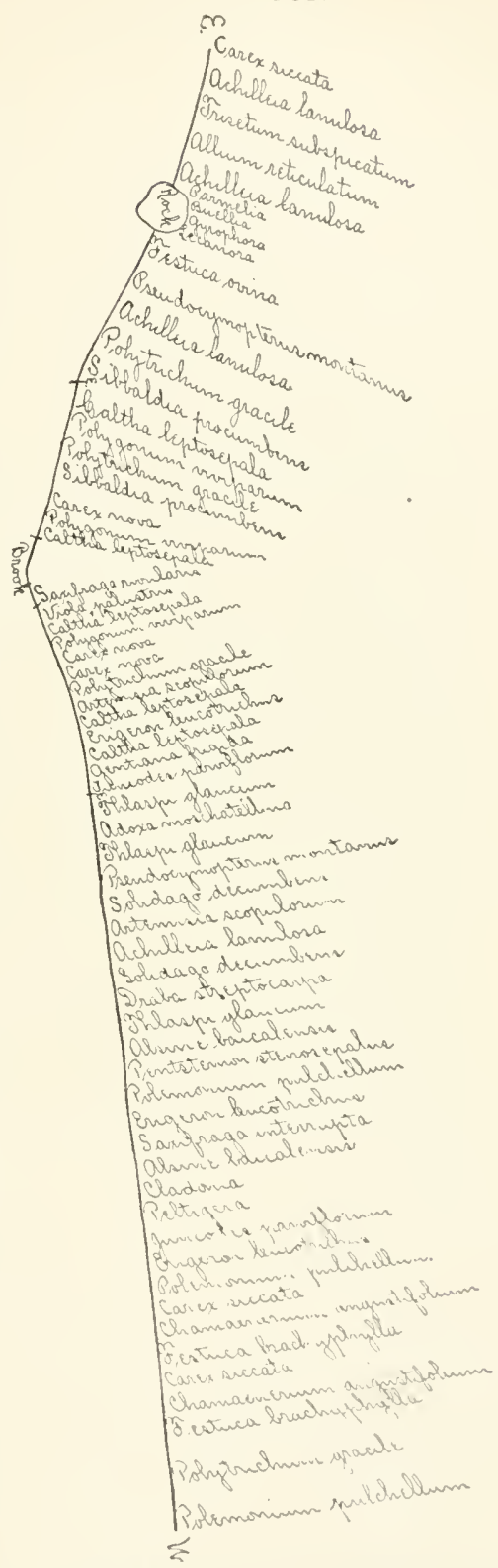

Fic. $76,--1$ line transert through a hog formation which has invaled a forest along a brook. The ecotones loy ween the two formations are shown at $e$. 
decimeter wide. The distance between them is checked here and there by a decimeter rule, and they are fixed firmly in place by quadrat stakes. The plants are recorded as for the line transect, except that the record is for a decimeter strip, and occupies the width of a centimeter on the plotting paper. An interval of a centimeter is left between the successive portions of the strip, in order that they may be copied readily upon the topographic outline. The latter is traced on the plotting paper as indicated for the transect, except that it consists of two lines a centimeter apart. The outline and the field record of the plants of the transect are combined upon a common scale, as in the line transect. Because of their value and the labor involved in making them, belt

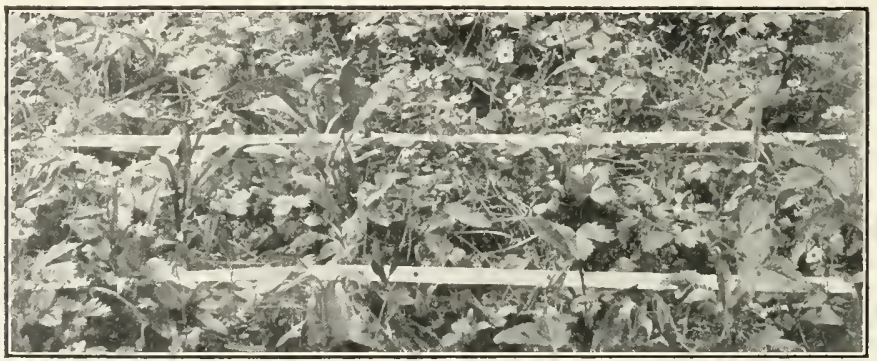

Fig. 77 . - A belt transect through the Fragaria society of a spruce forest.

transects are regularly made permanent by placing a labeled stake at each end.

The limits of zones are shown on charts of belt transects by single cross-lines, and those of alternating areas by parallel crosslines. Whenerer possible, the physical factors should be determined for the various areas through which the transect runs.

228. The migration circle. This is the method employed to show the movement or migration of plants outward from a parent individual or group. Such a movement usually takes place in all directions, and a circle is hence better to record it than a quadrat. Migration circles are regularly permanent in order that the yearly spread of the plants may be accurately followed. Circles of this sort are of great value in the study of competition and invasion. The actual movement of the migrants is often seen to the best advantage in denuded circles, but these are scarcely feasible except for protracted investigation. 
A simple migration circle is located so that a plant or group of plants of the species to be studied forms the center. The size of the circle is largely determined by the nature of the regetation, and especially by the height of the species, which has much to do with the distance to which seed or fruit is carried. A circle of 1-meter radius is best for ordinary purposes, though in open vegetation one of 5 -meter radius is desirable. The usual quadrat tape is used as a radius. This is fixed in the center and the position of each plant of the species concerned is noted as the tape is carried

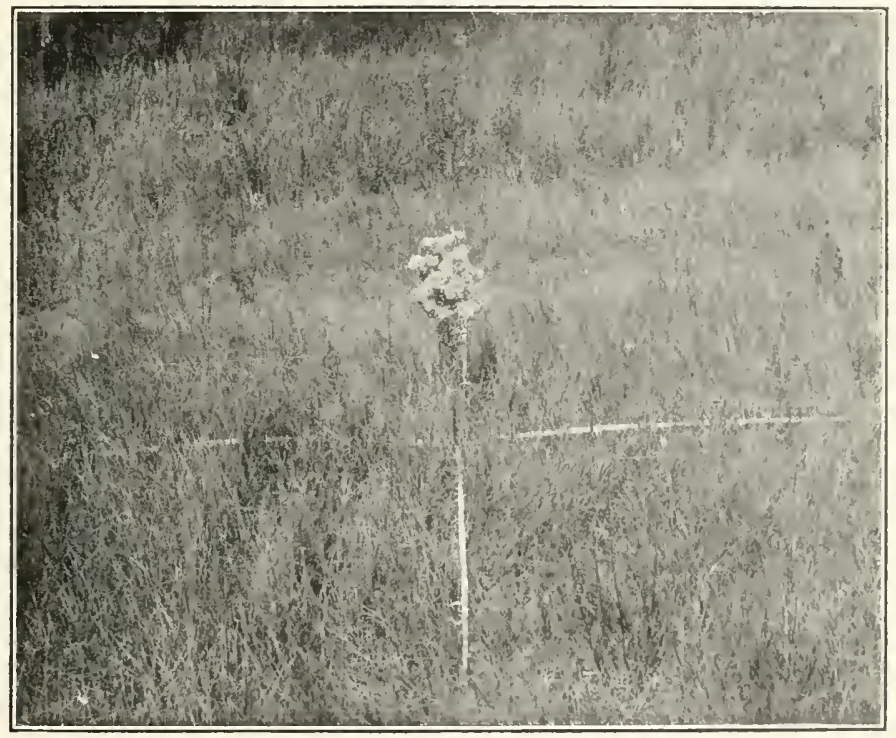

FIG. 7S.-A migration circle in a grass formation, used to determine the direction and amount of movement of the arhenes of Kuhnia glutinosa.

around the circle. The exact positions are indicated upon a chart circle whose radius is a decimeter. The chart is ruled in such a way that each quarter is divided by five rarlii, in order to ais in recording the individuals accurately and quiclily. After the mapping is completed, a labeled stake is fixed in the ennter, thus making the circle permanent. It is often desirable to noc a wroul) of individuals of different species as a center, and to record the movements of all upon the same chart.

229. Formation maps. In studying the structure of a formattion, it is important to make a graphic record of its principal 
features. This is most readily done by means of an outline map in which the various zones, consocies, communities, etc., are shown. Sufficiently reliable data for such maps can be obtained by pacing. In securing measurements for the map of a formation or some part of it, it is first necessary to select a base. This may be a road, ravine, ditch, pool, lake, or stream, or the peak or crest of a hill, ridge, or mountain. The width and length of the base are determined, as well as its general direction. The width and length of the various areas, zones, consocies, etc., are then measured, together with the distance and direction of each from the base. These are reduced to the scale desired, viz., 100:1 for small areas, and 1000:1 for larger ones. The base is first outlined upon a meter sheet, usually of plotting paper, and the various areas are then drawn in the proper size and position. Each area is labeled to denote its character, or it may be colored, thus causing the various parts to stand out more distinctly. 


\section{CHAPTER XI}

\section{THE PLANT FORMATION}

230. The nature of formations. A formation is an area of vegetation, such as a meadow, a forest, a prairie, a bog, a cliff

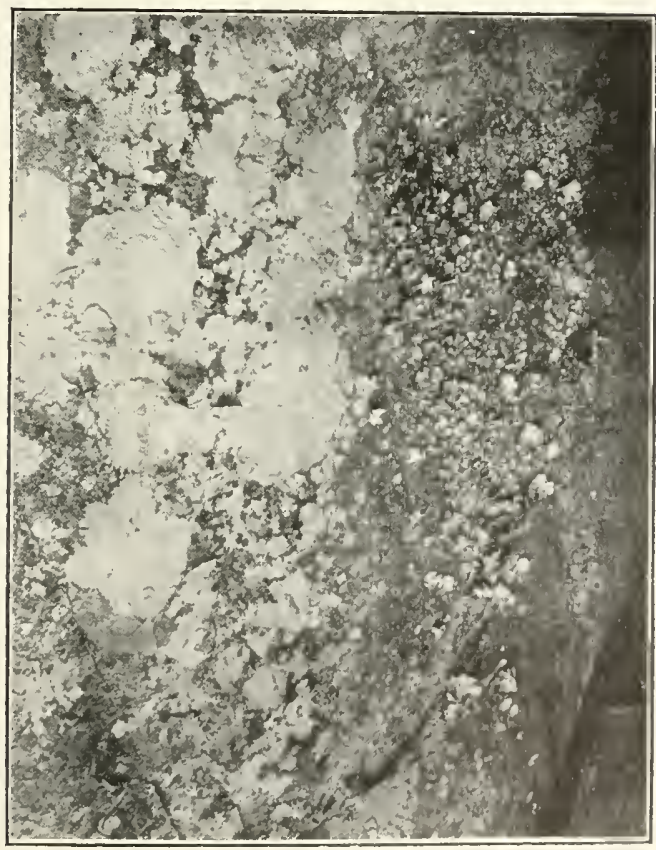

FIG. 79.-A lichen formation on the face of a cliff (Lecenore and L'mbiticeria).

covered with lichens, or a pond of water-lilies. Its limits may be sharply defined, as is true of the forest, cliff, and pond, or one formation may pass almost insensibly into another. Fior example 
a meadow may pass so gradually on the one side into a swamp and on the other into a prairie that it is impossible to say exactly where the one stops and the other begins. Nevertheless, meadow, prairie, and bog are three different formations, as is readily seen when areas typical of them are compared. In consequence, the real test of a formation is its character or composition rather than the sharpness of its limits. Adjacent formations of the same general nature usually shade gradually into each other, e.g., meadow and prairie, forest and thicket, etc. Those that are very different in character, e.g., meadow, pond, and forest, stop abruptly at the line of contact.

231. Recognition of formations. The formation is the unit of regetation. The plant covering of the earth is a vast complex, largely made up of different formations. In recognizing these units or formations, one or two precautions are necessary. The unit itself shows parts which may be mistaken for formations. This danger is considerable when a formation has been so broken up by natural or artificial forces that one or more of its parts have been separated from the original. The chance of confusion is greater when the original formation has disappeared from a region, leaving only one or two incomplete parts to represent it. In such cases the most careful study is necessary to determine the proper standing of these isolated areas. The need of caution is well illustrated in forested countries that have been largely cleared, and in grassland regions which have been almost wholly plowed up. Fragments of the original forest or prairie are left here and there, all more or less widely separated. Some of these are so different in composition that they appear by comparison with each other to be distinct formations. When these are all brought together, and especially when they are compared with larger areas in other places, they are found to be merely the more or less different portions of an original formation. In studying small areas of a few square miles or less, it must constantly be kept in mind that these are probably not different formations, but merely parts of an originally extensive formation which have now become separated. This is especially true of rugged regions, such as mountains, in which the pieces of one formation are very small and widely scattered.

Similar care is necessary in regard to areas which show different stages of development. One stage or formation changes slowly 
into the succeeding one, and during the process the regetation is really a mixture of the two. The same formation often appears on several new or denuded soil areas. In some of these it is composed of entirely different species, apparently indicating a number of distinct formations. If a critical comparison is made of all such areas, or their further development traced, it can be determined whether they are parts of one formation.

One part of a formation may lag behind the others in development, or a physical change or difference covering a small area

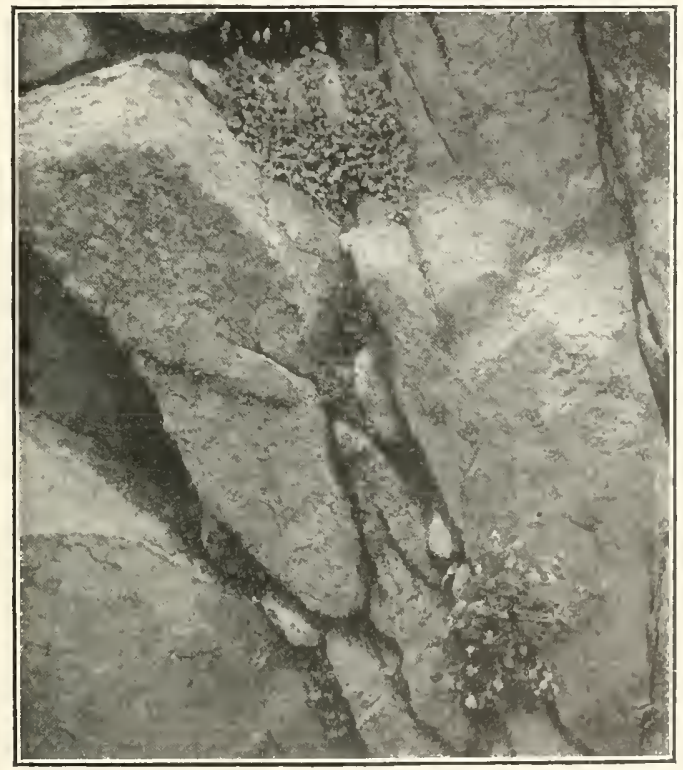

FIG. 80.-A cliff formation of saxifrage herbs and bushes (Ieuchera and Edwinia).

produces an alien group in a formation otherwise uniform. The lichen and moss groups that are found on rocks in forest and grassland furnish a good illustration of this. The lichens which grow on the forest floor and those which are found on the trees clearly belong to the forest formation. They are present because of the shade and moisture furnished by the trees. The same is true of those found among the grasses and sedges of meadows. The physical conditions are those of the formation, and the lichens are as much at home as the other plants. In the calse of rocks 
scattered through forest or meadow, the physical factors are changed, and the species growing on rocks are found to be typical of rock formations elsewhere. Each rock group is a fragment of a formation which is characteristic of a different habitat. The rock may have found its way by accident into the forest or meadow; it may have been uncovered and thus come to serve as a stratum for the lichens, or it may be a relict of a rock formation that has been displaced by other vegetation. In either event the lichen group is foreign to the forest or meadow.

From the above it is clear that the first task in field work is to distinguish as many different areas as possible in vegetation. The next and more important task is to compare the composition and development of these so carefully that the actual formations may be recognized, and the various pieces referred to the proper one. In any region the number of formations is very small in comparison with the number of parts, fragments, developmental stages, etc. It is a simple matter to recognize a forest, meadow, bog, or pond as formations in a locality, and very often the forests, meadows, etc., of the neighboring localities are merely different examples of the same formation.

232. Relation between habitat and formation. Since formations are groups of individual plants and these are dependent upon the habitat, it is evident that the habitat must have the same control over the formation. Strictly speaking, a formation is the mass of plants which cover a habitat. The limits of the two are necessarily the same. A habitat with sharply defined limits, e.g., a pond, a rock, a shaded area, is occupied by a formation whose boundaries are equally definite. One that shades imperceptibly into another shows a formation that grades into the adjoining one. The real characteristic of a habitat is a striking difference in one or more of the direct factors, water content, humidity, or light. A series of habitats thus set off from each other bear characteristically distinct formations, as, for example, xerophytic regetation on a gravel slide, shade plants in a forest, and bog plants in a wet meadow.

The formation is the product of its habitat. It not only shows a general and typical response to the latter, but it also conforms to the minor differences which occur in it. The conditions of water content and light that produce a spruce forest cause it to be sharply set off from a gravel slide formation produced by very 
different amounts of water and light. Within each habitat, however, these factors vary more or less, and their variation is reflected in the formation. In consequence, the formation shows corresponding differences in composition, and may be analyzed into a number of different parts. The latter are often characterized by different species, which give them a more or less distinct stamp. Close analysis shows, however, that these are all of the same general nature, and that the arrangement is a response to the minor variations of physical factors or to competition.

233. The historical factor. In many instances the variations in the arrangement of species and individuals are due to historical reasons instead of physical ones. An invading species may enter the formation at one point and spread slowly from this. It rarely or never happens that it spreads quickly and uniformly in all directions. In the development of vegetation, one or more species or individuals may persist as relicts for a long time after their fellows have disappeared. This may be due to the accidents of migration and competition, or to the fact that the plant itself has a certain ancestral or historical quality that enables it to persist. This historical element also explains why distant portions of a large formation may show differences that are independent of habitat. It also throws much light upon the puzzling changes of various isolated areas of it, since these are especially exposed to invasion. In regions remote from each other, similar habitats are occupied by similar formations, but the species concerned are largely or entirely different, owing to historical facts of migration or development.

234. Development and structure. Formations show certain changes and certain differences in composition. These may properly be called activities, or functions, and structures. The formation itself may be regarded as a complex organism which shows both development and structure. Practically all formations are undergoing constant change. These changes are rapid in the period of development, but are slow and almost imperceptible after the formation becomes stable. Tliey are cliaralcteristic of young formations, but occur in snllall degree in old ones.

The changes which make up development are brought alout by the movement and establishment of plants, by their reaction upon the habitat, and by the competition between them. Acrordingly, 
the activities of groups of plants are aggregation, migration, establishment, reaction, and competition. Migration and ecesis constitute the basis of invasion, while reaction and competition are typical of the complete invasion which causes one formation to replace another, i.e., succession.

In conjunction with the habitat, these functions produce and modify the grouping of the individuals and species of the forma-

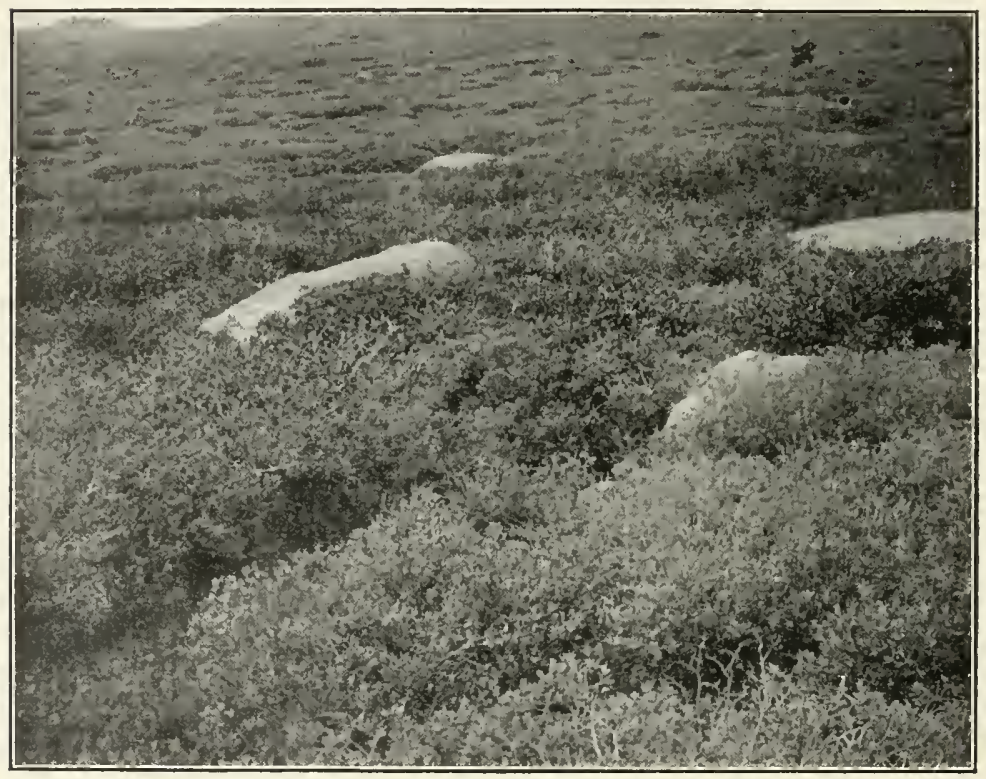

FIG. 81.-A willow thicket formation, consisting of several species of Salix, just above timber line on Pike's Peak.

tion. As has already been seen in the case of the plant, the activities of the formation furnish the clue to its structures. The latter are more or less definite areas produced by variations in the habitat, by the activities of the formation, or, in the majority of cases, by both. In addition formations are themselves grouped together in such a way that vegetation itself shows a more or less definite structure. In both cases, two distinct types of arrangement or structure may be distinguished. In the one the parts of formations or the formations themselves are arranged in zones, and the type of structure is called zonation. In the other the areas show 
no regular order, but seem to fit together in a haphazard fashion, which is termed alternation.

To avoid repetition, the development of the formation is treated together with that of vegetation in the three chapters that follow. Since the formation is the working unit in the study of vegetation, its structure and classification are taken up in detail here, while the general discussion of zonation and alternation is reserved for the final chapter.

235. Structure of the formation. No formation is uniform throughout its entire extent. Practically all show more or less striking differences at every step, so that minute and universal variation may be regarded as a law of formational structure. This characteristic variation is the result of the action of physical factors and of formational activities, i.e., migration, competition, etc., upon the number and grouping of individuals and species. It finds expression in three ways. Species come to be distinguished from each other with respect to number and to their importance in the formation. They adjust themselves to seasonal changes in such manner that they appear only at a certain time, or are more characteristic at one season than at another. Finally the variations within the habitat, together with aggregation, migration, and competition, arrange individuals and species in more or less typical groups or areas.

236. Facies. The importance of the part which each species plays in the formation is largely determined by the number of its individuals. Other factors also have considerable influence in determining this matter. It has already been pointed out that the size, i.e., height and width, of the individuals is an important factor. In addition other qualities of the plant, especially its duration, are of much importance. In determining the control which a species exerts in the formation, all of these points arr taken into account, though in many cases number alone afford: a satisfactory basis.

The dominant or controlling species of a formation are termed facies. These are, as a rule, the most abundant, or they make up) in size or duration what they lack in number. They are the most widespread species of the formation, though they are not neecssarily found everywhere in it. In forests, the faries are the dominant species of trees; in thickets, of shrubs; and in crassland, they are the controlling grasses or sedges. When grasses are of 
little importance or absent, as in deserts, wastes, denuded areas, bogs, ponds, etc., the facies consist of other herbaceous plants. In meadows, prairies, and plains, however, the rule is almost invariable that the dominant grasses alone are the facies. The latter are not necessarily the most conspicuous species of the formation. This is true in the case of forests and thickets, but in meadows and prairies other herbs often overtop and conceal the grasses. This is usually true for only a part of the growing period,

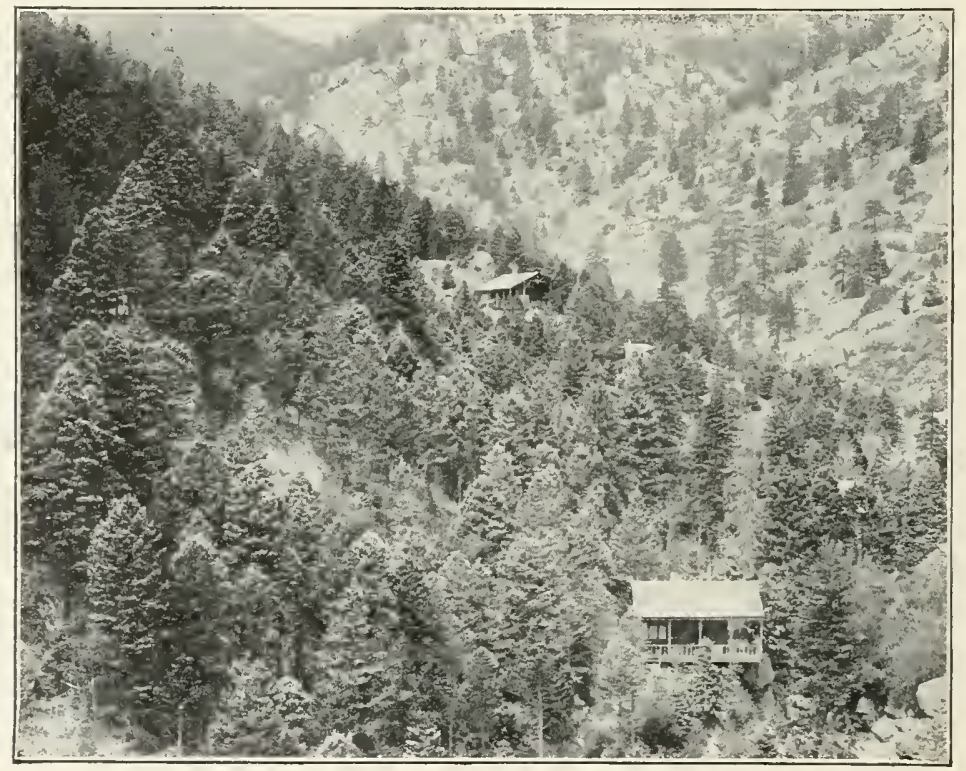

Fig. 82.-The spruce forest formation (Picea and Pseudotsuga) at Minnehaha,near Pike's Peak.

and at all other times such species are subordinate to the grasses, which always form the groundwork of the formation.

237. Principal and secondary species. The rank of the remaining species is determined largely by their abundance, with some reference to their size. The most abundant and characteristic, the facies excepted, are termed principal species, while those of less importance are secondary species. The line between the two groups must be fixed more or less arbitrarily. Abundant conspicuous species can be readily referred to the first group, just as sparse and inconspicuous ones belong to the latter. Between 
these lie the species of more or less importance. The order of these is determined by their abundance, and the place at which the line is drawn between principal and secondary species must be decided with reference to the species concerned.

238. Aspects. The general appearance of a formation changes more or less with the season. It usually has a different stamp during each season, and is said to show seasonal aspects. These are determined by the principal species which bloom at the season concerned, and give a particular impress to it. The facies take

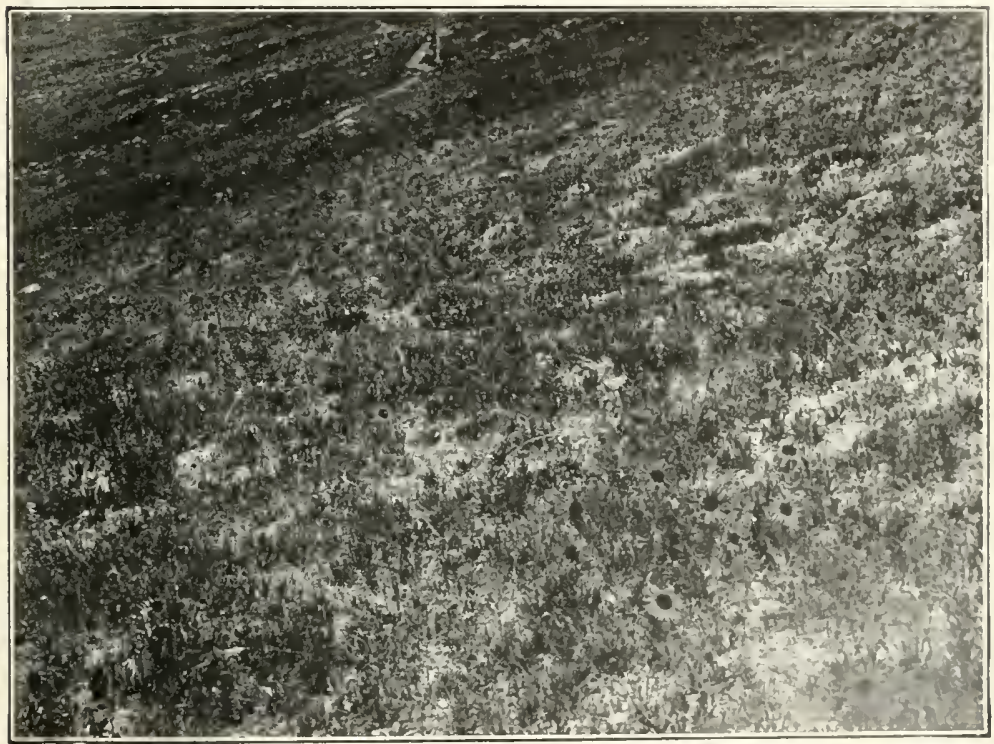

FIG. 83.- Early aspect of the alpine meadow formation, characterized ly Rydbergia grandiflora.

practically no part in this in the case of woody formations, where the seasonal change affects only the undergrowth. This is true to some extent in grasslands in which the facies are more or less obscured by taller herbs, though the flowers of the grases play an important part in one of the later aspects.

The growing periol is usually divided into four aspects. anresponding to the periods of flowering. These are the carly spring, the spring, summer, and autumn aspects, which are also ralled prevernal, vernal, estival, and autumnal. In ligh mountain 
regions the period of growth is so short that only two aspects appear, the early and the late. Since the period of flowering fluctuates from year to year and since some species bloom for a long time and others for a short one, it is impossible to set accurate limits to each aspect. Each one passes more or less gradually into the next, the first summer flowers appearing before the last spring blossoms have gone. Nevertheless, a careful study of a formation throughout the year will make it clear that the plants

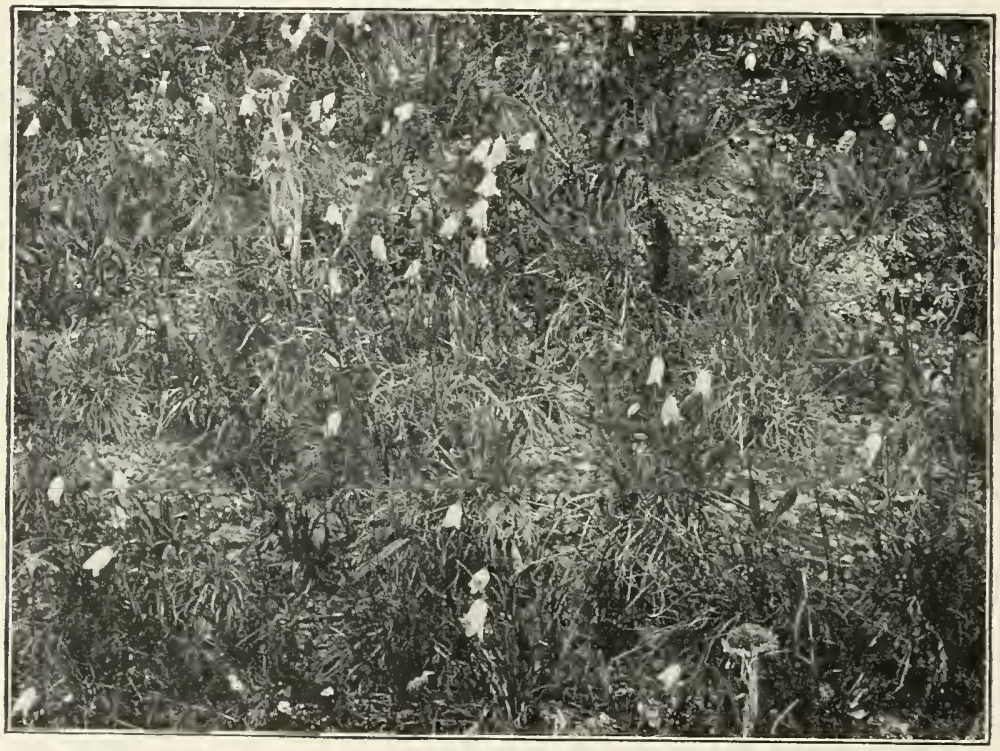

FIG. 81.--Late aspect of the alpine meadow formation, characterized by Campanula petiolata. Rydbergia is seen in fruit.

that flower in the spring are nearly all different from those of the summer, while the summer aspect contains few flowers that appear also in the next one. As a rule, the prevernal aspect includes the few early flowers that appear about the first of April. The spring aspect comprises April and May; the summer, June, July, and the early part of August; and the autumn aspect the remainder of the year.

Experiment 59. Study of abundance and of aspects. Select two representative areas in a prairie or meadow formation. Locate a quadrat in each and list the various species, indicating the abundance 
of each. Arrange them in the order of abundance as indicated in sertion 219, and decide which are facies and which principal or secondary species.

If the quadrat is listed in the earty spring, then marked and listed late in May or early in June, the prevernal and rernal aspects may be compared. When it is possible, it should be listed again at the end of July, and finally in September for the summer and autumn aspects.

239. The parts of a formation: the consocies. The heterogeneity of a formation is due to parts of rarying rank which are

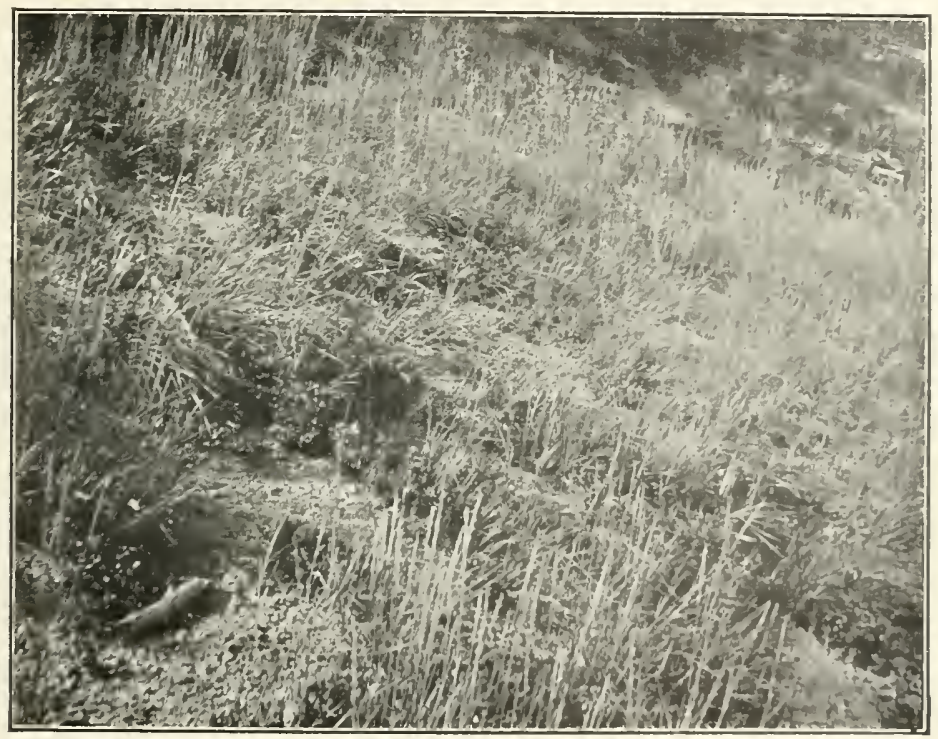

Fig. S5.-An area controlled by the rye grass, i.e., an Elymus conseries, in the Elymus-1Muhlenbergia formation.

called forth by historical as well as by physical factors. These parts or divisions, in the order of rank, are the consocies, the socitly, the community, and the family. In formations ontrollesl ly two or more facies, the latter are very rarely if ever uniformly distributed. One will be more dominant here, another there. and a third elsewhere, or certain ones miy he srouped towether in one place, and others in another. The variots areas that are controlled in this wiy by the facies are termed ronsories. In the grass formation of the prairies there are serelal facies, viz, 
Bouteloua, Andropogon, Kulera, Stipa, etc. In certain places two or more of these may meet on nearly equal terms to form a consocies, e.g., a Bouteloua-Külera-consocies. More frequently a ridge or slope is controlled by one facies, resulting in an Andropogon-consocies, a Stipa-consocies, etc. In some formations consocies are definite, in others they overlap or are indistinct, but in all that possess two or more facies they can usually be recognized. In grassland, however, they are often obscured by the more conspicuous groups of principal species.

240. The society. An area characterized by a principal species is a society, Unlike the consocies, sncieties usually do not cover

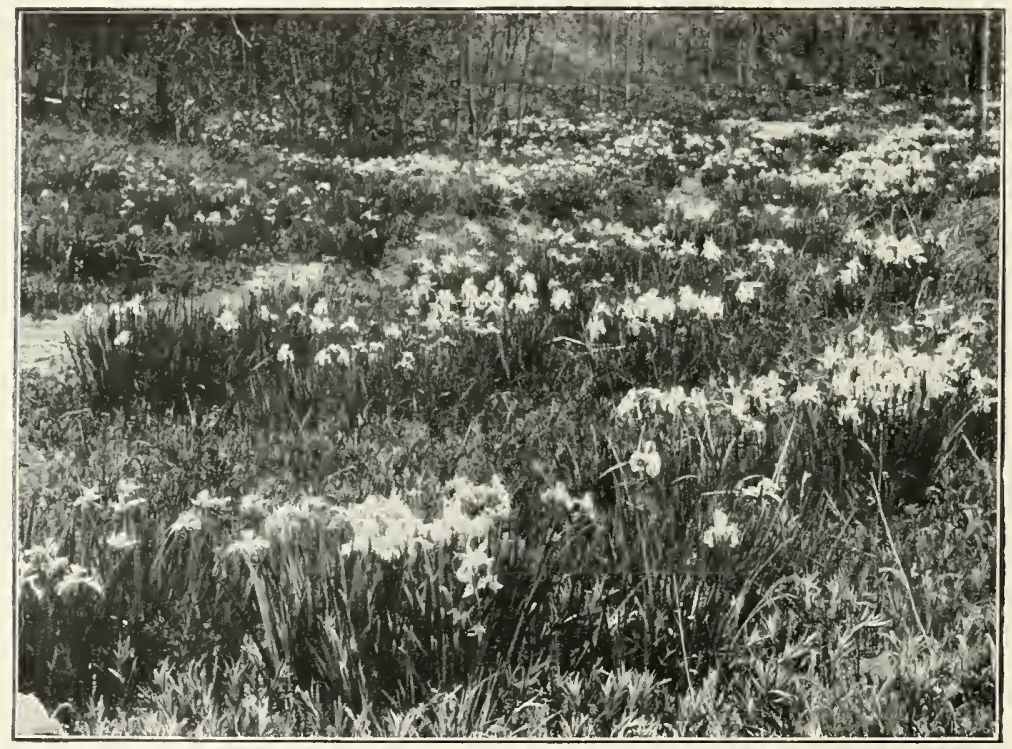

FIG. 86.-An Iris society, eharaeteristic of the spring aspect of the aspen formation in the Rocky Mountains.

the entire formation, but are separated from each other, the gaps being filled by secondary species and by the scattering individuals of principal ones. Societies moreover change with each aspect, as the principal species of one season replace those of the preceding one. In the prairie formation, for example, three characteristic societies of the spring aspect are the Astragalus, the Comandra, and the Lomatium societies. In the summer aspect these have 
disappeared from view, and Amorpha, Erigcron, Kuhnisteru, and Psoralea societies have taken their place. The latter in turn become inconspicuous as they stop flowering, and the character of the autumn aspect is given by societies of Aster, Laciniaria, Helianthus, Solidago, etc. A society, moreover, is often characterized by two or more principal species. Societies have no essential connection with consocies. In any aspert, a consocies may inclucle several or many societies, or it may not show a single one. Finally, a society may lie in two consocies, or it may oceur in any of them.

24I. The community. An inspection of plant societies shows that they are far from uniform. This is of course true of any

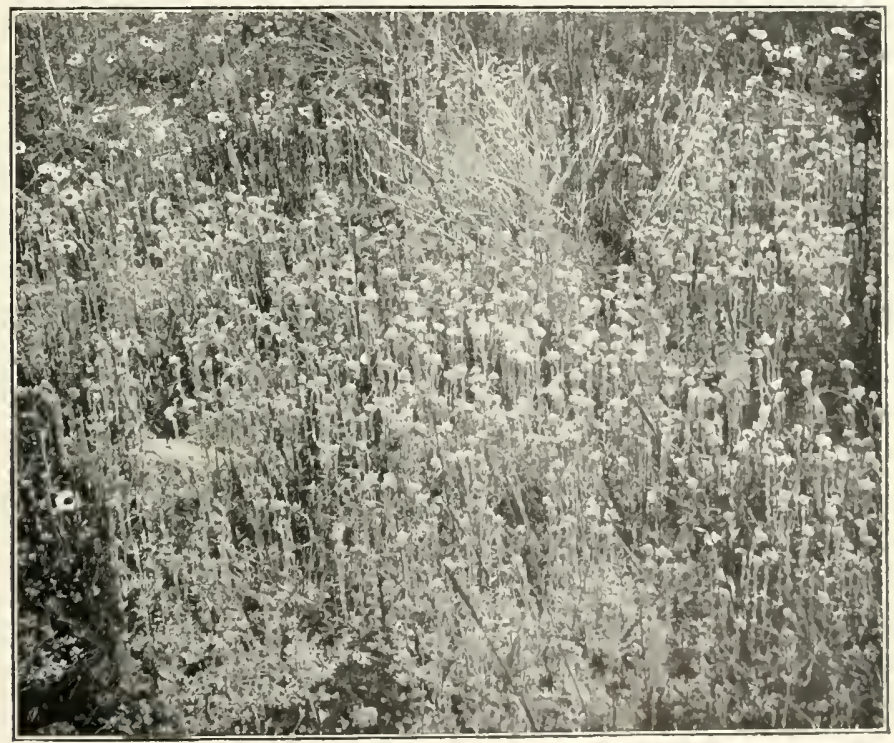

FIG. S7.-An Antennuria community of the aspen formation.

intervals that occur between them. In both places either principal or secondary species may form minor groups alled communitics. In many cases these are farly definite and may be readily recognized. In some instances, however, the number of speries is so large and the arrangement of the individuals so varying that distinct groups are lacking. Communities are easily reconnized in the case of species where individuals grow in groups, and especially where 
families have been invaded by plants of another species. A large number of prairie and meadow species occur in more or less definite communities, e.g., Anemone, Draba, Lithospermum, Rosa, Laciniaria, etc. Communities appear in nearly all formations, but they are most abundant in the open ones which develop in new or denuded habitats.

242. The family is a group made up entirely of individuals belonging to a single species. In many instances it springs from a single parent plant, but this is not necessarily the case. In size a family may consist of a few individuals or it may cover a large area. It passes into a community as soon as one or more indivicl-

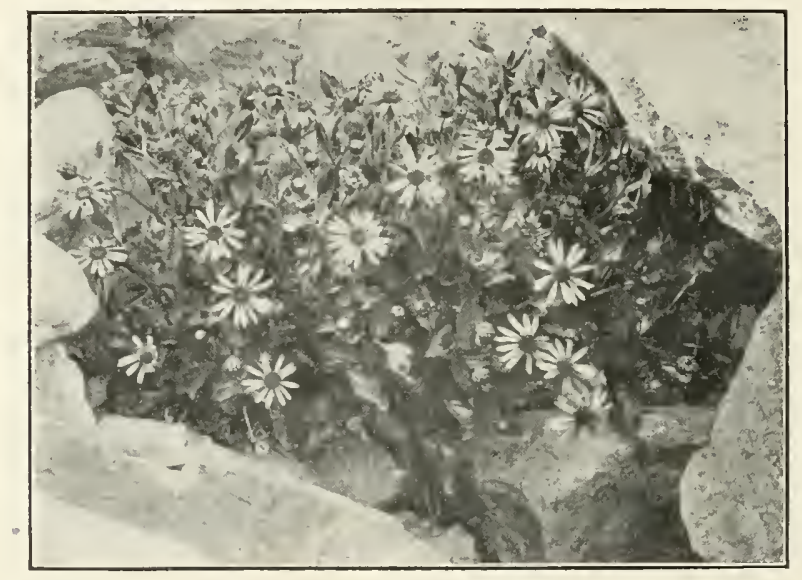

Fig. SS.-A Senecio family in the rock clefts on Pike's Peak.

uals of another species enter it. In consequence, families are usually small, since they are readily invaded when large. Species whose seeds are numerous and little or not at all modified for dissemination often form families. For this reason annuals are found to form families much more frequently than perennials do. Families are more or less characteristic of new or denuded soils, in which each pioneer usually serves as a center for its offspring. As the individuals become more and more numerous, they invade the neighboring families formed by other species and change them into communities. In the ordinary vegetation of forest and grassland, families are relatively rare, since they are readily turned into communities by the morement of their crowded 
neighbors. Occasionally a vigorous weed invades and by strong competition conquers a small area. This frequently happens when the original plants are destroyed over a small space, thus permitting some annual to enter and increase rapidly. Hordeum and Lepidium families are especially apt to appear in this fashion in grassland.

Experiment 6o. The structure of a formation. Examine a prairie, meadow, or forest for families and communities. Make a chart of each and note the differences between them.

Run a line transect through the formation from east to west, and north to south by pacing. Note the families, communities, societies, and consocies encountered.

243. Layers. Forests and thickets show a more or less definite arrangement of the plants below the facies into layers. There is

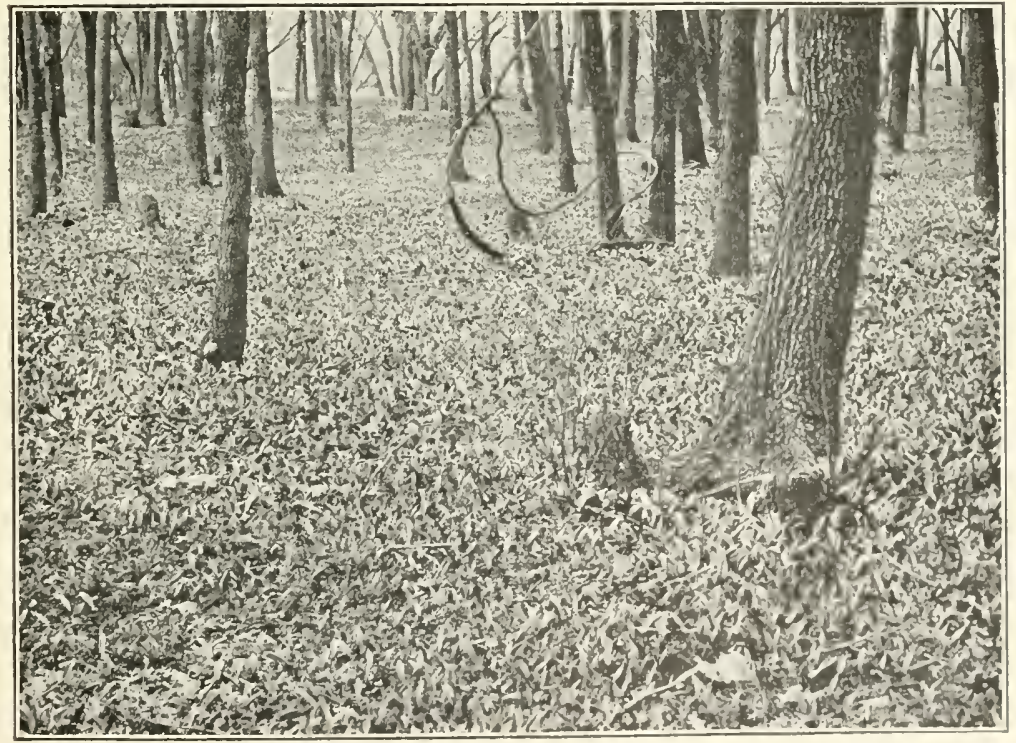

Fia. 89.-The Erythronium layer in the early spring aspect of the oakhickory forest at Lincoln.

also a suggestion of the latter in many grassland formations, while some thicket-like formations of tall herlss show much the samo conditions as ordinary thickets. Iayers are the result of the habit of growth of the various speries, and this is laredy a response 
to the reduced light of the habitat. Tall-growing plants which require the most light form the first layer below the facies, while the low forms which will grow in very weak light make up the lowermost layer. The number of layers in a forest depends upon the compactness of the primary layer of facies. When the light beneath the latter is reduced to .002 or .001 , layers are impossible, since practically no flowering plants can grow under these conditions. Layers are developed to the highest degree when the primary layer permits more or less sunlight to shine through it, i.e., in a light intensity varying from .1 to .01 . There is often a more or less incomplete secondary layer of shrubs and small trees. Below this usually occur two or three herbaceous layers. The upper one consists of tall plants about 2 meters high. It is followed by a middle layer about 1 meter high, in which the bushes are usually found, and the latter by a lower layer of small herbs 2-5 decimeters high. Beneath these is found a ground layer of mosses, lichens, cup-fungi, toadstools, etc., which is the only one that remains in the densest forests. The herbaceous layers are always more or less interrupted, owing to their close dependence upon light. Either one of them may be absent, or finally all of them may disappear, as has been indicated.

The explanation of layers, as well as that of consocies and societies, depends upon a knowledge of zonation and alternation and is to be found in the chapter dealing with these principles.

Experiment 6r. Layered formations. Make a careful examination of a forest or thicket, noting the number and extent of the layers present. Ascertain the characteristic species of each layer and note the various groups which they form in it.

244. Classification. Formations are classified with respect to habitat, development, position, dominant species, or their general character. Classification upon the basis of habitat places together formations which are similar in their response to physical factors and in general structure. Developmental classification is based upon the fact that the formations which follow each other in the development of regetation upon a new or denuded area have a certain organic relation to each other. In many cases it also brings out certain important relations to physiography. Grouping with respect to position is based solely upon geographical factors. The formations brought together in this way have little relation- 
ship to each other beyond the superficial one of location. Formations, especially contiguous ones, sometimes show more or less similarity in composition, i.e., they have a certain number of species in common. With respect to the grouping of their incividuals, they are distinguished as open when the plants and plant groups are scattered, and closed when they are so crowded that

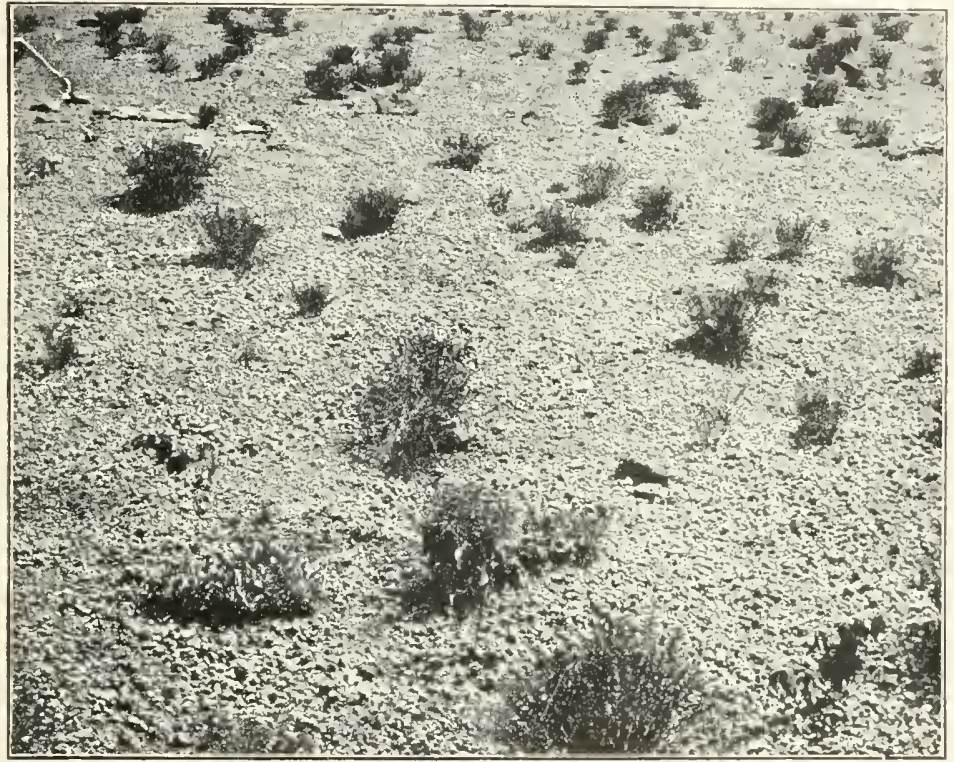

FIG. 90.--The gravel slide a xerophytic formation of the Rocky Mountains.

invasion is very difficult. Finally, a formation is said to be mixed when, owing to position or development, it is really a mixture of two or more distinct ones.

245. Classification by habitats. We have alrearly found that the most important differences of habitats so far as plants are concerned are due to water and light. What is true of plants must hold as well for the formations which they compose. In consequence, three great groups of formations are recognized corresponding respectively to hydrophytes, mesophytes, and xerophytes. Upon the basis of light, mesophytic formations are sul)divided into sun and shade formations. Within each group particular formations are arranged according to the type of habitat, i.e., pond, forest, meadow, dune, ete. Headow formations, for 
example, may differ from each other considerably or entirely in the species which compose them, but they are essentially alike in character and structure and hence belong to the same type.

The names of the particular formations of each type are obtained by adding the name of one or more facies to the general

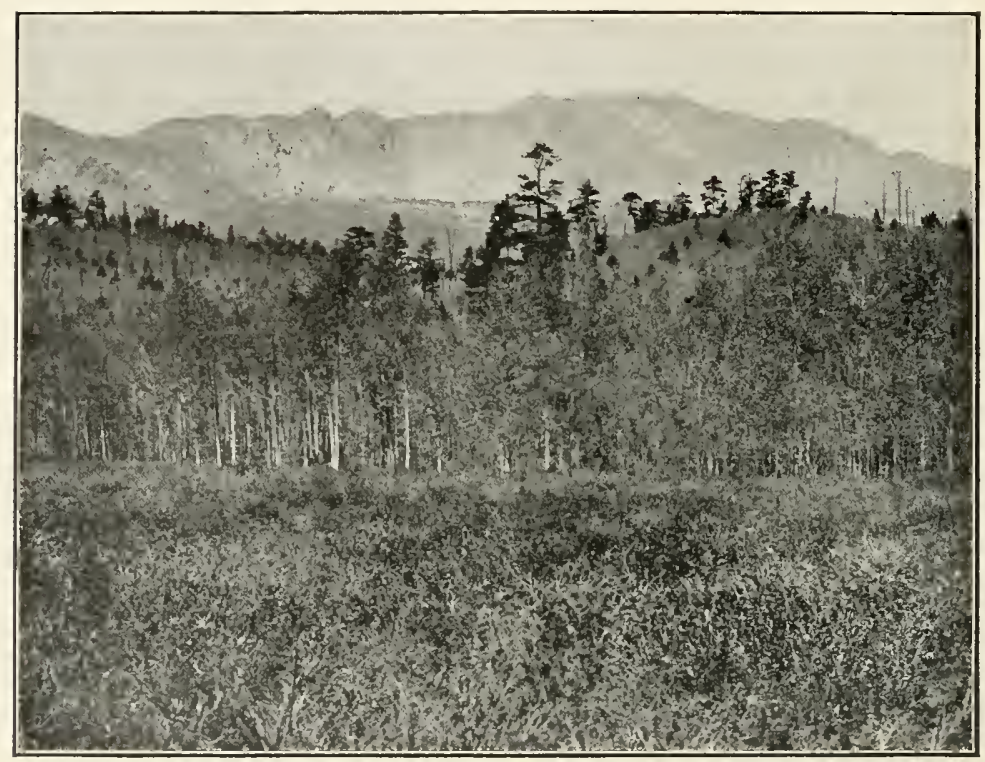

FrG. 91.-The aspen forest, a mesophytic formation. Pines appear on the drier ridges.

name of the type. Thus, an oak-hickory forest is essentially different from a balsam-spruce forest, though both belong to the group of forest formations. The buffalo-grass prairie is similarly distinct from the grama-bluestem prairie, etc. The same formation may occur in two or more separate localities, and in this case geographical terms are used to distinguish the different examples.

246. Types of formations. The following list shows the arrangement of the more common habitats.

I. Hydrophytic formations
(1) pond
(5) ditch
(2) marsh, bog
(6) meadow thicket
(3) stream
(7) bank
(4) spring
(8) sandbar 
II. Mesophytic formations

1. Shade plant formations

(9) forest

(10) grove

(11) open woodland

(12) thicket
2. Sun plant formations

(13) meadow

(14) pasture

(15) cultivated field

(16) wastes

III. Xerophytic formations
(17) desert
(22) dune
(18) plains
(23) cliff
(19) prairie
(24) saline area
(20) sanddraw
(25) heath
(21) strand

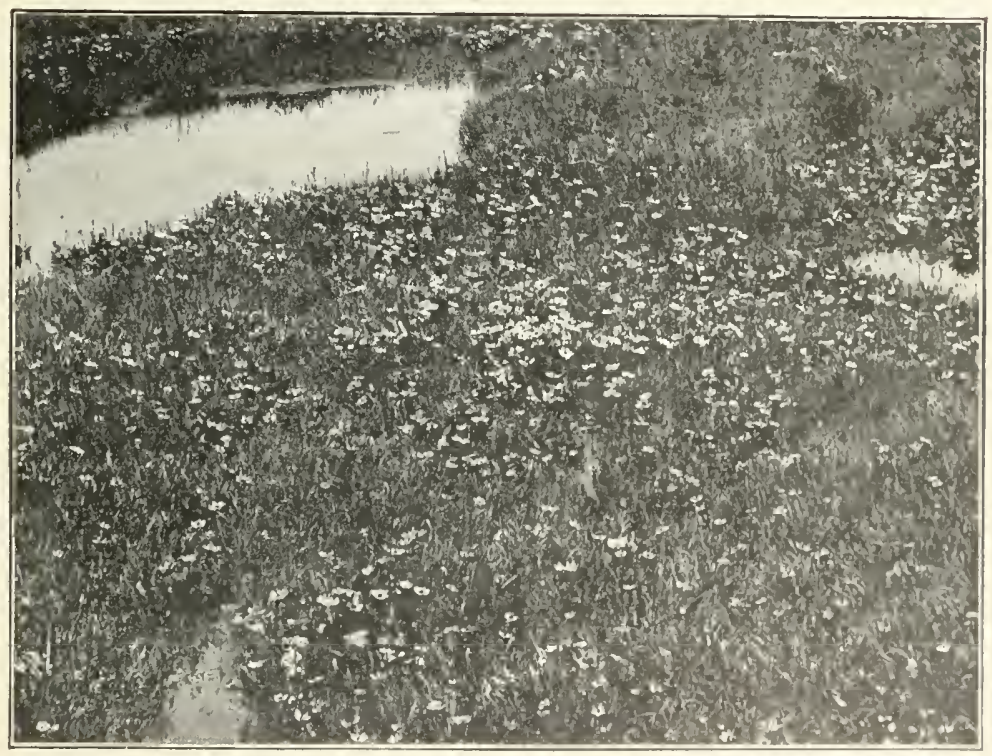

Fig. 92.-A bog of marsh-marigolds, a hỹdrophytic formation.

247. Developmental or physiographic classification. Ill the formations that belong to one suceession are classified together by virtue of being stages in the development of it. Such al grouping is often connected with changes in physingraphy. The formattions are in each ease arranged in the sequenee fommel in the prarticular sucession. A developmental classification is of great importance beeause it summarizes the history of striking whinges 
in regetation. 'The basis is entirely different from that of habitat classification and in consequence the two supplement each other. Both necessarily deal with the same formations, and are used to give different points of view of the regetation of a region. The habitat classification is simpler in that it considers only those formations actually on the ground, while development usually has to take account of formations that have disappeared.

248. Regional classification. The grouping together of formations that occur in the same region is warranted by the fact that

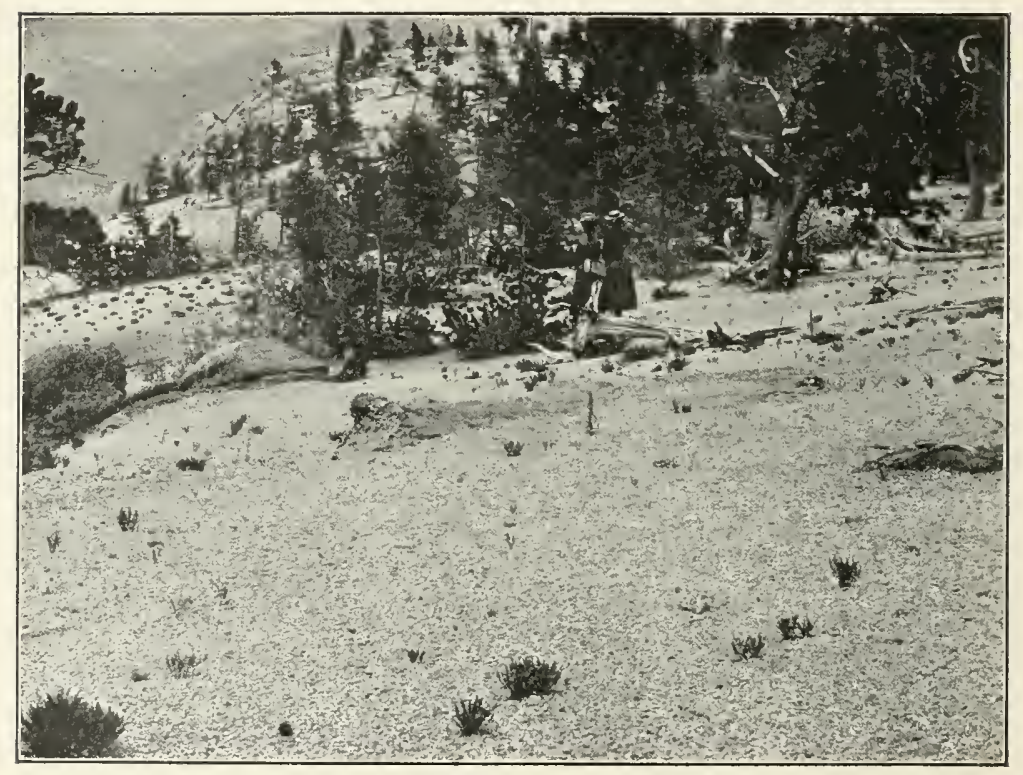

Fig. 93.-An open formation of pines.

they have a larger or smaller number of species and genera in common. This has arisen from the mutual invasion constantly taking place between adjacent formations. An additional reason for such a grouping is furnished by climatic factors, which are essentially uniform in each region. Classification with respect to general vegetation regions or topographic differences is frequently used. Its value lies in furnishing a simple summary of vegetation rather than in pointing out an essential relationship. In mountain countries, the grouping is a topographic one, determined by 
altitude, as follows: (1) lowland formations, (2) upland formations, (3) foothill formations, (4) subalpine formations, (5) alpine formations, (6) niveal formations.

249. Open and closed formations. These terms refer to the completeness with which the ground is occupied by plants, and indicate the relative ease with which newcomers may invade it. In open formations the habitat is slightly or partially occupied, and new plants enter readily without displacing those already present. The species of closed formations occupy the ground com-

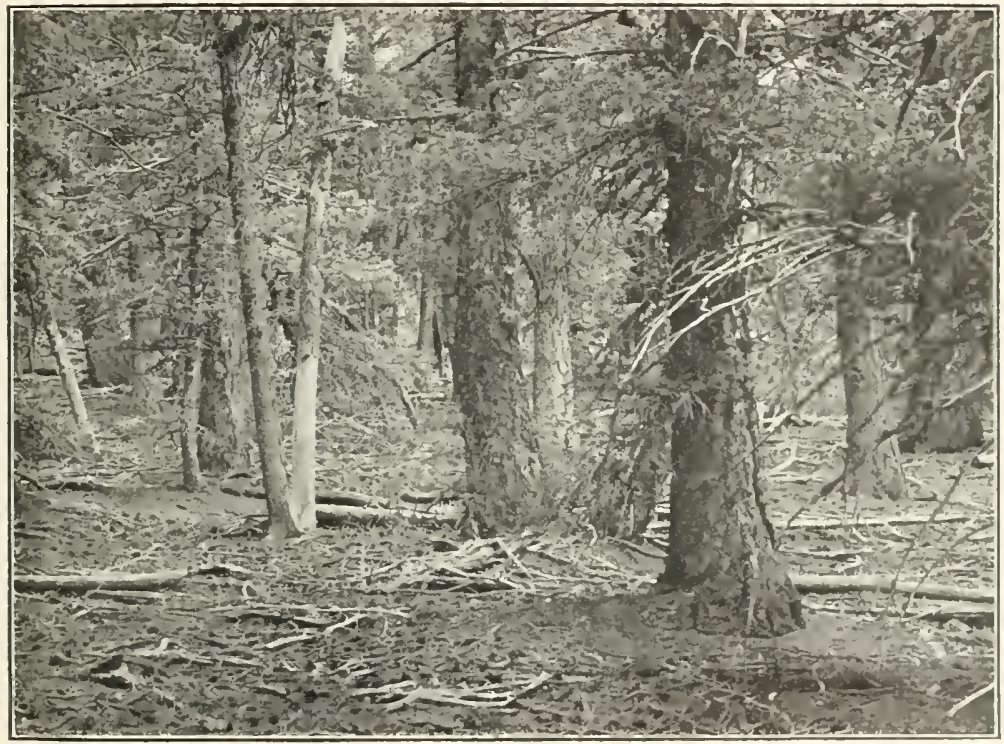

Fig. 94.-A closed spruce formation.

pletely. The competition is intense and new plants can enter only by displacing some of the original ones. Open formations form the earlier stages in the development of a particular area of regetation. They are typical of new or clenuded soils, such as blowouts, dunes, flooded areas, gravel slides, bumed plines, ete. Closed formations constitute the later stages of a suceession, and especially the final or stable condition. Forest, thicket, meatow. and prairie are good examples.

250. Mixed formations. These are proluced ly the intermingling of the species of two or more adjacent formations, ar of 
two successive stages of the same succession. The former usually results in a zone of varying width between the formations concerned. When one stage of a succession is gradually replaced by another, the entire habitat is often occupied for many years by a more or less equal mixture of the two. It is usually possible to determine the formations that produce the mixed one, while the relative abundance of their respective species indicates which formation

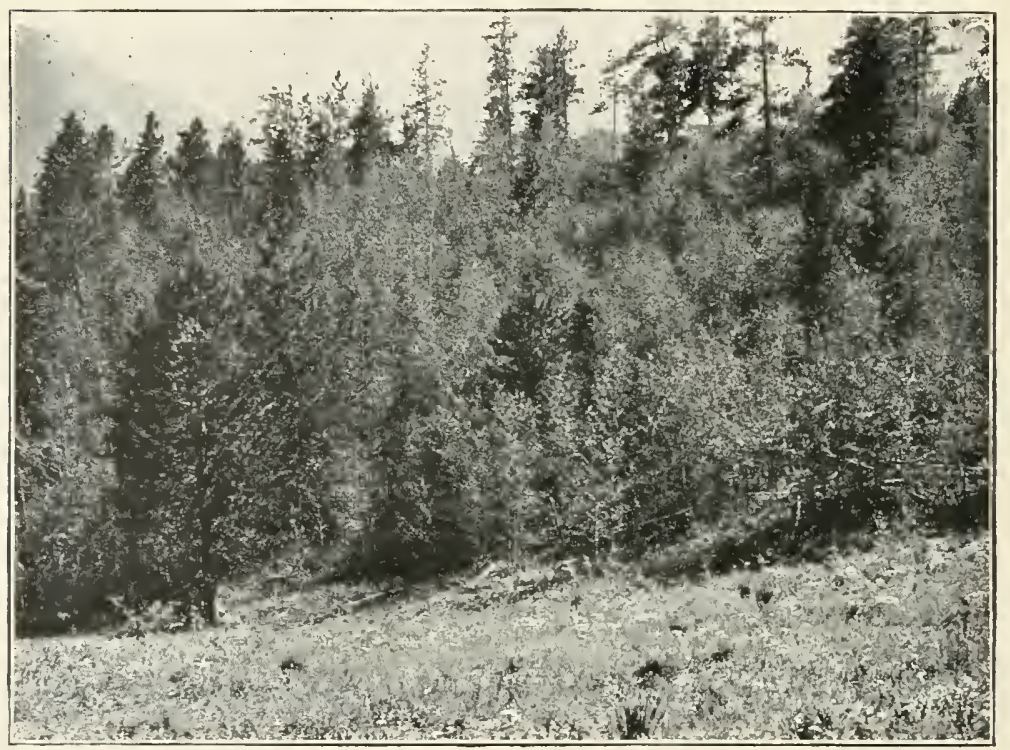

FIG. 95.-A mixed formation of aspens and spruces, produced by the coming in of the spruces, which will finally replace the aspens.

plays the most important part. Since mixed formations often persist for a long time, it is often necessary to consider them in detail, very much as though they were distinct formations. In some cases it is probable that new formations have arisen by the permanent mixing of two contiguous ones.

Experiment 62. Comparison of formations. Make a general study of several formations of the neighborhood. Determine the facies and principal species of each, and find out what species they have in common. Classify them with respect to habitat, distinguishing open from closed ones, and point out any that seem to be mixed formations. 


\section{CHAPTER XII}

\section{AGGREGATION AND MIGRATION}

25I. Aggregation. The coming together of individual plants is the process that produces regetation. It gives rise to the innumerable groups of varying rank which taken together make up regetation. This process is aggregation. In its simplest form aggregation is the immediate result of reproduction, but as a rule the movement or migration of the individuals plays an equally important part. The degree and kind of aggregation are consequently determined by the relation between reproduction and migration. Aggregation is also affected by the abundance of the parent individuals, which may occur singly or in groups.

The simplest cases of aggregation are independent of migration. Aggregation gives rise at once to competition between the aggregated individuals, and upon the outcome of this depends adjustment or establishment. In the majority of cases simple aggregation is prevented by the migration of the seeds or fruits away from parent plants. The result, however, is the same, the final grouping of the individuals depending upon competition and ecesis.

252. Simple aggregation. The simplest examples of this process occur in such alga as Glococapsa and Tetraspora, in which the plants resulting from fission are held together by a mucilaginous substance. The relation between the plants is essentially that of parent and offspring, even when the parent disappears regularly as in the fission alga, or sooner or later as in the case of ammuals. Such a group of individuals is a family, and correspouds more or less closely to the family in human society. Practically the same grouping occurs in the case of terrestrial forms, flowering plants especially, when the seeds of a plant mature and fall to the ground about it. The size and density of the family group are detormined 
by the manner of reproduction and especially by the number of seeds produced. The character of the family is also affected by the height and branching of the plant and by the position of the seeds upon it. In the case of species whose fruits or seeds are immobile, i.e., not well adapted for migration, the seeds fall directly beneath the parent. The resulting family is small and definite. A similar group is often produced by offshoots when these do not carry the new plants too far from the original one. If the fruits or seeds are readily carried, i.e.. are mobile, the degree of aggre-

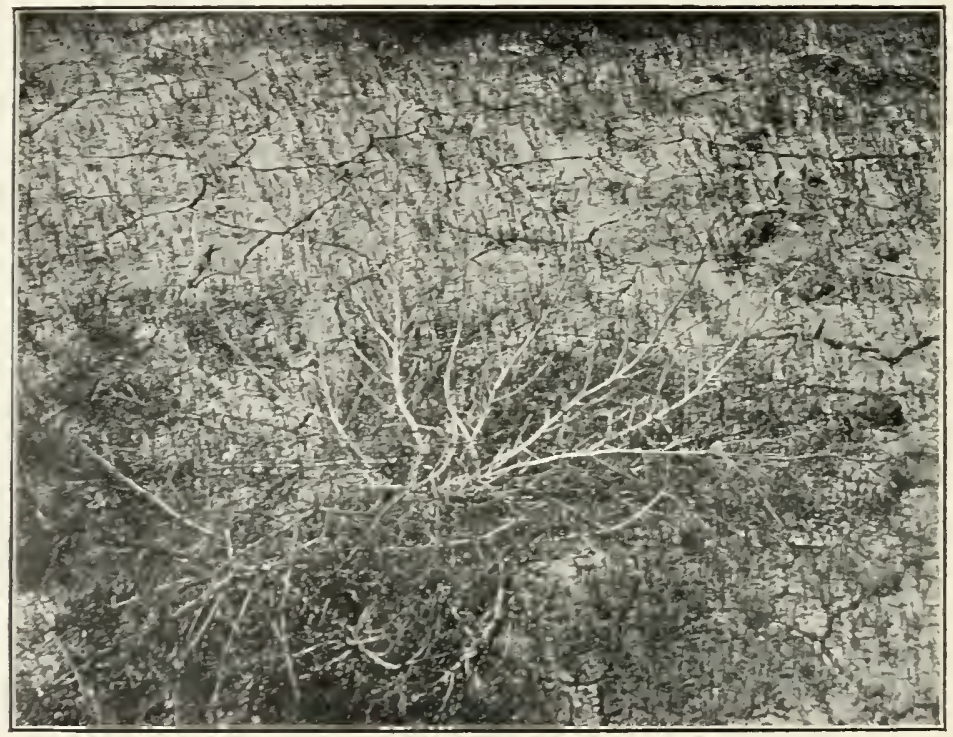

FIG. 96. - Simple aggregation of Corispermum seedling, beneath and about the parent plant.

gation in the family is correspondingly decreased, since the seeds are carried away from the parent. Very mobile forms, such as the dandelion, rarely produce families for this reason, and this is often true also of plants which produce few seeds. Annuals occur more frequently in families. owing to the large number of seeds and the frequent absence of derices for migration. Many perennials also arrange themselves in families. This is true of immobile perennials as well as those that migrate by means of underground parts. 
The above illustrates the law of simple aggregation. viz.. that lack of dissemination promotes the grouping of parent and offepring into families. while mobility hinders it. The production of families, moreover. takes place more readily in new and denuded habitats, i.e., in open formations, than in closed ones. since in the latter the individuals of various species have already become ningled with each other. If all species were immobile, families would be

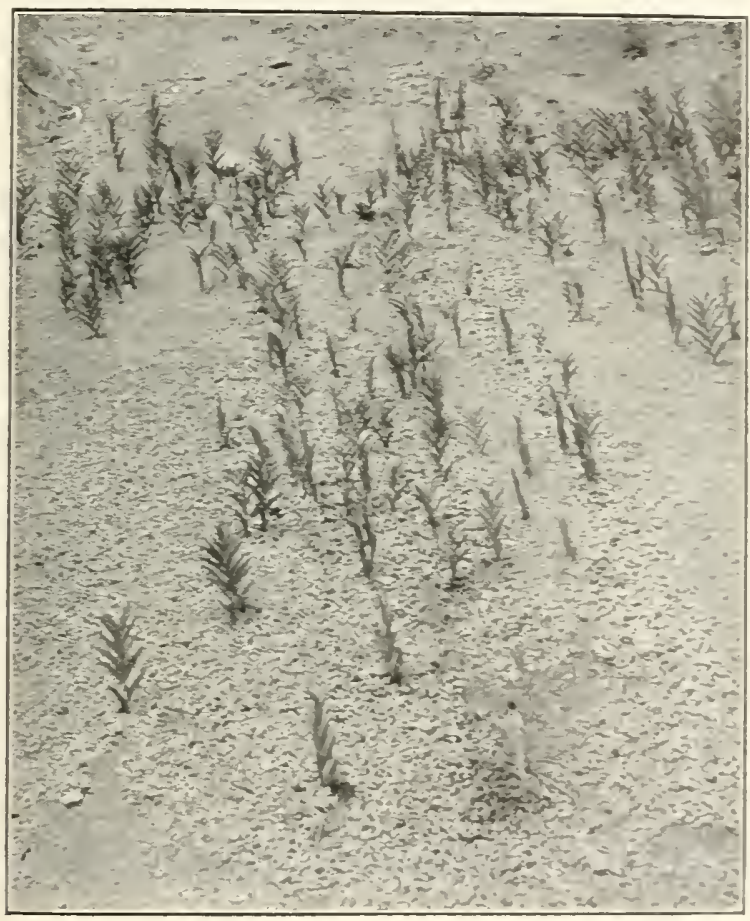

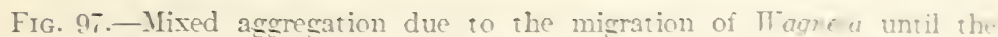
family includes individuals of . Yentsetia. Elymus, etc, and change- in to a community.

characteristic of vegetation to a large degree. Since the great majority are more or less mobile. grouns of this sort are the exception rather than the rule.

253. Mixed aggregation. Individuals are carriet away from the family group by migration. and strange indiriduais are trouch into it by the same means. In the early growth of a fumily. due 
to the gradual spreading of the plants, neighboring families approach each other and finally mingie more or less completely. In both cases the mixing of the two or more species to form a community is due to migration. The conversion of a family into a community takes place usually through the invasion of mobile species. The change occurs when one or more individuals of a second species becomes established in the family group. The real nature of the community becomes more evident when several generations have brought about a considerable increase in number. A community is a group of two or more families, regardless of the number of individuals in each. The families may remain more or less distinct from each other, or may become so intermingled that their identity is completely lost. The first condition is frequent in open formations, while the latter is the rule in closed ones, in which sufficient time has elapsed for repeated migration in all directions.

Communities vary greatly in size and definiteness. They may contain but two species, or they may consist of a large number. They may be entirely distinct, as often happens in open formations when they are separated from each other or from families by the bare soil. In denser vegetation they may be fairly distinct, or may blend into each other, and finally become indistinguishable.

Experiment 63. Study of families and communities. Stake out a permanent quadrat to include one or more distinct families, and one to include a definite community, preferably in an open formation. Make a chart of each quadrat. After the first year the development of family and community may be traced by comparing the new charts with those of previous years.

254. Migration. Migration includes all movements by means of which plants are carried from the original home, or away from the parent individual. It is distinct from ecesis, the act of becoming adjusted or established, but together with it gives rise to invasion, which contains the two ideas of movement and establishment. An analysis of migration shows that four factors enter into it, viz., mobility, agent, distance, and topography. These are not all present in each case of migration, but as a rule each factor plays some part. Mobility is the capacity of a plant for migration, as shown by the various modifications of fruit, seed, 
etc. The value of mobility to the plant is dependent upon the presence of proper agents for causing movement, and the operation of these two factors is much affected by distance and topography.

255. Mobility. Mobility indicates the power of the plant for movement. It depends primarily upon devices for bringing about dissemination, though the number of seeds is also an inportant factor in it. Mobility is most marked in those plants which are themselves motile, bacteria, diatoms, volvox, etc., or possess motile spores, such as most of the green algæ. On the other hand, it is little or not at all developed in those flowering plants with large, heavy seeds or fruits. By far the greater number of plants exhibit some degree of mobility. The range is extreme, from the almost immobile offshoots of lilies, which move by growth, to the non-motile but very mobile spores of fungi. There is no. necessary correspondence between mobility and motility. The latter is practically absent in terrestrial plants, and, in spite of its importance among the algæ, it plays a relatively small part in migration. The degree of mobility is determined cliefly by the nature of the device used in dissemination, but the number of seeds or spores produced has an important effect in increasing or decreasing it. A third factor of much influence is the position of seed or spore with reference to the action of the distributive agent.

256. Organs of dissemination. Plants differ much with respect to the organ modified or utilized for dissemination. Such modification, while it usually affects the fruit or seed alone. may act upon any organ, or upon the entire plant body. Special modifications are usually developed in comnection with spores and seeds, and mobility is most marked in species of this sort. It is much reduced in the case of offshoots and plant bodies, at least in terrestrial plants, notwithstanding a few striking exceptions, sucll as the tumble-weeds. The following indicates the grouping of plants with reference to the part distributed.

1. Spore-distributed. This group includes all plants possessing structures which are called spores, viz, algæ, fungi, liverworts, mosses, and ferns. Spores rarely have special derices for dissemination, but their minute size makes them extremely molile.

2. Seer-clistributed. This group comprises all flowering plants in which the seed is the part morlified or disseminater. Sects are 
not very mobile, except when they are minute, or are provided with wings or hairs.

3. Fruit-distributed. The modifications of the fruit for distribution exceed in number and rariety all other modifications for this purpose. Many structures, such as the achene, caryopsis, perigynium, utricle, ete., which are commonly mistaken for seeds, belong here.

4. Offshoot-distributed. To this group are referred all plants that produce lateral shoots, such as root-sprouts, rhizomes, runners, stolons, etc. The migration of such plants is very slow, but it is unusually effective, since the new plant is nourished by the parent until it becomes fully established.

5. Plant-distributed. This group includes submerged and surface water plants, both motile and non-motile, and those land forms in which the whole plant, or at least the aerial part, is distributed, as in tumble-weeds and many grasses.

257. Modifications for migration. Plants are arranged in the following groups according to the nature of the device by which migration is brought about.

1. Saccate (saccospores). The species of this group possess various fruits all of which agree in having a sack-like envelope. This may be membranous and serve for wind-distribution, as in Ostrya, Physalis, and Staphylea, or impervious and air-containing, as in Carex, Nymphaca, etc., where it serves for water-transport.

2. Winged (pterospores). This group includes all winged, margined, or flattened fruits and seeds, such as are found in Acer, Betula, Rumex, many U'mbelliferce, Graminacece, etc.

3. Comate (comospores). To this group belong those fruits and seeds with long silky hairs, Anemone, Asclepias, Gossypium, etc., and those with straight capillary hairs or bristles not confined to one end, Salix, Typha, etc.

4. Parachute (petasospores). These are the parachute-like achenes of Lactuca, Taraxacum, and other ligulate composites. Through Eriophorum, Senecio, etc., this group is connected with the preceding one. Parachute fruits represent the highest degree of mobility that has been obtained by special modification.

5. Chaffy (carphospores). In this group are placed those achenes with a more or less sealy or chaffy pappus which gives slight mobility, as in Brauneria, Helianthus, etc.

6. Plumed (lophospores). In fruits of this kind the style is 
the part usually modified into a long, plume-like organ, producing a high degree of mobility, as in Clematis, Pulsatilia, and Sieversia.

7. Awned (acospores). These are nearly all grasses, in which the awns serve for distribution by wind, water, or animals, and even by certain creeping movements. The degree of mobility in many cases is great.

S. Spiny (centrospores). This group contains a few species in which distribution of the spiny fruits is brought about by attachment, as Cenchrus and Tribulus. The mobility is fairly high.

9. Hooked (oncospores). The members of this group are extremely numerous, and the degree of mobility as a rulc is very high. All agree in the possession of hooks and barbs, which serve for attachment, though the number, size, and position of the hooks vary greatly.

10. Viscid (gloeospores). In these the inflorescence is more or less covered with a riscid substance, as in species of silene, or the fruit is beset with sticky hairs, as in Cerastium, Salvia, ete.

11. Fleshy (sarcospores). These are fleshy fruits which are scattered in consequence of being swallowed, especially by birds. The seeds are usually protected by a stony envelope which cnables them to resist digestion. The mobility raries greatly, but the area over which migration may be effected is large.

12. Flagellate (mastigospores). These are plants with ciliate or flagellate spores, as in Edogonium, Ulothrix, Vaucheria, etc., or with plant bodies similarly motile, Bacteriacea, and T'olvocacce.

258. Influence of seed production. The chances of migration depend in a large degree upon the number of fruits, seeds, or spores produced. A large seed production increases the movement of a mobile species. In the case of two species with cqually gool devices for distribution, the one with the largest number of scels is the more mobile. Even in immobile plants, sced production increases the few chances of movement.

Two kinds of seed production are distinguished upon the basis of the relation between number of seeds and of flowers. In one species the flowers are many, but the seeds few or single in each, as in composites, grasses, sedges, ete. In the other the number of seeds in each flower is large, as in lilies, orchids, violets, ete. In so far as the actual number of seeds produced is concermed, some species of one type do not differ greatly from some of the other. As a rule, however, species with many flowers are more 
highly specialized for migration, and are consequently more mobile. The number of fertile seeds is also much greater, a fact of much significance, since the movement of abortive seeds is of no benefit to the species. This fact taken in connection with their great mobility partly explains the supremacy of composites and grasses.

259. Position of disseminules. The position on the plant of the part disseminated, i.e., its exposure to the distributing agent, plays a part in mobility. In the majority of flowering plants, the position of the inflorescence gives a maximum of exposure, but in many cases special modifications are developed to place spores or seeds in a more exposed position. The height of the inflorescence from the ground or above the surrounding plants aids in increasing the distance to which the spores or seeds are carried in the first flight.

The most perfect device of this kind is found in such composites as the dandelion, in which the stalk stretches up after the head closes finally. By the time the involucre expands to release the parachute fruits, the flower stalk has grown to several times its original length. The carpotropic movements of various plants often serve to place seeds and fruits in a better position for dissemination. In certain composites the involucral scales are reflexed at maturity, thus loosening and lifting up the achenes. A somewhat similar result is obtained in such grasses as Stipa and Aristida by the twisting of the awns. In many mosses, liverworts, and puffballs, the spores are sifted out through slits or teeth, or the whole spore mass is elevated and held apart by the mass of elaters or threads. In most cup-fungi the spores are driven out of the cup by tensions within.

260. The agents of migration. The possibility of migration depends primarily upon the action of distributing agents. In the absence of these even the most perfect modification is without value, while their presence often brings about the movement of the most immobile plant. The amount and extent of migration are determined chiefly by the permanence and forcefulness of the agent concerned. Furthermore, the direction and rapidity of migration depend upon the direction and intensity of the agent.

Nigration results when spores, seeds, fruits, offshoots, or plants are moved out of their homes by water, wind, animals, man, gravity, glaciers, growth, or mechanical propulsion. In accordance the following groups are distinguished: 
1. Water (hydrochores). This group comprises all plants distributed by water whether in the form of ocean currents, tides, streams, or surface run-off. In the case of streams and run-off especially, the nature of the modification is of little importance, provided the disseminules are impervious, or little subject to injury by water. Motile plants, or those with motile cells, belong entirely: to this group.

2. Wind (anemochores). The group of wind-distributed species includes practically all terrestrial plants in which modifications

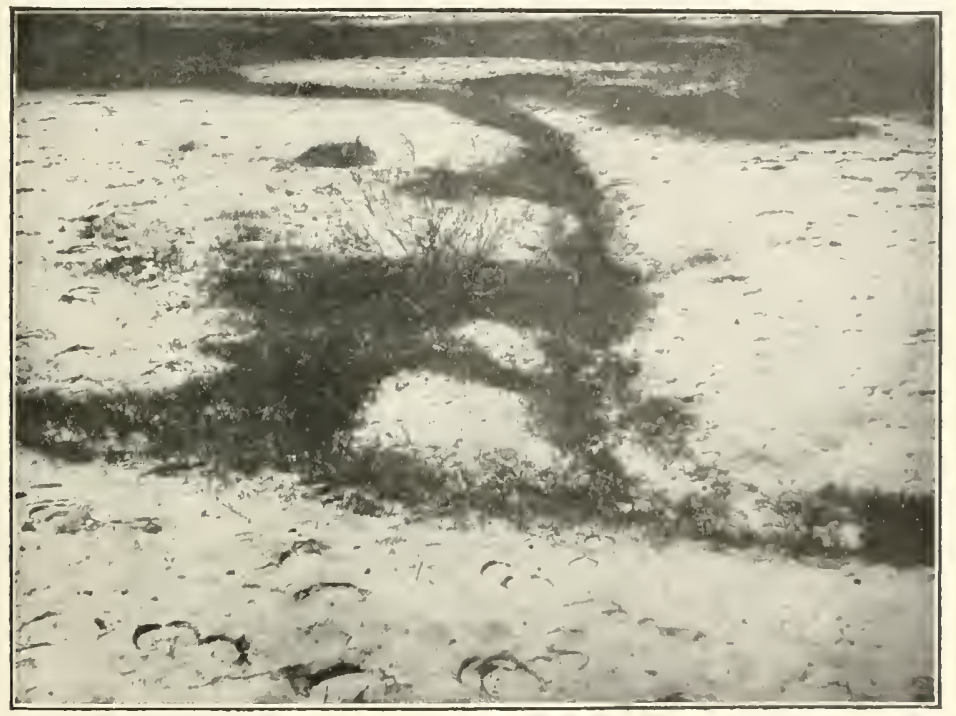

F1G. 98.-Migration of the immobile seeds of Corispermum by means of surface drainage.

for increasing the surface of seed or fruit have been greatly developed, or in which the part carried is minute. Sack-like, winged, hairy, parachute, pappose, plumed, and some awned seeds or fruits are the various types of modification for wind-distribution.

3. Animals (zoochores). Animals distribute seets in ronsequence of attachment, carriage, or use as fool. I)isimination by attachment has been specialized in a high degree. 'The three types of eontrivances for this purpose are found in spinose, hooked, and glandular fruits. Distribution by swallowing and that lyy aldrriage often play a striking part on aceount of the grealt distance 
to which the seeds may be carried. The one is characteristic of fleshy fruits, and the other of nut fruits.

4. Man (brotochores). Distribution by man has no necessary connection with mobility. It acts through great distances and over immense areas, as well as near at hand. It may be intentional, as in the case of cultivated plants, or unintentional, as in thousands of native or foreign species. No other disseminating agent can

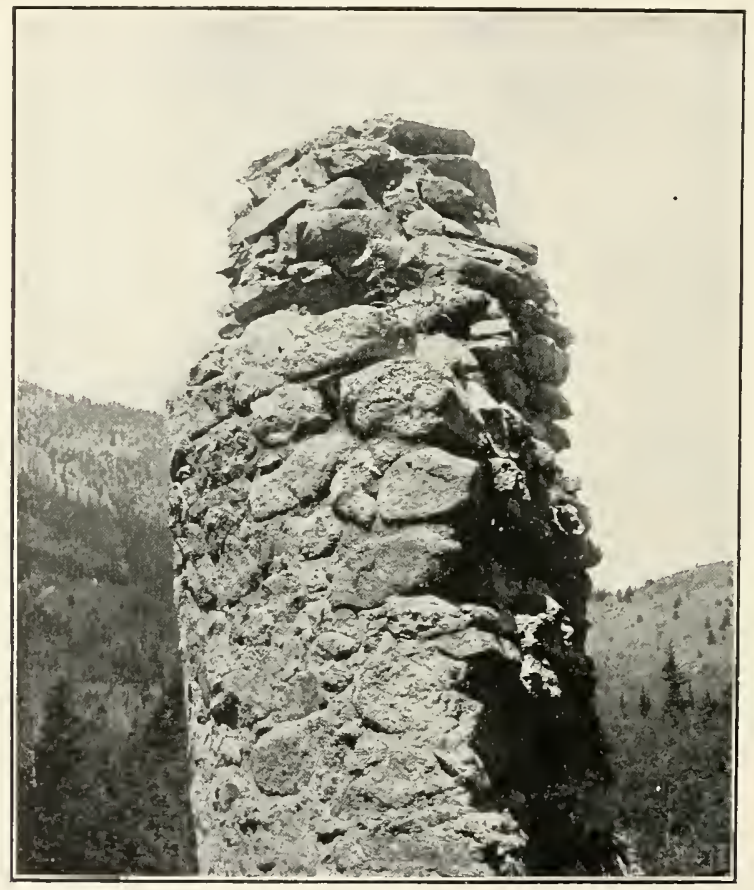

FIG. 99.-A plant of an aster established near the top of a tall chimney through the agency of the wind.

compare with man in respect to the amount or distance of migration.

5. Gravity (clitochores). Gravity is an agent of migration in hilly and mountain regions, where seeds and fruits regularly reach lower positions, either by falling from cliff or rock, or, more frequently, by the breaking away and rolling down of rock or soil masses. Dissemination by this method is necessarily local, though 
it plays an important part in the rock fields and gravel slides of mountains, especially in the case of immobile species.

6. Glaciers (crystallochores). Transport by glaciers is of slight importance at the present time, because of its restriction to alpine and polar regions, where the flora is poorly developed. In considering the migrations of the glacial epoch, however, distribution by glaciers is an important factor.

7. Growth (blastochores). The mobility of species disseminated by the growth of offshoots is extremely slight, and the annual movement relatively insignificant. The certainty of migration and of ecesis is so great, however, and the presence of offshoots so frequent in terrestrial plants that growth plays an important part in migration, especially within formations.

S. Propulsion (bolochores). Dissemination by mechanical propulsion, though it operates through insignificant distances, is very important on account of its cumulative action from year to year. The number of plants with contrivances for propulsion is very much smaller than the number of those with offshoots. All species of this group agree in having modifications by which a tension is established. At maturity this tension suddenly overcomes the resistance of sporangium or fruit, and throws the enclosed spores or seeds to some distance from the parent plant. In accordance with the manner in which the tension is produced, sling-fruits are classified as follows:

(a) Hygroscopic fruits. These include the ferns with annulate sporangia in which the expansion of the annulus by the alsorption of moisture bursts the sporangium more or less suddenly. The actual propulsion of the spores seems to be caused by the reflex movement due to drying.

(b) Turgescent fruits. Propulsion by turgescence occurs in a large number of fungi, such as the fleshy Discomycets, etc. Among flowering plants, Impatiens and Oxalis are familiar examples of fruits which split in consequence of increased turgidity.

(c) Dry fruits. The number of fruits which dohisce mon drying is very laree, but only a small portion of these expel their seeds forcibly. Erysimum, Lotus, Viola, ancl Geranium illustrute the different ways in which drying brings about the sulden split ting of fruits.

(d) Mortar fruits. In some plants, especially compusites. borages and mints, the achenes or mutlets are so placed in the 
persistent involucre or calyx that the latter serves as a kind of mortar for the projection of the seeds when the stem is sharply bent to one side by any force such as the wind or some animal.

26I. The work of migration agents. Two or more agents sometimes act upon the same disseminule, usually in succession. The possibility of such action in nature is great, but actual instances of it are not frequent, except when the activities of man enter into the question. Some parts, such as awned inflorescences, are carried almost equally well by wind or animals, and are often scattered by the action of both. Seeds and fruits are frequently blown by the wind into streams by which they are carried away. As a rule, however, parts adapted to wind-distribution are injured by immersion in the water, and the number of plants capable of being scattered by the successive action of wind and water is small. As a general rule, plants growing in or near the water, if modified for migration at all, are adapted to water-carriage. Species that grow in exposeck grassy or barren habitats are for the most part wind-carried. Those found in the shelter of forests and thickets are usually scattered by animals, though the taller trees and shrubs are generally wind-distributed by reason of exposure to the upper air-currents. There is seen to be a certain amount of correspondence, since hydrophytes are usually watercarried, shade plants are borne by animals, and the majority of sun mesophytes and xerophytes are wind-distributed. In each group, however, are numerous exceptions to the rule, owing to migration into various types of habitats.

With respect to their action, agents are constant or intermittent. The former include currents, streams, winds, gravity, growth, and propulsion; the latter, animals, including man. In the case of constant agents migration takes place more or less continuously from year to year, and usually in a definite direction. With intermittent agents dissemination is largely accidental; it is indeterminate in direction, and recurs only at irregular intervals, if at all. Migration is most effective when it is continuous, and least when it is intermittent. In the one case the migration is an annual one with the probability of the gradual adjustment of the seedling. In the other, species are usually carried not only out of their particular habitat, but often far beyond their native region, and establishment may become difficult or impossible. The rapidity of migration is usually greatest for intermittent 
agents, though it varies much for the same agent. The distance of migration is variable. It is often greatest in the case of man, other animals, ocean-currents, and wind, and small or scarcely perceptible when the movement is due to gravity, growth, or propulsion. Seeds may be carried half-way across a continent in a week by strong-flying birds, while migration by growth or expulsion is limited to a few centimeters or at most a few meters per year. This slowness is partly counterbalanced by the greater' number of disseminules, and the much greater chance of becoming established.

Experiment 64. Modifications for migration. List a number of species of the flora according to formations and arrange them in a table. Divide the table into five columns, and record the behavior of each species with respect to the part modified, the kind of modification, the seed production, position of disseminule, and the agent of migration.

262. The direction of migration. The direction in which a migrant moves is determined by the agent concerned. The general movement is forward or outward, the lines of travel radiating in all directions from the parent area. This is well illustrated by the action of winds which blow from any quarter. In the case of constant winds, migration is more or less definite, the exact clirection being determined largely by the fruiting period of the species concerned. The position of invaders with reference to the original home does not necessarily indicate the only direction of migration, since seeds are regularly carried to places in which they can not obtain a foothold.

The local movement of plants carried by animals takes place in all directions, while their distant migration follows the pathways of the migratory birds or mammals. Distribution by man is determinate when it takes place along commereial routes or along highways. In ponds, lakes, and other bodies of standing water, migration usually occurs in all directions, but in oceancurrents and streams it is determinate except for motile species. Dissemination by gravity, slopes, and glaciers is local and definite, while propulsion is entirely indeterminate. Migration by growth is equally indefinite, but it produces a radiate movement away from the parent mass, while propulsion throws seeds into the mass as readily as away from it. From the precerling it is criclent that distant migration may take place by means of water, wincl, animals, or man, and that it is in some derree determinate, since 
these agents usually act in a definite direction over great distances. On the contrary, local migration is indeterminate as a rule, except in the case of streams, glaciers, and slopes. The direction of

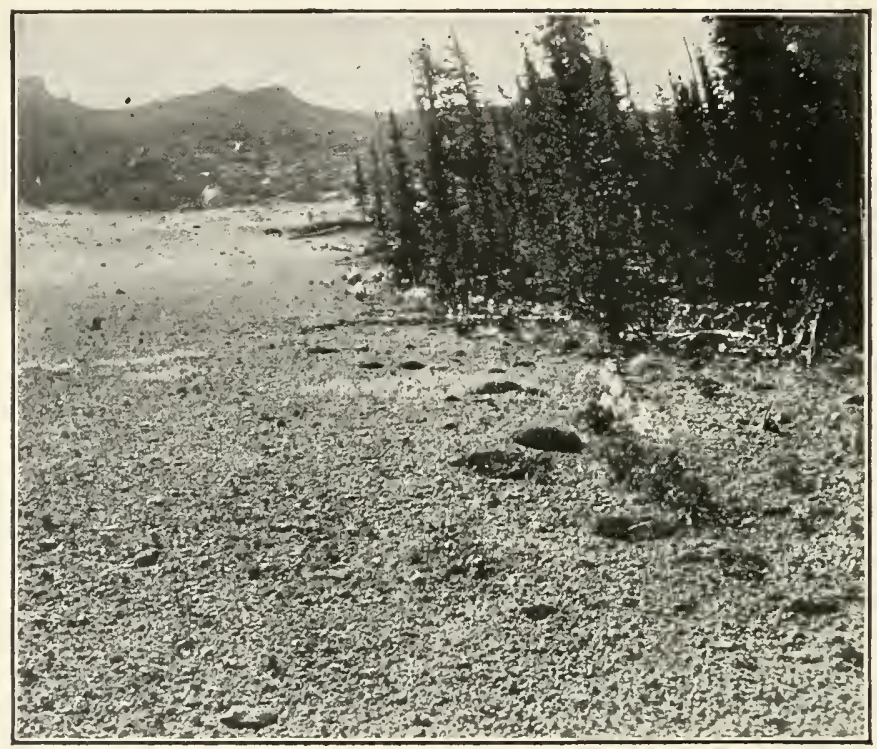

Fig. 100.-Determinate migration of the blue columbine, Aquilegia corrulea, down a gravel slide.

migration is thus seen to be controlled by the distributive agent. The distance is determined by the intensity and duration of the agent, as well as by the nature of the area through which it acts.

Experiment 65 . Amount and direction of migration. Nake a general study of a railroad track for the migration of introduced plants, especially weeds, and of a stream which flows through a prairie or meadow for the movement of forest species.

Establish two migration circles. Select a plant or group with comate or parachute fruits as the base for one, and an immobile speries for the other. If the plant chosen is just beginning to loosen its fruits, the use of a circle of $2 \mathrm{~m}$. radius shows the direction of movement and the varying distance of the first flight. The bases of the two circles are made permanent by driving a stake. In late spring the circles are again examined, the new plants counted, and their relative position with respect to the parent plant recorded. 


\section{CHAPTER XIII}

\section{COMPETITION AND ECESIS}

263. Competition. In consequence of aggregation, two or more individuals come to occupy the space previously occupied by one, or the group of plants already in possession of an area is greatly increased in number. Usually the immediate result is competition between the various individuals, though this is not always the case. The number of individuals may be so small and the distance between them suffieiently large, so that they do not compete with each other. Actual competition begins only when one plant encroaches upon the space occupied by another. Noreover, it sometimes happens that species are so different in their nature and their clemands upon the habitat that they may be crowded together without being in actual competition.

Competition occurs only between plants that meet each other on terms more or less equal. It is impossible to speak of competition between an oak and the tiny herb that grows beneath it. or between a puffball and the prairie grasses which surround it. Likewise, there is no competition between a host-plant and the parasite upon it, though two or more parasites upon the same host may compete with each other. Parasite competes with parasite and host with host, though a rust. for example, may often be a decisive factor in the competition between two wheat plants.

264. The struggle for existence. This popular phrase contains two different ideas. As Darwin pointed nut, a plant may stmegre against adverse conditions in the habitat, or it maty strugre with other plants for things necessary to it. 1 pioncer migrating into a new or denuded habitat must for a time make its way against conditions more or less unfavorable to it. Establislument, or ecesis, can take place only when it surecects in andjusting itcolf. 
When a plant is carried into a group of other plants, or is surrounded by its growing offspring, the struggle which results between the individuals is competition. In all cases where a migrant is carried into the vegetation of a very different habitat, it must meet both tests. In consequence, ecesis usually includes adjustment to competition as well as to physical factors. Competing plants are really trying to obtain certain necessary amounts of physical factors. Properly speaking, the struggle for existence

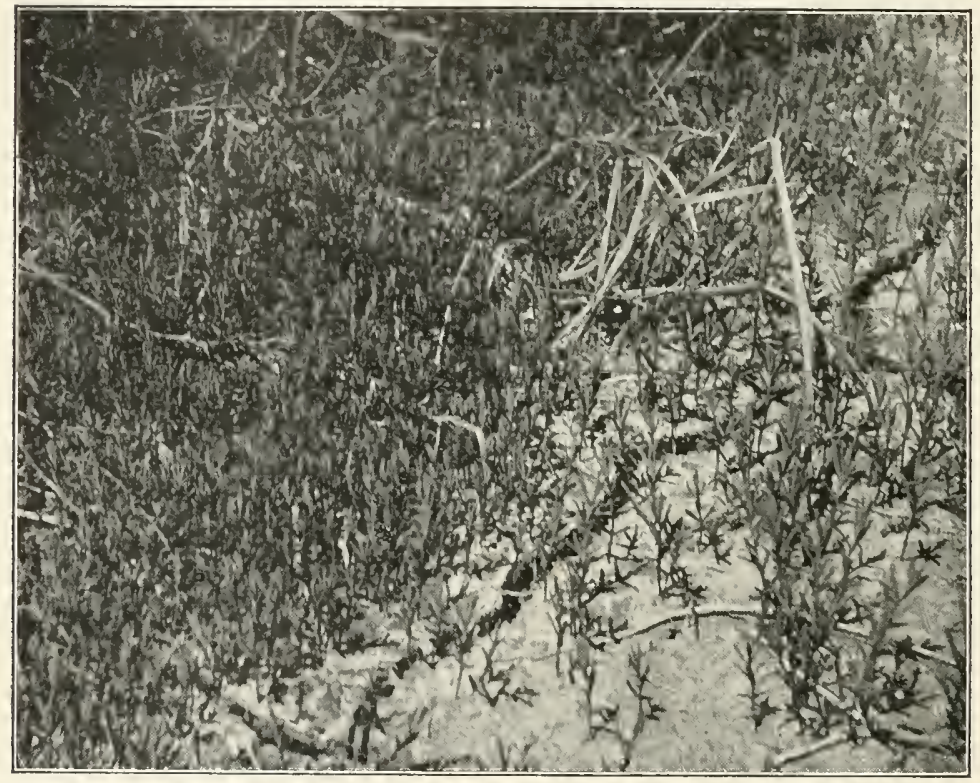

FIG. 101.-Competition in a family of Corispermum seedlings. The competition is much keener between the seedlings that have sprung up densely beneath the dead parent plant than between those arising from the seeds scattered between the parents.

in the plant world is a struggle between each plant and its habitat, the latter being changed by competition in consequence of the demands made upon it by other plants. The only exceptions to this rule are furnished by plants which serve as hosts to parasites. Between host and parasite there is a struggle not very different from that between two animals.

265. The nature of competition. Competition is purely a physical process. With a few exceptions, such as the crowding 
up of tuberous plants when grown too closely, an actual struggle between competing plants never occurs. Competition arises from the reaction of one plant upon the physical factors about it, and the effect of these modified factors upon its competitors. In the exact sense, two piants, no matter how close, do not compete with each other as long as the water content and the nutricnt material, the heat and light, are in excess of the needs of both. When the immediate supply of a single necessary factor falls below the combined demands of the plants, competition begins.

266. The factors involved. All of the factors essential to one or more of the primary functions of the plant play some part in competition. Such factors are water, humidity, light, and temperature. Of these humidity and temperature are relatively unimportant, while water content and light are decivive. In wet soils the question of air content seems to be of importance, but ordinarily this is apparently not true.

Plants are sometimes said to compete for room. This view is incomplete, and probably has resulted from the fact that plants show the effects of competition the more the closer they grow. The explanation is that the amount of water and light avilable for each decreases as the plants become more crowded. The moment that the roots of one enter the area from which the other draws its water supply, or the foliage of one overshades the leaves of the other, a change in factor results, which is unfavorable to one or the other, and competition begins.

267. Competition for water and light. Plants that grow in close or crowded masses compete with each other for water or light. In the majority of eases both factors are involved. l'ants with a larger, deeper, or more active root system react upon the habitat and reduce the amount of water available for those with poorer root systems. The stronger, taller, more branched or more leafy plants receive the larger share of the sunlight, and the others can obtain only what is left. This action of one competitor upen the habitat, and of the habitat upon the other competitor is cumullative. An increase in the leaf surface of a plant not only rechuess the amount of light available for the plant near it or beneath it; it also renders necessary the absorption of more mater and nutrient salts, and correspondingly decreases the amount arailalle. 'The result is that the successful individual prospers more and more, while the less successful one loses ground in the same degree. As 
a consequence, the unsuccessful competitor disappears entirely, or is so handicapped that it produces fewer or less vigorous seeds.

Competition for both water and light is the rule when plants of varying height are intermingled. This is always true when the plants are broad-leaved or branched. In the case of grasses, many mats, rosettes, etc., competition for light is relatively unimportant on account of the size or position of the leaves. With such forms as the leafless sedges and rushes, it seems to be entirely lacking. Plants which grow in saturated soils or in water apparently do not compete for the latter, though it is probable that a new factor, air content, enters the question. Finally, it is possible for plants to be densely crowded, and still not compete with each other This is nicely illustrated by duckweeds which often completely cover the surface of ponds and streams. The tiny fronds are on an equality with respect to light, and the water supply is far in excess of the demand.

268. Competition between parents and offspring. The simplest kind of ordinary competition is that in which the individuals belong to the same species. The various individuals of a family show relatively slight differences in height, width, leaf expanse, and root surface. Some have surfaces which are larger or better situated for receiving water or light, and the others are thus placed at a disadvantage. The former receive more than their share of water or light, or of both. The reaction which they produce upon these factors affects the plants subject to it. The usual result of such competition is great variation in the height, branching, and leaf area of the different individuals, and the inability of many to produce flowers. This is particularly true of annuals and of perennials belonging to the same generation. In the competition between the parents and offspring of the same perennial species, the former usually have a decided advantage. The younger plants are of ten unable to thrive, or even to germinate, and they finally disappear, leaving a free space beneath and about the stronger parents. Similar individuals make practically the same demands upon the habitat, and adjust themselves least readily to their mutual reactions. The more unlike plants are the greater the difference in their needs. Hence some are able to adjust themselves to the reaction of others with little or no disadrantage. From this is obtained the primary law of competition, i.e., competition is closest when the individuals are most similar. 
Consequently competition is more intense within families than within communities.

269. Competition between different species. Competition is closer between species of like form than between those that are dissimilar. Such similarity between species is based upon the form or nature of the plant body, and not upon systematic relationship. Leaf, stem and root characters ordinarily determine the outcome. The species most alike in these respects will be in close competition, regardless of taxonomic relationship. This is

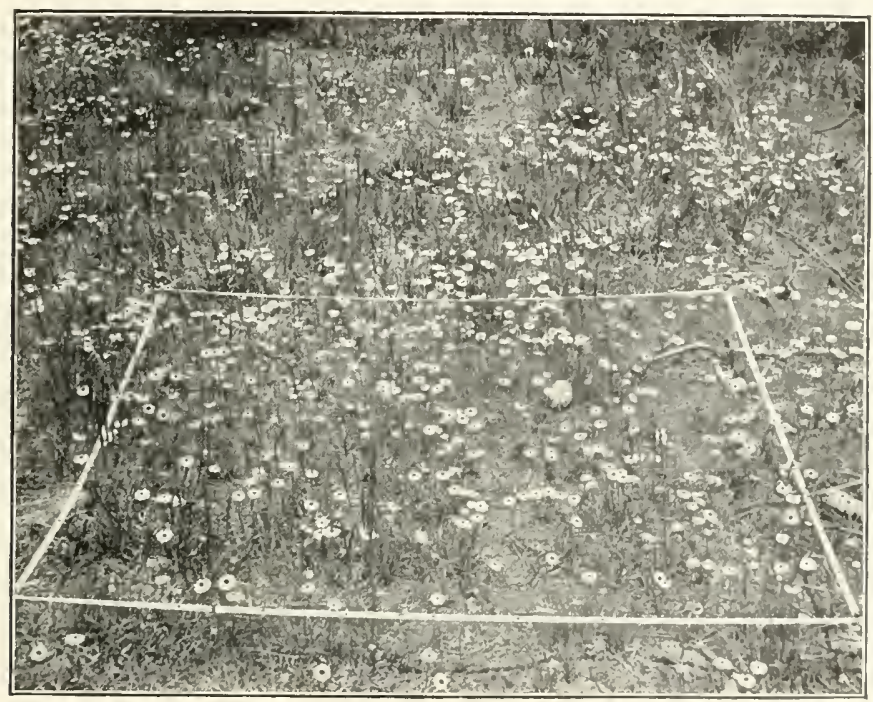

FIG. 102.-Competition between different species, in this case mountain daisies and grasses.

equally true of species of the same genus, and of those helonging to genera of widely separated families. This relation is expressed by a second law of competition, riz, the closeness of the competition between individuals of different species varies with their similarity in vegetation form or habitat form.

This law applies especially to the competition which arises between occupants and invaders in the various stages of suression. Those invading species that show the greatest resemblance to occupants in the form of leaf, stem, or root experience the greatest difficulty in establishing themselves. On the contrary, 
species which are so unlike the occupants that they enter at a clear advantage or disadvantage usually establish themselves readily. This principle lies at the base of the changes in succession which give a peculiar stamp to each stage or formation. A reaction sufficient to bring about the disappearance of one stage can be produced only by the entrance of invaders so different in form or nature that they change the impress of the formation materially or entirely. A formation becomes stable when the entrance of such invaders is no longer possible. For example, while many vegetation forms can still enter a forest, none of these are able to place the trees at a disadvantage. As a consequence the final forest stage, though it may change in composition, can not be displaced by another.

270. Influence of vegetation form and habitat form. The course and the result of competition are primarily dependent upon the vegetation form and the habitat form of the competing species. Species of the same vegetation form, i.e., two or more kinds of shrubs, compete closely with each other, and the result is a reduction in the number or size of the individuals, or the entire disappearance of one or more species. On the other hand, dissimilarity in vegetation form tends to diminish competition and to maintain the advantage of the superior form. Species of trees, as a rule, compete sharply with each other when found together. The same is true of other vegetation forms, shrubs, rosettes, etc. The relation of the shrubs to the trees or of the rosettes to the shrubs of a formation is one of subordination and not of competition. The matter of height and width often plays an important part in deciding this question. The amount and disposition of leaf surface are decisive factors in competition between species of the same vegetation form, in so far as this is governed by light. In plants in which the leaves are usually erect, e.g., grasses and sedges, competition between aerial parts is slight, and the result is chiefly determined by the roots. The effect of a difference in habitat form is unusually marked, since the invader must then adjust itself to the more or less unfavorable conditions of a new habitat, in addition to meeting the test of competition.

27I. The effect of position. The position of the competing individuals is of the greatest importance, as already indicated. The distance between the plants directly affects the degree of 
competition, i.e., the latter increases as the distance diminishes and the reverse. Their arrangement, i.e., whether in families or communities, and whether the individuals are scattered or grouped by species, exerts a marked influence by determining that the contest shall be between like forms or unlike forms. Position is controlled primarily by seed production and dissenination, though it is influenced in a large degree by the location of the first points occupied by an invader. The individuals of species which produce many seeds and are relatively immobile usually occur in dense stands. In these the competition is intense for the two reasons of similarity of form and density of arrangement. As a result the plants fall below the normal in height and width. When the seed production is small or the mobility great, the individuals are scattered among those of other species, and the closeness of the competition depends largely upon the similarity existing between them.

272. Vegetation pressure. Masses of regetation are often said to force the weaker plants or species toward the edge, thus producing an outward or forward pressure. Plants are likerise said to have been driven into the water or into unfavorable habitats by the pressure of stronger ones. The movement concerned is merely migration, which may or may not be followed by ecesis. It is determined by the nature of seed or fruit, and has no connection with stronger or weaker species, or the presence of a vital pressure. The direction taken by the migrants is largely inceterminate. Migration is outward, or away from the mass, because it is radiate. The chances of ecesis are greatest at the edge, where the similarity between the plant forms is less, and the competition correspondingly diminished. Hence the actual movement or invasion is ontward.

In the same way, the question of water plants is merely one of migration and ecesis. The plants that grow at the edge of a pond or stream are not forced into the water by stronger neighbors. They ean become water plants only in one of two ways, both of which are equally possible for strong and weak species. 'Their' seeds may be carried into water, either at one flirht, or by a grachial movement year by year, and those that adjust themselves become water plants. On the other hand, a gradual increase in the water of a habitat to the maximum may result in the extinction of sone forms, and the adjustment of others. 
273. The results of competition. A plant adjusts itself in so far as possible to the changes in factors brought about by its competitors. Hence competition may bring about changes in

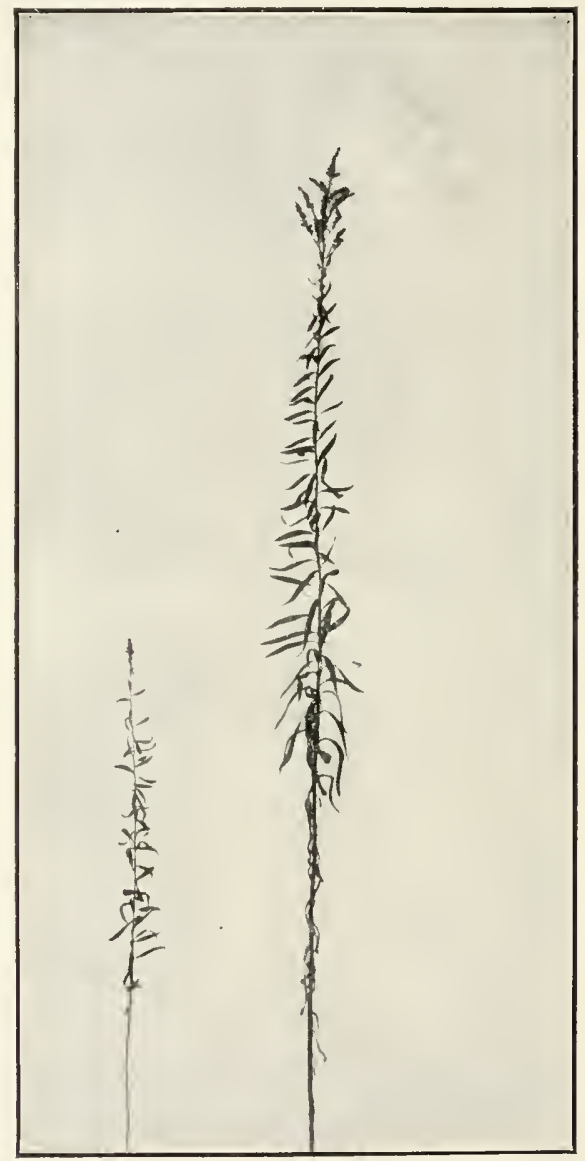

Fig. 103.-Effects of competition for light between individuals of Solidago canadensis. The tall plants grew in the edge of the family and shaded the small plants of the center.

size, form, and structure of the individuals, or in their arrangement, i.e., in regetation. Change in size and general form is one of the most striking effects wherever the plants are densely crowded. Changes in the form and structure of leaf and root 
occur regularly, and if the conditions which cause them continue, they may become fixed. Competition, like the physical factors through which it acts, may produce adaptations which characterize new forms.

Competition enters into practically all the changes of regetation. It is absent only in the rery beginning of open formations on new or denuded soils. It is one of the fundamental factors in invasion, and the reaction of competing occupant and invader is the decisive element in all successions. Competition plays a part in both alternation and zonation, but it is especially characteristic of the former. It not only modifies the alternation arising from physical factors, but it also exerts strong control over that due to the historical factor, i.e., the time of invasion.

274. The study of competition. The course of competition under natural conditions may be followed in the field, or competition may be artificially produced and studied in the planthouse. There is no essential difference in the nature of the competition in the two places, but the plant-house is ordinarily more favorable because the study can be kept under control. Various competition cultures are distinguished with respect to the point of attack, ${ }^{1}$ but only two of these are used for elementary work. Simple cultures are those in which a single species is used. The resulting group is a family, and the competition is between like individuals. In such cultures the problem of the factors in competition is reduced to its simplest terms. Mixed cultures are composed of two or more species, and are correspondingly more complex. Either culture is made permanent by allowing the plants to ripen and drop their seeds from generation to generation, just as in nature.

275. Competition cultures are a meter square, i.e., they are indoor quadrats. For a simple culture, the plot is usually divided into four squares to give different degrees of density. The density may be varied as desired, though, as a rule, 12 seeds are planted in one, 25 in another, 50 in the third, and 100 in the fourth. In making a mixed culture, the problem is simplified by using two species only. In one half of the plot the number of seeds of the one is double that of the other; in the other half, conditions anc reversed. At the time the plots are sown, scels are started in 
pots so that they may be grown without competition to serve as checks. When the plants become well grown and in actual competition, light readings are made for two or three leaves of the most successful competitors and of the least successful ones, and their starch content is also determined. From these figures the light intensity and starch content are determined for the total leaf area of each plant, and these results are checked by the control plants.

The relation of water to competing plants is a more difficult

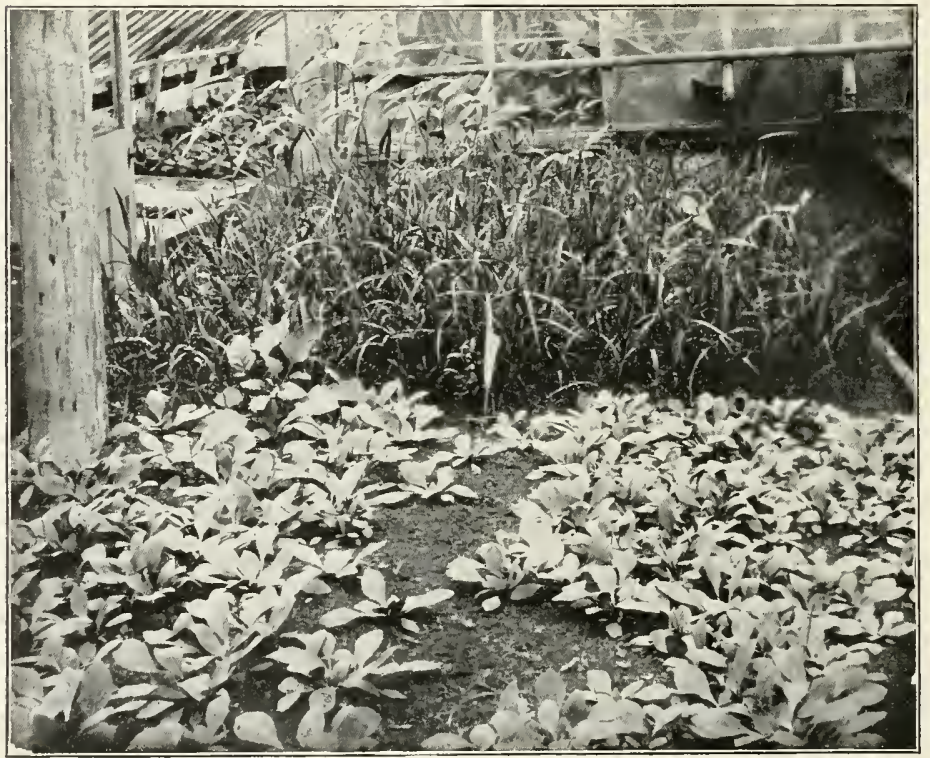

FIG. 104.-Competition cultures in the plant-house. In the foreground is a mixed culture of Solidago and Onagra.

task to study. It is necessary to determine the water available for the control plant, together with its water loss. These must also be determined for the competing individuals, and the two results compared. The water content is found for a block of the soil 2 or 3 decimeters square. The water loss of the plants in it can only be ascertained by cutting the block out and weighing it from time to time, or by sinking a pot or box in the plot at the beginning, and removing it when necessary. 
276. Competition quadrats. Practically any permanent quadrat will serve for the field study of competition. 1)enuded quarlrats are especially good, though they need to be followerl for a number of years. When rapid results are sought, a denuded quadrat is used for a competition culture by planting it in the manner desired. Other quadrats are used in a somewhat similar fashion by sowing the seeds of a. weed or other vigorously growing species among the original occupants. Interesting results are obtained with annuals by using a decimeter quadrat. Two quadrats of this size are staked side by side in a family of seedlings, and the number of individuals counted for one of them. The plants are then removed from one, taking care to leave two or three scattered ones undisturbed. As they develop, the behavior of the plants in the two quadrats indicates clearly the effect of competition.

Experiment 66. Competition. Make a simple and a mixed culture in the mamer indicated, using Helianthus, Datura, or other vigorous plants. Follow the development of each culture carefully, noting the differences of form and structure, and determining the relation to light, and also to water if this is possible. Allow the plants to go to seed, and determine the largest and smallest seed production for those that flower. Permit one example of each culture to become permanent for study during the following year.

Stake out two decimeter quadrats in the family of an annual, such as Polygonum avirulare, just after the seedlings appear above the ground. Count one quadrat and thin ont the other. Compare the development in the two throughout the season. Note the size and number of mature plants in each, and the number of seeds produced.

277. Ecesis. Ecesis is the adjustment of a plant to a new place or a new habitat. It includes all the phenomena shown by a migrant from the time it enters a new situation until it becomes thoroughly established there. It is the decisive factor in invasion, since migration is of no value unless follower ly it. The interaction of the two is intimate. Migration is usually followed by ecesis, which then establishes a new center from which further migration is possible, and so on.

Ecesis depends in a large measure upon the time, direction, rapidity, distance, and amount of migration. The time of yoar in which fruits mature and distributive agents act has a marked influence upon the establishment of a species. Seerls which 
ordinarily pass through a resting period are often brought into conditions where they germinate at once, and perish because of unfarorable factors, or because competing species are too far advanced. Spores and seeds capable of immediate germination may likewise be scattered abroad at a time when conditions make growth impossible. The direction of movement is often decisive because the seed or spore is either carried into a habitat sufficiently like that of the parent to secure establishment, or into one so dissimilar that germination is impossible, or at least is not

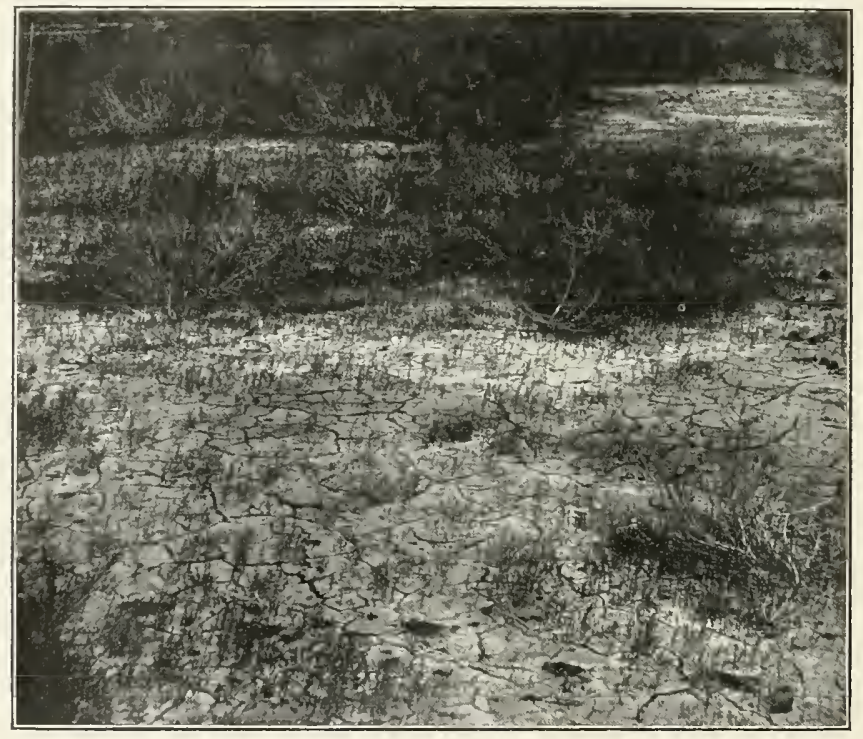

FIG, 105.-Detail of a salt basin formation, showing the ecesis beneath and about the parent plants of Corispermum.

followed by growth and reproduction. The rapidity and distance of migration have little influence, except in the case of conidia, gemmæ, etc., with little resistance to dryness. The amount of migration, i.e., the number of migrants, is of the greatest importance, since it directly affects the chances that vigorous seeds will be carried into places where ecesis is impossible.

278. The factors in ecesis. Ecesis may take place in a habitat covered with plants, or in one that is without a plant covering. The first case is by far the most frequent. In it, the invaders must not only adjust themselves to the general physical factors 
of the habitat, but also to the changes in them due to competition. Competition is consequently a most important factor in the ecesis of an invader in a formation. It is necessarily absent when an invader enters a new or denuded soil alone, but it appears quickly when a large number of plants invade at the same time.

Normally, ecesis consists of three essential processes, viz., germination, growth, and reproduction. This is the rule among terrestrial plants, in which migration regularly takes place by means of a resting part. In free aquatic forms the growing plant or part is usually disseminated, and ecesis consists merely in being able to continue to grow and reproduce. Moreover, ecesis is practically certain on account of the slight differences between aquatic habitats. In dissemination by offshoots, the conditions are somewhat similar, and ecesis consists of growth and reproduction alone, since the offshoot grows under the same conditions as the parent plant.

With respect to ecesis, migrants may behave in any one of four ways: (1) they may invade an area without germinating; (2) they may germinate and then disappear; (3) they may germinate and grow without reproducing; (4) they may reproduce either by flowers or offshoots, or both. Ecesis, and hence invasion, occurs only when a migrant enters a new place, in which it germinates, grows, and reproduces.

279. Germination of the seed. The germination of seed or spore is dependent upon its vitality and upon the nature of the habitat. Vitality, or viability, is determined by the structural characters of the fruit, seed-coat, and endosperm, as well as by the nature of the embryo. The first three promote germination by protecting the embryo against dryness or against injury due to carriage by water or by swallowing. This duty is chiefly discharged by the seed-coat, which usually contains thick-walled protective cells. The seed-coat also helps to insure germination at the proper time, by making the seed more or less resistant to a quantity of moisture and warmth insufficient to support the seedling. The presence of the endosperm or other food supply increases the chances of the seerlling.

The behavior of the seed with respect to germination depends in a large degree upon the nature of the embryo. Many secds are not viable because fertilization has not taken place and the embryo has not developed. This explains the low germinating 
power of some species which produce a large number of seeds. The seeds of some plants grow immediately after ripening, while others grow only after a resting period of uncertain duration. Even in the case of seeds from the same parent, the majority germinate the first year, but some lie dormant for one or more years. The period of time during which disseminules remain viable is extremely diverse, though it is much longer, as a rule, for seeds than for spores. The great vitality of weed seeds is probably due to the vigor of the embryos.

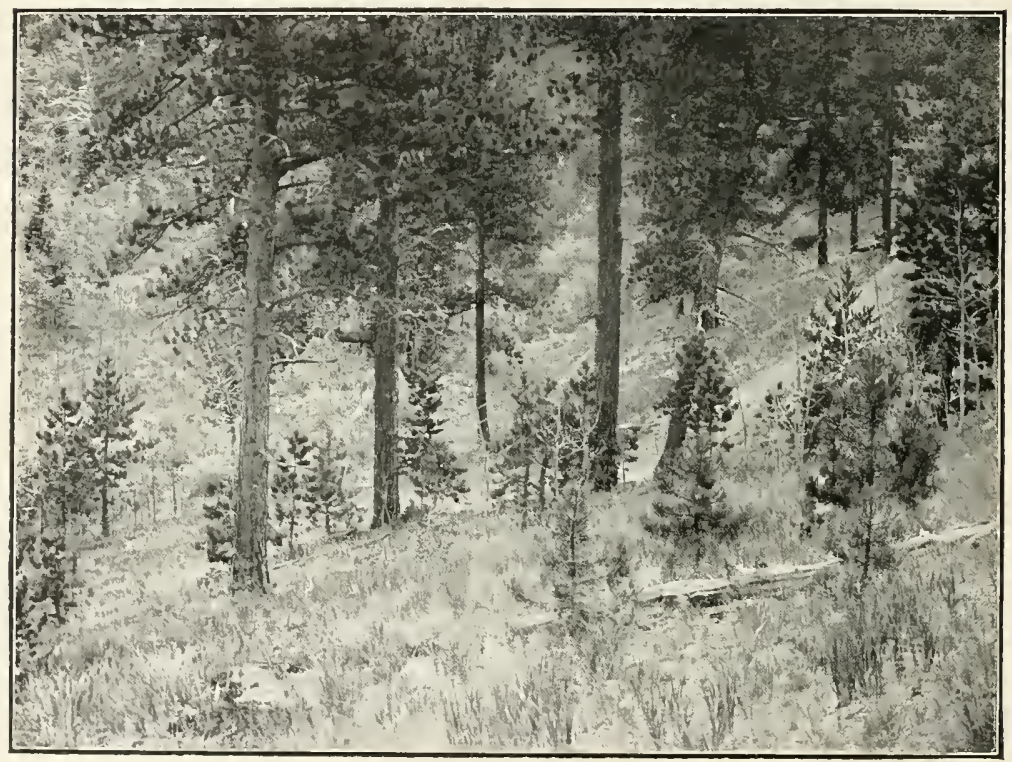

FIG. 106.-The ecesis of young pines beneath the parent trees.

280. The effect of habitat. The influence of the habitat upon germination is often decisive. Seeds may be carried into a number of different formations, any one or all of which may offer conditions unfavorable to germination. Habitats are of two sorts with respect to the chances of germination, those that are new or denuded, and those that bear plants. The probability of germination is usually greater in vegetation than in denuded areas, chiefly because the surface of such areas is relatively xerophytic. On the other hand, the lack of competition in a denuded area tends to make final establishment much more certain. 
28r. Adjustment to the habitat. Growth and reproduction in the new place or habitat depend upon the habitat form, the plasticity, and the regetation form of the plant. Even though it may germinate, a typical shade plant, such as Impatiens, will not thrive in an open meadow, nor will characteristic sun plants, such as most grasses, grow in deep shade. Xerophytes do not adapt themselves to hydrophytic habitats, nor hychophytes to xerophytic conditions. However, many mesophytes possess to a certain degree the ability to adjust themselves to somewhat xerophytic or hydrophytic situations, while plants of open woodland often invade either forest or meadow. This capability for acljustment, i.e., plasticity, is greatest in intermediate speries, those that grow in habitats not too wet or too dry, too sunny or too shaded. It is least in forms highly specialized with respect to water content or shade. Hence the rule is that ecesis is controlled largely by the degree of similarity between the old and the new habitat, except in the case of plastic species, which possess a wider range of adjustment.

The vegetation form of the invading species is often of the greatest importance in determining whether it will be established. It is characterized by modifications which were probably produced in the original home by competition, and are of primary value in securing and maintaining a foothold. These are practically all devices for enabling the plant to persist, such as root. rootstock, bulb, tuber, woody stem, etr. They find their greatest development among trees and shrubs, and their least among annual herbs.

Experiment 67. Influence of habitat form upon ecesis. Make a culture for the study of ecesis by sowing in a meter plot a given number of seeds of species representing amphibious plants, sun plants, shade plants, and xerophytes, and growing them under mesophytie conditions. Kote the number of seeds that germinate, and the number of individuals of each species that succed in producing flowers.

282. Barriers. Any feature of the topography or vegetation that restricts or prevents invasion is a barrier. Such features are usually permanent, and produce permanent harriers, though a barrier is often temporary, existing for a few years only, or for a single season. Barriers are distinguished as complete or incomplete with respect to the thoroughness with which they limit 
invasion. They often prevent or decrease migration, but as a rule their action is largely confined to ecesis. With respect to their nature, barriers are usually distinguished as physical and biological.

283. Physical and biological barriers. Physical barriers limit invasion by virtue of some marked physiographic feature, such as an ocean, lake, river, mountain range, or desert. Biological barriers comprise vegetation, man and animals, and plant parasites. Physical barriers act through their dominant physical factors by preventing the ecesis of species coming from very different habitats. A body of water is a barrier to mesophytes and xerophytes; deserts set a limit to the sprearl of mesophytic and hydrophytic plants. A mountain range is usually an obstacle to migration as well as to ecesis.

Formations, such as forests and thickets, etc., sometimes act as direct obstacles to the migration of tumbleweeds and other wind-distributed plants. Their greatest influence in decreasing invasion arises from their closed nature. When the competition is intense, the invading species, though suited to the general conditions of the habitat, are usually unable to secure a foothold. Man and animals affect migration by the destruction of disseminules. They act as a barrier to ecesis whenever they make conditions unfavorable to invaders, or when they turn the scale in the struggle for existence, through grazing, tramping, parasitism, etc. The absence of insects necessary for pollination sometimes acts as a serious barrier to ecesis. Parasitic fungi affect migration in so far as they destroy seeds, or reduce the number produced. They may prevent or restrict ecesis by destroying the invaders, or by placing them at a disadvantage in the competition.

284. Influence of barriers. Physical barriers are permanent as a rule, while biological ones are often temporary. A forest or meadow, which often acts as a barrier to invaders from adjacent vegetation, may disappear as a result of a land-slide, flood, or burn, or through the activity of man, and leave an area into which plants crowd from every direction. Such barriers as parasites and herbirorous animals may appear or disappear at any time. When the physical factors of a habitat form a barrier, these may be so modified by climatic changes that they no longer act as such. A meadow ceases to be a barrier to prairie xerophytes during a period of unusually dry years. Similarly, dry 
habitats are much less effective in checking the spread of mesophytes during wet years or seasons. Many xerophytic habitats, dunes, blowouts, gravel slides, prairies, ete., are barriers during summer and autumn, but not during spring, when rains are frequent and the surface remains moist. In the absolute sense no barrier is complete, since, at one time or another, practically any portion of the earth's surface is capable of supporting some linel of vegetation. In connection with the natural spread of terrestrial plants, however, it is convenient to distinguish partial barriers from complete ones. In this sense large bodies of water and

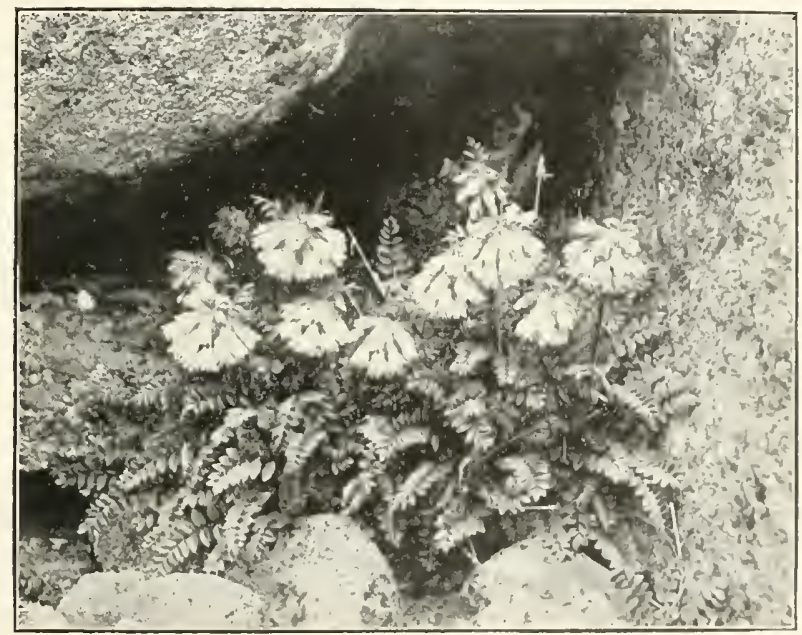

FIG. 107.-An endemic plant, Polemonium speciosum, found only in the rock clefts of the highest Colorado peaks, such as l'ike's, (iray's, cte.

mountain ranges furnish the best examples of complete barriers. Such barriers bring about the isolation of species, and tend to restrict species to a single formation or region.

285. Distance. Though hardly a barrier in the strict sense. distance plays an important part in the amount of invasion. The effect of distance is elearly seen in migration, especially in the case of a denuded area. The formations which touch the arear usually furnish more than three-fourthe of the species which serve to reclothe it. The chief reason for this is that the secels of the adjacent species are not so widely scattered hy the time the de- 
nuded area is reached, and hence a larger number fall within it. A second reason lies in the fact that migrants from more distant formations must pass through or over adjacent ones. In this case the number of disseminules becomes smaller and smaller as the distance increases, and the few invaders from a distance reach the denuded area only to find it already occupied. Owing to the radiate nature of migration, only a part of the fruits of a plant or a group can be carried ordinarily in any one direction. The bulk of these fall near the parent, the number de-

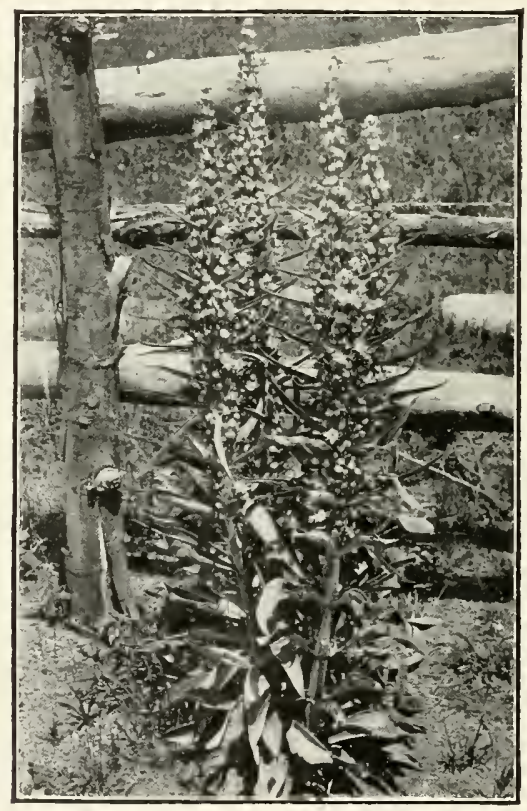

FIG. 10S.-A polydemic plant, Frasera speciosa, found in several of the mountain formations.

creasing rapidly as the distance increases, until at a few hundred meters or a few kilometers even the last fruits disappear.

286. Endemism. A species is said to be endermic when it occurs in a single region or country, and polydemic when it is found in two or more regions. These terms refer merely to position or distribution, and are distinct from indigenous, originating in the place where found, and exotic, native in a place other than that in which the species is found. A species is best said to be 
endemic when it is found in a single formation, and polydemic when it oceurs in two or more.

Endemism is due to the lack of migration, or the presence of barriers. Plants which are extremely immobile, e.g., those that migrate slowly by underground offshoots, are often endemic. IIany species of alpine regions and of oceanic islands are endemics, owing to the check offered by barriers to their spread. Immobile species which are surrounded by barriers are almost inevitably endemic. However, the most immobile plant may be scattered widely by new or unusual agencies, or the most formidable barrier may be sometimes overcome, especially through the activities of man. Endemism is also a direct result of erolution, since new forms as a rule are endemic at first. Whether they remain endemic depends upon their mobility and upon the presence of barriers to migration or ecesis. An endemic may also arise in rare instances by the disappearance of a polydemic in all regions or formations but one, owing to competition or to changed physical conditions.

A species usually becomes polydemic by virtue of being carried into two or more different formations or regions and becoming established there. A plant may also be polydemic in consequence of having originated in two or more places.

Experiment 68. Barriers and endemism. Nake a list of the species found in two or more neighboring ravines, separating those found in one ravine from those that occur in all. Nake a similar list for the intervening hills or ridges. Point out the action of barriers in several of the most striking instances. 


\section{CHAPTER XIV}

\section{INVASION AND SUCCESSION}

287. Invasion. The movement of one or more plants from one area into another and their establishment in the latter constitute invasion. Invasion may concern an individual or a num. ber of individuals of one or more species. It may take place between plant groups of any kind, though it is most conspicuous between different formations. Invasion is a regular occurrence between adjacent formations, but it also takes place into remote ones, as a result of long carriage by wind, water, birds, railroads, or ressels.

Migration and ecesis are both necessary factors in invasion. The former carries the spore or seed into the area to be invaded. In ecesis the spores or seeds germinate and grow and the new plants become established after more or less adjustment. In practically all terrestrial forms invasion is possible only when migration is followed by ecesis. In the case of aquatic forms distributed regularly by water, ecesis is of little or no importance, and migration often becomes identical with invasion.

288. The manner of invasion. Since ecesis is largely controlled by competition, the manner and amount of invasion are determined by the presence or absence of vegetation. Soils without vegetation are either new or denuded, while areas covered with vegetation are either open or closed. Each kind of area presents different conditions to invaders. Naked habitats, i.e., rocks, talus, dunes, are usually invaded with great difficulty, because of their xerophytic character, and the slowness with which invaders secure a foothold, in spite of the lack of competition. Denuded habitats usually offer the best opportunities for invasion. They ordinarily contain a large number of disseminules ready to spring up when the original occupants are destroyed. The sur- 
face offers good conditions for germination, and there is no competition to decrease the chances of ecesis. Open formations are readily invaded, since competition is slight, and physical factors rarely extreme. On the other hand, closed formations reduce invasion greatly, owing to the intensity of the competition which newcomers must meet.

Invasion takes place by the entrance of new individuals. The manner depends largely upon the nature of the seed or fruit. The invasion of wind-distributed species with comate or winged seeds or one-seeded fruits is by individuals as a rule. Migrants

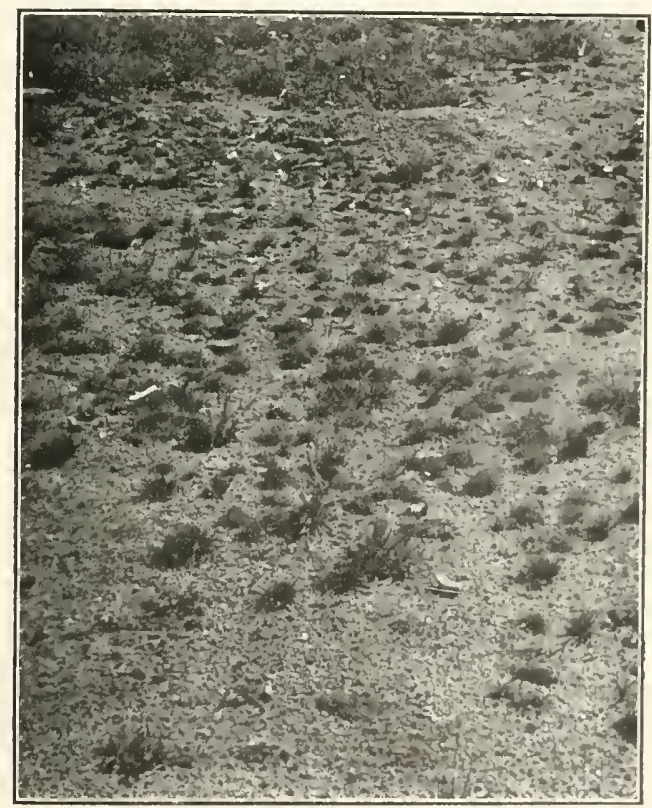

Fig. 109.-Invasion of the shore of a lake, almost wholly by rosette plants which have migrated from the mass in the background.

in which the disseminule is a many-seeded fruit or plant tend to produce a group of invaders. The accidents of migration sometimes bring a few separate seeds together into one group, or scatter those of a many-seeded fruit, but these are relatively rare exceptions to the rule. This difference in the manner of cutrance is an important factor in alternation, and is the basis of the two types of abundance, i.e., copious and gremarious. 
The seeds of two or more species which are intermingled or adjacent are frequently carried into a new area at the same time. This process of mass invasion is characteristic of new habitats and of the transition areas between formations or regions. The best examples of it are found in valleys, where there is a definite line of movement.

289. Invasion at different levels. The invasion of a formation or some part of it may occur at three different levels: (1) at the level of the facies, (2) below the facies, (3) above the facies. This is determined by the relative height of invaders and occupants. The level at which invasion occurs determines the whole future of the formation, as well as the structural modification of the plants concerned. The entrance of invaders of the same general height as the facies regularly produces a mixed formation. Facies and invaders are rarely so equally matched that they remain in permanent equilibrium. Any slight advantage of the one over the other tells sooner or later, and invader slowly yields to occupant, or the reverse.

When invasion takes place below the facies, the invaders are either slowly adopted into the formation, or gradually disappear. In either case there is usually little change in the formation, and its structure is modified slightly if at all. If the invaders overtop the facies in any considerable number, the entire formation is more or less modified, or it disappears entirely, as is the rule in succession.

290. Kinds of invasion. Continuous invasion occurs between formations or areas more or less alike, and is usually mutual. There is an annual movement from each one into the other, and often a forward movement through each, resulting from the invaders of the previous year. Most invasion is of this sort. Transition areas are good examples of continuous invasion, which is usually mutual also. Intermittent invasion commonly arises through migration to a distance. The movement is more or less accidental, and may never recur. Such invasion is relatively infrequent, but it is often striking, owing to the fact that the invader often wanders far from the original home.

Invasion is complete when the number of invaders is so great that the original occupants finally disappear. Such invasion occurs in many ruderal or weed formations, and is typical of many successions. It is ordinarily the result of continuous in- 
vasion. Partial invasion takes place when the number of invaders is sufficiently small that they may be adopted into the formation without changing it materially. Partial invasion is more frequent though less conspicuous than complete invision. When an invader persists for a few years and then disappears, invasion is temporary. This is usually the case in the earlier stages of succession which replace each other more or less rapidly. Permanent invasion occurs when a species becomes permanently established in a more or less stable formation. It is characteristic of the grassland and forest stages of succession.

29I. Indigenous and derived species. Species or forms that have arisen within a formation, or have belonged to it since its origin, are indigenous. Species that have invaded the formation at a later date are derived. The latter are termed vicine when they are fully established invaders from adjacent formations or regions, and adventitious when they have come from distant formations. Derived species which are unable to establish themselves permanently are adventive.

Experiment 69. Invasion. Stake a quadrat in an area denuded by flooding, or in consequence of cultivation or building. Trace the entrance of invaders, and determine their source in so far as possible. Stake a second quadrat in the transition area between two formations, and determine to which formation the various species belong.

292. Succession. The process by which a series of invasions occurs in the same spot is termed succession. This is always the result of invasion, but not all invasion leads to it. The number of invaders must be large enough or their effect sufficiently controlling to bring about the gradual disappearance of the original occupants. Partial or temporary invasion rarely causes succession. On the other hand, it is the regular consequence of complete and permanent invasion. Succession depends primarily upon invasion in such quantity and of such kind that the reaction of the invaders upon the habitat prepares the way for further invasion. The characteristic presence of stages, or formations, in a succession is due to invasion and reaction. In a denuded habitat, for example, mirration from the adjacent formations is constantly taking place, but a relatively small number of migrants become established. These reach a maximum development in size or number, and in so doing react upon the 
habitat so that new migrants find inereasingly favorable conditions. These in turn attain their maximum, and cause the gradual disappearance of the species of the first stage. At the same time they prepare the way for the plants of the succeeding stage. This successive replacement of one set of plants by another, which gives the name to this process, is due partly to the reaction of the plants upon the habitat, and partly to the competition between them. The close competition between individuals of the same or similar species causes them to displace each other,

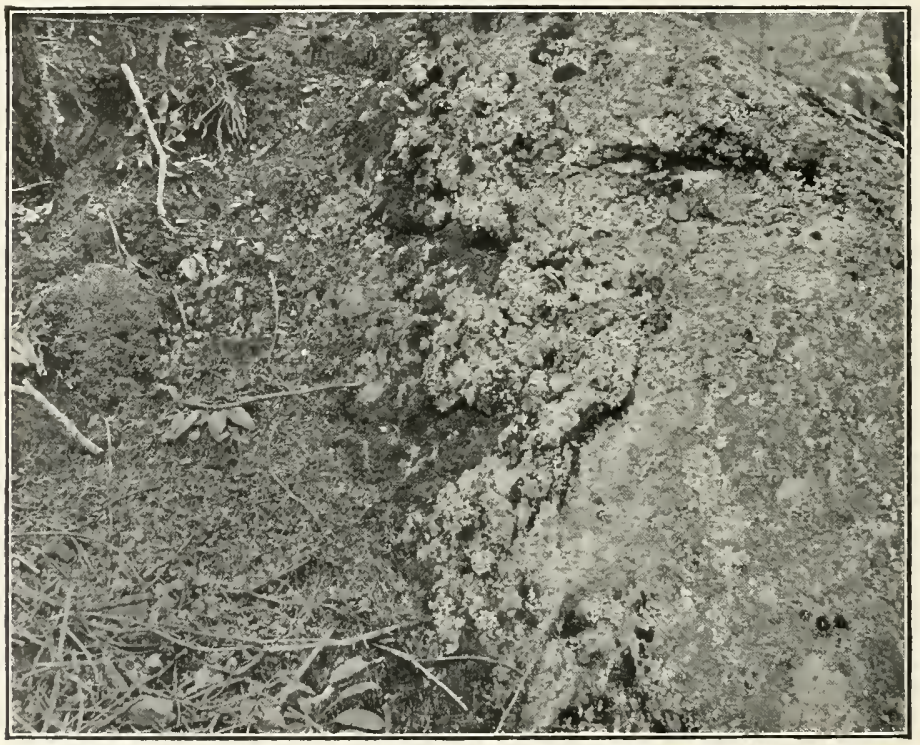

FIG. 110.- Stages of a primary succession. Owing to the partial breaking down of the rock, four stages which ordinarily follow each other are here found side by side. The solid surface is covered with crustose lichens, the crumbling edge shows foliose lichens, beyond these are mosses, and in the new soil mat and rosette herbs are appearing.

though they at the same time permit the entrance of invader's of a different character.

293. Kinds of succession. A particular succession is started by the physical or biological disturbance of a habitat or formation. With respect to the initial cause, successions are normal or anomalous. A normal succession begins with a bare habitat, and ends in a stable formation. An anomalous succession is one in which the facies of the usual final stage are replaced by other 
species, or one in which the development departs radically from the normal course. Normal successions occur everywhere, anomalous ones are infrequent.

Normal successions may arise upon soils or habitats newly formed, or upon those laid bare by the destruction of the plants upon them. New soils are more or less unfavorable to ecesis. They possess few or no seeds, and many changes are necessary before a stable formation can take possession. Consequently a succession in a new soil takes place slowly and exhibits many stages. It is termed a primary succession. Denuded soils as a rule offer much better conditions for ecesis owing to the action of the previous vegetation. Dormant seeds are more or less abundant. Revegetation takes place rapidly and shows few stages. Such a sucession is termed secondary.

A normal succession is usually perfect, i.e., its stages occur in the usual sequence from initial to final formations without an omission. Imperfect succession results when one or more of the stąes is omitted anywhere in the course, and a later stage appears before its turn. It may develop at any time when a new or denuded habitat is so surrounded by other vegetation that the usual invaders are unable to enter, or when the abundance, nearness, or mobility of certain species enables them to take possession before their turn.

294. Primary successions. These arise on newly formed soils or upon those exposed for the first time. In general they are characteristic of mountain regions, where weathering is the rule, and of lowlands and shores where sedimentation is constantly occurring. The physical processes that bring about the formation of new soils are: (1) elevation, (2) volcanic action, (3) weathering. The first two are infrequent and often local, and hence need not be considered here. ${ }^{1}$ Weathering is practically universal, and in comnection with the disposition of the weathered material furnishes the basis for distinguishing new soils. In accordance, the latter are divided into the following groups: (1) residuary soils, which are formed in the position occupied by the original rock, (2) collurvial soils, due to the action of gravity upon the weathered material, (3) alluvial soils, those arising by deposit in water, (4) acolian soils, which are former or deposited by winds, (5) grlacial soils, due to the action of gra-

${ }^{1}$ Research Methork, 241. 
ciers. The primary successions upon colluvial, alluvial, and aolian soils are by far the most frequent and important.

295. Succession in colluvial soils. Colluvial deposits are found at the base of cliffs, ledges, and mountain sides. The formation of talus, i.e., the mass of coarse irregular material at the base, is due to the action of gravity upon the fragments of rock split off by disintegration. Decomposition appears later as a secondary factor. The fragments forming the talus are extremely

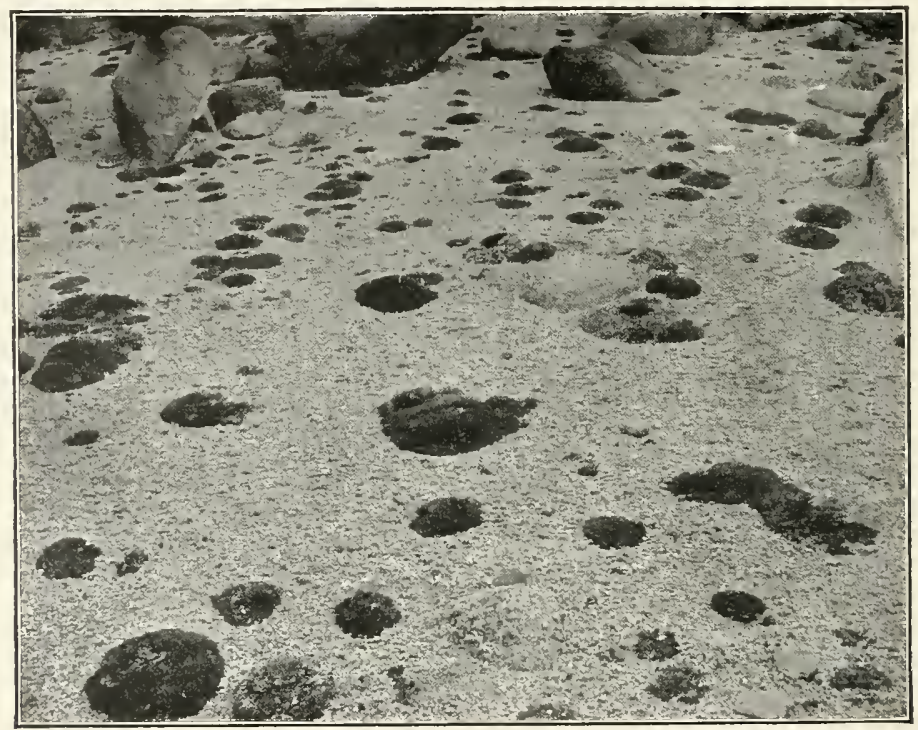

Frg. 111.-A mat formation, the first stage of an alpine colluvial succession.

variable in size, but they agree in their angular shape. Talus may originate from any kind of rock, the nature of the latter determining the size of its particles. Gravel slides differ from ordinary talus in consisting of more uniform particles, worn round by slipping down the slope in response to gravity and surface wash.

The character of the successions in talus depends upon the kind of rock in the latter. If the rock is igneous or metamorphic, decomposition is slow and the resulting soil is easily dried out. The corresponding successions consist of many stages, and the formations are for a long time open and xerophytic. In talus 
formed from sedimentary rocks decomposition is usually much more rapid, and the successions are simpler and more mesopliytic. 296. Succession in alluvial soils. Alluvial soils are formed when any obstacle retards the movement of water. This decreases its ability to carry sediment and causes the deposit of all or part of its load. Alluvial soils consist of more or less rounded, minute particles mingled with organic matter. Such deposits are common at the mouth of streams or rivers and in the valleys flooded by them. Alluvium is also formed by the filling of ponds

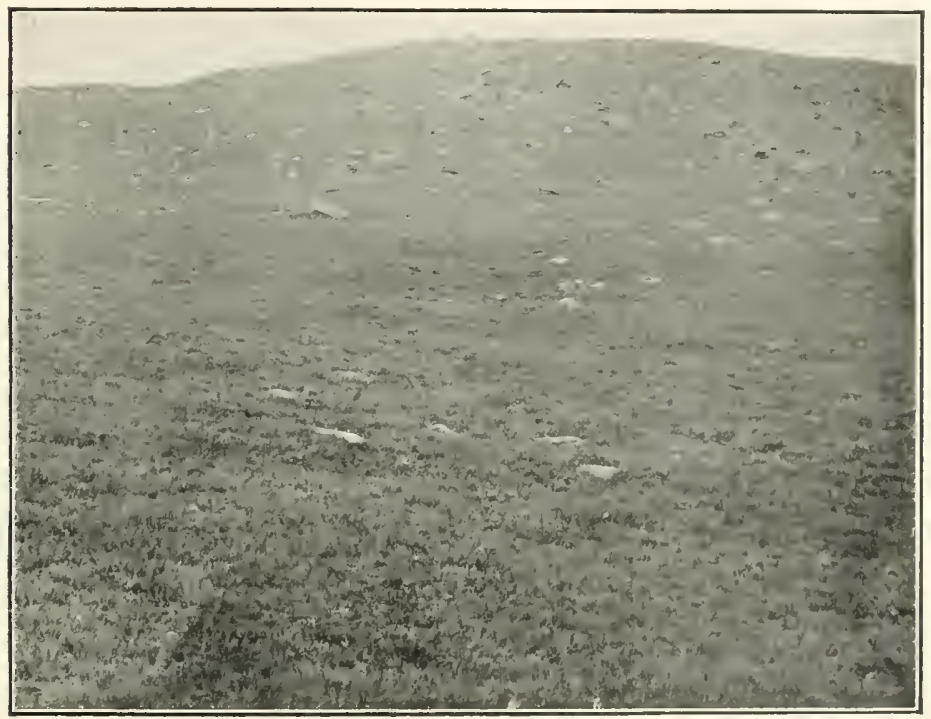

FIG. 112.-A meadow formation, the last stage of the alpine colluvial succession.

through surface wash and of lakes through the deposit of material by streams entering them. It occurs along coasts where bays and inlets are slowly converted into marshes, in consequence of being shallowed by the material washed in by waves and tides.

Two kinds of alluvial deposits are distinguished: (1) those black with organic matter and little disturbed by water, and (2) those of a light color, which are constantly swept by the waves. The corresponding suecessions are radically different. In the first the pioneer vegetation is hydrophytic; in the serond 
it is xerophytic. Both become finally more or less mesophytic, but in one this takes place by decreasing water content and in the other by increasing it.

297. Succession in æolian soils. Wind-borne soils are represented chiefly by inland and coastal dunes. These consist of rouncled sand particles of almost uniform size, although this varies greatly in dunes of different ages. The reaction of the pioneers upon dunes plays an important part in building them up, by virtue of binding and holding the shifting soil. A dune

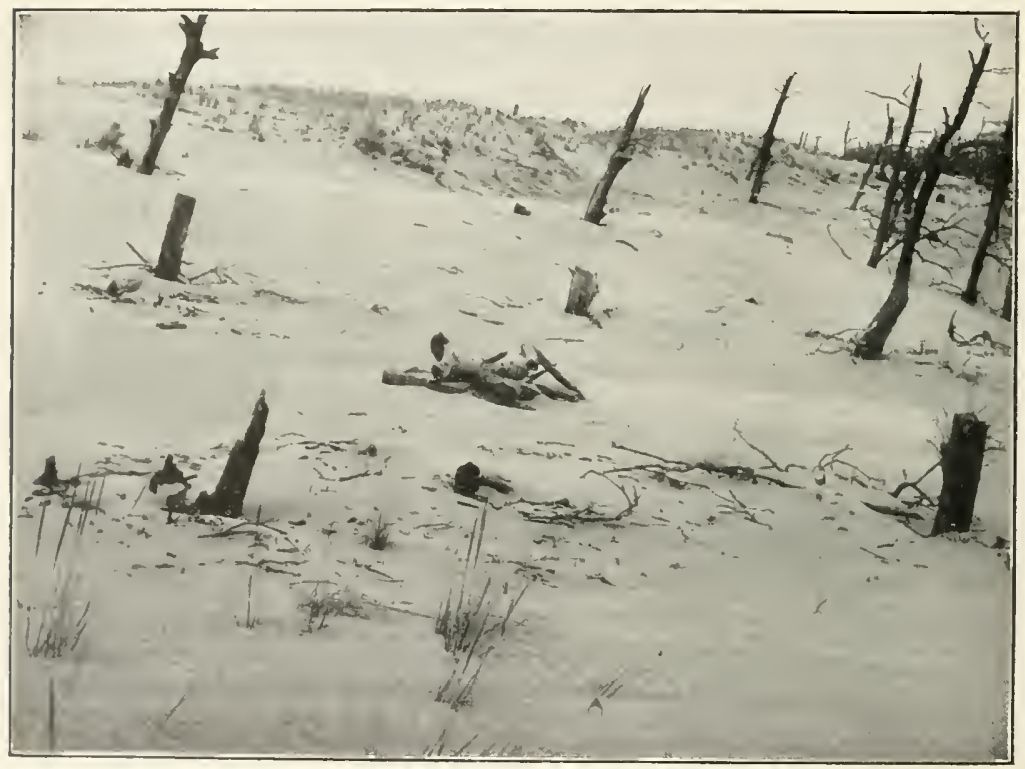

Fig. 113.-First stage of an wolian suecession, sand dunes of Cape Henry.

succession usually starts with xerophytes and terminates in inesophytic meadors or forests. Inland dunes occur in dry regions, and their successions are xerophytic throughout.

298. Secondary successions. Practically all successions on denurled soils are secondary. Exceptions occur only when the action of the denuding force is so intense that an entirely new soil is exposert, as in landslides. The great majority of secondary sucessions owe their origin to erosion, floods, or the activities of man. They oceur orlinarily upon soils of medium water con- 
tent. Such soils usually contain considerable organic mattel and a large number of dormant seeds. The successions upon them consist of relatively few stages, and are usually mesophytic in character. Secondary successions may arise in eroded, flooded, or drained soils; they may be caused by subsidence or landslides, or by animals or man.

299. Succession in eroded soils. Habitats are ordinarily eroded by the action of water. Sands and gravels are readily worn away, owing to their lack of cohesion, while loam and clay are easily eroded only on slopes. In the former the extreme porosity and slight capillarity of the soil result in a low water content. In the finer soils the water content is also low, on account of the excessive r'un-off. The action of wind in eroding soils which bear vegetation is not general. It is found to some

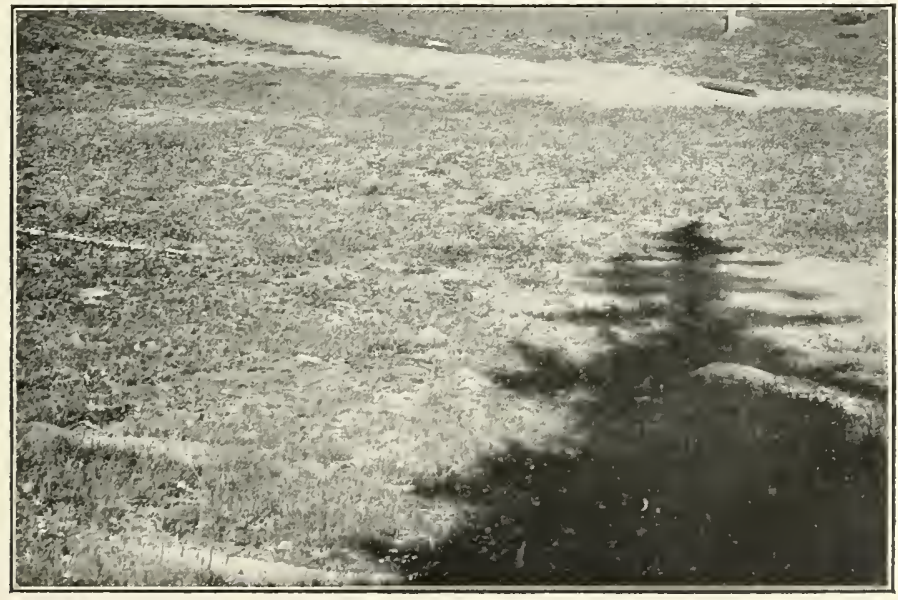

FIG. 114.-Secondary succession in a flooded area. The plants of the alpine meadow have been drowned out, and the soil entirely oceupied by one species, Bistorta bistortoides.

extent in dunes, and is frequent in sandhills, where it produces blowouts.

The early stages of successions in eroded soils are usually composed of xerophytes. In loose soils these are forms capable of binding the soil particles together, thus preventing wash and increasing the accumulation of fine particles, especially of organic matter. In compact soils the pioneers not only decrease erosion, but also increase the water content by retarding run-off. 
300. Succession in flooded soils. Floods are confined largely to the valleys of streams and to coasts. Flood waters spread out over the lowlands of the valley, forming a flood plain. The effect of the orerflow is to destroy or to place at a disadvantage all the plants of the flood plain that are not hydrophytes. At the same time a thin layer of fresh silt is deposited upon the floor of the valley. Mesophytic species are washed away by erosion, or are destroyed by immersion in the water. After a flood which destroys the vegetation, algæ, liverworts, and mosses come in

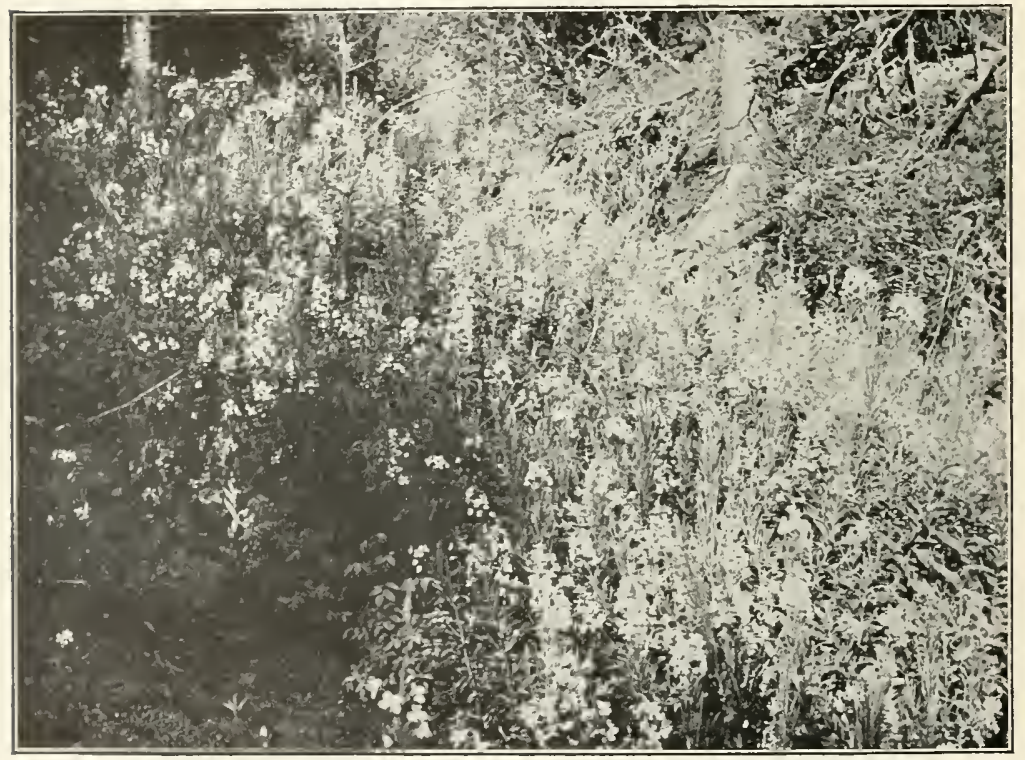

Fig. 115.-The fireweed, Chamenerium angustifolium, which forms the first herbaceous stage of a burn succession in the Rocky Mlountains.

quickly, as pioneers of the succession. These are followed the same year or the next one by weeds, which after a few years are displaced by the original species.

301. Succession due to man. Man destroys vegetation through fires, lumbering, and cultivation, as well as by drainage and irrigation, though the latter usually modify the water content merely. Such activities are almost universal. The resulting successions depend not only upon the cause, but also upon the region in which it operates. Man by his activities originates 
an immense number of successions, among which those of burned, lumbered, or cultivated areas are far the most frequent.

302. Succession in burned areas. From the nature of the vegetation, fires are of little significance in open formations, such as deserts, wastes, etc. In grassland the living parts are underground at the time when fires ordinarily occur. In consequence the annual burning of prairie or meadow disturbs the formation very little, and no succession results. All formations composed of woody plants, e.g., forests and thickets, are seriously injured

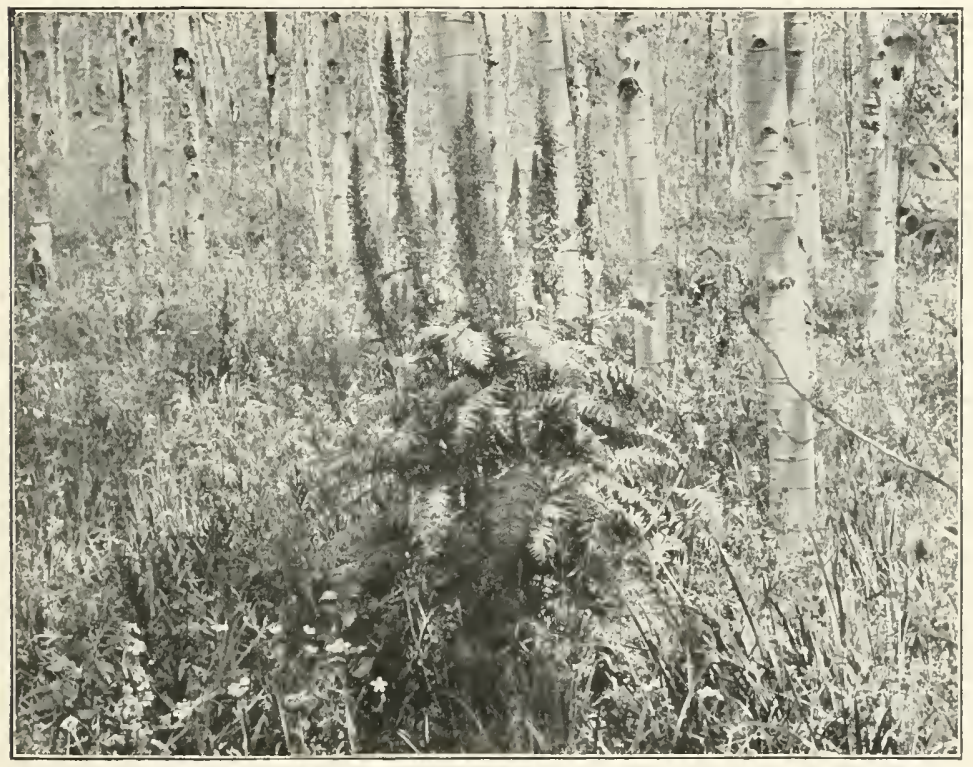

Fig. 116.-An aspen forest, the typical stage of the burn succession.

by fire. A severe general fire destroys the vegetation completely. A local fire destroys the growth in a restricted area, while a superficial burn removes the undergrowth and hastens the disappearance of the weaker trees. A local fire prepares the way for a succession in which the invaders come largely from the original formation, especially when this encloses the burned area more or less completely. When a particular formation is destroyed wholly or in large part, the first stages of the new vegetation are formed by invaders from the adjacent formations. The suc- 
ceeding stages contain an increasing number of species found in the original forest, until, in the final formation, the original facies have returned. The reconstruction of a mesophytic forest regularly takes place by means of mesophytes, owing to the fact that the change in soil is slight.

303. Succession in lumbered areas. Lumbering often results in complete or nearly complete lestruction of the vegetation through removal, or through the action of erosion upon the exposed surface. In the first case a short mesophytic succession results. In the second the succession is long and complex, passing through decreasingly xerophytic conditions to a stable nesophytic forest. Where a forest is cut over for certain species alone, the undisturbed trees usually take full possession. In some instances a newcomer usurps the first place, while in others the original species ultimately return.

304. Succession by cultivation. The clearing of forests and the "breaking" of grassland for cultivation destroy the original vegetation. The temporary or permanent abandonment of cultivated fields then permits the entrance of weeds, which are the pioneers of new successions. This occurs annually in fields after harvest, the same species reappearing year after year. In fields that lie fallow for several years or are entirely abandoned, the first ruderal plants are displaced by newcomers, or certain ones become dominant at the expense of the others. In a few years these are replaced by invaders from adjacent formations, and the field is ultimately reclaimed by the original regetation, unless this has entirely disappeared from the neighborhood.

Other activities of man, such as the construction of buildings, roads, railways, canals, ete, remove the native vegetation and make room for the rapid development of weed formations In and about cities, where the original formation has entirely disappeared, such initial stages persist as permanent formations. Elicwhere the usual succession takes place, and the ruderal vegetation is finally replaced by the original one. In mountain and desert regions, where ruderal plants are rare or lacking, their place is taken by native species of large seed production and much molility. These are gradually replaced by other native species of less mobility but greater persistence.

305. Reactions of plants upon the habitat. A succession starts wherever an area is unoceupied, denuded, or otherwise 
changerl, so that fairly complete and continuous invasion may take place in it. Its continuance is largely due to the reaction which each of its stages exerts upon the physical factors of the habitat. The reactions thus produced are as follows: (1) influence upon weathering, (2) binding rolian soils, (3) reduction of run-off and crosion, (4) filling with silt and plant remains, (5) enriching the soil, (6) exhausting the soil, (7) modification of atmospheric factors.

Plants influence weathering by hastening disintegration or decomposition, or more rarely by protecting the rock surface from the action of weather. This last effect is found in some degree where lichens or mosses cover rocks completely, though they serve at the same time to decompose the surface. Herbs, and especially shrubs and trees, hasten disintegration through the growth of roots into cracks and clefts. When present in masses, they increase the amount of water, and hence promote the action of the latter. The shifting soils of dunes, blowouts, etc., are inhabited chiefly by sand-binding plants, mostly perennial grasses and sedges. These usually have masses of fibrous roots, long, erect leaves, and vigorous rootstocks capable of pushing up rapidly through a covering of sand. They react by fixing the sand with their roots, thus preventing it from being blown away. They also catch the shifting particles among their stems and leaves, which also serve to accumulate regetable remains.

In habitats subject to erosion, plants delay run-off and prevent the formation of rills of sufficient size to erode the soil. Such plants are usually perennial grasses or composites with welldeveloped roots. On sand and gravel slopes the loose texture of the soil leads to the production of sand-binders and of mats and rosettes, which are especially effective in preventing the slipping of the soil. In hydrophytic habitats the plants check the movement of the water. In consequence they cause the deposition of part or all of the sediment carried by it, and they then retain and fix the particles deposited. The continuance of this action, together with the acemmulation of plant renains, grardually fills up the habitat. The enrichment of the soil by the lecay of the plants growing upon it is a reaction that is found in some measure in all formations. The reverse process, the exhaustion of the soil, is largely confined to eultivated fields. Only a few doubtful cases of such action oceur in nature. In layered for- 
mations the reaction of the taller plants in reducing the sunlight to shade, and in modifying humidity, temperature, and wind, determines the final course of the succession.

306. The laws of succession. The following arrangement of the principles which govern succession furnishes a helpful summary of the course of development.

I. Cause. The initial cause of a succession is the formation or appearance of a new habitat, or a striking change in an existing one.

II. Reaction. Each stage of a succession reacts upon the habitat in such a way as to produce conditions more or less unfavorable to itself, but favorable to the invaders of the next stage.

III. Mobility and nearness

1. The pionecrs of a succession are those species near at hand, or most mobile.

2. The number of migrants from any formation into a habitat varies inversely as the square of the distance.

3. The pioneers usually come from two or more different formations, since most formations contain some very mobile species.

4. The plants of the initial stage are usually algx and fungi, because of their minute spores, composites and grasses on account of their very mobile fruits, or ruderal plants owing to their large seed production.

IV. Ecesis.

1. The migrants into a new, denuded, or greatly modified habitat are sorted by ecesis into three groups: (1) those that are unable to germinate or grow, and soon die; (2) those that grow normally under the conditions present; (3) those that pass through one or more of the earlier stages in a dormant state, and appear in a later stage of the succession.

2. Whenever ruderal plants are present, they furnish a large number of the pioneers, on account of their ready ecesis. In other regions subruderal native species play this part.

3. Annuals and biemnials are characteristic of the earlier stages of secondary successions, on account of their great seed production and ready ecesis. 
4. In layered formations sun plants appear before shade plants, but yield to them, except when they belong to the primary layer.

5. Excessive seed production and slight mobility lead to the imperfect ecesis of individuals in dense stands, and hence usually produce groups that are temporary.

6. Each pioneer produces about itself a tiny area of ecesis and stabilization, which may be entered by its own offspring, by the seeds of its fellows, or by invaders from a distance.

7. Species that propagate by offshoots or produce immobile fruits in small number usually establish themselves readily, because the offspring appear within the area reacted upon by the parent forms.

V. Stabilization.

1. The universal tendency of vegetation is toward stabilization.

2. The ultimate stage of a succession is determined by the dominant regetation of the region. Lichen formations are often final in polar and niveal zones. Grassland is the final vegetation for plains and alpine stretches, and for much prairie, while forest is the last stage for all mesophytic habitats.

3. Grasslands or forests usually terminate successions, hence they are most frequent in regions showing few physiographic changes.

4. The end of a succession is largely brought about by the progressive increase in competition, which makes the entrance of invaders more and more difficult.

5. Stabilization radiates outward from the pioneer plants or masses. The movement of offshoots is away from the parent mass. The chances of ecesis are greatest near its edges in a narrow area in which the reaction is felt, but competition is not so intense.

VI. General laws.

1. The stages or formations of a succession are distinguished as initial, internediate, and ultimate.

2. Initial formations are open, ultimate formations are closed.

3. The number of species is small in the initial stages. It 
attains a maximum in the intermediate ones, and again decreases in the ultimate formation, on account of the dominance of a few species.

4. The normal sequence of regetation forms in succession is: (1) algae, fungi, and mosses, (2) annuals and biennials, (3) perennial herbs, (4) bushes and shrubs, (5) trees.

5. The number of individuals of a species increases constantly to a maximum for each stage, and then gradually decreases as the next stage develops.

6. A secondary succession does not begin with the initial stage of the primary one that it replaces, but usually at a much later stage.

7. At present successions generally tend to end in mesophytic formations, grassland, or forest, though many remain xerophytic or hydrophytic.

S. The operation of succession must have been essentially the same during the geological past that it is to-day.

307. The study of succession is carried on by the use of instruments for determining the physical factors of the habitat and the reaction of the stages upon them, and by the use of quadrat, transect, and migration circle to discover and record the changes in structure during the various stages. It is usually impossible to apply these methods to the initial stage of a succession and then to the succeeding stages, owing to the length of time taken by the development. A few secondary successions run their course within a few years, but ordinarily the period is much longer, especially in primary successions, where it may reach several hundred years. Since it is rarely possible to follow a succession from beginning to end, it is necessary to employ indirect methods of determining its course. The three methods used for the purpose are: (1) the method of alternating stages, (2) the relict method, (3) the experimental method. By the combined use of these, it is possible to reconstruct a succession with something of the same detail and accuracy that could be obtained by following it from beginning to end.

308. Method of alternating stages. The same succession of ten starts at the same time or at different times upon several areas of similar nature. When the start is made at different times, the various areas show different stages in derelopment. If one 
area shows an initial stage and another an intermediate one, the development of the former reveals the history of the intermediate stage, while that of the latter indicates the stages passed through to reach the ultimate one. Hence from a number of areas it is possible to work out in a few years the probable sequence of stages in a succession that requires several decades

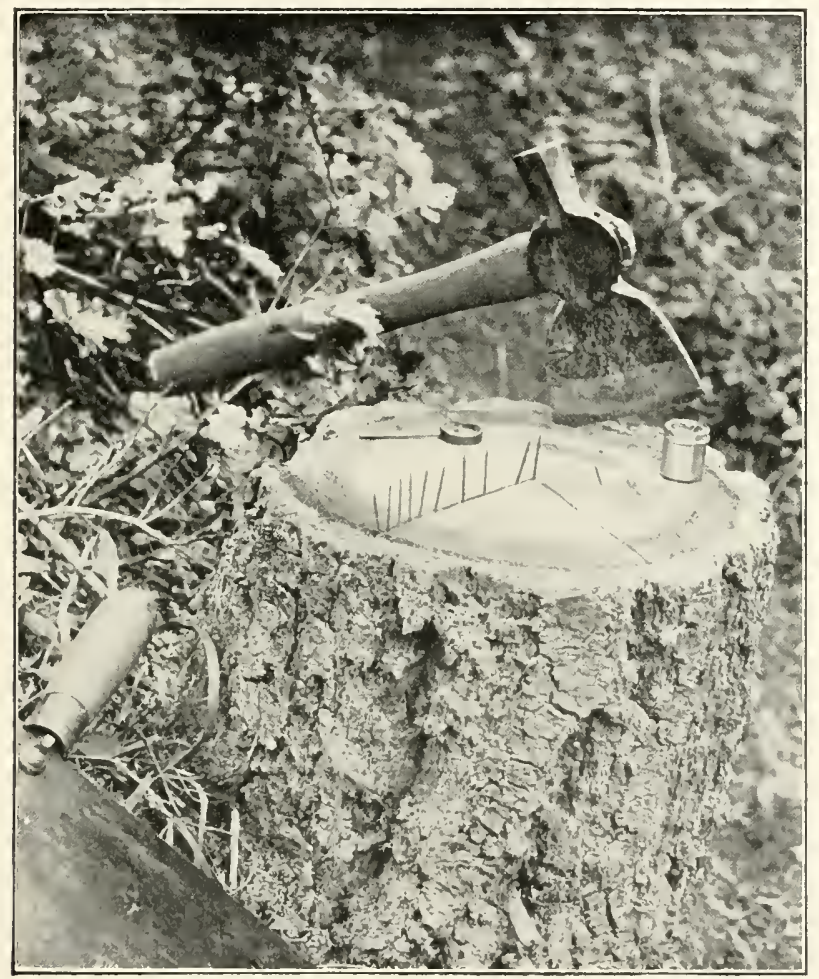

Fig. 117.-Decade method of counting the annual rings of a tree or shrul, to determine the age of a sluccessional stage or formation. ('herck pins are inserted in every tenth ring.

or more for its development. Such a method is not final, but it is the only feasible one for most surcessions.

309. The relict method. When one stage yields to another, some species persist for a longer or shorter period. Some last through the next stage, while a tew may persist through several successive stages. When the stages to which such relicts belong 
are known, their number and position often make it possible to throw much light upon the previous course of development. In the majority of cases the reliet is not modified, and is readily recognized as belonging properly to a previous stage. This is true of herbs in all the stages of grassland and in the initial ones of forest succession. The herbs and shrubs of the earlier stages, which persist in the final forest formation, are necessarily modified. 'Their abundance and position, however, usually make it elear that they are relicts.

The lifetime of the forest and thicket stages of succession is found by counting the annual rings of trees and shrubs. This important method may be readily employed in woody formations where stumps abound or a fire has occurred.

Experiment 70 . The study of a secondary succession. Select an abandoned field or a denuded area for study. List the species that are present, indicating their relative importance. Determine in so far as possible the formations from which the invaders have come. Examine similar areas, especially those that show other stages, and by means of comparison indicate the general course of succession.

Chart a permanent quadrat that has been previously established, and compare the chart with those of former years. 


\section{CHAPTER XV}

\section{ALTERNATION AND ZONATION}

310. The relation between alternation and zonation. The structure of all formations, as well as their arrangement into vegetation, rests upon two principles, zonation and alternation. Both of these are concerned in the structure of a formation. In some cases zonation predominates to such an extent that alternation is subordinated or becomes inconspicuous. More often the reverse is true. The alternation of various groups is so marked that zonation is completely obscured. Because of its striking character, zonation is usually more conspicuous than alternation. The latter, however, is more fundamental and more universal.

311. Alternation. This principle deals with the occurrence of a formation at different places in a region or of a plant group or species at separate points in a formation. It covers all responses of vegetation to the unlikeness of the many parts of the earth's surface. Alternation stands in sharp contrast to zonation, since it is caused by a lack of symmetry in habitats. It is found in vegetation areas and plant groups of every rank. The breaking up of vegetation into formations is a striking example of alternation. It is also found within every formation, where it is represented by consocies, sccieties, communities, and families, and gives endless variety to its structure. In brief, altemation deals with the structures and causes which give to regetation its typical and universal lack of uniformity.

312. Causes of alternation. The primary cause of alternation is unlikeness in the physical factors of various formations or areas of the same formation. This condition is universally present in vegetation; it occurs within zones as well as in formations that lack them. Alternation is due also to competition and to invasion, and naturally any two or all of these causes may act 
together to produce it. Migration carries seeds into the different areas of a formation or into different formations, with little respect to the physical nature of these. The physical differences between the various areas causes some of the migrants to be established in some places and not in others. Other migrants establish themselves in another series of the areas, and so on. Competition often hunders or prevents the ecesis of a species in an area in which the physical factors are otherwise favorable, and thus produces altemation independently. Invasion frequently

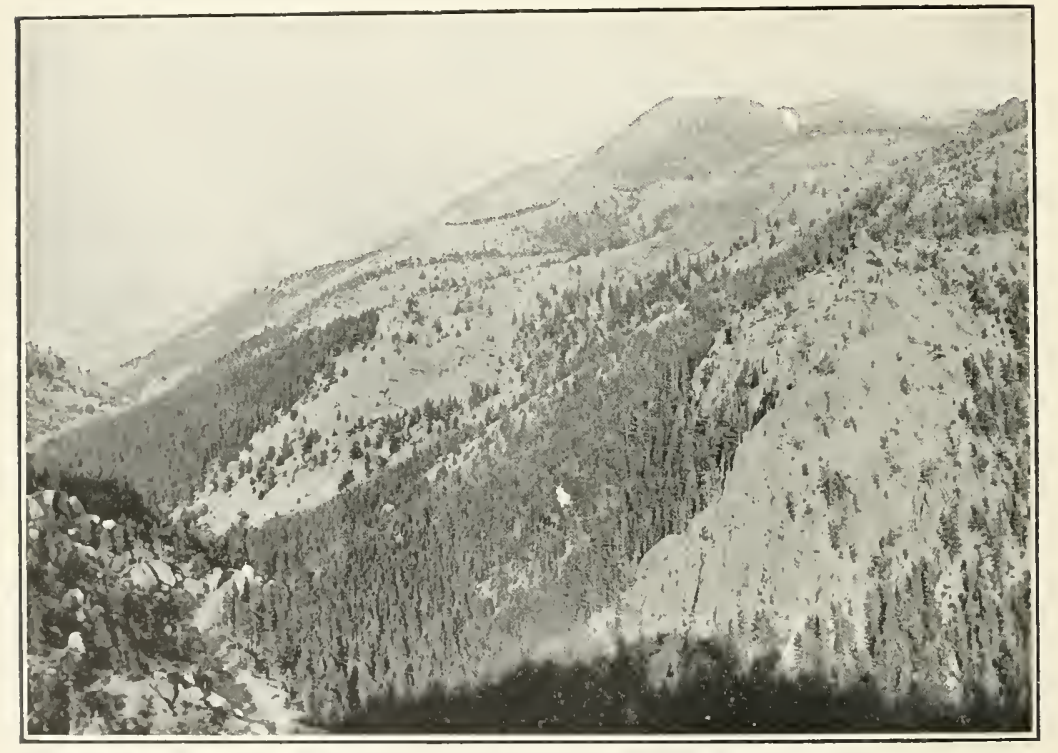

Fia. 118.-Alternation of spruce forests and gravel slides in Engelmann Ciñon above Manitou.

carries plastic species into a number of dissimilar habitats, or causes one species to appear in one or more similar areas, and a similar or corresponding species in the remaining areas of the series. In new or denuder areas invasion and physical factors act together to produce alternation, while in closed vegetation competition is a factor which operates independently, or in conjunction with the habitat.

313. Alternation due to ecesis. When seeds are carried into a number of more or less diverse areas or formations, alternation 
does not arise if the physical factors permit ecesis in all of them. This is a rare occurrence, however, and in the vast majority of cases ecesis is possible only in those areas closely resembling the original home. In cons auence the same species, together with its neighbors, which necessarily possess the same ability of adjustment, tends to recur in all similar areas of the formation. The same is true on a larger icais of the formations of a region. Examples of the same formution recur more or less regularly in the same kind of habitat, alternating with other formations which occur in habitats of another kind. From this it is evident that the type of alternation due to ecesis is a fundamental and universal feature of regetation. ${ }^{1}$

3I4. Alternation due to competition. The alternation produced by ecesis in similar areas is often affected by competition. The number and kind of individuals vary in the several areas. In some competition is much more intense than in others, consequently reducing the number of individuals of invader or occupant, or eliminating one or the other completely. In minor areas, in which the physical factors are little if at all different, plants persist more readily in areas with slight competition than in those where the latter is intense. As a result different groups appear, each one tending to recur in those spots where competition is least unfavorable to it.

315. Kinds of alternation. Alternation involves two ideas, viz., the alternation of different species or formations with each other and the alternation of the same species or formation in similar but separate situations. This is the result of a lack of symmetry in a habitat or region, in consequence of which adjacent areas are dissimilar and remote ones often similar. The same species, group, or formation is said to alternate between two or more similar situations, while different species, groups, or formations alternate with each other, occurring in situations differing in ecesis or competition. From the nature of alternation the two cases always occur side by side.

Alternation is distinguished as normal, mumerical, or corresponsive. The general mature of the first has just been indicated. Numerical alternation occurs when a species varies greatly in abundance and importance in the various areas in which it is found. In corresponsive alternation a species, group, or for-

${ }^{1}$ Research Methods, 283. 
mation is represented in one or more areas suitable to it by a similar or corresponding species, group, or formation.

Numerical and corresponsive alternation are variations of the normal process. They arise out of slight differences in physical factor's. or the course of competition, or out of migration from the surrounding vegetation.

316. Normal alternation of formations, consocies, etc. The alternation of formations or of minor areas is especially characteristic of greatly diversified regions, such as mountains. It is

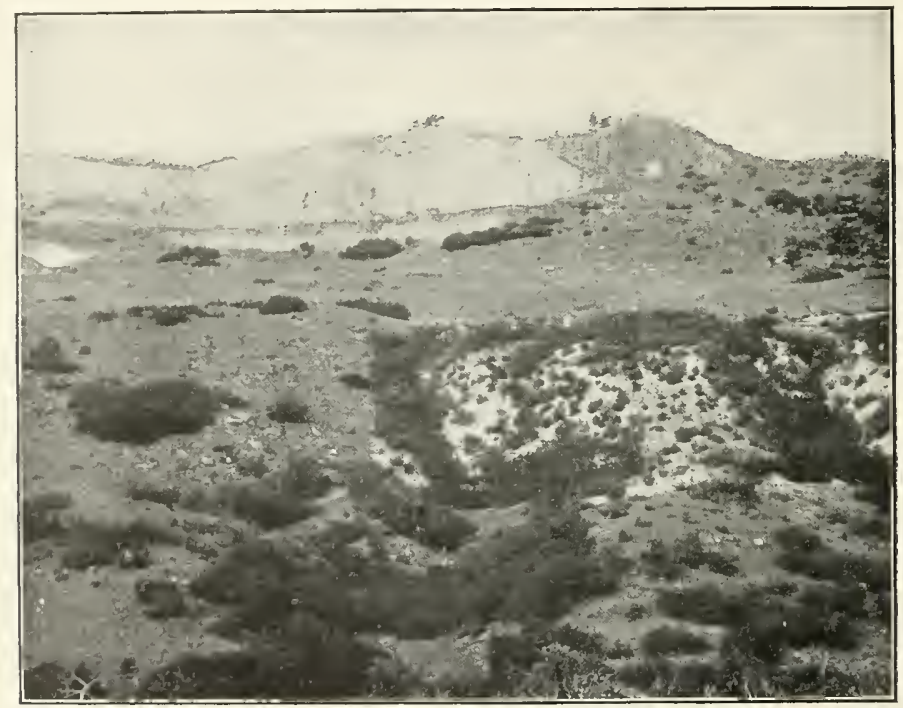

FIG. 119.-Normal alternation of consocies of the foothill thicket formation near Colorado City. (Quercus is found on the black soil, Cercocarpus on the limestone soil, and Rhus in the valleys.

naturally much less conspicuous in lands with a more uniform surface. A xerophytic formation alternates from ridge to ridge, a mesophytic one from one valley to another. Aquatic regetation altermates from pond to pond, or from stream to stream. The appearance of new or denuded soils upon which successions are established is the most important source of the alternation of formations. This is true in general of other causes of succession, such as erosion, flooding, burning, and cultivation, especially when they occur in areas physically similar. 
In an extensive formation the same consocies alternates between those areas that are similar. When the formation is broken up and occurs here and there in separate examples, a consocies often alternates from one to another of these.

317. Normal alternation of species. The alternation of species is the most typical feature of formations. The areas of a habitat which show minor differences in physical factors or in competition are occupied by individuals of one or more species able to adjust themselves to such differences. Individuals of such species tend to recur in all areas essentially similar, the intervening areas being occupied by species more or less different. Individuals that are scattered alternate as well as those that grow in groups, but their alternation is necessarily much less conspicuous. In habitats not too heterogeneous a number of species are sufficiently adjustable so that they occur throughout the entire formation. In the prairie formation Festuca, Koelera, Panicum, and Andropogon occur practically throughout, except in the moist ravines which are really meadows. Astragalus, Psoralea, Erigeron, and Aster grow on slopes and crests, but they are much more abundant in certain situations. Other plants, Lomatium, Meriolix, Anemone, Pentstemon, etc., recur in similar situations upon different hills. Lomatium alternates between sandy or sandstone crests; Meriolix and Pentstemon occur together upon dry upper slopes, while Anemone alternates between slopes and crests.

318. Numerical alternation. All species that alternate show a variation in abundance from one area to another. Frequently the difference is slight, and can be determined only by the use of the quadrat. Sometimes the variation is so great that a facies is reduced in number until it is less important than certain principal or secondary species. A principal species often undergoes a similar reduction in importance. This arises from the fact that the similar areas are sufficiently different to affect the abundance without entirely suppressing the species. 'This result is due partly, and sometimes wholly, to competition. It is especially noticeable in places where a species is placed at an increasing disadvantage. Numerical alternation is often due to recent invasion, in consequence of which the species has not yet had time to reach its normal abundance. Istragalus crassicarpus, for example, grows on nearly all the slopes of the prairie formation. 
On some it is as abundant as the facies, while on others it is represented by a few scattered individuals. Such alternation is much more striking in separate examples of the same formation, particularly when the abundance of a facies is normal in one and extremely reduced in another. This is a matter of much importance in the study of formations, since a separate consocies may otherwise be mistaken for the formation itself.

319. Corresponsive alternation. Owing to the accidents of migration and competition, similar areas within a habitat are not always oceupied by the same species or group of species. A species found in one area may be replaced in another by a different one of the same or another genus. Such genera and species are termed corresponding. They must be essentially alike in habitat form, i.e., in response to the habitat, though they may be entirely unrelated systematically. A good example of corresponding alternation is found upon exposed sandy crests of the prairie formation where Lomatium occurs upon some, but is represented upon others by Comandra or Pentstemon.

Experiment 7I. Alternation of species. Select several species of a heterogeneous formation, such as a hilly prairie, for study. Note the places at which each species occurs. From the physical nature and the location of the various places, indicate whether the alternation of each species is due to ecesis and competition or to accidents of migration.

320. Zonation. Zonation is the common response of plants to the way in which physical factors are distributed through a habitat or a series of them. In nearly all habitats one or more of the physical factors present decrease gradually in passing away from the point of greatest intensity. The result is that the plants of the habitat arrange themselves in more or less definite belts about this point, their position being determined by their relation to the factor concerned. Most formations show zonation of some kind, though the zones are often incomplete or obscure through various causes. In many cases, when the general structure of the formation reveals no zones, it will be found that some of the species are arranged zonally. As a rule, zonation is more characteristic of regetation, as a whole, than of the formation. This is seen in the zones of continents, though these are often interrupted, owing to elimatic and physiographic differences, so that they are not always continuous. 
321. Zones due to growth. The causes that produce zones are either biological or physical. The first are connected with some feature of the plant, the second with the physical factors of the habitat. Biological causes arise from the method of growth, the manner of migration, or the reaction of the species upon the habitat. The formation of circles as a result of radial growth is a very common occurrence. It is well known in the case of the "fairy-rings" of certain mushrooms. It is also found in a large number of molds, mildews, and other fungi, especially the

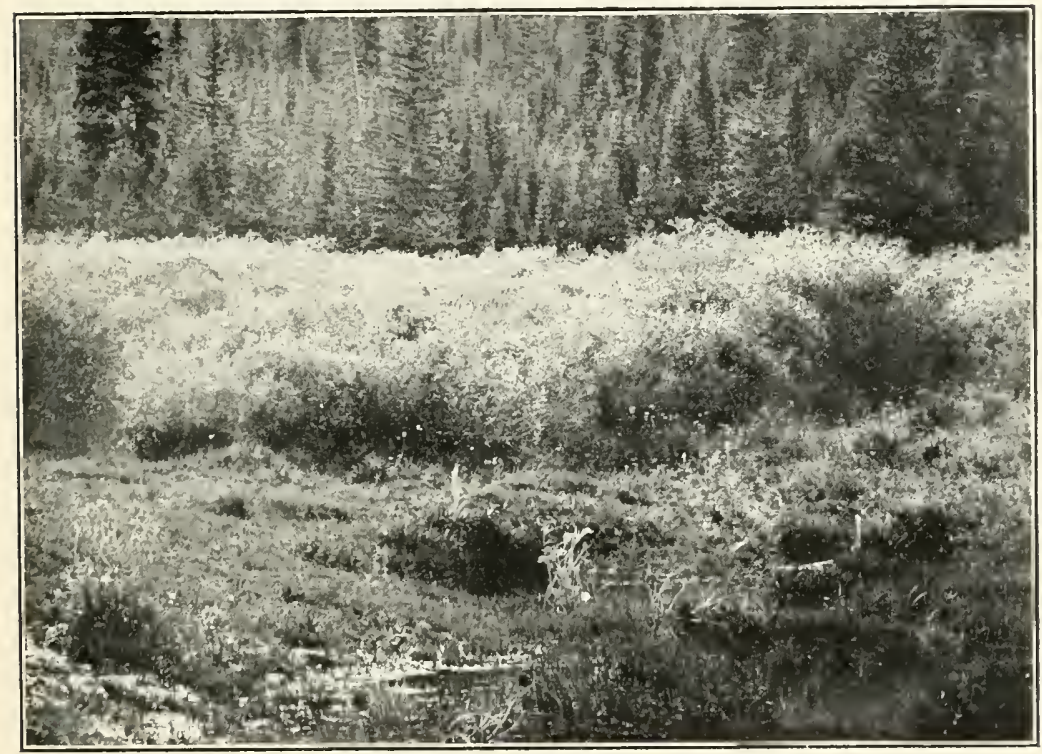

FIg. 120.-Bog, meadow, thicket, and forest zones at the upper end of Lake Moraine.

foliose lichens. The thalloid liverworts show a similar radial growth. Flowering plants, and many mosses also, furnish excellent examples in those species that form mats, turfs, or carpets.

Growth results in zonation only when the older central portions of the individual or mass die away, leaving a gradually widening belt of younger plants or parts. This seems to be due in part to the greater age of the central portion, and in part to the successful competition of the young, actively growing parts for the water and nutrient material of the soil. Such miniature 
zones of growth do not increase in size until they make the zones of formations, but they serve as examples of the action of growth in zonation.

322. Zones due to migration and ecesis. The growth of runners or rootstocks away from the plant or mass in all directions is a very effective means of migration. The seeding of the plants thus carried away from the central mass is most certain at the edge of the newly occupied area. The circle thus becomes larger

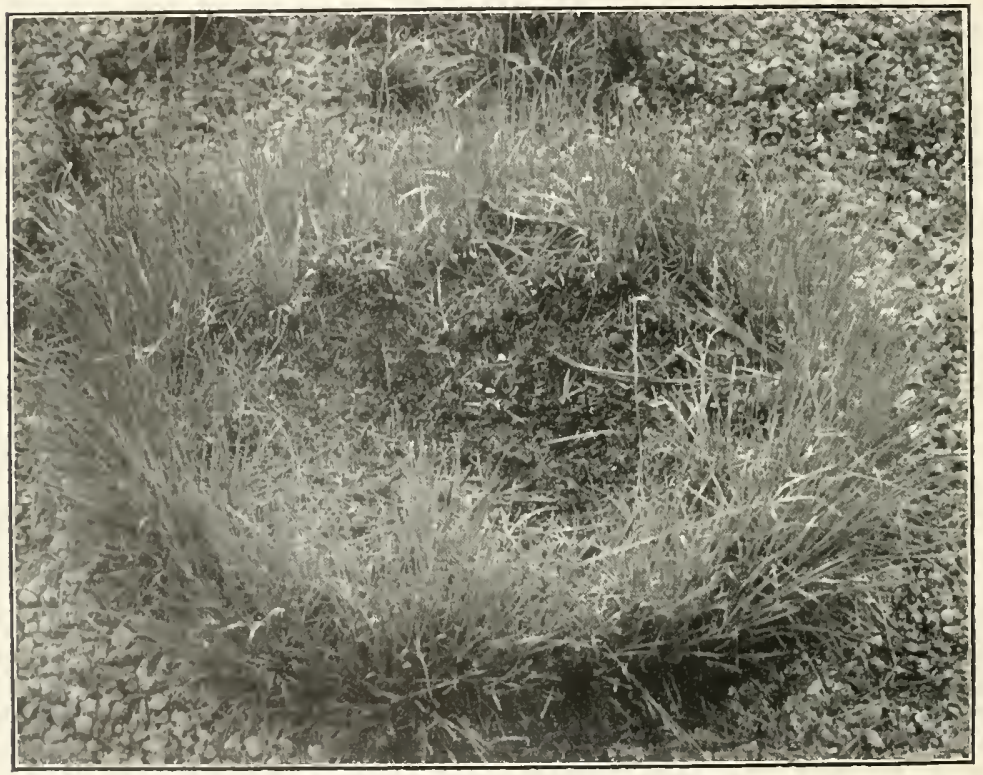

Fig. 121.-A growth zone of Muhlenbergia gracilis, produced by the radial growth of the original mat and the dying of the older parts.

year by year. Sooner or later the younger and more vigorous circumference becomes a more or less complete zone. This is due to the reaction of the central individuals upon the habitat, so that they are readily replaced by invaders, or to their increasing age and dying out.

323. Zones due to reaction. Certain reactions of plants upon habitats produce zonation. The zones of fungi seem to be caused by the exnaustion of the organic matter present. In the mats of mosses and flowering plants it is probable that the continued 
reaction of the central part has something to do with its disappearance. The reaction of a forest or thicket, or even of a layer of herbs, plays an important part in producing zones. The factor chiefly concerned here is light. The intensity is greatest at the edge of the formation, and also just below the primary layer. It decreases toward the center of the forest and toward the ground. In response to these changes, zones appear in both directions. The lateral zones are more or less incomplete, and are only due in part to differences of light. The rertical zones or layers are characteristic of forests and thickets, and are controlled wholly by differences in light intensity.

324. Zones due to physical factors. The physical causes of zonation are by far the most important. They arise from differences in water, temperature, and light. The great zones of vegetation are due to water and temperature differences. In a particular region or habitat, variation of water content and humidity are the most important, while light acts only in the case of forests and thickets. Physical factors produce zonation in a habitat or a series of habitats, when there is either a gradual and cumulative or an abrupt change in their intensity. Gradual slight changes are found in single habitats; abrupt marked changes in a series of them.

The change in a decisive factor takes place in all directions from the area of greatest intensity, making the habitat more or less symmetrical with respect to the factor concerned. If the area of greatest intensity is linear, the shading out takes place in two directions. The resulting symmetry is bilateral, a condition found along streams. On the other hand, a central intense area shades out in all directions, giving rise to radial symmetry, such as is found in ponds, lakes, etc. The close connection between the two kinds of symmetry becomes evident where a stream broadens into a lake, where a mountain ridge breaks up into isolated peaks, or a peninsula or landspit is cut into islands. The line that connects the points of accumulater or abrupt change in the symmetrical area is a stress line or ecotone. Such lines are usually well marked between formations, especially where the medium changes, as between a pond and a prairie. They are less evident within formations. In the one case the ecotone separates two distinct series of zones, and in the other merely two different zones of the same formation. 
325. Physiographic symmetry. The symmetry of a habitat depends primarily upon the distribution of water in it, and this is greatly affected by soil and physiography. Decisive differences in soil rarely occur within a single habitat, though this is often the case in a series. The strikingly zonal structure or arrangement of habitats is nearly always due to differences in water content produced by physiographic factors, slope, exposure, surface. and altitude. All of these have a pronounced influence upon water content and humidity. Consequently, wherever appre-

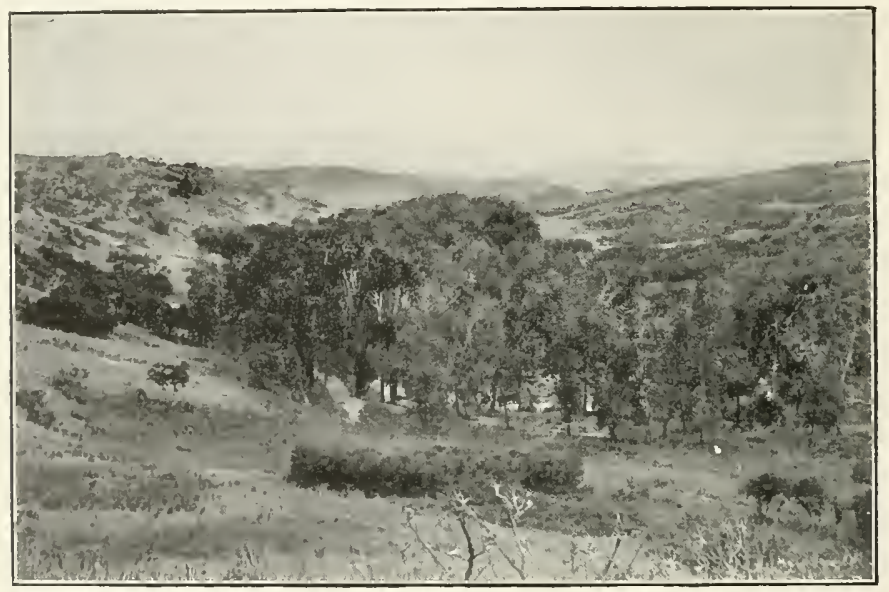

FIG. 122.--Physiographic symmetry shown by the valley of Bear Creek near Colorado Springs. The bilateral zones of Populus angustifolia are indistinct, owing to the narrow stream, but the thicket zones are marked.

ciable differences in physiography occur, they produce areas of excess or deficiency in water content about which this factor varies symmetrically. Peaks and hills are typical examples of areas of deficiency; ponds, lakes, and oceans of areas of excess. When such areas are extreme in character and close to each other, the resulting zonation is marked. When they are moderate, particularly if they are widely separated, the zones produced are obscure.

326. Symmetry in vegetation. The response of vegetation to habitat is so exact that physiographic symmetry everywhere produces a vegetational symmetry, which is expressed in zones. 
In consequence zones are regular features of vegetation. The zonal arrangement of formations is usually evident, but the zones of a formation are often obscured and sometimes lacking. The latter is regularly the case in a uniform area, such as a shallow pond or a new soil.

Zones are obscured in several ways. The plants are sometimes too scattered to make the response to physiographic symmetry evident. The alternation of conspicuous species not only interrupts zones, but often it also completely hides the zonation of species of lower habit. The ecotones of one factor may run at right angles to those of another, and the resulting series of zones may obseure each other. A physiographic feature such as a hill may have its symmetry interrupted by ridges or ravines, which deflect the zones downward or upward, or cause them to disappear altogether.

327. Kinds of zonation. Two kinds of zonation are distinguished with respect to the direction in which the controlling factor changes. When this is horizontal, as with water content and temperature, zonation is lateral. If the direction is vertical, as in the case of light, zonation is rertical. There sometimes exists a close connection between the two in forests, where the secondary layer of small trees and shrubs is continuous with a belt of trees and shrubs around the central nucleus and the lower layers of bushes and herbaceous plants with similar zones still further out. Lateral zonation is radial when the habitat or physiographic feature is more or less circular in form, and it is bilateral when the latter is elongated or linear. Tertical zonation is unilateral, i.e., the zones extend in but one direction.

328. Radial zonation is typical of elevations and depressions, especially mountain peaks, islands, lakes, ponds, etc. The zones of peaks are ordinarily quite perfect. They are due largely to temperature, though humidity also plays a part. The zonation of islands, hills, etc., is produced by water content. The zones of islands are often regular and complete, while those of lills are more often incomplete or obscure. Prairies and steppes do not show a series of zones, but their hills and ridges are more or less zoned. Ponds and lakes usually show complete zones, except in ponds so shallow that the ordinary marginal zone is able to extend over the entire bottom.

The line between an elevation and a depression, i.e., the edge 
of the water-level, is a sharply defined ecotone. It separates two series of zones, each of which constitutes a formation. One of these is regularly hydrophytic, the other usually mesophytic. The line between the two can rareiy be drawn at the water's edge, as this is not constant, owing to waves, tides, or periodical rise and fall. There is in consequence a more or less variable transition zone of amphibious plants, which belong properly to the hydrophytic formation. Many forest formations serve as a center about which are arranged several incomplete zones.

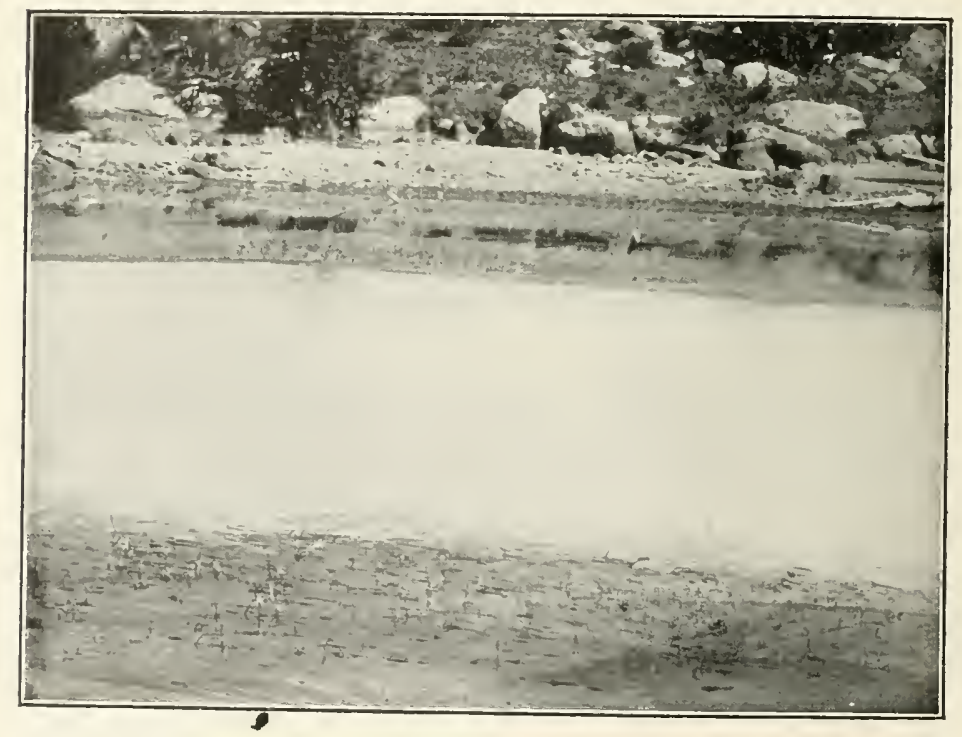

FIG. 123.-Radial zonation of Sparganium angustifolium in one of the Seven Lakes.

329. Bilateral zonation differs from radial only because it is produced by linear elevations and depressions rather than circular ones. With this difference, the zones of ranges and ridges correspond exactly to those of peaks and hills, while the same relation is evident between the zones of streams and of lakes and ponds. The ecotones are identical except in form; they are linear in one, circular in the other. Incompleteness is more frequent in bilateral zonation, though this is due largely to the length of lilateral zones. 
330. Vertical zonation is peculiar in that there is no ecotone present, on either side of which zones arrange themselves with reference to the factor concerned. This is due to the fact that the controlling factor is light, which falls upon the habitat in such fashion that it decreases in but one direction, i.e., downward. Vertical zones appear in bodies of water on account of the absorption of light by the latter. The most characteristic zones occur in forests, where the primary layer of trees acts as a screen. The density of this screen determines the number of zones or layers

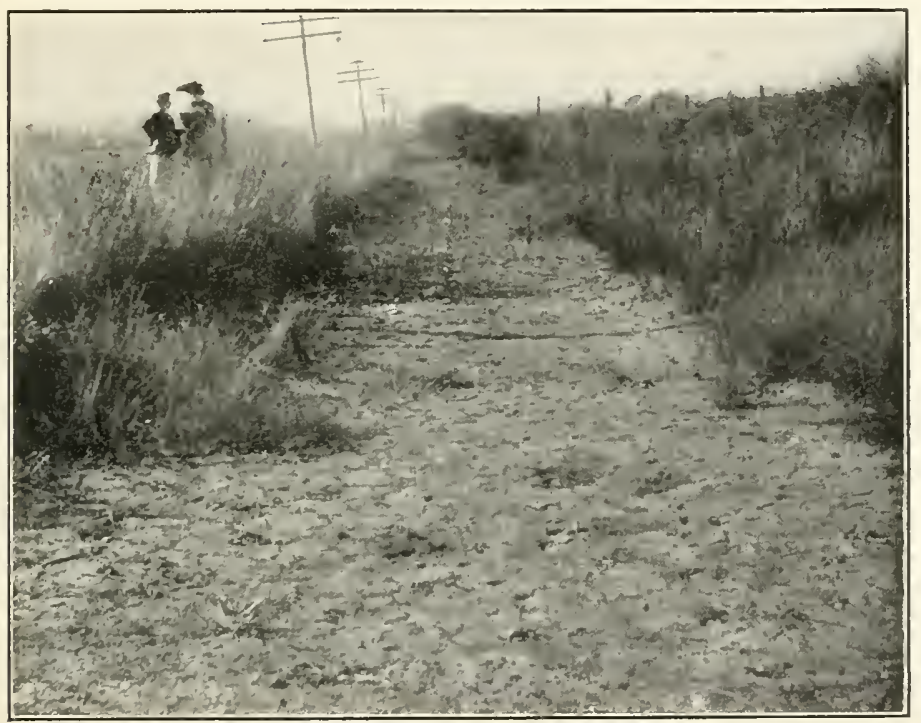

FIG. 124.-Bilateral zonation of cord grass, Spartina cynosuroudes, along a ditch.

present. In extreme cases the foliage is so dense that the light beneath is insufficient even for mosses and lichens. As a rule, however, there are one or more layers present.

A vertically zoned forest shows a complete series of reactions. The primary layer determines the amount of light, heat, and water for the subordinate layers in general. Wach of the latter further modifies the amount for those below it, the ground layer being subject in some degree to the reaction of every layer above it. The lower layers also influence the upper by reacting 
upon the habitat through absorption, transpiration, decomposition, etc.

33I. Vegetation zones. Zonation is the most striking feature of the regetation of contiments, a fact well illustrated by the vegetative covering of North America. It is produced by a gradual variation in both water content and temperature, though the former is much the more important. In accordance with the decrease of water content and temperature northward, three

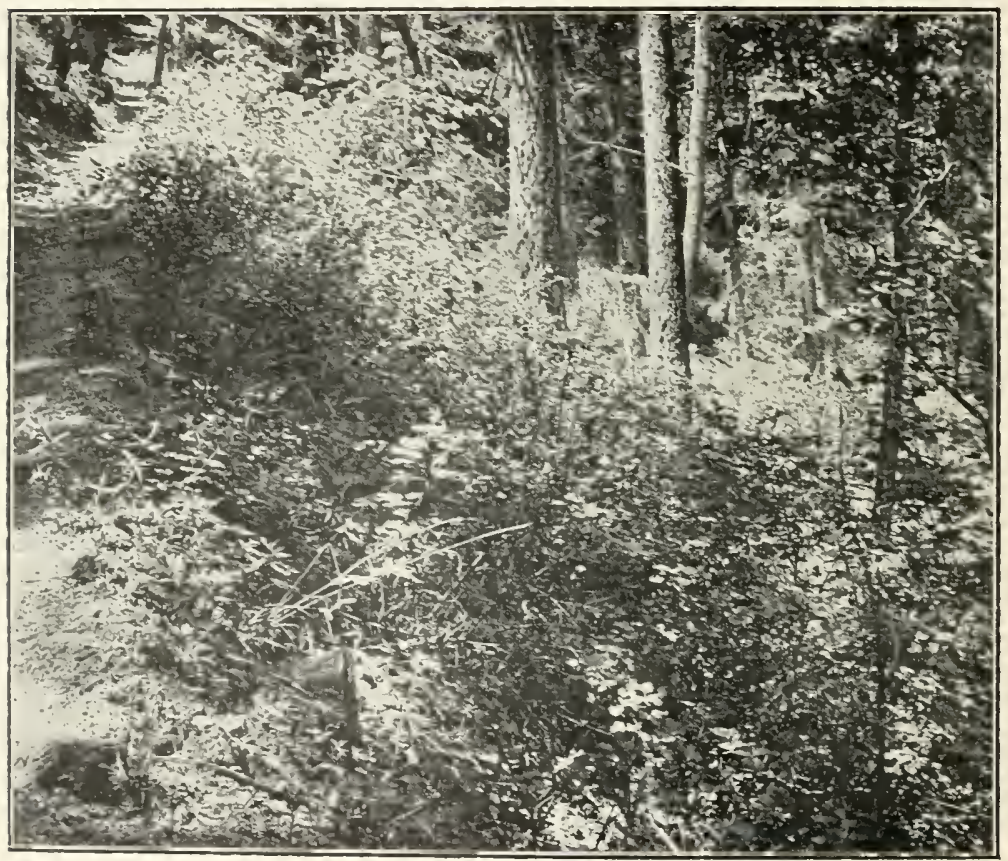

Fig. 125.- Vertical zonation, or layering, in a spruce forest.

primary belts of regetation stretch across the continent from east to west. These are forest, grassland, and polar desert. The first is further divided into the secondary zones of broad-leared evergreen, deciduous and needle-leaved forests. At right angles to this symmetry due to temperature and water lies a second one produced by water alone. In response to this, forest belts touch the oceans, but give way in the interior to grasslands, and these to deserts. The interference of these two series of zones has 
produced the primary features of the vegetation of North America. Tropical forests occur where heat and water are excessive, deserts where either is unusually deficient, deciduous and coniferous forests where the water content is relatively high, and prairie and plains where it is relatively low.

This primary arrangement is modified by the disturbing effect of three continental mountain systems. The Appalachian system is not sufficiently high to produce a pronounced effect upon humidity and rainfall. In consequence forests extend far beyond it into the interior before giving way to prairies and plains. On the other hand, the influence of the Rocky Mountains and the Sierra Nevada is marked. The latter rise to a great height relatively near the coast, and condense upon their western slopes nearly all of the moisture brought from the Pacific. The Rocky Mountains have a similar effect upon the drier winds from the east, and the two systems in consequence enclose a parched desert. All three systems carry the formations of the north far beyond their normal southern limit, owing to the low temperatures that prevail in high altitudes. The alpine grasslands of the Sierra Nevada and the Rocky Mountains are a southward extension of arctic grasslands, and the belts of coniferous forests along the slopes of the three systems are similar extensions of northern forests.

Experiment 72. Zonation of pond and meadow formations. Select for study a pond of some extent and depth. Note the rarious zones of vegetation and list the species of each. Make a map showing the general outline of the pond, and indicate the limits of the various zones of pond and meadow. 



\section{INDEX}

abnormal succession, 274

absolute humidity, 25

absorption, 38

relation between, and transpiration, 38

abundance, 205

Acacia, 162

Acer, 242

negundo, 126

achene, 132

Aconitum, 120

columbianum, 57

acospores, 243

Adansonia, 117

adaptation, 4, 190

origin by, 192

to excessive water supply, 152

to light, 171,181

to small water supply, 144

to water, 144

types produced by, to water, 155

adjustment, 4

abnormal, 5

kinils of, 5

normal, 5

to contact, 141

to gravity, 135

to the habitat, 265

to light, 71

to shock, 142

to temperature, 90

to water, 38

advent itious, 273

adventive, 273

æolian soils, succession in, 278

xestival flowers, 130

Agave, 160, 162

americana, 147

age of plants, 112

agents of migration, 244

aggregation, 220, 237

mixed, 239

simple, 237

Agropyrum caninum, 207

aianthous flowers, 130 air-spaces, 59, 175

Alisma, 167

alkalies, influence of, 147

Allionia, 157, 182, 184

lincaris, S6, 17S, 173, 179, 182, 184

nyctaginea, 182

Allium, 133, 207

recurvatum, 134

allogamy, 124

alluvial soils, succession in, 277

alpine plants, 27, 98

alternating stages, 286

alternation, 220,289

causes of, 289

corresponsive, 291, 294

due to competition, 291

due to ecesis, 290

kinds of, 291

normal, $291,292,293$

numerical, 291, 293

relat ion between, and zonation, 289

altitude, $22,27,63$

effect on light, 76

amides, 101

Amorpha, 227

amphibious plants, 153,166

ancestral factor, $1 \$ 6$

Andropogon, 226, 293

consocies, 226

Androsace, 120, 207

diffusa, 180

anemochores, 245

Anemone, 121, 207, 228, 242, 293

anemophilous flowers, 125,126

animals, in migration, 245

Antennaria, 159, 207, 227

ant hot ropism, 121

A pocymum androsemifolium, 145

Aquilegia corrulea, 250

Arabis femelleri, 157

Aracere, 120

Aragallus lamberti, 207

Arctestaphylus uva-ursi, 119, 157

Arisama, 120, 126

Aristida, 244 
Artemisia, 159, 160, 162, 165

frigida, 207

artifieial seleetion, 196

Ascle pias, "242

Asco phora, 105

asparagin, 101

Asparagus, 163

aspeets, 2223

Aster, 227, 246, 293

Astragalus, 226, 293

crassicarpus, 293

autogamy, 124, 127

direet, 127

indireet, 127

autotrophie plants, 104

autumn aspeet, 224

a vailable water, 9, 14

determination of, 13

arned disseminules, 243

\section{Buccharis, 162}

Bacon, on evolution, 18s, 192

Bacteriacca, 243

Bahia dissecta, 150, 164

barriers, 265

biologieal, 266

influence of, 266

physical, 260

helt transect, 211

berry, 131

Betula, 126, 242

Bicuculla, 120

Bidens bigelovii, 184

Bignonia, 126

bilateral zonation, 300

bological barriers, 266

biotie factors, 5

bisexual crosses, 198

Bistorta bistortoides, 279

blast ochores, 247

log plants, 168

"bog xerophytes," 19, 168

bolochore's, 247

Botrytium, 39)

Bouteloua, 2:6

Bouteloua-Kalcra-consocies, 226

Brassica alba, 42

Brauneria, 242

brot ochores, 246

Bryo phyllum, 162

buds, 114

bulblets, 115

bulbs, 115

burned a reas, succession in, 281

Bursa, 17s, 1s2

bursa-pastoris, 179

Cartacco, 164

calcium, 19, 101

Callitriche, 125, 167
Callitriche autumnal s, 167

bifida, 149, $16 \mathrm{~s}$

Calluna, 162

Caltha, 169

le ptose pala, 166

Calypso borealis, 60, 126

calyptra, 41

eambium, 41, 51, 53

Cam panula a parinoides, 121

petiolata, 2:4

rotundifolia, 121

capillarity, $16,18,20,55$

Capnoidcs aureum, 179

capsule. 132

earbonates, 19

earbon diox de absorption and diffusion. 81

Carex, 242

earphospores, 242

carpotropic movements. 132

Castillcia integra, 206, 207

eedar apples, 5

Cenchrus, 243

centrospores, 243

Cerastium, 243

Ccratophyllum, 125, 168

Cercocarpus, 292

ehaffy disseminules, 242

Chamenerium angustifolium, 123,136, $137,140,195,197$

changes of epidermal cells, 147

ehart quadrat, 204,205

ehemosynthesis, 100

chlorenehym, 57, 86

changes in, 150,172

ehlorides, 19

chlorophyll, absorption spectrum, 79 influenee of, 80

nature of, 79

production of, 79

chloroplasts, 177

influcnee of, 171

influence of light on number and position of, 85

number and position, 86

chlorovaporization, 63

ehresard, 9, 13, 14

Circea, 120

eircumnutation, 141

cladophyll form, 163

classifieation by habitats, 231

developmental, 233

of formations, 230

regional, 234

Claytonia, 131

eleistogamous flowers, 123

Clematis, 120, 243

climate, 27

elimatic faetors, influence of, 24

elinometer, 23 
clitochores, 246

closed formations, 235,271

cog psychrometer, 27,28

Colletia, 164

colluvial soils, suecession in, 276

Comandra, 226, 294

eomate disseminules, 242

community, 225, 227, 240

comospores, 242

compass plants, 145

competition, 251

alternation due to, 291

between different speeies, 255

between parents and offspring, 254

cultures, 259

effeet of position, 256

faetors in, 253

for water and light, 253

influence of vegetation form and habitat form, 256

law of, 255

mixed cult ures, 259

nat ure of, 252

primary law of, 254

quadrats, 261

result s of, $25 \mathrm{~s}$

simple eult ures, 259

study of, 259

consocics, 225

constaney, 187

constant and inconstant forms, 186

eontact, 141

copious, 205

Corallorhiza, 104, 105

Corispermum, 238, 245, 252, 262

com, 115

eorresponding species, 294

eortical region, 52

cover, 22, 24, 27

creatospores, 243

Crocus, 131

erosses, 197

cross-pollination, 124,125

erystallochores, 246

Cucurbita, 142

cultivation, succession by, 282

cult ures, eompetition, 259

Cupressus, 162

curvature, region of geotropic, 138

curves, combinations of, 34

intervals, 36

kinds of, 34

plotting, 35

cuticle, 57, 117

cutinized leaves, 157

Cyperace $, 126,161,163$

cytase, 100

cytoplasm, in growth, 106

darkness, influence of, $\mathrm{SO}$
Darwin, 187, 251

and the "Origin of Species," 188

evolution after, 189

on competition, 195

on single origin, 199

Datura, 261

day-bloomers, 120, 130

dccade method, 287

decomposition, 17

definite variation, 189

dehiseent dry fruits, 132

Delphinium, 120

denuded quadrat, 204, 209

derived spceies, 273

dermatogen, 39,41

developmental classifieation, 233

development of the format on, 219

De Vries, 200

on mutation, 190, 192

dew, 21

diaphragms, 167

diastase, 100, 103

dichogamy, 122

diclinism, 122

dieotyledons, stem structure of, 52

diffusion, 48, 84

in the leaf, $5 \mathrm{~s}$

digestion, 99

diphotie leaves, 174,182

diplophyll, 183, 1S 4

direct faetors, 5

direction of migration, 249

Discomycetes, 247

disintegration, 16

disposition of stamens and pistils, 122

dissected form, 160

dissemination, organs of, 241

disseminules, 242

position of, 244

division of labor, 116

dommant character, 198

dominant species, 221

Draba, 228

drupe, 132

dry fruits, 132,247

ecad , 155, 192, 193

ecesis, $98,220,261,270,284$

altemation due to, 290

factors in, 262

echard, 9, 14

Edwinia, 217

Elymus, 225, 239

Elymus-1Y uhlenbergia-formation, 225

endemic, 268

endemism, 268

endoderm, 41, 52

endosmose, 46

enzymes, 99, 100

Ephedra, 163 
ephemeral flowers, 123,130

epidermal cells, changes of, 147

layer of root, 42

region, 52

epidermis, changes of, 177

print, 78

protection of, 144

epiphytes, 151

Erica, 162

Ericales, 162

Erigeron, 131, 158, 227, 293

Eriophorum, 242 pinnatisectus, 161 speciosus, 178

eroded soils, succession in, 279

erosion, 283

Erysimum, 247

Erythronium, 120, 229

Eschscholtzia californica, 121

establishment, 220

et iolation, 81

etiolin, 80

Euphorbia, 164

evolution, 185

after Darwin, 189

experimental, 201

fundamental methods of, 191

exoderm, 41, 52

exosmose, 46

exotic, 268

experimental adaptation to water, 153

experimental evolution, 201

exposure, 22,27

facies, 221

factors, constant, 31

in competition, 253

in ecesis, 262

variable, 31

“fairy-rings," 295

family, 225, 228, 237

fermentation, 102

Festuca, 293

fibrovascular bundles, 51, 84 system, 52

system in transport, 51

flagellate disseminules, 243

flattened form, 163

fleshy disseminules, 243 fruits, 131

floating plants, 167

flooded soils, succession in, 280

flowering, period of, 128 time of daily flowering, 130

flowers, zygomorphic, 118

fluctuating variability, 189

follicle, 132

form of leaves, 178 of stems, 179

formaldehyde, $\$ 2$ formations, classification of, 230

closed, 231, 235

development and structure, 219

historical factor in, 219

hydrophytic, 232

maps, 213

mesophytic, 233

mixed, 231, 235

nature of, 215

open, $2: 31,235$

parts of, 225

plant, 215

recognition of , 216

relation between habitat and, 218

structure of, 221

types of, 232

xerophytic, 233

formula for vegetation, 205

for water content, 11

Fragaria, 212

Frasera speciosa, 269

freezing, 96

fructification, 131

fruit-distributed plants, 242

fruits, movements of, 132

Fuchsia, 137

functions influenced by temperature, 91

light, 71

of the stem, 54

of vegetation, 219

fungi, digestion in, 99

Galium, 182

gametophore, 115

Gaura parviflora, 181

geitonogamy, 124, 125

Genista, 162, 163

Gentiana, 120

geotome, 10

geotropism, 135

cause and reaction, $13 \vec{\imath}$

ecological significance of, 139

Geranium, 247

germination, 102

in ecesis, 263

Gilia, 120, 160, 162

glaciers, in migration, 146

Glococa psa, 237

glocospores, 243

glucose, 82, 84, 101

Gossypium, 242

Graminacea, 126, 242

grass form, 160

gravity, $\mathbf{1 0 8}$

in migration, 246

reaction time, $13 \mathrm{~s}$

region of curvature, 138

relation of plant to, 135

sensory zone, 138 
gregarious, 205

Grindelia, 159

squarrosa, 158

growth, 4, 106

amount and rate, 108

conditions that influence, 108

in migration, 246

of tissues and organs, 106

regions of greatest growth, 109

rhythm of, 110

zone of division, 110

zone of elongation, 110

zones due to, 295

guard-cells, 52

movements of, 61

Gyrostachys stricta, 175, 184

Haberlandt, on transpiration, 67

habitat, adjustment to, 265

effect on ecesis, 264

reactions of plants upon, 282

relation between formation and ,218 study, method of, 30

habitat-form, 155, 265

influence on competition, 256

habitats, 232

classification by, 231

hairs, 57, 148, 175

Hales, on transpiration, 67

halophytes, 156

IIelianthus, 159, 163, 165, 182, 227, 242,261

annuus, 182

pumilus, 176

heliophytes, 183

heliotropic plants, 88

Helleborus, 62

hemeranthous flowers, 130

Henslow, on adaptation, 190, 192

heterotrophic plants, 104

Heuchera, 217

II ibiscus trionum, 31

Hippurus, 167 vulgaris, 167

historical factor in vegetation, 219

Holacantha, 164

holard, 9, 14, 16

holophytes, 104

homogamous flowers, 122

hooked disseminules, 243

Hordeum, 229

hour readings, 33

humic acids, 169

humidity, $7,24,63$

effect of climate and habitation, 27

influence of pressure and physiography on, 26

influence of temperature and wind, 25

measurement, 27 humidity readings, 29

tables, 30

humus, 20

hybridation, origin by, 197

hybridization, 124

hydrochores, 245

hydrophilous flowers, 125

hydrophytes, 155,165

hydrophytic formations, 232

hydrotropism, 43,44

hygroscopic fruits, 247

hysterophytes, 104

nutrition of, 104

imbibition, 44,45

Impatiens, $126,247,265$

increase of water supply, 151

indefinite variations, 189

indehiscent dry fruits, 132

indigenous, 268, 273

mdirect factors, 5

insectivorous plants, digestion in, 99

invasion, 270

at different levels, 272

complete, 272

continuous, 272

intermittent, 272

kinds of, 272

manner of, 270

partial, 273

permanent, 273

temporary, 273

invertase, 100

I pomøe, 121

Iris, 120,226

iron, 79

isolation, 199

isophotic leaves, 174, 182

Juncus, 161, 162, 163

Kolera, 226, 293

Kuhnistera, 227

Kuhnia glutinosa, 213

Laciniaria, 227, 228

Lactuca, 242 scariola, 145

Lamarck, on evolution, 188, 192

Lanate leaves, 159,175

law of competition, 254, 255

of evolution, 185

of simple aggregation, 239

laws of succession, 284

layers 229

leaf position, decrease of water loss through, 145

print, 78,178

st ruct ure, 56

xerophytes, normal, 157 
leaf xerophytes, other, 159

xerophytes, types of, 156

leaves, out line, size and thickness of, 178

Lecanora, 215

legume, 132

Leguminosa, 105

Lemna, 167,168

Lemnacex, 167

Lepidium, 229

leucoplasts, 80 act on of, 85

levels, invasion at different, 272

lichens, 105

light, 5,63

action on chloroplasts, 85

adaptation to, 171

amount absorbed, 77

comparison with standard, 75

competition for, 253

functions, 71

intensity, $72,75,76$

intensities in forests, 230

measurement of, 72

readings, 74

recption and absorption, 77

relation of organs to, 171

relation of plants to, 71

standard, making a, 73

stimuli, 72

types of leaves, 182

Liguliflore, 121

line transcet, 210

Limnæus, on genera and species, 187

lipase, 100

list quadrat, 204

Lithospermum, 120, 228

Lomatium, 226, 293, 294

loment, 132

Lonicera, 126

lophospores, 242

Ludwigia, 169

lumbered areas, succession in, 282

Lygodesmia, 163

\section{Macheranthera, 178}

aspera, 125, 130, 179

magnesium, 19

major quadrat, 204

maltose, 101

Malva arborea, 67

man, agent in migration, 246

succession due to, 280

mapping quadrat charts, 206

maps, formation, 213

Natthews, 189

maximum temperature, 95

Mentzelia, 239

Meriolix, 293

meristem, 106, 107
Mertensia, 158

linearis, $15 \mathrm{~s}, 164$

Mesembryanthemum, 160

mesenchym, 41

mesophytes, 155, 164

mesophytic formations, 233

Micrampclis, $141,1+2$

migration, 99, 220, 237, 240, 270

agents, constant, 248; intermittent, 248

agents of, 244,248

circle, 212

determinate, 249

direction of, 250

indeterminate, 250

modifications for, 242

Mimosa pudica, 142

minimum temperature, 95

mixed aggregation, 239

mixed formations, 235

mixotrophic plants, 104

mobility, 241

and nearness, 284

modification, 4

modifications for migration, 242

modifying factors, 15

Moneses uniflora, 128

monoclinism, 122

monocotyledons, 53, 170, 172

Monotrora, 104

monotropic, 201

mortar fruits, 247

motility, 241

mountain zones, 303

movements of fruits, 132

of stems and leaves, 87

Nuhlenbergia, 162, 165

gracilis, 296

mutants, 196

mutation, 190

origin by, 196

mutualism, 104

mycorhiza, 105

ifyriophyllum, 168

natural selection, 1S9, 191, 196, $19 \mathrm{~S}$

nature of competition, 252

Naudin, 189

nectar flowers, 127

needle form, 161

night-bloomers, 120,130

nitrates, 19

nit rogen, 1s, 101

bacteria, 105

Nobbe, on root areas, 44

non-a vailable water, 9,14

normal alternation of formations, 292

alternation of species, 293

leaf xerophytes, 157 
normal succession, 274

Nostoc, 105

numerical aiternation, 293

nut, 132

nutrient salts, 18,68

Nym phaca, 168, 242

nyctanthous flowers, 130

nyct ot ropism, 89

oblate cells, 172

Odontoglossum, 131

Edogonium, 243

Enothera, 190, 200

lamarckiana, 190

offsets, 115

offshoot-dist ributed plants, 242

Onagra, 120, 122, 182, 260

oncospores, 243

open formations, $231,235,271$

optimum, 95

Orchis, 117

organs of dissemmation, 241

origin by adaptation, 192

by descent before Darwin, 187

by hybridation, 197

by mutation, 196

by variation, 195

of new forms, 185

“Origin of Species," 187, 188, 189

osmosis, 45

in root-hairs, 46

o:motic pressure, 55, 62

Ostrya, 242

outline of sun and shade leaves, $17 \mathrm{~S}$

Oxalis, 121, 247

oxides, 19

Pachylophus hirsutus, 129

palisade cell, 172

leaf, 183

tissue, $57,151,176$

Panicum, 293

parachute disseminules, 242

parasites, 104

kinds of, 104

parental care, 116

Parietaria, 126

pathology, 5, 6

Pedicularis procera, 164,184

Penicillium, 105

Pentstemon, 120, 157, 165, 293, 294

pepsin, 100

pepo, 132

periblem, 39, 41

pericycle, 41

periodicity of growth, 110

period of flowering, 128

permanent quadrat, 204, 208

perquadrat, 204

petasospores, 242 phenology, 131

Philotria, 168

phloem, 42, 52

phosphates, 19, 101

phosphorus, 18, 101

photometer, 72

photosynthesis, 81, 104

chemical changes during, 82

formulæ, 82

measurement of, 83

rays active in, 81

phototropism, 71,87

phyad, 155

phyllode form, 162

Physalis, 242

physical ba rriers, 266

factors, 30,36

factors, zones due to, 297

physiographic classification, 233

Plantago, 126

plant body, types of, 154

plant-distributed species, 242

plant formation, 215

temperatures, 92

plasmolysis, 47

plast ic forms, 186

species, 192

plasticity, 185, 265

plerome, 39,41

Pleurococcus, 105

plumed disseminules, 242

jod, 132

point readings, 33

polarity, 108

Polemonium speciosum, 267

pollen, amount of, 116

flowers, 127

production, 116

protection by movement, 120

protection of , 118

seasonal protection of, 121

source and distribution of, 124

structural protection of, 119

pollınation, agents in, 125

by insects, 126

kinds of, 124

polychronic, 201

polydemic, 268

polydemies, 184

polygamy, 122

polygenesis, 199

Polygonum, 163

aviculare, 261

polytopic, 201

poine, 132

Populus, 120, 126

porosity, 18,20

Portulaca, 122

position, effect on competition, 256 of disseminules, 244 
Potamogeton, 126

potassium, 19, 101

potometers, 64,67

precipitation, 21

pressure, 26

vegetation, 257

prevernal aspect, 224

flowers, 130

primary regions, root, 39

successions, 275

principal species, 222

production of pollen, 116

prolate cells, 172

propagation, 113

propagules, 112, 113

of flowering plants, 114

stems as, 114

propulsion, 247

Proserpinaca palustris, 167

protandrous flowers, 122

protection of pollen, 118

by movement, 120

seasonal, 121

structural, 119

proteids, 101

protogynous flowers, 122

protoplasm, selective power of, $4 \mathrm{~S}$

Pseudotsuga, 222

Psoralea, 227, 293

psychrometer, 27, 28, 29

pterospores, 242

Pulsatilla, 243

pulvinus, 142

pyxis, 132

quadrat, 202

chart, 204, 205

competition, 261

denucled, 204, 209

list, 204

major, 204

nlaking charts, 206

permanent, 204, 208

tapes, 204

quadrats, linds of, 203

marking out, 204

Quercus, 184, 292

novimexicana, 183

radial zonation, 299

rainfall, 21

gauge, 21

measurement of, 21

Ranumculus, 167, 169

delphinifolius, 153, 167

sceleratus, 149, 153, 155, 194

reactions of plants upon habitat, 282 , 284

zones due to, 296

readings, point and hour, 33 recessive character, 198

records, field, 33

reduced bundles, $5 \mathrm{~s}$

reduction of leaf or stem, 146

regional classification, 234

relative humidity, 25,27

relict method, 287

reproduction, 112

sexual, 115

respiration, 101

response, functional, 3

nature of, 3

st ructural, 3

to contact, 141

to shock, 142

to water, 7

to water stimuli, 38

resting period, 111

results of competition, $25 \mathrm{~S}$

rhizomes, 115

Rhus, 292

rhythm of growth, 110

roll form, 162

rolling of the leaf, 145

root-cap, 40, 41

root-hairs, $17,39,42$, $4 \mathrm{~s}$

effect of water content upon, 43

origin and struct ure, 42

root pressure, 55

primary regions, 39

structure, 40

system, 40

root tubercles, 105

roots, form of, 39

root stocks, 115

Roripa americana, 153, 167

Rosa, 228

Rumex, 126, 242

altissimus, 41

rumner, 114

run-off, 21

Ruppia, 125

Ruscus, 163

rush form, 163

Rydbergia, 224

grandiflora, 223

saccate fruits, 242

Saccharomyces, 105

saccospores, 242

Sachs, starch method, 83

Sagittaria, 167, 169

$$
\text { latifolia, } 169
$$

Saint-Hilaire, on evolution, 1SS, 192

Salix, 126, 220, 242

Salvia, 243

samara, 132

saprophytes, 99, 104

sarcospores, 243

saxifrage, $8 S$ 
scale form, 162

sciophytes, 183

Seirpus, 163

scutellum of grains, 100

Scutellaria, 178, 193

secondary species, 222

succession, 275, 278

sedimentation, 283

Sedum, 160, 162

Sedum stenopetalum, 160

seed-distributed plants, 241

seed, in ecesis, 263

production, influence of, 243

selection, 196

self-pollination, 124,127

Seneeio, 160, 228, 242

taraxacoides, 179

sensitive plant, 142

sensory a rea of tendrils, 141

serotinal flowers, 130

sexual reproduction, 115

shade leaves, 178

plants, 165,183

tents, 181

shock, 142

Sicyos, 141

Sieversia, 243

sieve tissue, 53,84

Silene, 243

silicle, 132

silique, 132

Silphium laciniatum, 145

simple aggregation, 237

law of, 239

simult a neous readings, $30,31,36$

size and thickness of leaves, 179

sling psychrometer, 27,28

slope, 22,27

influence of, 23

snowfall, 21

socict $y, 225,226$

soil, air-content of, 19

can, 10

chemical nature of, 18

influence on water content, 15

mechanical analysis of, 20

propert res, determination of, 19

samples, 10 ; deptlı of, 12

"sourness" of, 19

struct ure, 16,20

temperatures, 92

texture, 15,20

thermometer, 92

soils, origin and st ructure, 16,17

Solidago, 227, 260

canadensis, 258

decumbens, 191

oreoppila, 191

soluble salts, 18

absorption of, 48 soluble salts, influence of, 47

solutes, 18

Sparganium, 126

angustifolium, 152

sparse, 205

Spartina cymosuroides, 301

spiny disseminules, 245

Spirodela, 167

sponge cell, 172

leaf, 183

tissure, $57,151,174$

spongophyll, 183, 184

spore-distributed plants, 241

Sporobolus, 162

sporophore, 113, 115

sport s, 189,196

spring a spect, 224

stability, 170,185

stabilization, $2 \$ 5$

stable forms, 186

standard, comparison with, 75

making a , 73

Stapelia, 164

Sta phylea, 242

starch, $82,84,85,100,103$

determination of, 83

stations, 31

staurophyll, 183, 184

stems, form of, 179

functions of, .54

of monocotyledons, 53

of shade plants, 180

structure of herbaceous dicotyledons, 52

structure, types of, 51

xerophytes, 162 ; types of, 162

Stipa, 45, 162, 226, 244

consocies, 226

stimulatory action, 2

stimuli, extermal, 3

internal, 3

kinds of, 3

nat ure of , 1, 2

nature of light, 72

stimulus of gravity, 137

of shock, 143

stolon, 114

stomata, 52, 57, 153

functions, 61

in sun and shade leaves, 178

modifications of, 148

structure and position, 60

storage leaves, 58

of food material, 84

of water, 151

structure of formations, 219,221

of leaf, 56

of woody strms, 53

struggle for existence, 251

subcopious, 205 
subgrega rious, 205

submerged plants, 168

succession, 273

abnormal, $27 t$

by cultivation, 282

due to man, 280

in xolian soils, 278

in alluvial soils, 277

in burned areas, 281

in colluvial soils, 276

in eroded soils, 279

in flooded soils, 280

in lumbered areas, 282

kinds of, 274

laws of, 284

method of alternating stages, 286

normal, 274

primary, 274,275

relict method, 287

secondary, 275, 278

sturly of, 286

succulent form, 159, 164

sugar, 103

sulphates, 19, 101

sulphur, 18, 101

sum of temperatures, 97

summer aspect, 224

sun lcaves, 178

sun plants, 165, 183

support, 51

surface, 22

influence of, 23

symbiosis, 104

symmetry in vegetation, 298

physiographic, 298

\section{Tamarix, 162}

Taraxacum, 121, 182, 242

taraxacum, 182

Telcony.x jamcsii, Ss

temperat ure, 5,25

adjustment to, 90

effect of low, 98

favorable and unfavorable, 95

influence of clouds, winds, etc., 95

influence on vegetation, 98

maximum and minimum, 95

measurement of, 91

of the air, 91

of the plant, 92

of soils, 92

sum of, 97

variations of, 94

tendrils, 141

sensory area, 141

Tctraneuris, 159

Tctraspora, 237

Tcucrium, 120

texture of soil, 15,20

Thalictrum, $17 \mathrm{~S}$
Thalictrum sparsiflorum, 179

thermometer, 91

thermotropic plants, 91

thorn form, 164

Thuja, 162

Tilia, 120

time of daily flowering, 130

tonic action, 2

tracheary vessels, 53

Tradescantia, 122

transect, 210

belt, 211

line, 210

translocation, 83

transpiration, 56

ad justment to, 69

amount of, 66

compensation for increased, 68

influence of physical factors, 63

measurement of, 64 ; in field, 65

relation between absorption and, 68

transpiring surface, 59

transport, 50,54

Tribulus, 243

trypsin, 100

tuber, 115

turgescent fruits, 247

turgidity, $48,61,68$

types of formations, 232

of leaf xerophytes, 156

of leaves as determined by light, $1 S 2$

of plant body, 154

of stem xerophytes, 162

produced by adaptation to water, 155

Typha, 126, 242

Ulothrix, 243

Umbcllifere, 242

Umbilicaria, 215

unisexual crosses, 197

Urtica, 126

utricle, 132

Taucheria, 243

variability, fluctuating, 189

variants, 196

variation, definite, 189

indefinite, 189

origin by, 195

regetation, development and structure, 219

effect of temperature on, $9 \mathrm{~S}$

form, 155, 26.5

historical factor in, 219

influence of vegetation form on competition, 256

methods of studying, 202

pressure, 257 
vegetation, symmetry in, 298 zones, 302

vernal flowers, 130

rertical zonation, 301

Ticia faba, 109, 138

vicine, 273

Viola, 247

virgate form, 163

viscid disseminules, 243

Titis, 141

vixgregarious, 205

Tolvocacece, 243

T'agnera, 239

stellato, 40,146

Wallace, 189

water, 5

adaptation to, 144

adjustment to, 38

available, 9,14

capacity, 17

competition for, 253

content , $7,8,63$

computation of, 11

effect of acids and alkalies, 19

influence of other factors, 9

influence of precipitation, 21

influence of soil, 15

location of readings, 12

time of readings, 12

experimental adaptation to, 153

loss, 177

decrease by rolling of leaf, 145

decrease through leaf position, 145

migration, 245

non-a vailable, 9,14

of the habitat, 7

stimuli, 7

storage cells, 158,159

tissue, 152 water supply, adaptation to excessive, 152

adaptation to small, 144

increase and storage of, 151

upward movement in plant, 55

weat hering, 16,283

Wells, 189

Wiesner, on transpiration, 67

wilting, 69

winged disscminules, 242

wind, 25

in migration, 245

wit ches' brooms, 5

Wolffia, 167

wood fibers, 53

woody stems, structures of, 53

xenogamy, 124

xerophytes, $155,156,164$

general features of, 156

leaf, 157

stem, 162

xerophytic formations, 233

xylem, 42,52

zonat ion, 220, 294

bilateral, 300

kinds of, 299

radial, 299

relation between alternation and, 289

vertical, 301

zones, 212

due to growth, 295

due to migration and ecesis, 295

due to physical factors, 297

due to reaction, 296

vegetation, 302

zoochores, 245

zoophilous flowers, 125, 126

Zostcra, 125

zymogen, 100 




